Sistemas bio-inspirados para coordenação de múltiplos robôs móveis

\author{
Rodrigo Calvo
}



SERVIÇO DE PÓS-GRADUAÇÃO DO ICMC-USP

Data de Depósito:

Assinatura:

\title{
Sistemas bio-inspirados para coordenação de múltiplos robôs móveis
}

\author{
Rodrigo Calvo
}

Orientadora: Profa. Dra. Roseli Aparecida Francelin Romero

Tese apresentada ao Instituto de Ciências Matemáticas e de Computação - ICMC-USP, como parte dos requisitos para obtenção do título de Doutor em Ciências - Ciências de Computação e Matemática Computacional. VERSÃO REVISADA 
Ficha catalográfica elaborada pela Biblioteca Prof. Achille Bassi e Seção Técnica de Informática, ICMC/USP, com os dados fornecidos pelo(a) autor(a)

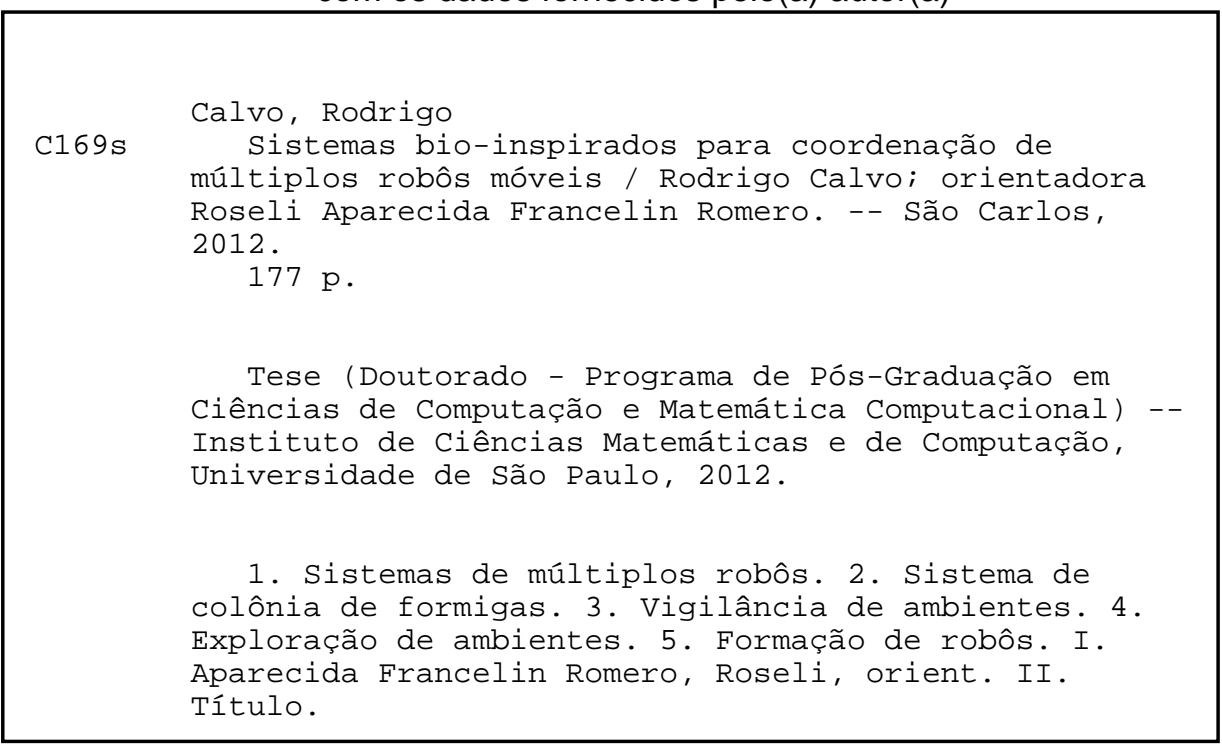




\section{Agradecimentos}

Agradeço a Deus pela grandiosa oportunidade que tem me concedido e pela fé e serenidade proporcionados nos momentos mais difíceis.

À minha família que sempre esteve do meu lado nos momentos mais difíceis. Meus pais, Milton e Helena, e meus irmãos, Fabio e Fernando. Pessoas que me ajudaram em todos os sentidos, e apoiando todo o tempo que estive longe de casa. Devo muito a eles, pela atenção e paciência.

À minha noiva, Dayane, pela sua compreensão e infindável paciência durante o período que estive ausente por me dedicar ao desenvolvimento deste trabalho, pelo companherismo e apoio em todos os momentos.

Agradeço a Profa. Dra. Roseli pelo esforço sem medida em me orientar, sempre disposta a ajudar. Agradeço pela confiança depositada, pela liberdade dada para trabalhar e pelos ensinamentos durante esse período de doutorado.

Ao Prof. Dr. Maurício Figueiredo pelo apoio, por ter me iniciado nessa caminhada. Tudo o que eu obtive devo às suas conversas, conselhos profissionais e dedicação em me apoiar nas minhas decisões.

Ao Prof. Dr. Denis F. Wolf e ao amigo Gustavo Pessin por indicarem a plataforma Player/Stage e pelos ensinamentos dos primeiros passos nesta ferramenta, fundamental para a obtenção dos resultados deste trabalho.

Ao Prof. Dr. Roland Siegwart por ter me recebido na Eidgenössische Technische Hochschule Zürich, Suíça, durante o período de doutorado sanduíche, ao Prof. Dr. Dizan Vasquez e ao seu aluno de doutorado Andreas Breitenmoser por inúmeras reuniões de onde surgiram ideias que foram essenciais para o desenvolvimento deste trabalho.

Agradeço carinhosamente aos amigos Eler's (Marcelo e Danilo), Quiles, Adriano, Renatinho, Marcelão, Marcelinho, Fernando Zuher, Luiz Coletta, Debora, Thiago, Murillão, Rosane, Paulo, Mari, Jão e Paula. Em especial, sou grato ao Janderson pela sua compreensão e por colaborar diretamente com a realização do trabalho, ao Danilo Doi pela sua dedicação em auxiliar nos estudos relacionados à segunda frente de pesquisa desta tese e aos amigos Bruno, 
Japa, Valéria, Rossi, Chris, Rafael e Eduardo Fraccaroli por não hesitarem em ajudar, generosidade e presença, principalmente, nas horas difíceis para me darem a força necessária pra seguir adiante.

Ao ao amigo Luiz Carlos por me apresentar Zurique e me abrigar nos primeiros dias de doutorado sanduíche, à Elisabeth Habermann por me receber em sua casa e pela amizade de Andreas Moeckli e sua família.

Agradeço ao amigo Marcelo Kaminski, que mesmo a distância sempre tinha algo de importante para acrescentar em minha vida. Agradeço a ele e a Bela por me abrigarem em uma das visitas à Suíça.

À todos os professores do ICMC por estarem sempre dispostos a ajudar, aos funcionários e ao pessoal da limpeza que sempre mantiveram os laboratórios limpos para trabalharmos. Aos vigilantes que se tornaram meus amigos, Gilberto, Senha, Fernando e Alexandre.

Agradeço também à CAPES, CNPq e FAPESP pelo auxílio financeiro para o andamento do doutorado. 


\section{Abstract}

The application of systems of multiple robots is desirable in various tasks. Some of them include: exploration, mining, land mine detection, security and rescue operations. An effective strategy for coordination is crucial to achieve performance improvements. In this project, two new strategies are proposed for the coordination of multiple robot systems, applied to the tasks of exploration, surveillance and formation. They are distributed, decentralized and performed in real time. The inspiration for both of them comes from the biological mechanisms that define a social organization of collective systems. Specifically, it was considered in this thesis a modified version of the Ant Colony System. The strategies are adaptable for scenarios where the number of robots and structure of the environment change. Regarding the first strategy, the experiments consider two performance criteria: average surveillance cycles and average iterations for each patrolling interval. Simulation results confirm that the exploration and surveillance emerge from the synergy of individual behaviors of robots. The data obtained show that the coordination strategy is efficient and and suitable to perform the tasks of exploration and surveillance. Regarding the second strategy, the system presents the characteristics desirable to maintain the formation: separation, alignment and cohesion. Empirical evidence showed that the system has good dispersive ability, which promoted an increase in coverage, and that it was able to adapt to new group topologies and environment settings. 


\section{Resumo}

A aplicação de sistemas de múltiplos robôs é desejável em várias tarefas. Algumas delas são: exploração de ambientes, mineração, detecção de minas terrestres, segurança e operações de resgate. Uma estratégia eficiente de coordenação é decisiva para alcançar melhoras no desempenho. Neste projeto, duas novas estratégias são propostas para a coordenação de sistemas de múltiplos robôs, aplicadas para as tarefas de exploração, vigilância e formação. Elas são distribuídas, descentralizadas e ocorrem em tempo de execução. A inspiração para ambas advém de mecanismos biológicos que definem uma organização social de sistemas coletivos. Especificamente, considerou-se nesta tese uma versão modificada do sistema de colônia de formigas. As estratégias são adaptáveis para cenários em que o número de robôs e a estrutura do ambiente mudam. Em relação à primeira estratégia, os experimentos consideram dois critérios de desempenho: a média de ciclos de vigilância e a média de iterações em cada intervalo de segurança. Os resultados de simulação confirmam que a exploração e vigilância emergem da sinergia dos comportamentos individuais dos robôs. Os dados obtidos mostram que a estratégia de coordenação é eficiente e satisfatória para realizar as tarefas de exploração e vigilância. Quanto à segunda estratégia, o sistema apresenta as características desejáveis para que a formação seja mantida: separação, alinhamento e coesão. Evidências empíricas mostraram que o sistema possui boa habilidade dispersiva, o que promoveu o aumento da cobertura, e que o mesmo foi capaz de se adaptar a novas topologias de grupo e configurações de ambiente. 


\section{Sumário}

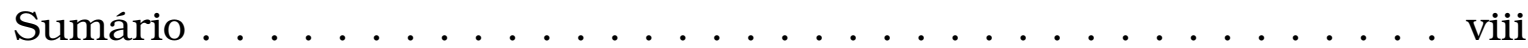

Lista de Figuras . . . . . . . . . . . . . . . . xii

Lista de Tabelas . . . . . . . . . . . . . . . . . xiii

Lista de Algoritmos . . . . . . . . . . . . . . . . . . xv

1 Introdução 1

1.1 Contextualização . . . . . . . . . . . . . . . . . . . 1

1.2 Alguns Aspectos Relevantes em Sistemas de Múltiplos Robôs . . . 4

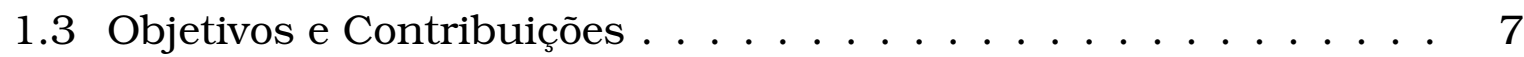

1.4 Organização do Trabalho . . . . . . . . . . . . . . . . 7

2 Trabalhos Relacionados $\quad 9$

2.1 Considerações Iniciais . . . . . . . . . . . . . . . . . . . . . . 9

2.2 Exploração de ambientes . . . . . . . . . . . . . . 10

2.3 Cobertura de ambientes . . . . . . . . . . . . . 13

2.4 Formação de robôs . . . . . . . . . . . . . . . . . 17

2.5 Considerações Finais . . . . . . . . . . . . . . 26

3 Otimização por Colônia de Formigas $\quad 29$

3.1 Considerações iniciais . . . . . . . . . . . . . . . . . . . . 29

3.2 Fundamentos teóricos . . . . . . . . . . . . . . . . 30

3.3 Algoritmo ACO . . . . . . . . . . . . . . . . . . 32

3.4 Aplicação do ACO para problemas combinatoriais . . . . . . . 34

3.4.1 O problema do caixeiro viajante . . . . . . . . . 34

3.4 .2 Solução por ACO . . . . . . . . . . . . . . 35

3.5 Considerações finais . . . . . . . . . . . . . . . . . 38

4 Coordenação de Múltiplos Robôs Móveis para Vigilância de Ambientes $\quad 39$

4.1 Considerações Iniciais . . . . . . . . . . . . . . . . . . . . . . 39

4.2 Formulação do Problema . . . . . . . . . . . . . . . . . . 40 
4.3 Sistema de Exploração e Vigilância . . . . . . . . . . . . . . 43

4.3.1 Sensores do Robô . . . . . . . . . . . . . . . . 45

4.3 .2 Sistema de Navegação . . . . . . . . . . . . . . . 46

4.4 Resultados Experimentais . . . . . . . . . . . . . . . . 52

4.4.1 Comparações entre os Mecanismos de Ajuste de Direção Adotados . . . . . . . . . . . . . 56

4.4.2 Posição Inicial dos Robôs . . . . . . . . . . . . . . . . 60

4.4.3 Coordenação de Movimento em Função do Número de Robôs 71

4.4.4 Estrutura dos Ambientes . . . . . . . . . . . . . 75

4.4.5 Métodos de Estigmergia e Influência do Parâmetro $\gamma$. . . 79

4.5 Considerações Finais . . . . . . . . . . . . . . . . . 85

5 Coordenação de Múltiplos Robôs Móveis para Formação 89

5.1 Considerações Iniciais . . . . . . . . . . . . . . . . . . . 89

5.2 Conceitos Básicos . . . . . . . . . . . . . . . . 90

5.3 Sistema de Formação Auto-Adaptativo . . . . . . . . . . . . . . 94

5.3.1 Sensores do Robô . . . . . . . . . . . . . . . . . 99

5.3 .2 Núcleo Decisório . . . . . . . . . . . . . . . . . . . . . . 102

5.3 .3 Módulo de Hierarquia . . . . . . . . . . . . . . . . . 108

5.3 .4 Módulo de Inicialização . . . . . . . . . . . . . . . . . . . 110

5.3 .5 Módulo Líder . . . . . . . . . . . . . . . . . . . . . . . . . 112

5.3 .6 Módulo Seguidor . . . . . . . . . . . . . . . . . . 113

5.3 .7 Módulo de Desvio . . . . . . . . . . . . . . . . . . . . . . 122

5.3.8 Módulo de Feromônio . . . . . . . . . . . . . . . . . . . . 122

5.4 Resultados experimentais . . . . . . . . . . . . . . . . 123

5.4.1 Dispersão dos Robôs . . . . . . . . . . . . . . . . . . . . 125

5.4.2 Agregação das Forças de Atração . . . . . . . . . . . 128

5.4 .3 Mudança de Líder . . . . . . . . . . . . . . . . . 136

5.4 .4 Adição de Líder . . . . . . . . . . . . . . . . . . . . . . . 142

5.5 Considerações Finais . . . . . . . . . . . . . . . . . . . 148

6 Conclusões $\quad 151$

6.1 Contribuições . . . . . . . . . . . . . . . . . 151

6.2 Trabalhos futuros . . . . . . . . . . . . . . . . . 154

$\begin{array}{ll}\text { Referências } & 175\end{array}$ 


\section{Lista de Figuras}

3.1 Exemplo do processo de busca pelo caminho ótimo entre o ninho e a fonte de alimento . . . . . . . . . . . . 33

3.2 Exemplo do problema do caixeiro viajante . . . . . . . . . . . 34

4.1 Diagrama arquitetural do sistema cibernético para um único robô. 44

4.2 Sensores do robô . . . . . . . . . . . . . . . . . 46

4.3 Escala de cores para a distribuição da concentração de feromônio. 55

4.4 Estrutura do ambiente. . . . . . . . . . . . . . . . 56

4.5 Boxplots da distribuição da média do intervalo de segurança para diferentes mecanismos de ajuste de direção. . . . . . . . . . . 57

4.6 Desempenho da estratégia IAS-SS de acordo com os diferentes mecanismos: (a) EU; (b) AE; (c) AEE. . . . . . . . . . . . . . . . . 58

4.7 Mapa da média de concentração de feromônio de acordo com os diferentes mecanismos: (a) EU; (b) AE; (c) AEE. . . . . . . . . . . . 59

4.8 Estrutura do ambiente. . . . . . . . . . . . . . . . . 61

4.9 Boxplots da distribuição da média do intervalo de segurança para diferentes configurações de posicionamento. . . . . . . . 63

4.10 Desempenho da estratégia IAS-SS de acordo com os tipos de posicionamento inicial e o mecanismo AEE: (a) CS; (b) CA. . . . . . . . 64

4.11 Número máximo de iterações sem visita nas salas. . . . . . . . . 65

4.12 Boxplots da distribuição da média do intervalo de segurança para diferentes configurações de posicionamento: ambientes (a) x2; (b)

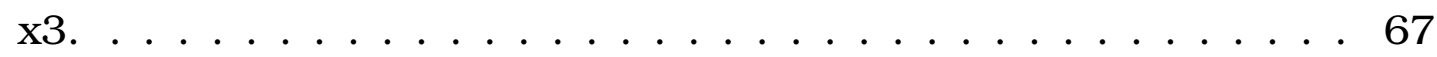

4.13 Desempenho da estratégia IAS-SS de acordo com diferentes configurações de posicionamento para o mecanismo AEE no ambiente $\mathrm{x} 2$ : (a) CS; (b) CA. . . . . . . . . . . . . . . . . . . 69

4.14 Desempenho da estratégia IAS-SS de acordo com diferentes configurações de posicionamento para o mecanismo AEE no ambiente x3: (a) CS; (b) CA. . . . . . . . . . . . . . . . . . 70 
4.15 Número máximo de iterações sem visita nas salas: ambientes (a) $\mathrm{x} 2$; (b) $\mathrm{x} 3 \ldots \ldots \ldots \ldots \ldots \ldots \ldots \ldots \ldots \ldots \ldots$

4.16Trajetórias dos robôs durante as tarefas de exploração e vigilância para configuração de ambiente CA com o mecanismo AEE: (a) ambiente $\mathrm{x} 1$; (b) ambiente $\mathrm{x} 2$; (c) ambiente $\mathrm{x} 3 . \ldots \ldots$. . . . 73

4.17 Modelo do ambiente. . . . . . . . . . . . . . . . . 73

4.18 Boxplots da distribuição da média do intervalo de segurança para diferentes números de robôs. . . . . . . . . . . . . . . . . 75

4.19Desempenho do sistema IAS-SS com diferentes números de robôs em um mesmo ambiente: (a) 2; (b) 7; (c) 10; (d) 15 robôs. . 76

4.20 Moldelo de ambientes: (a) ambiente dividido em salas; (b) grafo de conexão entre as salas; (c)-(1) ambientes de \#1 a \#10. . . . . . . 77

4.21 Boxplots da distribuição da média do intervalo de segurança para diferentes graus de complexidade do ambiente. . . . . . . . . . 79

4.22 Trajetórias dos robôs e mapa da média de concentração de feromônio de acordo com diferentes estruturas de ambientes: (a)-(b) \# 1; (c)-(d) \#3; (e)-(f) \#5; (g)-(h) \#8; (i)-(j) \#10. . . . . . . . . . . . . 80

4.23 Liberação de feromônio para trás. . . . . . . . . . . . . . . 81

4.24 Liberação de feromônio no perímetro do robô. . . . . . . . . . . . . 82

4.25 Modelo do ambiente. . . . . . . . . . . . . . . . 83

5.1 Modelo matemático da Triangulação de Delaunay e Diagrama de Voronoi. . . . . . . . . . . . . . . . . . . . . . . 93

5.2 Nível dos robôs em formação. . . . . . . . . . . . . . . . . . 97

5.3 Diagrama arquitetural do sistema cibernético para um único robô no SAFS. . . . . . . . . . . . . . . . . . . . . . 98 98

5.4 Modelo do sensor de feromônio atrativo. . . . . . . . . . . . . . 100

5.5 Diagrama arquitetural do Núcleo Decisório. . . . . . . . . . . . . . 102

5.6 Topologia da vizinhança de um robô definida pela Triangulação de Delaunay: (a) vizinhos detectados pelo raio de comunicação $R_{C}$; (b) vizinhos adjacentes. . . . . . . . . . . . . . . . . 109

5.7 Truncamento da região de Voronoi infinita para um robô que: (a) não detecta obstáculo; (b) que detecta um obstáculo. . . . . . . . 117

5.8 Truncamento da região de Voronoi infinita para um robô: (a) sem vizinho; (b) com um vizinho. . . . . . . . . . . . . . . . . . 118

5.9 Posicionamento do centroide em uma região de Voronoi limitada: (a) pelo círculo de Voronoi; (b) por um obstáculo. . . . . . . . . . . 119

5.10Escala de cores para a distribuição da concentração de feromônio atrativo. . . . . . . . . . . . . . . . . . . . 124 
5.11 Processo de dispersão dos robôs com a utilização da força de atração do centroide e 10 robôs: (a) configuração inicial (robôs compactados); (b) configuração final (robôs dispersos); (c) diagrama de Voronoi na configuração inicial; (d) diagrama de Voronoi na configuração final. . . . . . . . . . . . . . . . . . . . .

5.12 Intensidade da força de atração do centroide. . . . . . . . . . . . 128

5.13 Processo de dispersão dos robôs com a utilização da força de atração do centroide e 5 robôs: (a) configuração inicial (robôs compactados); (b) configuração final (robôs dispersos); (c) diagrama de Voronoi na configuração inicial; (d) diagrama de Voronoi na configuração final.

5.14 Processo de dispersão dos robôs com a utilização da força de atração do centroide e 20 robôs: (a) configuração inicial (robôs compactados); (b) configuração final (robôs dispersos); (c) diagrama de Voronoi na configuração inicial; (d) diagrama de Voronoi na configuração final.

5.15Sequência de quadros da simulação em que o grupo de 10 robôs passa por um corredor nas iterações: (a) 0; (b) 60; (c) 150; (d) 210; (e) 270; (f) 330; (g) 390; (h) 420; (i) 510; (j) 540; (k) 570; (l) 630.

5.16Sequência de quadros do diagrama de Voronoi da simulação em que o grupo de 10 robôs passa por um corredor nas iterações: (a) 0; (b) 60; (c) 150; (d) 120; (e) 270; (f) 330; (g) 390; (h) 420; (i) 510; (j) 540; (k) 570; (l) $630 . \ldots \ldots \ldots$

5.17 Distância do vizinho mais próximo. . . . . . . . . . . . . . . 135

5.18 Sequência de quadros da simulação em que o grupo de 5 robôs passa por um corredor nas iterações: (a) 0; (b) 10; (c) 30; (d) 60; (e) 90; (f) 120; (g) 140; (h) 160; (i) 180; (j) 210; (k) 240; (l) 270. . . 137

5.19Sequência de quadros da simulação em que o grupo de 20 robôs passa por um corredor nas iterações: (a) 0; (b) 60; (c) 150; (d) 210; (e) 270; (f) 330; (g) 390; (h) 450; (i) 570; (j) 630; (k) 660; (l) 750 .

5.20 Sequência de quadros da simulação para um grupo de 10 robôs quando há a mudança de líder: (a) 0; (b) 60; (c) 120; (d) 180; (e) 210; (f) 240; (g) 270; (h) 330. . . . . . . . . . . . . . . . . . . 140

5.21 Sequência de quadros do diagrama de Voronoi da simulação para um grupo de 10 robôs quando há a mudança de líder: (a) 0; (b) 60; (c) 120; (d) 180; (e) 210; (f) 240; (g) 270; (h) 330.

5.22 Distância do vizinho mais próximo quando há a mudança de líder. 143 
5.23 Sequência de quadros da simulação para um grupo de 10 robôs quando há a adição de líder: (a) 0; (b) 60; (c) 120; (d) 180; (e) 210; (f) 240 ; (g) 300; (h) $330 \ldots \ldots \ldots \ldots \ldots \ldots$. . . . . . . . . . 145

5.24 Sequência de quadros da simulação para um grupo de 10 robôs quando há adição de líder: (a) 0; (b) 60; (c) 120; (d) 180; (e) 210;

(f) 240 ; (g) 300; (h) $330 \ldots \ldots \ldots \ldots \ldots$. . . . . . . . . 146

5.25 Distância do vizinho mais próximo quando há a mudança de líder. 148 


\section{Lista de Tabelas}

4.1 Desempenho dos mecanismos de ajuste de direção. . . . . . . . 57

4.2 SE por mecanismo de ajuste de direção. . . . . . . . . . . . . . . . 60

4.3 Salas monitoradas a cada ciclo SE . . . . . . . . . . . . 60

4.4 Desempenho da estratégia IAS-SS de acordo com a combinação dos posicionamentos iniciais e os mecanismos de ajuste de direção. 62

4.5 Desempenho da estratégia IAS-SS de acordo com a combinação dos posicionamentos iniciais e os mecanismos de ajuste de direção no ambiente $\mathrm{x} 2 . . . \ldots$. . . . . . . . . . 66

4.6 Desempenho da estratégia IAS-SS de acordo com a combinação dos posicionamentos iniciais e os mecanismos de ajuste de direção ambiente x3. . . . . . . . . . . . . . . . 68

4.7 Desempenho da configuração de posicionamento CA com o mecanismo de ajuste de direção AEE para o crescente número de robôs.

4.8 Desempenho da configurações de ambiente com o mecanismos de ajuste de direção AEE para o crescente grau de complexidade do ambiente. . . . . . . . . . . . . . . 78

4.9 Períodos de intervalos de segurança. . . . . . . . . . . . . 84

5.1 Tabela comparativa de características. . . . . . . . . . 96

5.2 Identificação dos robôs . . . . . . . . . . . . . . 126

5.3 Identificação dos robôs. . . . . . . . . . . . . . . . . 139

5.4 Quantidade de feromônio repulsivo no instante da mudança de líder. . . . . . . . . . . . . . . . . . . . . 139

5.5 Identificação dos robôs . . . . . . . . . . . . . . . . 142

5.6 Quantidade de feromônio repulsivo no instante da adição de líder 147

5.7 Niveis dos robôs. . . . . . . . . . . . . . . . . . . . . . 147 


\section{Lista de Algoritmos}

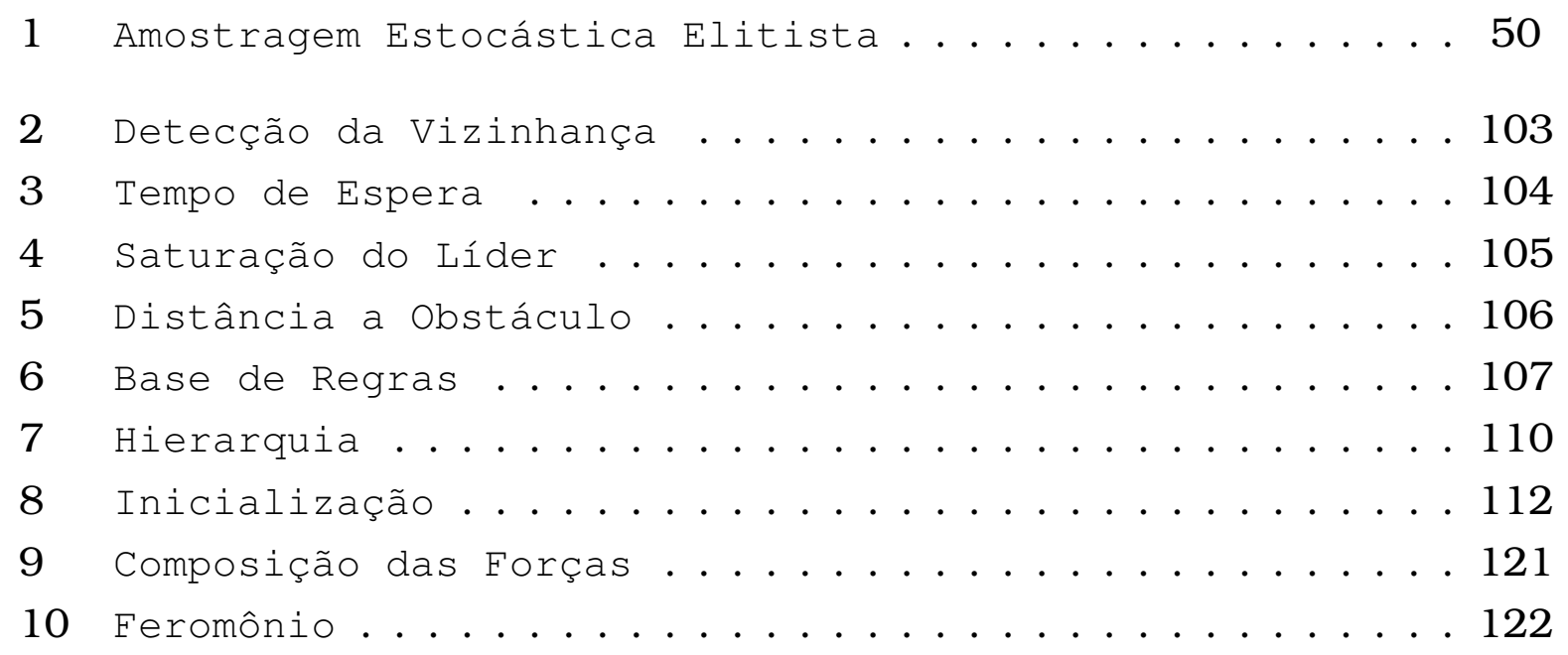




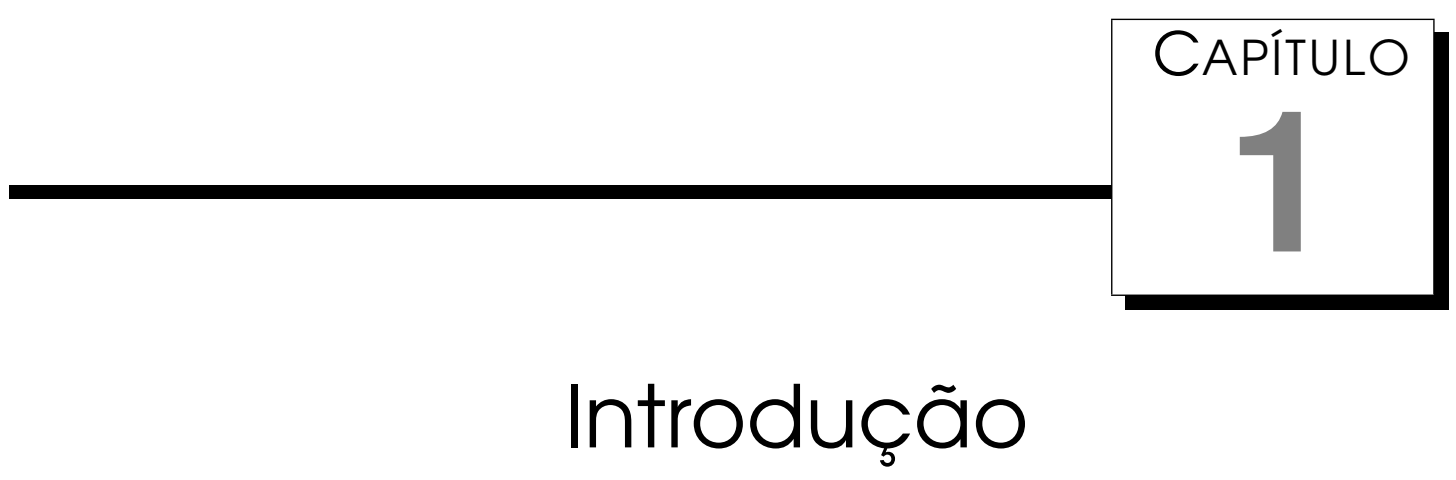

\subsection{Contextualização}

A presença de máquinas que operam de forma independente (sem a intervenção humana) remonta há um passado longínquo. Nos antigos engenhos, os moinhos eram máquinas totalmente mecânicas que operavam de forma independente. A energia capturada do vento ou de cursos de água era transformada por meio de um conjunto de engrenagens e outros mecanismos para, por exemplo, beneficiar grãos. Atualmente, é variada e comum a presença de máquinas que operam de forma independente e auxiliam as pessoas no cotidiano. Motivado por sua característica autônoma, muitas máquinas presentes no dia-a-dia passam despercebidas. Este é o caso de diversos aparelhos domésticos, incluindo a simples geladeira ou uma sofisticada máquina de lavar roupa.

A indiferença à autonomia das máquinas deixa de ser tão forte à medida que as máquinas exibem maior complexidade em suas operações. Além disso a curiosidade, a admiração e o interesse são aguçados em maior grau diante de um grupo específico de máquinas: os robôs. A princípio, os robôs devem operar de forma independente, mas certamente esta é uma característica muito abrangente e que reúne em um mesmo grupo máquinas que não são reconhecidas vulgarmente como robôs. Por outro lado, tomando-se por base os diversos exemplos de máquinas que são denominadas, não é possível induzir alguma regra para a sua identificação; e realmente não há uma definição formal para tal. Em muitos casos, máquinas são assim referenciadas por conta da aparência semelhante, de alguma forma, em parte ou no seu todo, a algum 
ser vivo. Também conta o fato da máquina reproduzir algum comportamento ou tarefa tipicamente associado aos seres vivos. Assim entendido, em alguma medida surge à tona o motivo pelo qual se justifica denominar de robôs não só os braços mecânicos (comuns em sistemas de manufatura e capazes de executar algumas tarefas básicas, como: pinturas, soldas e montagens) mas também uma grande variedade de outras máquinas protótipos, como por exemplo: pássaros-robôs (e outros animais-robôs) e aspiradores-robôs.

Uma forte expansão da robótica se sucedeu nos segmentos científicos, tecnológicos e de produção com o progresso da área computacional. Em especial, com o advento dos microprocessadores e microcontroladores, este processo se consolidou de forma definitiva. Sendo por si só um autômato, além de programável, tais dispositivos ofereceram um ambiente muito favorável e prolífico para a concretização dos mais diversos projetos de natureza robótica.

Apesar dos robôs estarem atuantes em diversos segmentos produtivos da sociedade, atualmente estão longe de atenderem expectativas que exijam um maior grau de autonomia como, por exemplo, automóveis auto-guiados. Em geral, os robôs desempenham tarefas em ambientes controlados, ou seja, em que os robôs não sejam colocados diante de situações não previstas durante sua fase de projeto. Em casos em que tal situação ocorra por acidente, é muito provável que seu comportamento seja entrar em um estado suspenso (hibernação) para evitar danos mais graves. Talvez um dos mais desafiadores objetivos da pesquisa em robótica seja justamente tornar factível o projeto e a implementação de um robô com características fortemente autônomas (capaz de aprendizagem sem auxílio externo).

A pesquisa em robótica tem se mantido intensa ao longo dos anos. Sem dúvida é um segmento estratégico e tem se intensificado de forma acelerada atualmente. A grande aposta é que algum avanço alcançado nesta corrida garanta uma importante e confortável dianteira qualitativa à sociedade que detiver tal conquista.

O caráter multidisciplinar da pesquisa demanda empenho de profissionais especializados em variadas áreas do conhecimento científico e tecnológico, que podem contribuir tanto no desenvolvimento da parte física quanto da parte cibernética do robô. Na cibernética, um dos interesses de pesquisa foca na navegação de robôs móveis, ou seja, em como dotar o robô de habilidades e comportamentos básicos para movimentação em ambientes, particularmente não controlados ou desconhecidos, por exemplo: desvio de obstáculos, busca de alvos, exploração, fuga, perseguição, entre outras.

Sob a hipótese de um cenário futuro em que os robôs móveis detenham maior autonomia e possam ser produzidos a baixos custos, a vertente de pesquisa que trata de sistemas de múltiplos robôs vem demonstrando uma 
franca expansão. Neste cenário, parece plausível o emprego de um grupo de robôs e não de apenas um único, isoladamente. Nestes sistemas é crucial estabelecer a coordenação dos robôs de forma que apresentem um comportamento colaborativo. As dificuldades para alcançar este objetivo são várias. Uma percepção preliminar das dificuldades envolvidas para alcançar este objetivo pode ser induzida se imaginada a situação mais característica e usual nestes sistemas: vários robôs movimentando-se livremente, cada qual com um micro-objetivo definido em tempo de execução da tarefa comum. Considere-se ainda que a sinergia dos robôs é dependente de diversas habilidades gerais, a saber: navegação, comunicação, planejamento; desenvolvidas simultaneamente e em sincronia. Além disso, o conjunto de decisões geradas por cada um dos robôs a cada instante é relativamente numeroso e a lista de variáveis e parâmetros envolvidos é extensa. Este é o panorama de desafios a serem enfrentados no projeto dos sistemas de múltiplos robôs.

Mesmo diante dos enormes desafios a serem enfrentados, em particular no caso de sistemas de múltiplos robôs, a pesquisa vem se desenvolvendo intensamente. A vertente cibernética da pesquisa (aquela que trata do controle e comunicação dos robôs) tem progredido sob uma densa influência da Inteligência Artificial. Ao contrário do que acontece com as técnicas mais tradicionais da Engenharia, as técnicas da Inteligência Artificial em geral dispensam modelos matemáticos definidos a priori para construírem suas soluções. Esta característica é vista como um dos fortes diferenciais em favor da Inteligência Artificial, desde que suas técnicas podem ser adotadas na abordagem de problemas de extrema complexidade, em que modelos físico-matemáticos são difícieis de gerar ou de equacionar a priori.

Há relatos de máquinas pioneiras que foram projetadas para causar admiração aos visitantes de jardins das épocas medievais. À medida que os visitantes caminhavam pelo jardins, seus passos disparavam o início da operação de uma máquina hidráulica implementada basicamente por alavancas. Tal máquina produzia os movimentos em modelos humanos. Eram os primeiros autômatos. Há exemplos em que modelos humanos exibiam movimentos muitas vezes complexos, e.g., tocar flautas.

Dada a atenção dispensada aos robôs pelos segmentos produtivos, justificada pela relevância do papel que assumem na sociedade contemporânea e que, de acordo com as expectativas, tende a aumentar, esta tese apresenta contribuições científicas associadas aos sistemas de múltiplos robôs móveis, especificamente em dois tipos de aplicações, a saber: vigilância e formação. Em especial, trata da organização espacial dos mesmos, sua formação, quando estes se deslocam pelo ambiente. 


\subsection{Alguns Aspectos Relevantes em Sistemas de Múlti- plos Robôs}

As máquinas automáticas (que operam de forma independente) e que são capazes de se movimentarem livremente pelo seu ambiente melhor satisfazem as expectativas em torno de robôs. A mobilidade é uma capacidade muito associada aos seres vivos e, por tal motivo, acabam por justificar ainda mais a denominação de robô às máquinas com tal capacidade.

A literatura é rica em relatos de pesquisa e desenvolvimento desta classe de robôs para uma diversidade de aplicações, tais como: limpeza de superfícies (assoalhos, tanques industriais, dutos, etc.) (Lee et al., 2009), transporte de documentos (Fujii et al., 2007; Groß and Dorigo, 2009; Wu et al., 2011), atividades agrícola (Pota et al., 2007) e sistemas de segurança (Lee et al., 2010). Espera-se que futuramente os robôs possam contribuir de forma bem expressiva em operações reais desempenhadas em ambientes inóspitos, por exemplo: resgate em catastrofes, exploração espacial e combate contra incêndios (Murphy, 2004).

O sistema de navegação autônoma instalado é responsável por gerar as trajetórias seguidas pelo robô. O sistema gera sinais que chegam aos atuadores de direção, velocidade e aceleração; fazendo com que o robô assuma comportamentos diversos de acordo com as demandas que se apresentam ao longo do curso da navegação. O projeto de sistemas de navegação é dependente do tipo da tarefa e das características do robô e do ambiente. Diversos aspectos são considerados, por exemplo: oclusão de obstáculos, perda de tração, alvos e/ou obstáculos móveis, áreas de navegação restritas, requisitos de aproximação e manobra; e restrições de velocidade. Devido ao alto grau de complexidade envolvida, as técnicas baseadas em Inteligência Artificial acabam por ser preferidas na maioria dos projetos. A preferência é resultante da relativa simplicidade com que são compreendidas e aplicadas, por não serem dependentes de modelos físicos-matemáticos definidos a priori e por apresentarem resultados satisfatórios na maioria dos casos (Arkin, 1999; Siegwart and Nourbakhsh, 2004).

Muitas das aplicações atribuídas a um único robô móvel podem ser executadas com vantagens por sistemas de múltiplos robôs. Existem razões que justificam a eventual preferência por esta segunda alternativa. Uma vantagem muito evidente está associada à robustez a falhas. Por atuarem em conjunto, no caso de um dos robôs deixar de operar, a perda pode ser compensada pelos demais; garantindo a execução da tarefa. Também, na maioria dos casos espera-se que esta abordagem agregue um melhor desempenho considerandose, por exemplo, o tempo de execução (sendo menor no caso de múltiplos 
robôs). Além disso, em alguns casos é a única abordagem factível, por exemplo, se os requisitos necessários para a execução da tarefa excedem aqueles presentes em um único robô.

No caso dos sistemas de múltiplos robòs, além dos requisitos naturalmente associados ao deslocamento de um robô, o sistema de navegação deve satisfazer requisitos adicionais, a saber: aqueles que garantam as características inerentes a um sistema de múltiplos robôs; e aqueles que são associados às particularidades da tarefa. Nem sempre robôs operando e compartilhando um mesmo ambiente, de forma a atender um mesmo objetivo geral, fazem parte de um sistema de múltiplos robôs.

Há abordagens tradicionais para o controle do modelo de domínio dinâmico do robô e para derivar políticas matematicamente baseadas. Embora teoricamente bem fundamentadas, essas abordagens dependem fortemente da precisão do modelo de mundo. Esse modelo não só exige considerável conhecimento para ser desenvolvido, mas aproximações, como linearização, são frequentemente introduzidas para tratabilidade computacional, degradando o desempenho. Outras abordagens, tais como aprendizagem por reforço, orientam as políticas de aprendizagem ao fornecer um retorno de recompensa sobre a conveniência de visitar determinados estados. Definir uma função para fornecer a recompensa, no entanto, é conhecido por ser difícil, além de exigir considerável experiência para resolver. A demonstração também tem a característica prática de focalizar o conjunto de dados para as áreas do espaço de estado realmente encontradas durante a execução da tarefa (Argall et al., 2009).

Para que os robôs integrem um sistema, é necessário que operem sinergeticamente, ou seja, o objetivo geral a ser alcançado deve ser resultante da cooperação entre robôs, em que cada um contribua na execução da tarefa, executando alguma de suas possíveis frações. Além disso, no que se refere às tarefas assumidas por cada um dos robôs, duas eventuais deficiências devem ser minimizadas: a redundância entre tarefas, ou seja, qualquer tarefa não deve ser prescindível por ter dupla atribuição; e o tempo ocioso de cada robô. Ainda uma outra característica inerente a tais sistemas é a capacidade de comunicação de cada um dos robôs.

Duas aplicações têm sido frequentemente vinculadas à pesquisa focada no projeto de sistemas de navegação dirigidos aos sistemas de múltiplos robôs, a saber: exploração de ambientes e vigilância de ambientes. No caso da tarefa de exploração, os robôs devem ser capazes de executar o sensoriamento completo do ambiente considerado. Observe que não é necessário que cada ponto do ambiente seja visitado (que pelo menos um robô ocupe cada ponto do ambiente), mas basta que cada ponto tenha sido avaliado segundo 
alguma grandeza (referente ao sensor utilizado). Nesta tarefa, pode ser exigida a condição de que o tempo necessário para cumprir a tarefa seja mínimo.

A tarefa de vigilância é cumprida se o sensoriamento de cada ponto do ambiente é repetidamente e indefinidamente executado, exigindo-se algum comprometimento em termos do intervalo em que o sensoriamento se repete. É possível entender que a tarefa de vigilância é executada tal como se o ambiente fosse explorado repetidamente. Sob esta interpretação, uma das restrições impostas à tarefa é que o tempo máximo correspondente à execução de sensoriamento completo do ambiente (a cada nova exploração) sejam minimizados.

A disposição espacial relativa dos robôs durante a navegação tem se tornado um tópico frequentemente abordado em esforços de pesquisa. Tal disposição espacial é também denominada formação de robôs. Os sistemas de navegação que agregam alguma estratégia de formação devem dispor espacialmente os robôs de forma que atendam algum requisito, por exemplo: o espaço delimitado pela linha imaginária que une os robôs representa, mesmo que grosseiramente, uma figura geométrica (e.g.: polígono ou círculo) ou; a cobertura definida pelos robôs ao longo do deslocamento deve ser máxima, entendendo que a característica de cobertura é observada se a região sobre a qual o sensoriamento é concluído em cada instante é totalmente contígua (sem espaços não atendidos pelo sensoriamento de algum robô, no polígono formado pelas linhas imaginárias que unem os robôs).

Em que pese a existência de propostas apoiadas em modelos matemáticos, agregados a modelos físicos ou não, para projeto de sistemas de navegação de múltiplos robôs, os projetos baseados em técnicas oriundas da Inteligência Artificial parecem ocupar maior espaço na literatura corrente. São técnicas atraentes devido ao fácil entendimento e à simplicidade com que podem ser adotadas; além de serem versáteis, considerando os resultados satisfatórios alcançados.

Um conjunto particular de tais técnicas parece bem ajustado ao caso de sistemas de múltiplos robôs. São técnicas inspiradas em sociedades biológicas do tipo enxame, as quais vêm sendo reunidas em uma área específica denominada Inteligência Coletiva. Pelo fato dos robôs operarem de forma sinergética, visando alcançar um objetivo comum, permite estabelecer uma correspondência mínima, mas ao mesmo tempo instigante, entre os dois sistemas (multiplicidade de agentes, objetivo comum e sinergia). A plausibilidade biológica é relativamente direta, ou seja, existe um respaldo biológico no sentido de que tais técnicas (inseridas no âmbito da Inteligência Coletiva) sejam consideradas promissoras no projeto de sistemas de navegação em sistemas de múltiplos robôs. No presente trabalho, o enfoque é dado em técnicas de inteligencia coletiva baseadas no comportamento de formigas. 


\subsection{Objetivos e Contribuições}

Esta tese tem como objetivo o desenvolvimento de duas estratégias bioinspiradas de coordenação de múltiplos robôs. A primeira está voltada para a aplicação em tarefas de exploração e vigilância de ambientes, enquanto que a segunda para a formação de robôs. Tais estratégias apresentam as seguintes características em comum:

- descentralizada e distribuída: os robôs operam de forma independente e utilizam apenas informação local para a tomada de decisão;

- mínima informação possível: uma vez que os robôs são estruturas simples e independentes, a única tarefa deles é detectar feromônio e decidir a nova direção;

- independência de parâmetros: a estratégia independe do número de robôs e da estrutura artificial do ambiente.

Em relação à estratégia de formação, destaca-se a habilidade de mudança e adição de um robô responsável pelo deslocamento do grupo, denominado como líder.

Além disso, pretende-se avaliar as estratégias propostas, realizando diversos experimentos com o objetivo de testá-las extensivamente, explorando as características de cada uma delas, principalmente em termos de robustez, flexibilidade e eficiência.

\subsection{Organização do Trabalho}

Esta tese de doutorado está organizada do seguinte modo:

- Capitulo 2: são apresentadas algumas definições básicas no contexto de sistemas de múltiplos robôs. O enfoque é dado a três aspectos de tais empreendimentos, a saber: exploração de ambientes desconhecidos, cobertura de ambientes e formação de robôs. Uma revisão de trabalhos relacionados em cada um desses tópicos é fornecida a fim de contextualizar as duas frentes de pesquisas abordadas nesta tese.

- Capitulo 3: é apresentado o algoritmo de inteligência coletiva baseado no comportamento de formigas. Suas propriedades mais salientes são discutidas, como estigmergia e emergência.

- Capitulo 4: é descrita a estratégia de coordenação descentralizada proposta neste trabalho, aplicada à tarefa de exploração e vigilância. Após 
a definição formal do problema de vigilância, o sistema em si é apresentado, com detalhamento de todos os seus módulos integrantes. Posteriormente, um conjunto abrangente de experimentos é apresentado a fim de avaliar o desempenho do sistema proposto.

- Capítulo 5: a estratégia de coordenação aqui desenvolvida é apresentada no contexto de formação de robôs. Inicialmente, discute-se acerca das características desejadas do sistema de formação proposto. Em seguida, são descritas suas funcionalidades e, por fim, é fornecida uma análise experimental.

- Capítulo 6: são apresentadas as conclusões desta tese, suas contribuições, limitações e propostas para trabalhos futuros. 


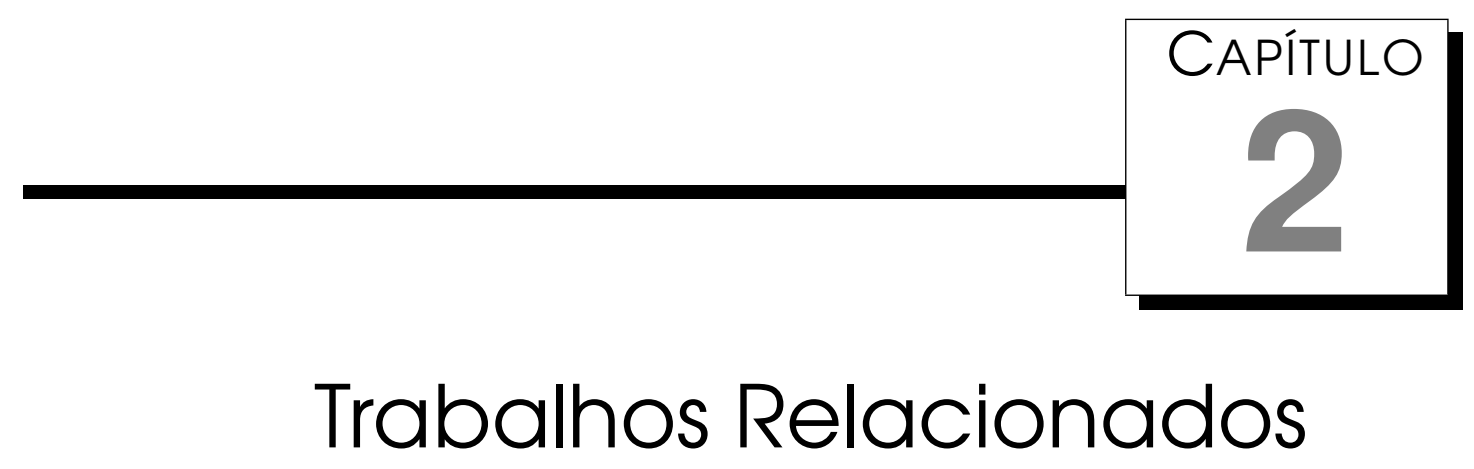

\subsection{Considerações Iniciais}

A utilização de sistemas de múltiplos robôs pode ser vantajosa em diversas situações (Iocchi et al., 2001; Fierro et al., 2005). Primeiro, algumas tarefas podem ser demasiadamente complexas para que um único robô consiga realizá-las de maneira eficiente. Nesse sentido, Dudek et al. (1996) descreveram cenários em que a cooperação entre diversos agentes poderia ser benéfica, seja para a completude da tarefa em si ou para a melhoria do desempenho do sistema como um todo. Segundo, quando um grupo de robôs está disponível para a realização da tarefa, duas características complementares importantes do sistema podem ser mais facilmente gerenciadas (Parker, 1998): adaptabilidade e robustez. A robustez refere-se à capacidade do sistema de acomodar eventuais falhas nos robôs ou na comunicação entre eles, permitindo que o sistema continue operando. A adaptabilidade refere-se à capacidade do sistema de modificar seu comportamento, de acordo com mudanças no ambiente, no grupo ou na própria tarefa, tal que o desempenho do sistema seja mantido. Terceiro, ao observar-se a dinâmica social presente no grupo de robôs, pode-se obter um maior entendimento dos problemas fundamentais de ciências sociais e biológicas.

Segundo Cao et al. (1995), para que tais vantagens sejam possíveis na prática, diversos aspectos devem ser considerados quando da concepção e emprego de sistemas robóticos. Durante sua pesquisa, o autor focou em três tópicos: exploração, cobertura e formação. O primeiro está intrinsecamente relacionado à necessidade de os robôs desempenharem sua tarefa, de acordo 
com o conhecimento sobre o ambiente extraído por seus sensores. O segundo refere-se ao problema de maximização da área sensoriada pelos robôs, visando a visitação completa do ambiente em que eles estão inseridos. O terceiro está relacionado à maneira como os robôs são coordenados para que o grupo mantenha uma configuração alinhada, coesa e livre de colisão interna. Uma revisão acerca desses tópicos é fornecida neste capítulo, com a intenção de oferecer suporte à pesquisa aqui desenvolvida.

Este capítulo está organizado como segue. Na Seção 2.2, discute-se a exploração de ambientes desconhecidos por meio de sistemas robóticos, com a apresentação de estudos na área. Na Seção 2.3, o problema de cobertura é abordado e as estratégias comumente utilizadas no contexto são descritas. Na Seção 2.4, a questão de posicionamento dos robôs para a manutenção do grupo é tratada, com uma apreciação sobre os métodos computacionais aplicados para tal fim. Por fim, na Seção 2.5, as considerações finais do capítulo são tecidas.

\subsection{Exploração de ambientes}

A atuação de um sistema robótico móvel em situações reais implica no conhecimento da área onde ele está inserido, a fim de que ele possa realizar suas tarefas de forma eficiente. Neste contexto, a exploração de ambientes é fundamental para a autonomia de robôs munidos de mecanismos de percepção sensorial, pois possibilita a construção de mapas do meio a ser percorrido (Makarenko et al., 2002). Desta forma, o comportamento exploratório auxilia no processo de tomada de decisão pelo sistema, indicando o conjunto de ações que permita aos robôs atuar em um ambiente desconhecido. Assim, durante a navegação, as decisões tomadas são baseadas no conhecimento adquirido sobre o ambiente e na escolha de ações que minimizam a incerteza em relação ao mesmo.

Os métodos de navegação em ambientes podem ser classificados em três tipos, de acordo com a incerteza envolvida na aplicação (Dam, 1998): 1) métodos globais são baseados no conhecimento total do ambiente de atuação e na localização do robô. Neste caso, a navegação se restringe ao planejamento de um caminho entre posições definidas do mapa. Abordagens desse tipo de método são mapas de caminhos (roadmaps) (Okabe et al., 2000), decomposição celular (Russell and Norvig, 2009) e campos potenciais (Latombe, 1993); 2) métodos locais permitem ao robô construir apenas um mapa local a partir das informações sensorias obtidas na posição atual do robô; e 3) métodos híbridos combinam a aplicabilidade dos métodos locais e globais, tornando um modelo completo. Estes métodos possibilitam uma navegação 
mais robusta e precisa através da aquisição da estrutura do ambiente, por meio da integração de diferentes mapas locais em um mapa global. Isto permite um melhor desvio de obstáculos, uma correção mais refinada de erros de posicionamento do robô e uma diminuição de informações inconsistentes do mapa.

Para que o planejamento exploratório de ambientes desconhecidos seja realizado, métodos de navegação híbridos são geralmente utilizados, dada sua superioridade em termos de flexibilidade, precisão e robustez. Neste contexto, as estratégias de exploração podem ser divididas basicamente em duas vertentes (Romero et al., 2000): abordagens reativas e abordagens baseadas em modelos. No primeiro caso, as decisões acerca da movimentação do robô são tomadas com base somente em informações providas por seus sensores e, portanto, fornece uma exploração localizada. O método reativo mais representativo é conhecido como seguir paredes (Rekleitis et al., 2001). Ele posiciona o robô ao longo das paredes do ambiente para compor o mapa do mesmo. Tal abordagem é limitada a configurações de ambiente simples e esparsas. Caso contrário, há o risco de uma exploração incompleta, devido a mínimos locais (Lee, 1996). No segundo caso, a exploração é guiada em direção às regiões menos visitadas do ambiente (Lee, 1996). Para isso, o robô deve fazer uso tanto das informações adquiridas pelos seus sensores quanto do conhecimento disponível até o momento sobre o meio. Dentre as técnicas desta abordagem, aquelas que aplicam fronteiras estão entre as mais utilizadas. A seguir, alguns trabalhos baseados nesse conceito são descritos.

Um dos trabalhos mais difundidos na área de exploração foi proposto por Yamauchi (1997). Nele, o autor define fronteira como a região entre uma área explorada e uma não explorada. Assim, a região de fronteira é localizada na borda de cobertura do sensor. Considerando um sistema composto de um único robô, novas fronteiras surgem à medida que o robô se movimenta. Elas são, então, armazenadas em uma estrutura do tipo árvore, que é percorrida posteriormente em profundidade. Para a detecção de várias fronteiras, o robô move-se em direção à fronteira mais próxima, de maneira sucessiva. $\mathrm{O}$ processo de exploração é finalizado quando não houver mais fronteiras para serem exploradas.

Em Al khawaldah et al. (2010), focou-se na exploração baseada em fronteira com um par de robôs móveis cooperativos. Nesse cenário, surge a necessidade de considerar a sobreposição entre eles. Com o objetivo de reduzi-la e, com isso, minimizar o tempo de exploração total, os autores apresentaram um algoritmo de concorrência entre os robôs. Ele implementa uma função de ponderação entre o custo e a utilidade de cada robô em posicionar-se em determinada região do ambiente. O custo é definido pela distância entre o 
robô e a célula de fronteira. A utilidade enfatiza quanto de incerteza acerca do ambiente é reduzida, caso o robô avance em determinada direção. Através de um termo, que também inclui na decisão a distância entre os robôs, a exploração realizada pelo sistema robótico é otimizada.

A fim de considerar sistemas de múltiplos robôs para exploração de ambientes, Yamauchi (1998) introduziu uma generalização da proposta original de fronteiras. Nela, os robôs compartilham o mapa e a árvore contendo as posições das fronteiras. Com posse de todas as fronteiras, um robô pode decidir em explorar uma fronteira descoberta por outro robô, desde que esta seja a mais próxima. Embora seja um aprimoramento importante, esta abordagem apresenta algumas limitações. A principal é que, como o controle de cada robô no grupo é independente, a estratégia não evita redundâncias no sentido de vários robôs navegarem para a mesma fronteira.

Para sanar essa deficiência, Burgard et al. (2000) apresentaram uma abordagem probabilística para coordenar os robôs de maneira que estes atinjam fronteiras distintas. Assim, após a integração dos mapas (grades de ocupação (Elfes, 1989) foi o método utilizado) e, consequentemente, das fronteiras, é associado a cada uma delas um custo de alcance e de utilidade. O custo de alcance depende da probabilidade das células vizinhas da célula da fronteira e da distância da fronteira até essas células. Para a utilidade de uma célula (onde está uma fronteira), encontra-se a probabilidade de que a célula seja visível, a partir da posição de outras fronteiras associadas aos demais robôs. Uma vez que uma fronteira é selecionada, sua utilidade é reduzida para impedir que outros robôs a selecionem. Portanto, cada robô é associado a uma fronteira, distribuindo a tarefa de exploração.

Outra estratégia de exploração cooperativa é proposta em Franchi et al. (2009). Primeiramente, grupos de robôs são identificados por meio do raio de comunicação entre eles, e a área de cobertura de cada robô é compartilhada no grupo. Desta área resultante, obtém-se regiões ocupadas por obstáculos, regiões já exploradas e regiões de fronteira. Dentre as regiões de fronteira, aquela com maior extensão é eleita como o novo objetivo (alvo) do robô. A cada instante em que um robô alcança um objetivo, este é representado por um vértice do grafo, que representa o ambiente. Neste grafo, o caminho entre dois objetivos consecutivos é representado por uma aresta. Em situações de intersecção de caminhos de robôs do mesmo grupo, um líder é selecionado para distribuir os alvos entre os robôs do grupo, evitando colisões. Ao verificar que não há mais fronteiras para serem exploradas, o robô retorna para sua posição inicial, seguindo os vértices do grafo construído. Como desvantagem dessa estratégia, percebe-se que ela é funcional somente para ambientes estáticos. Qualquer mudança no ambiente pode prejudicar o desempenho do 
sistema, uma vez que o grafo resultante não o representaria de forma fiel.

\subsection{Cobertura de ambientes}

Em um sistema de múltiplos robôs, cada um de seus componentes é dotado de capacidades de sensoriamento, de computação e de comunicação (Tan et al., 2004). Quando os agentes do grupo realizam uma determinada tarefa, de forma cooperativa, transmitindo a seus pares informação percebida no ambiente, diz-se que uma rede de sensores está constituída (Cortes et al., 2004). Um dos mais importantes requisitos para o estabelecimento de tal rede é a definição de uma estratégia de coordenação adequada para reposicionar os robôs do grupo. Porém, devido a severas restrições e condições de um ambiente, manter a topologia da rede de sensores não é trivial.

Uma estratégia de coordenação adequada traz inúmeras vantagens para o desempenho de uma tarefa pré-estabelecida, tais como: a minimização dos esforços do robô (no que diz respeito, principalmente, à distância percorrida e ao gasto com bateria) e do tempo para manter a topologia desejada, minimização do custo computacional e maximização da área de cobertura (Choset, 2001). Quando o mapa do ambiente é conhecido, o desenvolvimento de uma estratégia ótima para coordenar um grupo de robôs, garantindo os benefícios citados, torna-se menos complexo (Mannadiar and Rekleitis, 2010). Porém, o desafio é maior quando informações do ambiente não estão disponíveis ou podem ser alteradas devido à presença de obstáculos ou objetos móveis (Ge and Fua, 2005). Neste contexto, a eficácia de muitas aplicações que envolvem rede de sensores é avaliada em termos do grau de cobertura obtido (Lee et al., 2009; Zheng et al., 2005).

Segundo Gage (1992), o problema de cobertura é definido como a maximização da área sensoriada (área de cobertura) por todos os robôs em um determinado instante. Neste sentido, diversas abordagens têm sido propostas na tentativa de solucionar o problema de cobertura. Elas podem ser agrupadas em duas linhas de pesquisa. Na primeira, os robôs se movem isoladamente a fim de que a combinação das áreas sensoriadas por eles corresponda a toda a área do ambiente. Neste caso, o ambiente é particionado de modo que cada porção seja sensoriada por um robô do grupo e, por meio da capacidade de comunicação de todos, a informação sobre as áreas já cobertas é compartilhada. Alguns trabalhos relacionados a esta abordagem são descritos a seguir.

Um algoritmo que opera segundo essa política foi apresentado em Kong et al. (2006). Baseado no algoritmo de decomposição celular, denominado Boustrophedon (Choset and Pignon, 1997), o ambiente considerado é dividido, virtualmente, em pequenas áreas de largura fixa. Inicialmente, os robôs são 
distribuídos em regiões distintas do ambiente e são responsáveis por cobrir sua área correspondente. O ambiente é representado por um grafo de modo que cada vértice indica uma dessas áreas. Dois vértices são conectados por uma aresta se as respectivas áreas são adjacentes. À medida que os robôs cobrem uma área, o vértice é inserido no grafo e tal informação é repassada aos demais. Desse modo, todos os robôs possuem o estado do grafo atualizado. Assim, eles são capazes de decidir quando o ambiente está totalmente coberto, finalizando o processo. A maneira limitada como os robôs se locomovem no interior de cada área impede que ambientes com configurações arbitrárias sejam considerados, como aqueles em que há a presença de pequenas passagens, tais como corredores e portas.

Baseado ainda na ideia de que os caminhos percorridos pelos robôs do grupo sejam representados por grafos, Agmon et al. (2009) aplicou a noção de árvore geradora para construir uma cobertura eficiente do ambiente. Tal abordagem foi inicialmente considerada em (Gabriely and Rimon, 2001), em que os autores descrevem um método para encontrar um caminho hamiltoniano capaz de cobrir todo o ambiente, utilizando apenas um único robô. Assim, um robô de formato quadrangular de lado $D$ atua em um ambiente divido em $N$ células de lado $D$. Agrupando quatros células e, assim, formando um quadrado maior, constrói-se, então, uma árvore geradora sobre as células desse ambiente de menor granularidade. A cobertura é obtida percorrendo-se as arestas de tal árvore. Quando sistemas de múltiplos robôs são considerados, a escolha da árvore geradora pode alterar significativamente a distância relativa de um robô ao outro, impactando no tempo de cobertura. Agmon et al. (2009) descreve um algoritmo heurístico que maximiza a distância entre robôs ao longo do caminho da árvore gerado. Ele possui duas fases. Na primeira, sub-árvores são criadas gradualmente para cada robô, tal que a cada iteração, ela seja expandida em direção contrária àquelas dos demais robôs. $\mathrm{Na}$ segunda fase, as sub-árvores são conectadas tal que a árvore resultante não contenha ciclos. Uma vez que a árvore é obtida, os robôs podem percorrê-la, a partir de suas posições iniciais, segundo a família de algoritmos de locomoção descrita em Hazon and Kaminka (2005).

Na segunda linha de pesquisa, os robôs, navegando próximos uns aos outros, devem evitar o desperdício de recursos sensoriais, reduzindo a sobreposição dos mesmos. Entretando, a dispersão do grupo não deve ser tal que ocasione espaços não cobertos em seu interior. De acordo com Gage (1992), os métodos desta abordagem podem ser divididos em 3 tipos básicos: blanket, barrier e sweep. No primeiro, os robôs devem alcançar um conjunto de pontos estáticos que maximize a área total coberta por eles. No segundo, a cobertura dá-se por um arranjo estático dos robôs do grupo em formato de 
barreira, a fim de preservar alguma área. No terceiro, o objetivo é mover o grupo de robôs em um ambiente, maximizando a área de cobertura. A seguir, trabalhos relevantes das três abordagens são brevemente descritos.

Considerando-se a abordagem de barrier, Kumar et al. (2005) forneceram a fundamentação teórica necessária para o estabelecimento de um arranjo adequado de robôs, com fins de proteção de uma dada região. Eles introduzem a definição de cobertura por $k$-barrier, em que $k$ refere-se à quantidade mínima de robôs que detectam a passagem de um intruso, quando este deseja alcançar a região protegida. A partir desta definição, os autores desenvolveram algoritmos baseados na teoria de grafos tanto para detectar se uma região é coberta por $k$-barrier quanto para estabelecer uma disposição ótima de robôs para que ela seja $k$-barrier. Como verificou-se nesse estudo, tal detecção não pode ser realizada localmente por cada agente do grupo, devido às restrições de comunicação. Para lidar com a situação, Cheng and Savkin (2011) introduzem o conceito de cobertura barrier de localidade $L$, segundo o qual pode ser garantida a detecção de todos os caminhos de intrusão possíveis de trajetória confinada em uma porção de tamanho $L$ da região coberta pelo grupo de robôs. Embora esse tipo de cobertura seja mais restrito, esperase que, quando o grupo atue em ambientes sufucientemente estreitos, ele se aproxime- da cobertura por $k$-barrier original. Experimentos realizados validam o algoritmo local desenvolvido nesse trabalho, os quais corroboram tal hipótese, ampliando sua utilidade em cenários reais de proteção de uma região.

Enquanto os métodos da abordagem anterior apresentam comportamento estático, aqueles baseados em sweep possibilitam o deslocamento dos robôs. Neste contexto, diversos estudos têm focado em aplicações de planejamento de caminhos. Outra vertente, mais condizente com a definição dada por Gage (1992), consiste no desenvolvimento de técnicas que promovem o deslocamento do grupo de forma coesa, assemelhando-se a uma estrutura do tipo barrier com movimento. Dois trabalhos relacionados são destacados a seguir.

$\mathrm{Na}$ abordagem apresentada em Alboul et al. (2010), um conjunto composto por três robôs foi empregado para cobrir um ambiente desconhecido. Estes se movimentam no ambiente com o objetivo de manter a proximidade entre eles. Inicialmente, o ambiente é coberto por uma grade virtual triangular que se expande infinitamente em todas as direções. Os vértices dos triângulos correspondem a áreas que podem ser sensoriadas pelos robôs e, portanto, ocupadas por estes em algum instante, enquanto que as arestas indicam o caminho entre os vértices. Durante a navegação do grupo, os robôs constroem um mapa topológico do ambiente, representado por um grafo, cujos vértices correspondem àqueles dos triângulos virtuais. O posicionamento dos 
robôs é estimado a partir de dados de sensores de distância e de comunicação. Primeiramente, dois robôs denominados sentinelas são posicionados nos vértices de um mesmo triângulo virtual. Desde que a posição e orientação dos sentinelas sejam conhecidas, assim como os dados provenientes do sensor de distância, é possível estimar a posição de um objeto (ou robô) dentro da área de cobertura do sensor. Ao estimar a posição de um terceiro robô, tal informação é transmitida, informando-o sobre o novo vértice a ser ocupado. A partir deste instante, o terceiro robô torna-se autônomo para decidir o ajuste de sua direção, requisitando a informação dos sensores dos sentinelas para corrigir o erro de odometria. Para o êxito desse mecanismo de exploração, é necessário que os robôs sentinelas permaneçam próximos ao terceiro robô, inclusive para que todos estejam dentro do raio de comunicação. Independentemente da intenção dos autores, a proximidade dos robôs estabelece uma formação triangular (devido à grade virtual inicial) com distância fixa entre os robôs. Observa-se, neste caso, que o deslocamento dos robôs é possível somente em ambientes cuja disposição dos obstáculos possibilite a movimentação dos robôs na formação triangular, sem distorcê-la.

Também utilizando o conceito de sweep, Cheng et al. (2011) desenvolveram um esquema de controle descentralizado, capaz de coordenar múltiplos robôs ao longo de uma linha. Ele baseia-se em um conjunto de regras inspiradas na agregação animal observada na natureza. Assim, cada componente do grupo é orientado de acordo com uma ponderação entre os estados atuais de seus próprios sensores e dos de seus vizinhos, fazendo com que um consenso entre os comportamentos dos robôs seja obtido.

Considerando a abordagem blanket, em Howard et al. (2002), um sistema de múltiplos robôs é empregado para a tarefa de cobertura sem conhecimento da configuração do ambiente. Para tanto, os robôs devem se dispersar de modo que a área de cobertura aumente, porém, evitando que algum robô se desconecte do grupo. Sendo assim, uma abordagem baseada em campos potenciais (Khatib, 1985; Latombe, 1993) é descrita, considerando os robôs como partículas móveis virtuais sujeitos a forças virtuais. Como princípio da técnica de campos potenciais, as partículas sofrem o efeito da força de atração originária da posição de destino, combinado com a força de repulsão resultante dos obstáculos do ambiente. Considerando um cenário em que somente as forças de repulsão atuam, as partículas tendem a se distanciar umas das outras e dos obstáculos. Sua movimentação ocorre até o instante em que o grupo atinge o estado de equilíbrio, o qual é determinado pela anulação das forças de repulsão. A partir deste momento, os robôs permanecem imóveis e, então, é analisada a cobertura do ambiente gerada pelo grupo. Com esta abordagem, mesmo que os robôs iniciem a navegação, compactados em um mesmo local, 
estes são dispersos devido às forças de repulsão. Ao estabilizar-se, o formato do grupo obedece ao formato do ambiente para maximizar a área de cobertura. Destaca-se ainda que os parâmetros que influenciam na intensidade da força de repulsão são determinantes para a eficiência da cobertura.

Um trabalho correlato foi investigado em Tan et al. (2004), no qual é proposto um modelo distribuído para a cooperação de múltiplos robôs, em uma rede de sensores móveis. Ele define a relação geográfica entre os robôs, em ambientes convexos, utilizando diagrama de Voronoi e a triangulação de Delaunay (Guibas and Stolfi, 1985; de Berg et al., 2008; Shewchuck, 1997; Kallmann et al., 2003). Uma vez encontrada a região de Voronoi para todos os robôs, é definido o centróide de cada uma delas. À medida que o robô se aproxima do seu centróide, ele se afasta dos demais. No instante em que todos os robôs alcançam o centro de suas regiões, a distância entre eles é estabelecida, promovendo a cobertura do tipo blanket.

\subsection{Formação de robôs}

Uma das motivações para a pesquisa em estratégias de coordenação de robôs advém da observação do comportamento auto-organizável de grupos biológicos. Este tipo de comportamento é resultado da interação entre os agentes. Na natureza, agentes da mesma espécie atuam de forma coordenada, o que facilita a execução de tarefas complexas, algumas delas, impossíveis de serem efetuadas por um único robô. Exemplos de sistemas multiagentes são observados em diferentes escalas na organização biológica: desde a interação entre moléculas e células como bactérias (Waters and Bassler, 2005) até o comportamento coletivo de animais (Sumpter, 2006; Couzin, 2009; Sumpter, 2010; Frewen et al., 2011), tais como, conjunto de pássaros, peixes e insetos. Apesar da grande diferença nas escalas de agregação, a similaridade no padrão de movimento que cada grupo produz sugere que princípios básicos sejam responsáveis pela coordenação de movimento dos indivíduos do grupo. Estes grupos exibem, frequentemente, comportamentos coletivos complexos e coordenados, que proporcionam estudos do comportamento individual dos agentes em relação a suas interações em um grupo.

A maneira pela qual os indivíduos integram um grupo de forma autônoma, gerando uma dinâmica complexa, atrai a atenção de pesquisadores. A descoberta das regras que governam essa dinâmica de movimento e como os princípios da física estão relacionados com o comportamento de cada indivíduo estão entre as questões de interesse de matemáticos, físicos, cientistas da computação e biológos (Gueron et al., 1996; Couzin and Krause, 2003; Lu et al., 2008). Outra questão que intriga os pesquisadores é o motivo pelo qual 
os agentes biológicos tendem a se locomover em direção àqueles de mesma espécie, mantendo o grupo enquanto se movem (Toner and Tu, 1995; Dutta, 2010).

Dentre os grupos de animais mais conhecidos e fontes de inspiração para diversas pesquisas, estão bando de pássaros e cardume. A característica principal desses grupos é a uniformidade. Os grupos são compostos por indivíduos de mesma espécie e tamanho que se deslocam com velocidades idênticas na mesma direção. Em grupos com grande quantidade de indivíduos, não há a presença de um líder que guia o movimento do grupo (Radakov, 1973; Dutta, 2010). Assim, não há qualquer tipo de hierarquia (Partridge, 1982). A direção de movimento do grupo é determinada individualmente pelos agentes que interagem com os demais autonomamente. Comportamentos essenciais guiam os indivíduos de um grupo. São eles: evitar colisão contra os demais indivíduos (movimento de repulsão), aproximar-se deles (movimento de atração) e movimento paralelo, o que mantém a coesão do movimento.

Embora o cardume seja um dos exemplos mais citados a respeito de comportamento social animal, até recentemente foi pouco explorado. Um dos motivos para isto é o comportamento inato observado no padrão de movimento, caracterizado pela mudança brusca de posição e direção dos peixes em um curto espaço de tempo. Responsável por isto, o órgão sensitivo localizado ao longo do corpo, em ambos os lados, capaz de detectar a movimentação e vibração da água, auxilia na percepção de peixes próximos e locomoção em ambientes com pouca visibilidade. De acordo com Partridge (1982), este órgão (ou linha lateral) é tão importante quanto a visão para manter a formação do cardume. Experimentos em tanques artificiais foram realizados para certificar a real influência da linha lateral. Peixes com os olhos vendados (uma lente opaca foi posicionada nos olhos), permaneceram mais distantes de seus vizinhos mais próximos do que o esperado. Em contraste, quando a linha lateral é inutilizada, a distância entre os peixes é menor do que geralmente ocorre. No entanto, para ambos os experimentos, os peixes estabeleceram uma formação. Com base nesses experimentos, pesquisadores concluem que a visão tem maior influência na força de atração (os peixes permaneceram mais próximos com este sentido), enquanto que a força de repulsão é decorrente da linha lateral. A coesão do cardume, portanto, é resultado do balanceamento das forças de atração e repulsão. Contudo, ambos os sistemas sensoriais são importantes para manter o cardume em movimento.

Em virtude do que foi mencionado, uma importante questão referente ao comportamento biológico de animais é como os grupos coordenam seus movimentos enquanto se locomovem. Neste sentido, estudos em simulações têm sido úteis no entendimento não somente de como a coordenação ocorre, 
mas também de como o comportamento difere em distintos grupos de animais (Reynolds, 1987; Sumpter, 2010). Com o avanço da tecnologia nas áreas de visão computacional e sistemas de posicionamento global, sistemas artificiais são desenvolvidos a fim de reproduzir o comportamento de grupos biológicos, em que os agentes são representados por robôs. Nestes sistemas, o comportamento do grupo de robôs é reduzido ao conjunto de trajetórias geradas. Assim, a modelagem das interações de um agente pode ser obtida através da observação de sua trajetória, o que leva ao caminho inverso para encontrar a solução do problema. Esta maneira de encontrar a solução não é trivial, e mesmo quando isto é possível, geralmente não há uma única solução para o problema.

Para sanar essa dificuldade, muitas estratégias de coordenação têm sido propostas seguindo o, então denominado, modelo de partículas autoimpulsionadas (self-propelled particle modules) (Reynolds, 1987; Cucker and Smale, 2007; Liu et al., 2009; Yates et al., 2010). Este modelo sugere que um indivíduo tome suas decisões de acordo com informações locais (Aoki, 1982; Viscido et al., 2004; Nabet et al., 2009; Aureli and Porfiri, 2010; Abaid and Porfiri, 2010). Sem conhecer o estado do grupo, um indivíduo considera somente informações (por exemplo, velocidade, direção e distância) daqueles mais próximos.

Um dos pioneiros na tentativa de reproduzir o padrão de movimento de um cardume, o modelo de Aoki (1982), foi inspirado em sua observação e investigação empírica da interação dos peixes. Seu modelo tem sido base para o desenvolvimento de diversas abordagens, com o intuito de aprimorar o conhecimento do comportamento do cardume (Inada, 2001; Oboshi et al., 2002; Shinchi et al., 2002; Viscido et al., 2004; Zheng et al., 2005; Kelly and Pujari, 2010; Couzin et al., 2011).

Aoki (1982) define três áreas ao redor de um indivíduo, nas quais este é capaz de perceber a presença de outro. Dependendo da área onde ocorre tal percepção, o indivíduo toma uma decisão sempre objetivando a manutenção do cardume. Um detalhe importante diz respeito ao tamanho dessas áreas e à distância a que estão do indivíduo em questão. As áreas são definidas como circunferências de raios $R_{r}, R_{p}$ e $R_{a}$ (com centro na posição do indivíduo) em todo o campo de visão, referentes às áreas de reação repulsiva, orientação paralela e reação atrativa, respectivamente, tal que $R_{r}<R_{p}<R_{a}$. A explicação para os nomes das áreas vem a seguir.

Considerando o indivíduo A em um ambiente bidimensional, ao perceber outro indivíduo B na área de reação repulsiva, ou seja, a uma distância $d<R_{r}$, o comportamento gerado por A é de repulsão em relação a B. Este tipo de comportamento evita colisões entre indivíduos que se aproximam durante o 
movimento do cardume. Em situações em que o indivíduo B se encontra na área de orientação paralela, ou seja, a uma distância $R_{r}<d<R_{p}$, i.e. $\left(d-R_{r}\right)<\left(R_{p}-R_{r}\right)$, o indivíduo A ajusta sua direção de movimento para que seja similar à direção de $\mathrm{B}$. Tal direção é em relação ao seu eixo de movimento. Assim, os indivíduos tendem a se locomover na mesma direção. Por último, o indivíduo A é atraído pelo $\mathrm{B}$ quando este for percebido a uma distância $R_{p}<d<R_{a}$, i.e. $\left(d-R_{p}\right)<\left(R_{a}-R_{p}\right)$, na área de reação atrativa. A ideia da geração desse comportamento é evitar que a dispersão dos indivíduos desfaça o grupo. A coesão do cardume é, portanto, resultado do balanceamento das forças de repulsão, atração e orientação.

Além da facilidade de desempenhar tarefas mais complexas, outra vantagem dos animais se locomoverem em grupo é aumentar a capacidade de defesa e a possibilidade de sobrevivência da espécie. Em particular, para o grupo de peixes, Partridge (1982) afirma, por meio de observações reais e simuladas, as chances de um peixe ser capturado por um predador, quando não está em um cardume, é maior. O fato dos peixes permanecerem isolados (dispersos do cardume) significa que em diversas regiões há a presença de um peixe, e não somente em uma única região como é o caso do cardume. Assim, a probabilidade do predator alcançar alguma dessas regiões e capturar uma presa é maior, pois há mais regiões com a presença de peixe. Por outro lado, quando os peixes estão concentrados em uma única região, formando o cardume, o número de possíveis locais em que o predador pode encontrar sua presa é reduzido. Outra vantagem aparece mesmo quando o predador encontra o cardume. Neste, um peixe do grupo é selecionado para ser devorado. No entanto, os demais peixes próximos (e praticamente idênticos) a este, juntamente com o movimento brusco do cardume, confundem o predador. Experimentos reportados em Partridge (1982) mostram dois modos de evacuação dos peixes em caso de ataque de um predador. No primeiro deles, os peixes se dispersam formando uma esfera. Porém observou-se a eficiência dos órgãos sensitivos, uma vez que não há detecção de colisões. O outro modo consiste na divisão do cardume em dois grupos, os quais se movem em direções opostas e voltam a formar um único cardume após a passagem do predador. A manutenção dos cardumes, mesmo após a divisão, ocorre devido aos comportamentos anteriormente citados no modelo de Aoki.

Apesar do modelo de Aoki apresentar comportamentos essenciais para a manutenção do movimento coordenado, tornando possivel a reprodução de movimentos similares àqueles observados na natureza, ele não prevê a existência de um predador. Modelos que destacam a relação entre presa e predador são descritos em Ward (2001); Oboshi et al. (2002); Morihiro et al. (2006, 2007). Utilizando o conceito de áreas ao redor dos peixes, Zheng 
et al. (2005) define quatro novas áreas para tratar a interação entre a presa e predador. São elas: área de captura, área de urgência, área de atenção e área de paciência. Os raios das circunferências das áreas são definidos de maneira que $R_{c}<R_{u}<R_{a t}<R_{p c}$, respectivamente. A presença de um predador em uma dessas áreas dispara um comportamento distinto. À medida que o predador se aproxima da presa, o peixe tende a se distanciar por duas maneiras descritas. Já com a presença do predador na área de captura ou urgência, o peixe muda sua direção para se afastar o máximo possível do predador, possibilitando seu isolamento do grupo ou, além de tomar esta ação, considera a presença (e direção) dos peixes mais próximos para manter o cardume, mesmo fugindo do predador. No segundo caso, a média das forças (de repulsão do predador e atração do cardume) resulta na nova direção do movimento do peixe. O comportamento de fuga (de peixes e outros animais) também é investigado nas abordagens apresentadas em Domenici and Batty (1997); Cury et al. (2005); Higashitani et al. (2006); Ishikawa (2009); Knadler (2008).

Diferentemente de animais sociais que permancem próximos para formar um grupo, o que resulta em comportamentos coletivos (e sociais), como bando de pássaros (flocking), há outros animais cuja sobrevivência só é possível graças aos comportamentos denominados solitários (Giraldeau, 2008). Exemplos de animais solitários são tigres, leopardos e aranhas. Estes animais desempenham suas tarefas de forma isolada dos demais de sua espécie, principalmente a caça. Entre os tigres, os machos da espécie só compartilham o mesmo território que as fêmeas em épocas de acasalamento e no período da cria dos filhotes recém-nascidos. Em alguns meses de vida, os filhotes acompanham somente a fêmea em sua caça até atingirem a maturidade e tornarem-se aptos a efetuar a caça sozinhos.

De acordo com Giraldeau (2008), os animais solitários se mantêm distante dos demais de sua espécie, com o objetivo de maximizar a área territorial de cobertura, tanto para a procura de presas quanto para a preservação da área a fim de proteger algo (sua cria, por exemplo), e minimizar a sobreposição de territórios patrulhados por outros machos. Para isso, tais animais solitários demarcam seu território através da estigmergia (comunicação indireta), por meio de arranhões em árvores ou emissão de glândulas e substâncias formando trilhas. Seguindo seus instintos, os machos não estão preocupados com o objetivo de maximizar a área patrulhada, mas sim evitar que outro macho rival compartilhe seu território disputando as mesmas presas. Assim, a maximização do território emerge naturalmente do instinto animal. Entre os animais solitários, há, portanto, uma relação de cooperação (Miao et al., 2010).

Com base na cooperação observada em sistemas biológicos, em que in- 
divíduos da mesma espécie trabalham de forma coordenada, o problema de controle cooperativo tem atraído a atenção de pesquisadores na área de controle. Seguindo o mesmo princípio de sistemas naturais, agentes artificiais (robôs, satélites, aeronaves), atuando de forma cooperativa e por meio de iterações simples, possibilitam a execução de tarefas complexas em inúmeras aplicações como o controle de veículos aéreos (Fiorelli et al., 2006; Stipanovic et al., 2002; Bellingham et al., 2002; Barnes et al., 2008; Dasgupta, 2008; Alighanbari and How, 2005; Gonçalves et al., 2011; Shaw and Mohseni, 2011 ; Saaj et al., 2006), incluindo veículos espaciais (Bauer et al., 3821; Weng et al., 2006; Yu et al., 2008; Haddadi et al., 2008; Ma and Schilling, 2009), exploração submarina (Sujit et al., 2009; Peng et al., 2011), vigilância e escolta (Stoeter et al., 2002; Kerr and Spears, 2005; de Freitas et al., 2010) e transporte de objetos (Yamashita et al., 2000; Stilwell and Bay, 1993; Kadioglu and Papanikolopoulos, 2003; Iba et al., 2004; Fujii et al., 2007; Groß and Dorigo, 2009; Wu et al., 2011).

Em muitas dessas aplicações, exige-se que os agentes envolvidos alcancem uma formação específica para melhor eficiência da tarefa. Por exemplo, em tarefas de transporte de objetos e escolta, a formação tem papel fundamental. Nestes casos, o posicionamento inadequado dos agentes prejudica o desempenho da tarefa. No contexto da abordagem proposta nesta tese, a formação de robôs é definida como um conjunto (ou rede) de agentes interconectados mediante as especificações da estratégia (de controle) utilizada. A conexão de um agente a outro, definida pela estratégia, diz respeito à direção relativa e à distância entre eles. Dessa maneira, o objetivo da estratégia de formação consiste em determinar trajetórias dos agentes, além de permitir que cada um deles atinja uma posição, direção e até mesmo velocidade específicas para estabelecer uma formação.

Reynolds (1987) definiu critérios para estabelecer uma formação independente da estratégia adotada: separação, alinhamento e coesão. Tais critérios se aproximam dos conceitos introduzidos por Aoki (1982), na tentativa de modelar a formação de um cardume. Para o critério de separação, os agentes são repelidos por aqueles que se encontram mais próximos, a fim de evitar colisões. O alinhamento exige que os agentes assumam a mesma orientação. Para satisfazer o critério de coesão, a formação deve ser mantida enquanto o grupo se locomove. O comportamento de atração, essencial para a modelagem de Aoki, não aparece explicitamente nos critérios de Reynolds. Porém, o comportamento de atração está intrínseco ao critério de coesão, uma vez que este implica na manutenção da formação. Além disso, somente com os critérios restantes, a tendência é que os agentes se dispersem. Diversas abordagens foram desenvolvidas seguindo estes critérios e, embora não haja uma 
definição clara, estas abordagens são agrupadas nos seguintes métodos de controle de formação: abordagem comportamental, consenso, líder-seguidor, estrutura virtual e função potencial com líder virtual.

Na abordagem comportamental, um conjunto de comportamentos é definido, os quais os agentes de um grupo devem assumir. Dependendo da situação encontrada pelo agente, um ou mais comportamentos devem ser evidenciados. Assim, a ação de controle é definida como a média ponderada das ações associadas aos comportamentos. As variações, no entanto, ocorrem de acordo com o objetivo a ser alcançado. Alguns dos comportamentos utilizados em trabalhos são evitar colisões (contra obstáculos e outros agentes) e alcançar uma região de interesse (seja para cumprir um objetivo ou seguir um agente). Uma das grandes virtudes dessa abordagem é o controle de formação descentralizado. É necessário, somente, que cada agente interaja com aqueles que estão em sua proximidade (ou vizinhança) para, então, tomar uma decisão. Na maioria dos casos, a região de vizinhança é delimitada pela área na qual o agente é capaz de perceber a presença dos demais. Utilizando derivações da abordagem comportamental, Tanner et al. (2007a) propuseram funções de controle baseadas em campos potenciais artificiais (Khatib, 1985; Park et al., 2001; Zhang et al., 2011) e na velocidade dos agentes vizinhos para a formação de robôs, possibilitando que as velocidades dos robôs se aproximem, enquanto evitam colisões. O problema de mínimo local, encontrado em tarefas de desviar de obstáculo, é solucionado por Zhang et al. (2010) ao considerar somente o obstáculo mais próximo para gerar o comportamento de desvio. Em (Kaliappan et al., 2011), o controle de formação baseado na abordagem comportamental é aplicado em veículos aéreos, para que estes sobrevoem uma determinada região, mantendo, em média, uma mesma distância (com baixas variações) entre eles para tarefas de vigilância, resgate e exploração. A característica desfavorável dessa abordagem é a dificuldade em comprovar, matematicamente, a estabilidade da formação, o que a torna não confiável.

O controle de formação, baseado no consenso, é fundamentado na comunicação (passagem de informação) entre os agentes. Como o próprio nome da abordagem sugere, os agentes entram em consenso para executar uma tarefa ou simplesmente tomar alguma decisão em comum. A partir de um fluxo distribuído de informações e um protocolo de comunicação, todos os agentes do grupo atualizam suas informações, de tal maneira que estas convirjam para um valor comum. O algoritmo de consenso pode ser usado para o grupo desviar de algum obstáculo ou escolher a ação mais adequada em um determinado instante. Fusão de sensores (Xi et al., 2010; Sundaram and Hadjicostis, 2007) e alocação de tarefas (Luo et al., 2011; Burger et al., 2011) são algumas 
das aplicações de sistemas multiagentes, por meio do algoritmo de consenso. Para o controle de formação, Ren (2007a) lida com a comunicação entre os agentes quando a informação é variante no tempo. Além disso, o valor resultante da convergência das informações é especificado por um valor de referência. Porém, o acesso à esta informação é restrita somente a alguns agentes. Um aspecto importante do fluxo de informação em um grupo de agentes é a topologia estabelecida para que a comunicação ocorra. Muitas aplicações em formação de robôs consideram que a topologia (conexão) do grupo é constante no decorrer do tempo. Isto facilita o uso do algoritmo de consenso, uma vez que a comunicação ocorre através de conexões existentes entre os agentes (essas conexões que determinam os vizinhos de um agente). Em ambientes dinâmicos, é inevitável a alteração da estrutura do grupo no decorrer da navegação. No modelo apresentado por Vicsek et al. (1995), o tempo é discreto em que os agentes se movem em um plano. Cada um desses agentes atualiza seu estado baseando-se nas informações recebida pelos seus vizinhos. Resultados mostram que, apesar da ausência de um controle centralizado, os agentes se movem em uma mesma direção. Além disso, os resultados são suficientes para afirmar que para qualquer organização possivel entre os agentes, o controle de coordenação é capaz de manter o grupo navegando em uma mesma direção. A análise realizada em Savkin (2003) comprova essa característica mesmo que o grupo de agentes se separe. A topologia do grupo e a maneira pela qual a comunicação entre os agentes ocorre (unilateral ou bilateral) influencia no algoritmo de consenso. Esta questão também é abordada em Ren and Beard (2005); Moreau (2005); Ren (2007b).

Para a formação obtida, segundo a abordagem líder-seguidor, um dos agentes do grupo é selecionado como líder, enquanto os demais são denominados seguidores. O papel do líder não é definir a formação do grupo, mas indicar o caminho a ser seguido. Os seguidores, no entanto, além de perseguir o líder, devem manter a coesão do grupo, tendo como referência aqueles agentes mais próximos. Por esse motivo, alguns pesquisadores consideram que um mesmo grupo pode ter mais de um líder. Neste caso, para cada agente associa-se um vizinho como líder (ou ponto de referência), para auxiliar em seu deslocamento. Em Li and Chen (2005a), por meio de um controle individual baseado em redes neurais adaptativas, os robôs alcançam uma formação guiada por um líder. Uma extensão foi apresentada em Li and Chen (2005b), em que a técnica de otimização por enxame de partículas é aplicada, com o objetivo de aproximar o movimento do grupo com uma trajetória pré-determinada. Tan et al. (2004) fazem uma comparação da análise do deslocamento de um grupo de robôs quando o líder transmite e, em outro caso, omite informações sobre a trajetória a ser percorrida. Em Kuppan et al. 
(2011), o controle de formação é baseado em uma estratégia, onde os robôs podem assumir comportamentos de manutenção da formação, navegação e desvio de obstáculos. Outra abordagem que visa evitar obstáculos é apresentada em Ogren and Leonard (2002). A vantagem da utilização do controle de formação, baseado na abordagem líder-seguidor é a simplicidade de implementação. Embora, diversos modelos reportados na literatura mostram que as respectivas estratégias são capazes de estabelecer uma formação, a limitação da abordagem está no fato de que o líder é um ponto vulnerável da formação. Em caso de falha do líder, a formação do grupo é prejudicada, devido à perda de comunicação com os seguidores. Outra desvantagem é que o líder não tem conhecimento do estado dos seguidores. Assim, havendo perturbações em algum seguidor, a formação pode não ser mantida.

A abordagem de estrutura virtual envolve um importante problema na robótica cooperativa, que consiste em manter uma formação geométrica e fixa durante o movimento do grupo. Nesta abordagem, a formação como um todo é considerada uma única estrutura. Lewis and Tan (1997) definem uma estrutura virtual como uma coleção de elementos (por exemplo, robôs) que mantém uma relação geométrica (semi-) rígida entre eles. Em outro ponto de vista, a formação geométrica definida por um meio externo, e não através da interação dos agentes, é chamada de uma estrutura virtual. Assim, em tarefas que exigem alta precisão da posição dos robôs, a estrutura virtual é uma alternativa para manter a formação (Lewis and Tan, 1997). Para desenvolver um controle de formação utilizando uma estrutura virtual, é necessário o entendimento da cinemática rotacional e dinâmica de corpos rígidos. Sendo assim, definese a dinâmica desejada da estrutura virtual e ajusta-se a movimentação do grupo com a trajetória desejada. Em seguida, leis de controle de rastreamento são determinadas. Em Ren and Beard (2003), a abordagem de estrutura virtual é aplicada no controle de formação de um grande número de veículos aéreos. Robôs móveis são empregados na tarefa de exploração em ambientes virtualmente triangularizados em Alboul et al. (2010). Inicialmente, os robôs se posicionam nos vértices desses triângulos de maneira que todos estejam conectados pelas arestas. Tais arestas limitam o movimento do grupo. Apesar da estrutura ser mantida rigidamente, a trajetória, o remanejamento dos robôs permite que o grupo se adapte às dificuldades apresentadas pelo ambiente. Uma vantagem da abordagem de estrutura virtual está na facilidade de estabelecer o comportamento do grupo. Além disso, a estrutura virtual pode manter uma formação fixa e rígida durante o movimento. Por outro lado, o sistema multiagentes é restrito a um conjunto de ambientes nos quais a formação permanece intacta. Sem a possibilidade de ajustar o formato do grupo, a disposição dos obstáculos nesses ambientes é definida de maneira a favore- 
cer a formação pré-determinada. Por exemplo, a largura de passagens como portas e corredores deve ser adequada para o tipo de formação triangular ou circular.

Como uma alternativa para a utilização de uma estrutura virtual, a abordagem de função potencial define uma função potencial para intensificar a interação dos agentes vizinhos e, consequentemente, manter a distância entre eles. A formação obtida pelo grupo é dependente da função potencial utilizada e da maneira como os agentes estão conectados (para fins de comunicação). No entanto, esta abordagem somente estabelece a formação. Com o objetivo de deslocar o grupo, um líder virtual é definido para ditar o movimento. Assim, uma lei de controle é derivada para tratar as interações dos agentes com o líder virtual, para que a formação desejada seja mantida, enquanto seguem uma trajetória. Retomando a abordagem apresentada em Howard et al. (2002) e já discutida na Seção 2.3, esta pode ser analisada sob o ponto de vista de formação de robôs. Nesta abordagem, são construídos campos potenciais para dispersar robôs, a fim de maximizar a área de cobertura em um ambiente. Cada robô é repelido pelos obstáculos e pelos outros robôs até que o grupo alcance um estado de equilíbrio, no qual as forças de repulsão sobre um mesmo robô se anulam. A principal desvantagem dessa estratégia é que a convergência para a formação desejada não é garantida para todas as possíveis condições iniciais (Tanner and Kumar, 2005; Dimarogonas and Kyriakopoulos, 2006). Sanando essa dificuldade, Hernandez-Martinez and Aranda-Bricaire (2008) obtiveram, através de resultados, condições necessárias e suficientes para a convergência da formação além de permitir que os robôs desempenhem trajetórias livres de colisão. Considerando que a topologia da formação sofre mudanças dinamicamente, em Tanner et al. (2007b) é utilizada uma função potencial para gerar regras de interação descentralizadas, partindo do princípio de que cada agente troca informações com aqueles que estão mais próximos. A abordagem baseada em função potencial tem sua convergência da formação comprovada matematicamente para uma configuração qualquer, que minimiza a função potencial adotada. A principal desvantagem é a dificuldade em se obter uma função potencial em que o mínimo global represente a formação desejada. Outro ponto negativo é o problema de mínimo local possivel presente nas soluções encontradas. Neste caso, algoritmos devem ser desenvolvidos na tentativa de solucionar tal problema e garantir a convergência da formação. 


\subsection{Considerações Finais}

Neste capítulo, apresentou-se uma revisão de trabalhos selecionados em três áreas de estudo relevantes à construção de sistemas robóticos. Inicialmente, a exploração de ambientes desconhecidos foi discutida de maneira gradativa, partindo de solução envolvento um único robô até métodos mais complexos, que consideram a interação de múltiplos robôs. O enfoque foi dado a técnicas que utilizam a noção de fronteira, uma vez que tal conceito serve de base para o método exploratório proposto no Capítulo 4. Em seguida, maneiras de maximizar o grau de cobertura da área percebida pelos robôs são discutidas. Duas linhas de pesquisa foram distinguidas. Na primeira, os robôs deslocam-se de forma isolada para sensoriar o ambiente e a cobertura do mesmo é feita por meio de combinação das informações. Uma estratégia de cobertura baseada nesta vertente é introduzida no Capítulo 4. Na segunda, os robôs navegam próximos uns aos outros para visitar o ambiente, minimizando, com isso, o desperdício de recursos. As abordagens do tipo blanket e sweep serviram de base para o método desenvolvido no Capítulo 5 . Por fim, discutiu-se o problema de coordenação de robôs para a formação de grupos. Cinco técnicas foram apresentadas. Devido à sua flexibilidade quanto ao formato imposto ao grupo e a sua liberdade em relação à configuração do ambiente, três delas, comportamental, líder-seguidor e consenso, foram selecionadas pare servir de base ao método concebido no Capítulo 5. 


\section{CAPÍTULO \\ Otimização por Colônia de Formigas}

\section{1 Considerações iniciais}

Processos e mecanismos biológicos e da natureza têm inspirado pesquisas para o desenvolvimento de novos paradigmas computacionais. Nesse contexto, a Computação Natural emprega conceitos de diversas áreas do conhecimento, tais como Computação, Biologia, Física, Engenharia e Química, para a solução de problemas de cunho prático. Segundo Castro (2006), a Computação Natural ou Bioinspirada é formada por três frentes de estudo:

Computação inspirada pela natureza: busca inspiração em processos e mecanismos naturais para a concepção de novas técnicas computacionais. Essa abordagem é motivada pela observação de que a natureza é capaz de fornecer soluções eficientes para problemas em que a computação tradicional apresenta limitações, como o reconhecimento de padrões (Bishop, 1996);

Computação para simulação de processos naturais: tem por objetivo obter um maior entendimento de fenômenos observados na natureza, por meio de síntese e simulação de seus padrões e comportamentos;

Computação com materiais naturais: estuda o uso de materiais naturais, como moléculas de DNA, para realizar computação, dando origem a abordagens computacionais alternativas.

Este trabalho situa-se na primeira frente de estudo, pois faz uso de uma técnica denominada Otimização por Colônia de Formigas (Ant Colony Opti- 
mization - ACO), que está inserida no ramo de pesquisa conhecida como Inteligência de Enxames (Bonabeau et al., 1999). De maneira geral, pode-se dizer que esse paradigma refere-se ao uso de agentes cooperativos que apresentam um nível superior de inteligência dentro do comportamento social. Esses agentes devem ser capazes de interagir entre si e com o ambiente, mimetizando o comportamento de algumas espécies sobre vários aspectos, em especial suas habilidades em encontrar comida, dividir trabalho e até mesmo evitar predadores e facilitar a caça (Castro, 2006). Nesse contexto, os sistemas baseados em inteligência coletiva possuem cinco princípios (Millonas, 1994):

proximidade: os agentes de uma população devem interagir entre si;

qualidade: os agentes devem ser capazes de avaliar a interação entre si e com o ambiente;

diversidade: a capacidade de um sistema reagir contra ações inesperadas;

estabilidade: os agentes não podem modificar seu comportamento em resposta a todas as modificações do ambiente;

adaptabilidade: os agentes devem ser capazes de se adaptar às mudanças do ambiente e da população.

Este capítulo está organizado como segue. Na Seção 3.2, descrevem-se conceitos básicos acerca da técnica de otimização baseada em formigas. Na Seção 3.3, apresentam-se os principais aspectos algorítmicos do ACO. Na Seção 3.4, aborda-se a utilização de ACO para otimização combinatorial, com ênfase no problema do caixeiro viajante. Por fim, na Seção 3.5, as considerações finais são fornecidas.

\subsection{Fundamentos teóricos}

A técnica de Otimização por Colônias de Formigas (Ant Colony Optimization - ACO), introduzida por Dorigo (1992) e outros pesquisadores (Dorigo et al., 1991b,a), é uma abordagem meta-heurística, inicialmente utilizada para resolver problemas de otimização discreta. Meta-heuristícas podem ser definidas como estratégias de alto nível que guiam uma heurística durante o processo de busca de um dado problema. O objetivo é explorar eficientemente o espaço admissivel de soluções a fim de encontrar aquelas mais promissoras, minimizando o risco de convergência prematura a mínimos locais (Blum and Roli, 2003).

Para este fim, ACO baseia-se no comportamento de populações de formigas a procura de alimento e na organização do trabalho. Embora as formigas sejam agentes relativamente simples, no que diz respeito à sua estrutura 
e funcionalidades, uma colônia torna-se uma estrutura complexa capaz de exercer tarefas com alto grau de dificuldade, tais como o transporte de objetos e construção de ninhos e pontes (Bonabeau et al., 2000; Dorigo et al., 1999). Tais características são consequência de atividades coletivas descentralizadas realizadas por meio da auto-organização. Bonabeau et al. (1999) descreve auto-organização como um mecanismo estrutural dinâmico resultante das interações dos membros do grupo. Duas forças são capazes de influenciar tais interações: realimentação positiva e negativa (Camazine et al., 2001). A primeira ocorre quando formigas são atraídas para caminhos já percorridos com sucesso por outras em busca de alimento. Essa atração acontece por meio de modificações no ambiente feitas por essas formigas. Assim, essa trilha tende a ser preferida sobre as demais à medida que elas são mais utilizadas. Para que um caminho não seja exclusivo na procura por alimento, a realimentação negativa utiliza mecanismos para equilibrar e estabilizar os efeitos da realimentação positiva.

Tais interações entre as formigas podem acontecer de forma direta ou indireta. A direta ocorre por meio de antenas, contato visual ou químico, enquanto que, na interação indireta, o agente responde à alteração do ambiente realizada por outra formiga. Portanto, diz-se que a informação é transferida por meio de modificações no ambiente (Bonabeau et al., 1999). Este tipo de comunicação é também denominada estimergia (Castro, 2006). Segundo Dorigo et al. (2006), estimergia é o estímulo recebido pelos indivíduos para motivar a execução de uma tarefa. O termo estimergia refere-se à coordenação das tarefas e organização dos grupos de insetos, definindo o ambiente como meio de comunicação entre eles. O fato da estimergia ser quantitativa e flexível implica que suas consequências podem ser detectadas e analisadas, o que facilita sua associação às formigas artificiais.

Para a colônia de formigas, seres desprovidos de capacidade visual, a comunicação indireta é realizada por meio de trilhas (caminho ou rastro) de feromônio, uma substância química produzida pelas formigas (Dorigo et al., 2006) é liberada no solo ao longo de seu movimento. Essa substância pode ser detectada pelas demais formigas da colônia, tal que quanto maior a quantidade de feromônio em um trajeto, maior é a probabilidade de este ser escolhido. Assim, uma vez que a formiga escolhe o caminho com a presença de feromônio, este é reforçado. Desta maneira, percebe-se que as trilhas de feromônio são um tipo de informação numérica distribuída, que é modificada pelas formigas para refletir sua experiência na resolução de um problema em particular (Blum, 2005).

Segundo Bonabeau et al. (1999), as características básicas do algoritmo de colônia de formigas são: 1) reforço da concentração de feromônio no caminho 
de acordo com a qualidade da solução; 2) feromônio, denominado virtual, que é adicionado ao caminho se este for uma boa solução, ou reduzido, caso contrário, para evitar a estagnação; 3) comportamento cooperativo das formigas; e 4) reforço da concentração de feromônio dos caminhos das formigas que obtiveram as melhores soluções.

\subsection{Algoritmo ACO}

Como primeiro passo para o desenvolvimento de um algoritmo para otimização combinatorial utilizando ACO, um modelo simples para tal fim é exemplificado. Considere $F=\left\{f_{1}, \ldots, f_{n}\right\}$, com $n \in \mathbb{N}$ o conjunto de formigas e o grafo $G(V, E)$, em que $V=\left\{v_{n}, v_{a}\right\}$ é o conjunto de nós e $E=\left\{e_{1}, e_{2}\right\}$ consiste no conjunto de arestas de $G$. Os nós $v_{n}$ e $v_{a}$ representam o ninho das formigas e o local de alimento, respectivamente, que são conectados por dois caminhos, representados pelas arestas $e_{1}$ e $e_{2} \in E$. A cada uma das arestas é associado um valor $l_{i}, i=1,2$ que indica o tamanho do caminho, tal que $l_{1}>l_{2}$. Isso significa que $e_{2}$ representa o menor caminho entre o ninho e a fonte de alimento, porém, essa informação é desconhecida pelas formigas. A concentração de feromônio $\tau_{e_{i}}$ no caminho $e_{i}$ é discretizada e seu valor é incrementado em uma unidade sempre que uma formiga utilizar esse caminho. A probabilidade $P_{e_{i}}$ da formiga escolher o caminho $e_{i}$ é dada por:

$$
P_{e_{i}}=\frac{\tau_{e_{i}}}{\sum_{i=1}^{m} \tau_{e_{i}}}
$$

em que $m$ é o número de arestas decorrentes do nó onde se encontra uma formiga. Independente de estar no nó $v_{n}$ ou $v_{a}, m=2\left(e_{1} \mathrm{e} e_{2}\right)$.

Como observado na natureza, a concentração de feromônio está sujeita à evaporação continuamente, podendo ser nula no caso de ausência de formigas por longos períodos de tempo. De forma análoga, a concentração de feromônio em $e_{i}$ é reduzida à medida que esse trecho não é percorrido. A evaporação conduz à convergência das formigas a uma solução subótima, tornando mais frequente a exploração de caminhos aleatórios. Este fenômeno limita a quantidade máxima de feromônio, o que evita a estagnação da solução em ótimos locais. A evaporação do feromônio, no tempo discreto $t$, é modelada como segue:

$$
\tau_{e_{i}}(t+1)=(1-\rho) \tau_{e_{i}}(t)
$$

onde, $\rho \in[0,1]$ é a taxa de evaporação do feromônio.

Inicialmente, as formigas, posicionadas no ninho $v_{n}$, movem-se aleatoriamente em busca de alimento, ou seja, realizam uma busca exploratória por 
possíveis soluções. Como não há depósito de feromônio em nenhum dos caminhos disponíveis (a quantidade inicial nas arestas são $0<\tau_{e_{1}}=\tau_{e_{2}}<1$ ), as probabilidades de escolher $e_{1}$ ou $e_{2}$ são iguais. Considerando quatro formigas $(n=4)$, supõe-se que as formigas $f_{1}$ e $f_{2}$ escolham $e_{1}$, e $f_{3}$ e $f_{4}$ escolham $e_{2}$. Pelo fato de $l_{1}>l_{2}$, as formigas $f_{3}$ e $f_{4}$ alcançam o destino $\left(v_{a}\right)$ mais cedo e, portanto, $\tau_{e_{2}}=2$. Ao retornar ao ninho, a probabilidade de escolher $e_{2}$ é maior, pois $\tau_{e_{2}}>\tau_{e_{1}}$ e, então, $\tau_{e_{2}}=4$. No instante em que $f_{1}$ e $f_{2}$ alcançarem $v_{a}$, tem-se $\tau_{e_{1}}=2$ e ao retornar, a probabilidade de escolher $e_{2}$ continua sendo maior. A pouca utilização de $e_{1}$ favorece o desaparecimento precoce do feromônio neste caminho. Dessa forma, a concentração de feromônio em $e_{2}$ é acrescida de tal forma que o caminho $e_{1}$ raramente seja utilizado nas próximas buscas por alimento. Isto evidencia que o menor (ou melhor) caminho é caracterizado pela maior concentração de feromônio (Deneubourg et al., 1990). Este processo é ilustrado na Figura 3.1.

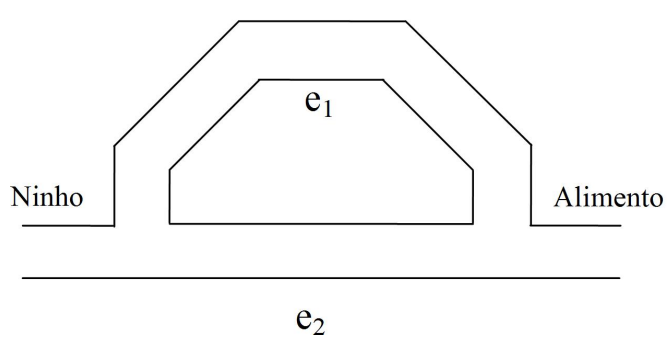

(a)

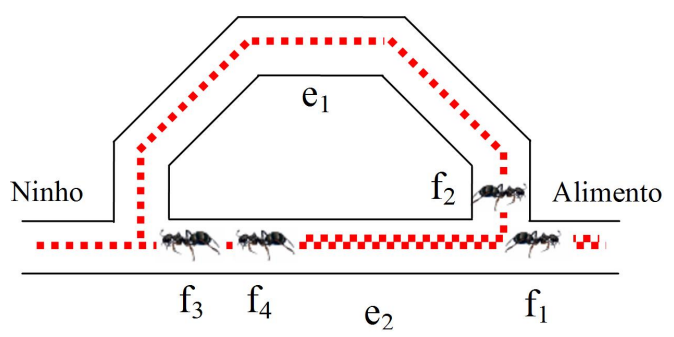

(c)

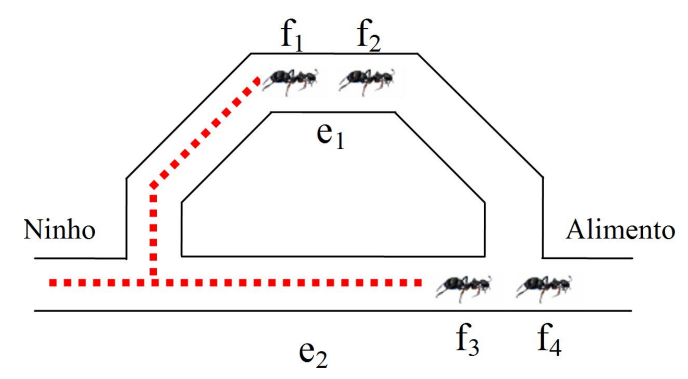

(b)

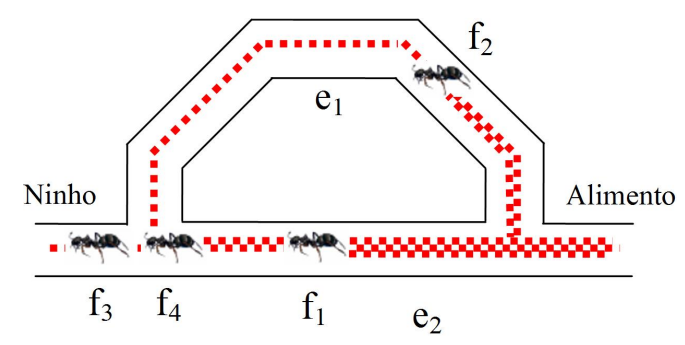

(d)

Figura 3.1: Exemplo do processo de busca pelo caminho ótimo entre o ninho e a fonte de alimento

Em Beckers et al. (1992), é descrito o depósito de rastros de feromônio de um tipo de formiga denominada Lasius Niger, cujo depósito de feromônio ocorre tanto no caminho de ida quanto de volta (Dorigo et al., 1999). No entanto, nota-se que há diversos tipos de formigas que adotam diferentes formas de depositar o feromônio (Schatz et al., 1999). Em algumas abordagens de otimização por colônias de formigas, o rastro de feromônio é depositado somente no caminho de volta para o local de origem. Durante o caminho de retorno ao ninho, o depósito de feromônio pode ser mais intenso, indicando a 
qualidade do trajeto (menor distância e/ou a quantidade de alimento encontrada).

\subsection{Aplicação do ACO para problemas combinatori- ais}

ACO tem sido aplicado com sucesso em problemas de otimização combinatorial (Bonabeau et al., 1999), em que um grande conjunto de soluções discretas é admissivel. Nesses casos, técnicas tradicionais, como programação dinâmica, podem não ser eficientes. Castro (2006) lista alguns desses problemas: roteamento de veículos, ordenação sequencial, coloração de grafos, escalonamento de máquinas e caixeiro viajante. A fim de ilustrar a aplicação do ACO, discute-se, nesta seção, o último problema.

\subsection{O problema do caixeiro viajante}

Um exemplo clássico em otimização combinatorial é o Problema do Caixeiro Viajante (Traveling Salesman Problem - TSP) (Deneubourg et al., 1990). Em sua versão tradicional, um caixeiro deve visitar $n$ cidades em sua área de atuação. Ele começa por uma cidade base e visita cada uma das $n$ cidades uma única vez e retorna ao ponto de partida. O custo de viajar entre duas cidades é proporcional à distância entre elas. A solução final do problema consiste em percorrer a rota com a menor distância total.

Na prática, o TSP é representado por um grafo ponderado, em que cada cidade corresponde a um nó, e o peso das arestas indicam a distância entre as cidades conectadas. O grafo é dito completamente conectado quando há ligações entre todos os pares de nós e parcialmente conectado caso contrário. A Figura 3.2 ilustra um exemplo de TSP. Nela tem-se um grafo ponderado totalmente conectado.

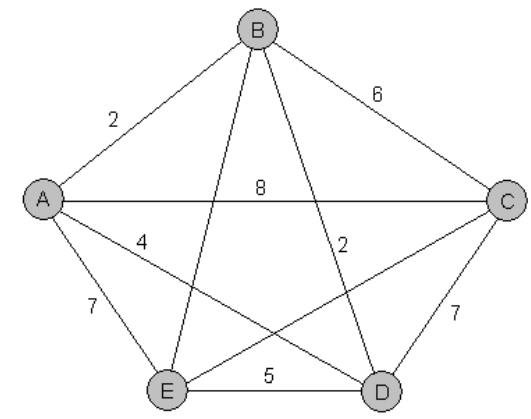

Figura 3.2: Exemplo do problema do caixeiro viajante

Apesar de parecer trivial, o TSP é um problema NP-Difícil (Dorigo et al., 2006), sendo que seu custo computacional cresce fatorialmente em função do 
número de cidades. Para $n$ cidades completamente interconectadas, há $(n-1)$ ! rotas possiveis, o que demanda $(n-1)(n-1)$ ! operações de soma para que todos os possíveis ciclos sejam encontrados utilizando métodos exatos. Por exemplo, para calcular todos os possiveis caminhos entre 50 cidades, seria necessário calcular aproximadamente $10^{64}$ operações de soma. Uma alternativa para o alto custo computacional dos métodos exatos na solução do TSP é o uso de meta-heurísticas, que são capazes de encontrar boas soluções, mas não necessariamente ótimas, em um intervalo de tempo razoável.

\subsubsection{Solução por ACO}

Dorigo (1992) desenvolveu o primeiro algoritmo heurístico de otimização por colônia de formigas, nomeado Ant System (AS). Esse algoritmo pode ser aplicado a problemas mais complexos àquele exemplificado na Figura 3.1, em que os valores para os feromônios são associados diretamente à solução do problema, ou seja, um único parâmetro para o caminho mais curto e outro para o mais longo. Esse modelo implica que as soluções sejam conhecidas previamente. No entanto, em problemas de otimização combinatorial, os valores de feromônio são parte da solução, que é desconhecida, e a combinação das partes resulta na solução ótima do problema.

Nesse sentido, Dorigo adaptou o comportamento das formigas para encontrar soluções ótimas para o TSP. Uma instância do TSP pode ser representada pelo grafo completamente conectado, não direcionado e valorado $G(V, E)$, onde $V=\left\{v_{1}, v_{2}, \ldots, v_{n}\right\}$ representa o conjunto de vértices (localidades) e $E=\left\{e_{i, j}=\{i, j\} \mid v_{i}, v_{j} \in V, i \neq j\right\}$ consiste no número de arestas (estradas, por exemplo) do grafo. Cada aresta $\{i, j\}$ possui seu respectivo custo (distância) para o agente ir de $v_{i}$ até $v_{j}$. Portanto, o espaço de busca $C$ é formado por todos os ciclos possíveis em $G$. A função objetivo de um ciclo $c \in C$ resulta na soma do custo das arestas que estão em $c$. O modelo mais comum para o problema TSP é o binário, em que uma aresta é marcada como visitada ou não visitada para compor a solução final.

Aplicando o algoritmo AS para solucionar o problema TSP, os agentes equivalem às formigas e a colônia de formigas tem a função de encontrar o menor caminho tal que todos os vértices do grafo sejam visitados uma única vez (voltando ao vértice de origem). Nota-se, então, que a aresta $e_{i, j}$ é considerada parte da solução do menor caminho. Diferentemente do exemplo anterior, no TSP, a formiga deve encontrar combinações de arestas cujo trajeto seja o mais curto possível. À medida que uma formiga constrói sua solução (completa seu ciclo), as demais são atraídas a realizar o mesmo percurso se esta for considerada uma boa solução. Para construir a solução, as arestas do grafo são inicializadas com quantidades iguais de feromônio $\tau_{e_{i, j}}$. Assim, as 
probabilidades para a formiga escolher qualquer outro vértice são idênticas. Todos os vértices do grafo devem ser marcados como não-visitados, exceto o(s) vértice(s) de origem, que é(são) escolhido(s) aleatoriamente e onde todas as formigas iniciam seu ciclo (onde cada formiga inicia em um vértice distinto). A partir desse ponto, cada formiga move-se do seu vértice corrente até outro que ainda não esteja visitado, assinalando-o, em seguida, como visitado. As arestas escolhidas são agregadas a fim de construir uma solução candidata. Um ciclo é finalizado quando todos os vértices estão marcados como visitados por uma formiga e esta volta à sua origem. Esta maneira de encontrar uma solução candidata implica que cada formiga $k$ possui uma memória $T_{k}$, que armazena os vértices já visitados, indicando o caminho percorrido. Por meio de $T_{k}$, é possível contabilizar o tamanho do caminho percorrido pela formiga $k$ após completar seu ciclo, que é denotado por $L_{k}$. No entanto, o interesse do algoritmo é minimizar a função objetivo $f(c)$, que consiste no tamanho do ciclo $c$ (percurso) realizado pelas formigas

Um fator relevante para a construção da solução é a escolha da próxima aresta. Um dos problemas encontrados nesse processo é a saturação da concentração de feromônios, levando a colônia a tender por soluções locais (ótimos locais). Conforme o sistema citado em Dorigo et al. (1991a), dois fatores devem ser considerados no processo de escolha de uma determinada localidade:

- A visibilidade da localidade, denotada por $\eta_{i j}$, é dada por $1 / d_{i, j}$, em que $d_{i, j}$ é a distância entre os vértices $v_{i}$ e $v_{j}$. Essa visibilidade considera a proximidade (custo) da localidade no processo de escolha, fornecendo ao algoritmo uma característica de uma heurística construtiva;

- A intensidade de feromônio no caminho, dada por $\tau_{e_{i, j}}(t)$, onde o sistema considera o quão interessante é o caminho, visto que quanto maior o valor de $\tau_{e_{i, j}}(t)$ maior é a probabilidade desse caminho ser escolhido. Com este fator, a heurística ganha a característica de autocatalítica.

Diante disso, a probabilidade da formiga $k$ se mover do vértce $v_{i}$ para o vértice $v_{j}$ no instante $t$ é dada por:

$$
p_{i j}^{k}(t)=\frac{\left[\tau_{e_{i, j}}(t)\right]^{\alpha}\left[\eta_{i, j}\right]^{\beta}}{\sum_{j \notin T_{k}}\left[\tau_{e_{i, j}}(t)\right]^{\alpha}\left[\eta_{i, j}\right]^{\beta}}
$$

em que $\alpha \geq 0$ controla a influência do feromônio e $\beta \geq 1$ controla a influência da informação heurística. Além disso, ambos controlam a qualidade da aresta (de acordo com a quantidade de feromônio depositada) e sua visibilidade.

Uma das peculiaridades desta abordagem consiste no depósito de feromônio nas arestas em $T_{k}$ somente quando a formiga completar seu ciclo, in- 
duzindo que outras formigas tenham maiores chances de passar pelas mesmas arestas. É considerado que a quantidade de feromônio depositada nas arestas percorridas é constante para todas as formigas. A concentração de feromônio deixada pela formiga $k$ ocorre durante o deslocamento entre dois vértices, portanto, entre os instantes $t$ e $t+1$, e é denotada como:

$$
\Delta \tau_{e_{i, j}}^{k}(t, t+1)=\left\{\begin{array}{l}
\frac{Q}{f(c)}, \text { se } e_{i, j} \in T_{k} \\
0, \text { caso contrário }
\end{array}\right.
$$

em que a constante positiva $Q$ é um parâmetro do modelo e a função objetivo equivale ao comprimento do percurso realizado, $f(c)=L_{k}$. Em outras palavras, a quantidade de feromônio adicionada em uma aresta depende do comprimento do caminho escolhido representado por uma solução candidata: quanto menor o caminho, maior é a concentração de feromônio adicionada. Esta variação de feromônio permite que os caminhos mais curtos sejam alcançados pela intensificação da concentração de feromônio nas melhores arestas.

Após todas as formigas completarem um ciclo, a adição de feromônio em cada aresta do grafo é dada por:

$$
\Delta \tau_{e_{i, j}}(t, t+1)=\sum_{k=1}^{n} \Delta \tau_{e_{i, j}}^{k}(t, t+1)
$$

em que $n$ é o número de formigas.

Assim, a concentração de feromônio nas arestas é modelada como segue:

$$
\tau_{e_{i, j}}(t+1)=(1-\rho) \tau_{e_{i, j}}(t)+\Delta \tau_{e_{i, j}}(t, t+1)
$$

em que $\rho$ é a taxa de evaporação do feromônio (ver equação (3.2)).

O algoritmo para encontrar a solução do problema TSP é iterado aplicando $n$ formigas em cada iteração. Durante a construção da solução, as formigas são atraídas a percorrer o caminho com maior quantidade de feromônio deixada pelas formigas nas iterações anteriores. O processo é executado até que um critério de parada seja satisfeito, por exemplo, número máximo de iterações, limite de tempo ou estagnação do sistema. No caso de estagnação, é mais provável que a solução ótima seja encontrada. Desde que a quantidade de feromônio depositada nas arestas é proporcional à qualidade do caminho no qual estas pertencem, os caminhos que representam as melhores soluções possuirão maior concentração de feromônio. Ao longo das inúmeras iterações, o caminho que representa a melhor solução passar a ser mais utilizado, ou então, a única utilizada pelas formigas, ocasionando na estagnação do sistema e resultando na descoberta da solução do problema (o caminho ótimo). 


\subsection{Considerações finais}

Embora a aplicação do algoritmo AS tenha se mostrado capaz de adequar o comportamento natural das formigas para solucionar problemas de otimização discreta, seu desempenho é considerado inferior aos algoritmos mais recentes. Diversas extensões e aperfeiçoamentos sobre o algoritmo AS são propostas, respeitando o conceito da metaheurística ACO. Dentre elas, destacamse: MAX-MIN Ant System (MMAS) (Stützle and Hoos, 1997), Ant Colony System (ACS) (Dorigo and Gambardella, 1997) e o $\mathrm{AS}_{R A N K}$ (Bullnheimer et al., 1997). Recentemente, Xia et al. (2008) e Socha and Dorigo (2008) propuseram o algoritmo $\mathrm{ACO}_{R}$ para problemas de otimização contínua.

Neste capítulo, apresentou-se o algoritmo ACO em sua forma mais genérica. O objetivo foi fornecer ao leitor noções básicas necessárias para uma melhor apreciação do presente trabalho. Em especial, os conceitos aqui discutidos são relevantes para o entendimento das estratégias de coordenação propostas nos Capítulos 4 e 5, que baseiam-se em modificações do ACO. Tais modificações resumem-se na propriedade repulsiva do feromônio, induzindo os robôs a se deslocarem para locais com pouca quantidade de feromônio, possibilitando a executação das tarefas de exploração e vigilância de ambientes, e a maneira pela qual os robôs depositam a substância no ambiente. Mesmo na ausência de informação a respeito da importância de uma região ser explorada, os robôs depositam feromônio. No entanto, a principal contribuição pela utilização do ACO vem da simplicidade de cada agente em termos de suas funcionalidades e da capacidade em que um grupo desses agentes possui para realizar tarefas complexas, como as propostas nesta tese. 


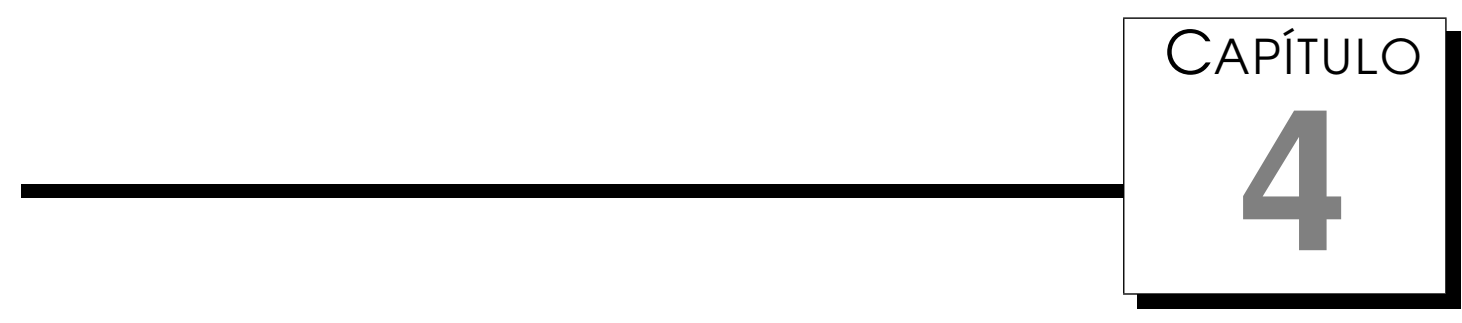

\section{Coordenação de Múltiplos Robôs Móveis para Vigilância de Ambientes}

\section{1 Considerações Iniciais}

Em Elmaliach et al. (2009), o termo vigilância é definido como a ação de percorrer uma região, em intervalos regulares, a fim de promover proteção ou supervisão da mesma. Dessa forma, para que estratégias de patrulha sejam eficazes, agentes (humanos ou artificiais) necessitam estabelecer uma coordenação adequada entre si, para que locais de um dado ambiente sejam visitados repetidas vezes ao longo do período de monitoramento. Nesse contexto, a utilização de sistemas de múltiplos robôs para a tarefa de vigilância tem sido comumente estudada (Portugal and Rocha, 2011). Por exemplo, em Amigoni et al. (2009), o problema de vigilância foi modelado como um jogo sequencial entre um vigia e um invasor, tal que sua solução forneça a estratégia ótima para o monitoramento de uma área. Elmaliach et al. (2009) estudaram a situação em que a movimentação cíclica dos robôs por pontos específicos do ambiente possibilita uma frequência ótima de monitoramento. Para tanto, os robôs precisam apenas ser distribuídos uniformemente ao longo da rota de custo mínimo calculada. Em Chevaleyre (2004), duas classes de estratégias de vigilância foram descritas e comparadas. Elas baseiam-se, respectivamente, em técnicas de particionamento de espaço e de percurso em grafo, para segmentar o ambiente e atribuir aos robôs regiões a serem patrulhadas. Machado et al. (2002) realizaram uma avaliação empírica de diversas heurísticas de patrulhamento, enfatizando o comportamento multi-agente das abordagens. 
O problema de vigilância utilizando múltiplos robôs também pode ser tratado aplicando-se algoritmos de inteligência coletiva (Bonabeau et al., 1999). As abordagens desse tipo, inspiradas primariamente na dinâmica social de certos animais, consideram agentes com capacidade sensorial e computacional limitada, que, em conjunto, logram completar a tarefa especificada. Nesse contexto, formigas oferecem uma analogia adequada para a construção de sistemas de vigilância (Koenig et al., 2001). De maneira geral, em tais empreendimentos, os robôs navegam pelo ambiente com base em informação local limitada e em marcações depositadas em regiões já visitadas pelos demais membros do grupo. Estas marcações apresentam comportamento volátil, sendo indicadoras do tempo em que tal área foi patrulhada. Através desse esquema de comunicação indireta, os robôs podem se orientar sem ter conhecimento explícito da configuração do ambiente e de sua própria localização, além de não precisarem estabelecer planos sobre as rotas a serem seguidas. Essas características ajudam a manter o sistema simples, robusto e adaptável. Exemplos de aplicação de algoritmos de inteligência coletiva ao problema de vigilância podem ser encontrados em Glad et al. (2009); Marino et al. (2009); Chu et al. (2007). Em geral, eles mantem uma representação topológica do ambiente de maneira que o movimento dos robôs são restringidos pelas arestas do grafo correspondente ao mapa topológico. Além disso, marcações no ambiente são realizadas nas arestas ou nos vértices do grafo. Em especial, na abordagem de Wagner et al. (1999), a marcação é distinta nos dois sentidos de uma aresta. Essas aplicações de algoritmos de inteligência coletiva serviram de motivação ao desenvolvimento da estratégia de coordenação de múltiplos robôs proposta durante a pesquisa conduzida nesta tese e detalhada no presente capítulo.

Este capítulo é organizado como segue. Na Seção 4.2, uma formulação do problema de vigilância como entendido neste trabalho é apresentada. Com ela, pretende-se explicitar matematicamente o comportamento esperado do sistema. Na Seção 4.3, a estratégia de coordenação proposta é descrita. Ela é uma aproximação da solução matemática anteriormente discutida. $\mathrm{Na}$ Seção 4.4, os experimentos de simulação conduzidos são detalhados, assim como os resultados obtidos. Por fim, na Seção 4.5, as conclusões do capítulo são fornecidas.

\subsection{Formulação do Problema}

É comum o leitor encontrar neste texto termos que fazem referência à ação do robô visitar (sensoriar ou cobrir) uma determinada região, tais como: vigiar, monitorar e observar uma determinada região. Mesmo que os robôs utiliza- 
dos nos experimentos somente percebam a região de atuação através de sensores, a navegação de forma contínua e repetida sobre um mesmo conjunto de regiões permite que os robôs desempenhem tarefas referentes aos termos mencionados. Para tanto, a integração de uma câmera de vídeo, por exemplo, ao sistema robótico tornaria possível a execução de tais tarefas.

Dois termos utilizados para a descrição e avaliação da estratégia bioinspirada são: Ciclo de Vigilância e Intervalo de Vigilância (Surveillance Epoch (SE) e Surveillance Interval (SI), respectivamente). Um intervalo de segurança é qualquer intervalo de tempo em que todos os pontos do ambiente são sensoriados pelo menos uma vez e pelo menos um ponto é sensoriado uma única vez. Este intervalo corresponde a uma parcela da tarefa de vigilância. A tarefa de sensoriamento em um período SI é denominada de ciclo de vigilância. Se o intervalo de segurança é considerado desde o início da tarefa, então, os SI's são unicamente determinados. Partindo de um instante $T_{0}^{*}$, os agentes iniciam a navegação pelo ambiente para explorá-lo e vigiá-lo. Após um período, precisamente no instante $T_{1}^{*}$, todos os pontos são sensoriados pelo menos uma vez; e pelo menos um ponto é sensoriado exatamente uma vez. O intervalo entre $T_{0}^{*}$ e $T_{1}^{*}$ é o primeiro SI. O segundo SI inicia-se no instante $T_{1}^{*}$. É importante destacar que imediatamente após $T_{1}^{*}$, considera-se que nenhum ponto do ambiente foi sensoriado para que a tarefa seja iniciada novamente, agora, em $T_{1}^{*}$. Com a movimentação constante dos agentes, em $T_{2}^{*}$, todos os pontos são sensoriados (novamente) pelo menos uma vez; e pelo menos um ponto é sensoriado uma única vez. O intervalo entre $T_{1}^{*}$ e $T_{2}^{*}$ é o segundo SI. Os demais SI's são definidos de forma análoga. O critério de avaliação adotado para a tarefa de vigilância consiste em considerar o tamanho dos intervalos SI e do comprimento médio de um ciclo SE.

Para formalizar o problema de vigilância, um modelo matemático é proposto a seguir. Considere que robôs $r_{k}, k=1, \ldots, N, N \in \mathbb{N}$ se desloquem em um plano $Q \subset \mathbb{R}^{2}$ e que um ponto arbitrário em $Q$ é denotado por $q$. Considera-se que o tempo $t$ é discreto. Seja $L_{t}^{k} \subset Q$ a área de cobertura do $k$-ésimo robô por meio de seu sistema sensorial no instante $t$. Portanto, o $k$-ésimo robô sensoria o ponto $q$ no instante $t$, se $q \in L_{t}^{k}$. Seja a função $I_{k}(.,$.$) definida para associar o$ estado que considera a presença do robô $r_{k}$ em um ponto $q$ no instante $t$ dada por:

$$
I_{k}(q, t)=\left\{\begin{array}{l}
1, \text { se o robô } r_{k} \text { está na posição } q \text { no instante } t \\
0, \text { caso contrário }
\end{array}\right.
$$

Considerando o intervalo entre $T_{i-1}^{*}$ e $T_{i}^{*}$, a função $\Omega_{i}(.,$.$) contabiliza a pre-$ sença de qualquer robô no ponto $q$ no intervalo de $T_{i-1}^{*}$ enquanto $t<T_{i}^{*}$, ou seja: 


$$
\Omega_{i}(q, t)=\left\{\begin{array}{l}
0, \text { se } t=T_{i-1}^{*} \\
\sum_{\mu=T_{i-1}^{*}}^{t} \sum_{k=1}^{N} I_{k}(q, \mu), \text { caso contrário }
\end{array}\right.
$$

Então, o problema de vigilância consiste em minimizar o comprimento do intervalos de segurança. Para tanto, é suficiente minimizar o maior intervalo encontrado em toda a tarefa de vigilância. Assim, o comprimento dos demais intervalos são reduzidos. Dessa forma, a função o bjetivo para a tarefa de vigilância é dada por:

$$
\min \max _{1 \leq i \leq C}\left(T_{i}^{*}-T_{i-1}^{*}\right)
$$

sujeito a:

$$
\begin{aligned}
& \Omega_{i}\left(q, T_{i}^{*}\right) \geq 1, \forall q \in Q \\
& \exists q \in Q \mid \Omega_{i}\left(q, T_{i}^{*}\right)=1 \\
& \sum_{i=1}^{C}\left(T_{i}^{*}-T_{i-1}^{*}\right) \leq T^{F}
\end{aligned}
$$

onde: $T_{i}^{*}$ e $T_{i-1}^{*}$ são os limites do $i$-ésimo SI; $C \geq 0$ é o número de ciclos $\mathrm{SE}$ completados; e $T^{F}$ é o instante que define o término da tarefa de vigilância.

Assim, o objetivo é minimizar o tamanho de um SI entre $T_{i-1}^{*}$ e $T_{i}^{*}$, desde que todos os pontos $q \in Q$ sejam visitados pelo menos uma vez por qualquer robô até o instante $T_{i}^{*}$. Além disto, pelo menos um desses pontos deve ser visitado uma única vez até $T_{i}^{*}$.

A solução ideal para esse problema é um conjunto de $k$ trajetórias, cada uma associada a um robô, evitando redundância de pontos visitados, ou seja, pontos visitados por um robô não são visitados também por outros. Além disso, a distribuição da tarefa deve ser mais próxima da ótima possível, visando minimizar a expressão dada na equação (4.3). Porém, torna-se uma tarefa muito difícil alcançar tal solução, uma vez que o ambiente é desconhecido.

É importante mencionar que o problema definido na equação (4.3) não é resolvido exatamente por algum método clássico de otimização, mas sim de uma forma aproximada. Isto se deve ao fato do problema ser altamente complexo. Esta complexidade é ainda mais evidente quando muitos agentes atuam para desempenhar a tarefa. De acordo com Pasqualetti et al. (2010), a tarefa de vigilância tal como descrita é considerada um problema NP-completo.

Um dos aspectos do problema de vigilância descrito é que o ambiente é desconhecido. Neste sentido, vale ressaltar que a tarefa de exploração é parte 
da tarefa de vigilância, desde que o ambiente é completamente explorado ao final de cada ciclo SE. Neste instante, todos os pontos do ambiente são sensoriados, ou seja, não há nenhum ponto que ainda não tenha sido visitado. No que segue, o foco está na tarefa de vigilância enquanto que a exploração é uma mera coincidência.

\subsection{Sistema de Exploração e Vigilância}

Como mencionado anteriormente, o objetivo do presente trabalho está na concepção de um sistema de navegação autonôma multiagentes para solucionar o problema de vigilância descrito. Os agentes são robôs móveis (ou formigas artificiais) idênticos cada qual equipado com sensores para detecção de características do ambiente. A princípio, esta abordagem mostra-se atrativa com uma plausível conclusão: múltiplos robôs executam a tarefa de vigilância mais eficientemente do que um único robô. Porém, esta conclusão é verdadeira se, pelo menos, houver uma estratégia capaz de coordenar adequadamente os robôs. Isto significa que trajetórias para todos os robôs devem ser geradas pela estratégia, guiando-os para todas as regiões do ambiente repetidamente, satisfazendo algum critério de desempenho, como a minimização do intervalo entre dois instantes em que um ponto é sensoriado.

A estratégia de coordenação que está sendo proposta é denominada Sistema de Vigilância, baseada na Modificação do Sistema Colônias de Formigas (IAS-SS, Inverse Ant System-Based Surveillance System), e é baseada nas principais ideias de um sistema artificial de colônias de formigas (Dorigo, 1992). Nesta modificação, o comportamento colaborativo dos robôs é repulsivo à substância que estes depositam enquanto se movimentam na busca por um objetivo, ao invés de atrativo, como ocorre no algoritmo das formigas.

Assim como no caso das formigas biológicas, a estrutura de um robô na estratégia IAS-SS é extremamente simples. Simplificando, o papel de um robô é perceber feromônio do ambiente e tomar a decisão a respeito da direção a ser seguida de acordo com a informação recebida. Dessa maneira simples, o sistema cibernético de cada robô consiste de dois componentes: controlador de navegação e o dispersor de feromônio. A Figura 4.1 representa estes componentes e suas respectivas conexões com os demais componentes do sistema, incluindo o ambiente externo.

Por meio da informação detectada (feromônio depositado no ambiente) pelos sensores, o controlador de navegação é responsável por gerar o comportamento de repulsão dos robôs. Como resposta, este componente fornece ao atuador a direção na qual a concentração de feromônio é baixa. Após a detecção da substância e a ação do controlador de navegação, o componente de 


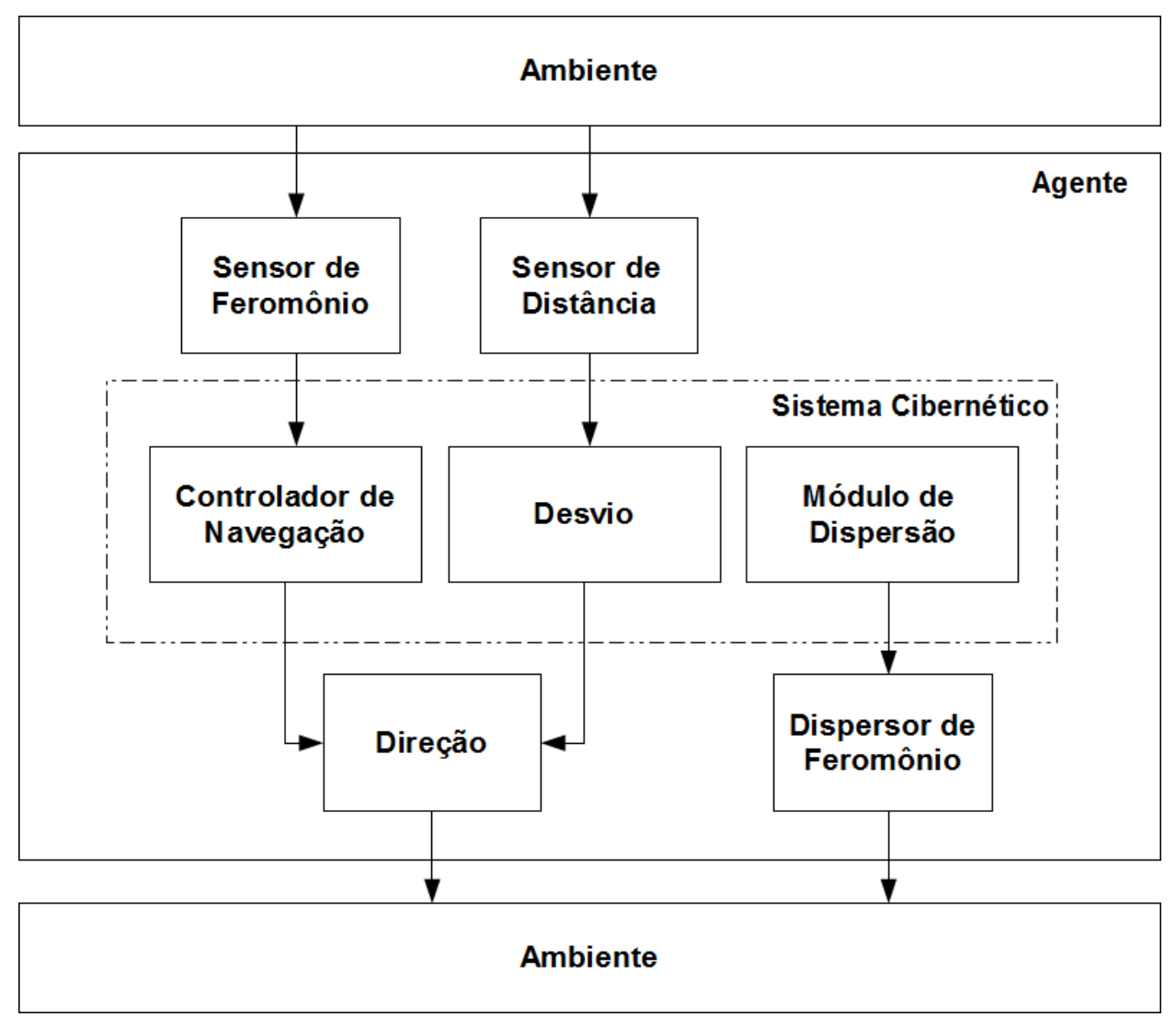

Figura 4.1: Diagrama arquitetural do sistema cibernético para um único robô.

dispersão de feromônio é acionado e, portanto, o robô deposita feromônio na área correspondente à area de cobertura de seu sensor no instante atual. $\mathrm{O}$ depósito de feromônio nesta região é justificado pela tarefa a ser executada pelos robôs. Por se tratar de uma tarefa de exploração, o depósito de feromônio se estende pela área que o robô observa a partir de sua posição. É evidente que uma área já observada por um robô não deve ser uma área atrativa para os demais. Diferentemente de abordagens tradicionais, em que o feromônio é depositado em forma de trilha indicando o caminho percorrido pelo robô (Lee and Lee, 2010; Han et al., 2011), na estratégia IAS-SS, o feromônio é disperso para uma área além da posição do robô. Assim, torna-se desnecessário o deslocamento do robô para toda e qualquer região do ambiente, basta que seu sistema sensorial seja capaz de captar informação de tal região.

Mesmo que a dispersão de feromônio ocorra após o ajuste de direção do robô, nota-se na Figura 4.1 que não há uma conexão entre o meio externo e o módulo de dispersão de feromônio. Isso se deve ao fato de que o dispersor é independente de qualquer informação proveniente do ambiente ou gerada pelos demais módulos do sistema cibernético. Além disso, nota-se também a ausência de um componente equivalente à evaporação de feromônio. O robô não é capaz de controlar a evaporação de feromônio, uma vez que tal fenômeno ocorre de maneira natural, independentemente da ação do robô.

A estratégia de coordenação IAS-SS aplicada aos robôs é reativa e dis- 
tribuída. Cada robô move-se independentemente e toma decisões baseado no estímulo que recebe do ambiente. A coordenação é baseada no mecanismo de comunicação indireta (estigmergia) observado em colônia de formigas biológicas. Enquanto os robôs navegam, estes depositam uma substância específica no ambiente. Tal substância, chamada feromônio, é análoga ao feromônio de formigas biológicas. A cada instante, um robô detecta (por meio de seus sensores) o estímulo proveniente do ambiente, que corresponde à quantidade total de feromônio depositada na área de alcance do sensor. A quantidade de feromônio é acumulada nesta área, uma vez que possivelmente outros robôs já estiverem neste mesmo local. Após ajustar sua direção de movimento, o robô deposita feromônio no ambiente antes de se deslocar para uma outra posição.

\subsubsection{Sensores do Robô}

Os sensores utilizados para a tarefa de vigilância são apresentados na Figura 4.2. Os robôs são dotados de diferentes classes de sensores com o objetivo de obter informações provenientes do ambiente, que são: sensores de distância a obstáculos e sensores de feromônio. Durante a navegação, a velocidade dos robôs é constante.

Cada sensor de distância a obstáculos determina a distância entre um robô e o obstáculo mais próximo situado na direção do sensor. O sensor de distância a obstáculos está disposto na parte frontal do robô $\left[-90^{\circ}, 90^{\circ}\right] \mathrm{em}$ um total de 361 leituras, uma a cada $0.5^{\circ}$. Embora o foco principal deste trabalho não seja a construção de mapas, o sensor de distância a obstáculos é utilizado para este fim e também para indicar ao robô áreas livres de obstáculos a fim de depositar feromônio e, posteriormente, deslocar-se em direção elas. Os mapas locais gerados a cada instante pelos robôs não são determinantes para definir a trajetória do robô, uma vez que o mapa resultante da navegação dos robôs não é um critério para avaliar o desempenho da estratégia IAS-SS. O mapa completo de um ambiente não indica o grau de desempenho da estratégia. Indica somente que o ambiente foi totalmente explorado pelo menos uma vez. No entanto, não garante que os robôs visitaram constantemente todas as regiões do ambiente executando a tarefa de vigilância.

As informações que são fundamentais para determinar a direção de movimento dos robôs são obtidas pelo sensor de feromônio. O sensor abrange a área à frente do robô, de $90^{\circ}$ a direita até $90^{\circ}$ a esquerda. O sensor adotado é modelado de maneira que detecta feromônio em sua borda (Figura 4.2). A borda é uma circunferência de um círculo de raio $R$ na área frontal de abrangência do sensor. A extensão da borda de $180^{\circ}$ é dividida em intervalos angulares idênticos cada qual medindo $\alpha^{\circ}$. Cada intervalo angular é represen- 
tado pelo seu centro e definido em ângulos $A_{s}, s=\{-S, \ldots,-1,0,1, \ldots, S\}$, tal que: $(2 S+1) \alpha=180$ e $A_{s}=s \alpha$. Assim, diz-se que a informação obtida em um ângulo $A_{s}$ equivale à informação de seu intervalo angular. Desse modo, no decorrer do texto, é comum referenciar $A_{s}$ como ângulo ou intervalo angular.

Durante a navegação, os robôs detectam feromônio em posições do ambiente que coincidem com a posição ou ângulos $A_{s}$. Portanto, a baixa quantidade de ângulos prejudica o desempenho da estratégia, já que a percepção de feromônio torna-se mais restrita.

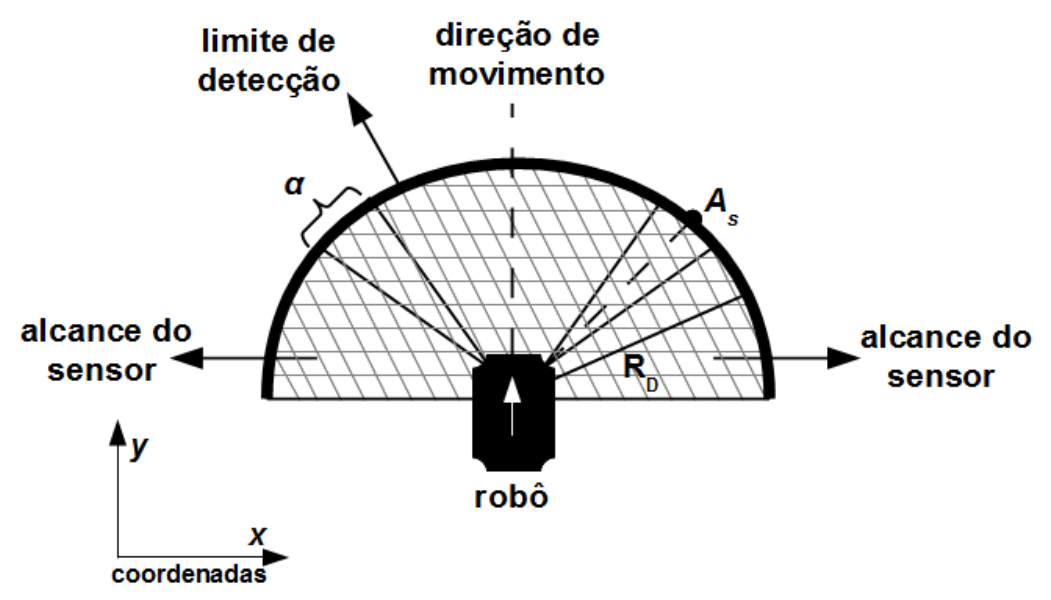

Figura 4.2: Sensores do robô

Para a tarefa de exploração, são os sensores de distância a obstáculos que definem as áreas já visitadas pelo menos uma vez. Para que estas áreas não sejam atrativas aos robôs, é necessário que elas recebam uma quantidade de feromônio significativa de maneira que os robôs sejam repelidos. Assim, para cobrir por completo estas áreas, faz-se necessário que o raio do sensor de feromônio seja idêntico ao raio dos sensores de distância a obstáculos.

\subsubsection{Sistema de Navegação}

De acordo com a estratégia de coordenação IAS-SS, os robôs depositam feromônio após o ajuste da direção de movimento, mas antes de se locomover. Devido à característica repulsiva do feromônio, os robôs tendem a se deslocar para regiões com baixa quantidade de feromônio. O comportamento observado dos robôs é que estes se movem para regiões não exploradas ou raramente visitadas. Uma região, sendo visitada por um robô, dificilmente será visitada também por qualquer outro. A alta quantidade de feromônio evita que robôs visitem uma mesma região. Como efeito, os robôs mantêm distância considerável entre eles.

Um comportamento emergente da estratégia IAS-SS e que vale ressaltar é o de desvio de obstáculos. À medida que os robôs se aproximam de um obstáculo, ocorre o acúmulo de feromônio na região de contorno desse obstáculo. 
Assim, o robô gera comportamento aversivo a esta região devido à alta quantidade de feromônio. Consequentemente, o robô se distância dos obstáculos. Através das trajetóras geradas, a estratégia IAS-SS, por si só, não guia os robôs a uma situação de colisão. Porém, há raras exceções devido à dimensão dos robôs. Para evitar completamente qualquer possibilidade de colisão, um sistema de desvio de obstáculos é ativado somente se um robô estiver muito próximo de um obstáculo ou de outro robô.

O sistema de desvio de obstáculos não é o foco dessa proposta e, portanto, sua descrição é omitida. É suficiente mencionar que tal mecanismo é acionado nos instantes em que a distância entre um robô e um obstáculo (ou outro robô) é menor que uma constante pré-definida $\eta$.

Na maior parte da execução da estratégia IAS-SS, ou seja, quando o sistema de desvio não está ativado, os robôs são guiados pelo controlador de navegação (ver Figura 4.1) para executar a tarefa de vigilância de ambientes. Uma descrição geral do mecanismo de ajuste de direção dos robôs, que compõe o controlador de navegação, é tal como segue. A cada instante, um conjunto de estímulos é detectado, o que corresponde à quantidade de feromônio depositada em diferentes ângulos $A_{s}$ (direções), sempre na região de alcance do sensor de feromônio (ou borda do sensor). Quanto menor a quantidade de feromônio detectada em uma direção, maior é a probabilidade do robô seguila. A lógica associada com a decisão que seleciona o ajuste de direção dos robôs é oposta àquela adotada na teoria clássica de colônia de formigas, ou seja, gera uma retroalimentação positiva. Aplicando a teoria clássica na tarefa de exploração, direções com grande quantidade de feromônio teriam maiores probabilidades de serem escolhidas.

A nova direção de um robô é definida por meio de duas versões do mecanismo de ajuste de direção. O primeiro, denominado, Amostragem Estocástica (AE), considera todos os possiveis estímulos de feromônio que o sensor detecta em sua borda. O segundo, Amostragem Estocástica Elitista (AEE), determina o ajuste de direção baseado em um seleto conjunto de estímulos detectados na borda do sensor. Esses mecanismos de ajuste de direção são definidos a seguir.

\section{Amostragem Estocástica $(A E)$}

O estímulo de feromônio corresponde à quantidade de feromônio depositada em um intervalo angular. Um valor de probabilidade é atribuído a cada ângulo discreto na amplitude do alcance do sensor. A probabilidade atribuída ao ângulo $A_{s}$ é inversamente proporcional à quantidade de feromônio depositada no respectivo intervalo angular, ou seja, quanto menor é a quantidade de feromônio detectada, maior é a probabilidade associada ao ângulo em questão. 
Especificamente, a probabilidade $P(s)$ atribuída ao ângulo $A_{s}$ é dada por:

$$
P(s)=\frac{1-\tau_{s}}{\sum_{i=-S}^{S}\left(1-\tau_{i}\right)}
$$

onde $\tau_{s}$ denota a quantidade de feromônio no intervalo angular $A_{s}$.

O ajuste da direção é determinado por meio de uma variável aleatória discreta $a$ definida através da probabilidade $P(s)$, assumindo valores no conjunto

$$
\left\{A_{s} \mid s=-S, \ldots,-1,0,1, \ldots, S\right\} .
$$

A cada instante $t$, o ajuste de direção é dado por:

$$
\Theta_{k}(t)=\Theta_{k}(t-1)+\gamma A_{s}^{*}
$$

onde $\Theta_{k}(t)$ é a direção do movimento do robô $k$ no instante $t ; \gamma \in[0,1]$ é a constante de suavização para o ajuste da direção e $A_{s}^{*}$ é a direção selecionada pela probabilidade dada na equação (4.4), ou seja, é o valor de uma variável aleatória $a$ no instante $t$ para algum $s=s^{*}$.

Por considerar todos os intervalos angulares do robô e devido à natureza estocástica da estratégia, a possibilidade do mecanismo AE selecionar direções desfavoráveis a serem seguidas pelos robôs aumenta. Direções desfavoráveis à tarefa de vigilância são aquelas que guiam o robôs para regiões com alta quantidade de feromônio, o que indica que tais regiões foram recentemente visitação. Situações em que os robôs navegam por ambientes amplos (sem obstáculos), a distribuição de feromônio se mostra mais uniforme e, como consequência, as quantidades de feromônio em regiões próximas tendem a ficar muito próximas. Isto implica que probabilidade de todos os ângulos $A_{s}$ são semelhantes (mas não idênticas), o que torna possível a seleção desses ângulos desfavoráveis. Para evitar esta dificuldade e maximizar a área explorada em um período de tempo reduzido, um segundo mecanismo é investigado.

\section{Amostragem Estocástica Elitista (AEE)}

Diferentemente da Amostragem Estocástica, neste mecanismo nem todos os intervalos angulares são considerados para se definir a direção do robô, mas apenas dois subconjuntos, $U$ e $V$, tal que suas respectivas cardinalidades são $\varphi$ e $\omega$; e $\varphi+\omega \leq(2 S+1)$, ou seja, o número de intervalos angulares considerando os dois subconjuntos é menor que o total de intervalos definidos na borda do sensor de feromônio. O subconjunto $U$ consiste de ângulos $A_{s}$ cuja quantidade de feromônio é considerada baixa. O subconjunto $V$ consiste de elementos escolhidos aleatoriamente, de acordo com uma distribuição uni- 
forme, dentre os ângulos $A_{s}$ que não estão no subconjunto $U$. Dessa forma, a probabilidade de uma intervalo angular favorável a tarefa de vigilância ser escolhido é maior devido à pré-seleção de ângulos com baixa quantidade de feromônio. A intenção da proposta do mecanismo AEE é aprimorar o AE com a expectativa de tornar o desempenho da tarefa de vigilância mais eficiente. Após, a construção dos subconjuntos, as seguintes regras são aplicas a eles:

\section{- Subconjunto $U$}

$$
\text { se } A_{s} \in U \text { e } A_{z} \notin U \text {, então } \tau_{s} \leq \tau_{z}
$$

\section{- Subconjunto $V$}

se $A_{s} \in V$, então $A_{s} \notin U$; e $A_{s}$ é escolhido aleatoriamente

onde $\tau_{s}$ é a quantidade de feromônio no intervalo angular $A_{s}$ e $s, z \in$ $\{-S, \ldots,-1,0,1, \ldots, S\}$.

Um valor de probabilidade é associada a cada ângulo discreto em ambos os subconjuntos $U$ e $V$. Utilizando a mesma lógica do mecanismo AE, a probabilidade é inversamente proporcional à quantidade de feromônio detectada no respectivo intervalo angular e definida por:

$$
\overline{P(s)}=\frac{1-\tau_{s}}{\sum_{i \in\left\{s \mid A_{s} \in(U \cup V)\right\}}\left(1-\tau_{i}\right)}
$$

Considere o ângulo $A_{s}=A_{s}^{*}$ como o escolhido de acordo com uma variável discreta aleatória a definida pela probabilidade $\overline{P(s)}$, assumindo valores no conjunto $\left\{A_{s} \mid A_{s} \in(U \cup V)\right\}$, onde o operador $\cup$ denota a união OU. A partir do ângulo escolhido, o ajuste de direção do robô $k$ no instante $t$ é dada pela equação (4.5).

Os passos básicos para a execução do mecanismo AEE são apresentados no Algoritmo 1 para um único robô. O procedimento recebe como entrada o conjunto de todos os ângulos $A_{s}$ para, a partir dos subconjuntos $U$ e $V$, selecionar o ângulo que define o ajuste de direção do robô.

\section{Liberação e Evaporação do Feromônio}

Em sistemas de colônia de formigas artificiais tradicionais, os agentes liberam feromônio apenas em suas respectivas posições, sinalizando exatamente o caminho percorrido pelos robôs (Dorigo, 1992; Bonabeau et al., 2000). Este modo de liberar feromônio resulta em trilhas que têm o intuito de marcar o histórico de experiências passadas (caminhos percorridos) pelos robôs de 


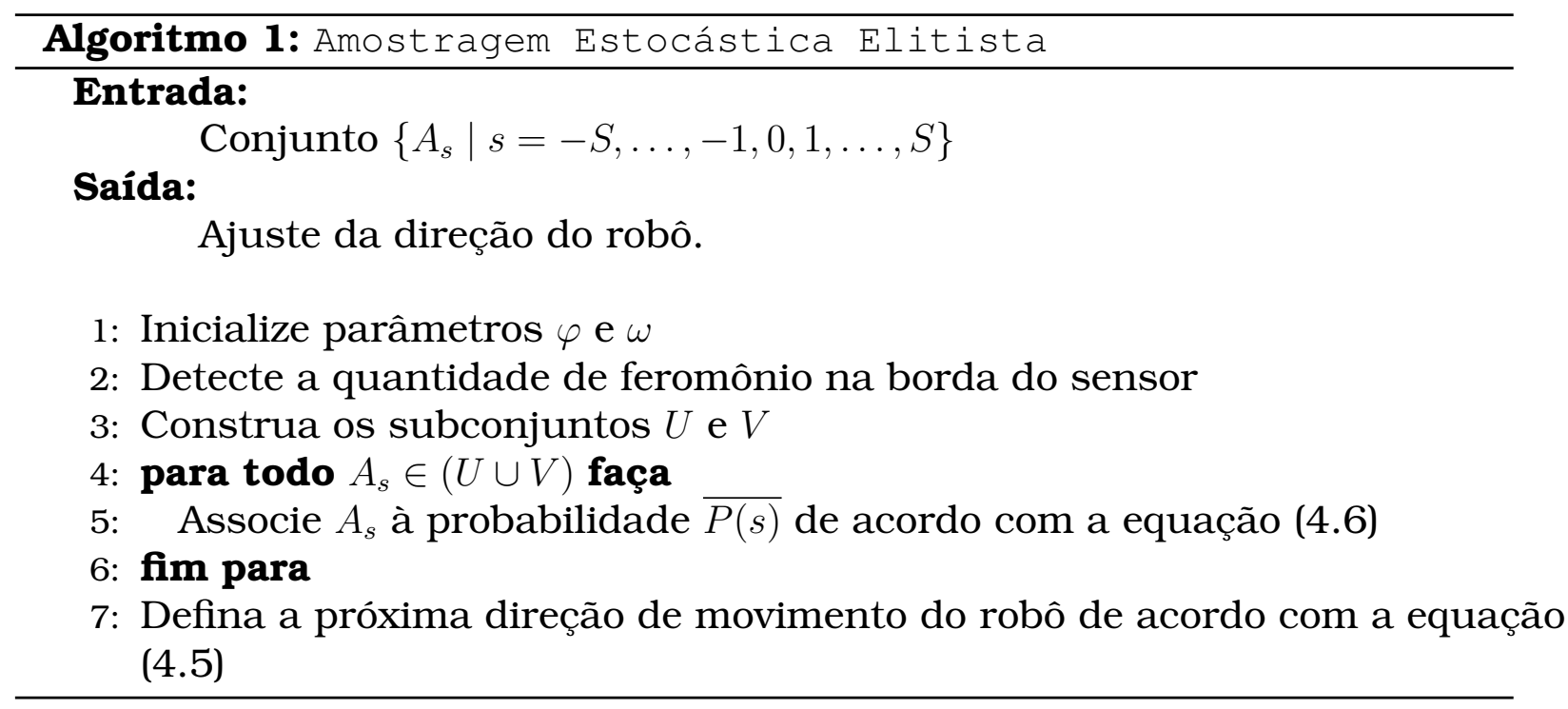

maneira a auxiliá-los em situações futuras. Os agentes artificiais no IASSS, ao contrário, espalham feromônio sobre uma ampla área frontal às suas respectivas posições, correspondente à área de alcance do sensor. Como justificado na Seção 4.3, a área onde o feromônio é depositado sustenta a tarefa de exploração.

Embora haja diversos tipos de feromônios liberados por muitas espécies de formigas, representando informações que provocam comportamentos distintos, os robôs que promovem a tarefa de vigilância de ambientes na estratégia IAS-SS lidam com somente um tipo de feromônio artificial, em particular, feromônio que provoca comportamento repulsivo dos robôs. A ausência deste tipo de feromônio indica regiões promissoras para a exploração e monitoramento. Assim, espera-se que essas regiões atrativas recebam a visita frequente de robôs, minimizando o tempo que elas permanecem sem monitoramento, o que resulta em melhoras no desempenho. Por outro lado, regiões marcadas com esse feromônio indicam a visita recente de robôs, tornando desnecessário o monitoramento dessas regiões em um futuro próximo. O comportamento repulsivo dos robôs evita que estes visitem regiões com feromônio, priorizando aquelas com baixa concentração da substância.

$\mathrm{Na}$ abordagem proposta, após o robô determinar sua nova direção (ver equação (4.5)) e antes de se mover, este espalha feromônio. A quantidade (ou concentração) de feromônio depositada decresce a partir da posição do robô em direção à borda do sensor de feromônio. Em outras palavras, considerando a área de abrangência do sensor de feromônio, a quantidade de substância é maior naquelas posições mais próximas à posição do robôs.

Antes de modelar a dispersão de feromônio, é importante destacar um aspecto referente à implementação computacional deste mecanismo. Mesmo que o depósito de feromônio seja um fenômeno contínuo, utiliza-se uma rep- 
resentação discreta para sua modelagem. Considera-se que cada posição do ambiente é representada por uma célula em uma grade. A informação contida em cada célula (por exemplo, a quantidade de feromônio) corresponde à informação de todo o espaço contínuo mapeado por ela. Da mesma forma, a posição do robô também é definida como uma célula dessa grade. Assim, a quantidade de feromônio $\Delta_{q}^{k}(t)$ liberada pelo $k$-ésimo robô na posição $q$ e na iteração $t$ é dada por:

$$
\begin{aligned}
& \Delta_{q}^{k}(t)=\left(\tau_{\max }-\tau_{q}(t-1)\right) \Gamma_{q}^{k}(t), \mathrm{e} \\
& \Gamma_{q}^{k}(t)=\left\{\begin{array}{l}
\delta e^{\frac{-\left(q-q_{k}\right)^{2}}{\lambda^{2}}}, \text { se } q \in L_{t}^{k} \\
0, \text { caso contrário }
\end{array}\right.
\end{aligned}
$$

onde $q_{k}$ é a posição do $k$-ésimo robô; $\tau_{\max }$ é o limite máximo de saturação para a concentração de feromônio; $\lambda$ é a dispersão ou a taxa de propagação do feromônio; e $\delta \in(0,1)$.

A maneira como o feromônio é liberado, obedecendo a equação (4.8), mostra que, em uma ação de depósito de feromônio, a maior concentração se encontra na posição do robô $\left(q_{k}\right)$. Nas proximidades do robô ainda é possível encontrar alta concentração de feromônio, que decai em direção à borda do sensor. Isto evidencia outro comportamento emergente como resultado do modelo de liberação de feromônio e sua natureza: os robôs tendem a manter uma certa distância uns dos outros. Este comportamento provoca a distribuição dos robôs pelo ambiente, o que beneficia a tarefa de vigilância.

Embora os robôs depositem feromônio a uma taxa constante, o que realmente é adicionado depende da quantidade de feromônio já existente no local como está indicando a equação (4.7). O nível de aproveitamento do feromônio destinado a posição $q$ é proporcional a diferença entre a quantidade de feromônio no local e o limite máximo $\left(\tau_{\max }\right)$. Ou seja, quanto menor a quantidade de feromônio em $q$, maior é a parcela de aproveitamento do feromônio liberado, sempre respeitando a quantidade máxima de feromônio $\tau_{\max }$.

$\mathrm{O}$ acúmulo de feromônio em um determinado local ocorre por duas maneiras. Na primeira delas, um robô deposita feromônio em um local e, à medida que se aproxima mais dele, mais feromônio é acumulado. Outra maneira consiste na ação de múltiplos robôs monitorarem em um mesmo local simultaneamente. Neste caso, a quantidade total de feromônio no local depende da contribuição de cada robô. Em ambos os casos, o acúmulo de feromônio é guiado pela equação (4.7).

É de conhecimento que o feromônio não é uma substância estável, ou seja, este evapora a uma taxa específica a todo instante $t$. Após um determinado 
período, a quantidade de feromônio em uma região decai devido ao fenômeno da evaporação. Regiões que antes eram evitadas pelos robôs, passam a ter alto potencial para manter a continuidade da tarefa de vigilância devido ao efeito da evaporação. Em termos práticos, a evaporação influencia diretamente no desempenho da tarefa de vigilância. É por meio desse fenômeno que regiões do ambiente já visitadas tornam-se atraentes para serem visitadas novamente.

A quantidade total de feromônio que evapora $\Phi_{q}(t)$ na posição $q$ no instante $t$ é modelada como segue:

$$
\Phi_{q}(t)=\rho \tau_{q}(t)
$$

onde $\rho, 0 \leq \rho \leq 1$ é a taxa de evaporação e $\tau_{q}(t)$ é a quantidade total de feromônio na posição $q$ no instante $t$.

Portanto, a quantidade total de feromônio na posição $q$ é resultado da combinação entre a quantidade restante após a evaporação e o que os robôs adicionam em $q$ (equação 4.7). Em termos matemáticos, a quantidade total de feromônio $\tau_{q}(t)$ em $q$ no instante $t$ é dada por:

$$
\tau_{q}(t)=\left(\tau_{q}(t-1)-\Phi_{q}(t-1)\right)+\sum_{k=1}^{N} \Delta_{q}^{k}(t)
$$

\subsection{Resultados Experimentais}

Simulações experimentais são realizadas para avaliar, preliminarmente, a estratégia de coordenação bio-inspirada IAS-SS. A estratégia é considerada para gerar a dinâmica de sistemas de múltiplos robôs aplicados a tarefas de exploração e vigilância e a expectativa para a tarefa de vigilância de ambientes é que os robôs se mantenham em movimento alternando regiões de um ambiente para monitorá-lo constantemente. Para maximizar a área monitorada em um mesmo instante, a estratégia IAS-SS deve manter os robôs em diferentes regiões, evitando o desperdício de recurso sensorial e reduzindo o tempo em que uma região permanece sem a presença de um robô.

A estratégia de coordenação é validada em experimentos simulados. O uso da simulação apresenta alguns benefícios pelo fato de não requerer aptidão técnica e disponibilidade de recursos para dotar um robô real com as características sensoriais mencionadas, assim como a manipulação de componentes eletrônicos e dispositivos mecânicos. Além disto, permite uma análise mais criteriosa dos resultados obtidos, já que muitos aspectos podem ser investigados em um número elevado de testes. Juntamente com esses fatores, a quantidade de robôs e a ausência de espaço físico necessários para avaliar a abordagem proposta justificam a adoção de robôs virtuais em simulações nas 
quais o ambiente também é virtual.

A plataforma Player/Stage $e^{1}$ é utilizada para executar os experimentos simulados. Player/Stage é um servidor para robôs projetado pela Universidade do Sul da Califórnia ${ }^{2}$ para controle distribuído. Player opera em um ambiente cliente/servidor, sendo que a comunicação entre as arquiteturas ocorre através de protocolo TCP/IP. Stage é um simulador de robôs e sensores para ambientes bidimensionais. Player/Stage modela e controla uma grande variedade de sensores e atuadores, simulando simultaneamente suas dinâmicas exatas, incluindo modelos que representam erros de odometria. Para propósitos experimentais, é utilizado o modelo do robô Pioneer $2 D X$ equipado com o sensor laser SICK LMS 200 capaz de mapear o ambiente (obstáculos em geral, por exemplo: paredes e objetos).

Para simular o feromônio, os robôs controem mapas locais, utilizando o sensor laser (também simulado), por meio da abordagem de grade de ocupação (Elfes, 1989). As células da grade resultantes do mapeamento armazenam o valor da probabilidade de estarem ocupadas por um obstáculo além do valor que representa a concentração de feromônio depositada nas regiões correspondentes.

Os experimentos apresentados neste capítulo são divididos em cinco grupos. O primeiro consiste nos experimentos que são voltados para os mecanismos de ajuste de direção AE e AEE. Os mecanismos são comparados com um modelo completamente uniforme. O segundo grupo é projetado para investigar a influência das posições iniciais dos robôs na execução de suas tarefas. Os experimentos do terceiro grupo visam analisar o impacto do número de robôs no desempenho do sistema. Experimentos em diferentes estruturas de ambientes caracterizam o quarto grupo, onde a robustez da estratégia de coordenação é averiguada. No quinto grupo, são apresentados dois métodos de estigmergia. Diferentemente do método já descrito para a liberação de feromônio, a substância é depositada na parte de trás do robô e em todo o seu perímetro.

O ambiente no qual ocorre a navegação é desconhecido. A trajetória dos robôs não é planejada a priori, mas determinada de acordo com a estratégia de coordenação, pois o sistema não é deliberativo. Dessa forma, a topologia do ambiente não é um requisito para a execução da tarefa de exploração e vigilância. O sistema proposto é do tipo reativo, ou seja, suas decisões são consequência das entradas instantâneas obtidas pelos sensores. O ambiente é bidimensional, podendo conter inúmeros obstáculos de diferentes tamanhos e formas. Os ambientes utilizados nos experimentos são divididos em pequenas regiões conectadas, denominadas aqui como salas. No contexto dos seguintes

\footnotetext{
${ }^{1}$ http://robotics.usc.edu/player

${ }^{2}$ www.usc.edu
} 
experimentos, uma sala é dita visitada (ou monitorada) se pelo menos um robô alcança qualquer posição pertencente a esta sala. Portanto, o cenário considerado é uma instância do problema formulado na Seção 4.2.

É importante ressaltar que a divisão do ambiente é realizada somente para fins de avaliação da estratégia. Os robôs não possuem o mapa do ambiente, tampouco a divisão deste em salas. A disposição das salas não tem nenhuma influência sobre a tomada de decisão do sistema, os robôs consideram somente os estímulos de feromônio para executar suas tarefas. O comportamento do sistema é eventualmente desenvolvido durante a navegação. Esse é um dos motivos que torna esta estratégia atraente. Espera-se que os robôs sempre se desloquem para regiões com pouca quantidade de feromônio, o que ocasiona, como consequência, o monitoramento de todas as regiões do ambiente.

Para a análise dos resultados obtidos nos experimentos dos grupos citados, recorre-se à apresentação do desempenho da estratégia de coordenação na forma de gráficos. Os gráficos são compostos por subgráficos, cada um dos quais corresponde ao comportamento de um robô. O eixo y representa as salas do ambiente e o eixo $x$ representa as iterações da simulação. A partir dos gráficos, obtém-se o histórico de salas visitadas pelos robôs, assim como seu exato local em um determinado instante. Ainda mediante os gráficos, é possível acompanhar a distribuição dos robôs no ambiente e observar a ocorrência de um ciclo de vigilância SE (ciclo de sensoriamento). As linhas verticais indicam as iterações nas quais os robôs completaram os ciclos de sensoriamento de todo o ambiente (os robôs visitaram, cooperativamente, todas as salas), considerando que uma nova etapa de sensoriamento é iniciada assim que o sistema conclui um ciclo.

A distribuição do feromônio por todo o ambiente também é um indício da eficiência da estratégia. A estratégia se mostra mais eficaz à medida que a concentração de feromônio se distribui de forma mais igualitária pelo ambiente. Neste sentido, a média da concentração de feromônio em todas as regiões do ambiente compõe o mapa de distribuição de feromônio. Esta média, obtida através do histórico da substância, indica a frequência com que uma região foi visitada em relação às demais. Para efeito de interpretação dos mapas, a escada da Figura 4.3 ilustra as cores e suas variações de tom que estão associadas a cada região do ambiente. Locais com pouca concentração de feromônio estão indicados pela cor azul, enquanto a cor vermelha representa os locais com alta concentração de feromônio, ou seja, locais mais frequentemente visitados. Como será explicado posteriormente, a quantidade de feromônio varia no intervalo $[0,1)$.

Os dados experimentais são selecionados assumindo as seguintes perspec- 


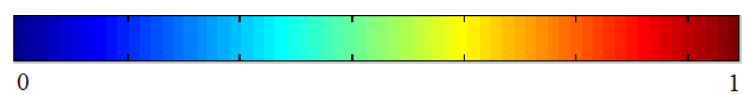

Figura 4.3: Escala de cores para a distribuição da concentração de feromônio.

tivas. Primeiro, a tarefa de exploração é executada se o ambiente é completamente coberto, ou seja, o sistema é capaz de fornecer informações suficientes para mapear o ambiente. Contudo, quanto mais rápido o sistema completa esta tarefa, melhor é o seu desempenho. Segundo, o sistema realiza a tarefa de vigilância se não existe um instante $T^{*}$ tal que, depois deste instante, exista alguma região no ambiente que não foi ainda visitada. Apesar desta definição para a tarefa de vigilância ser precisa, esta não é adequada, uma vez que encontrar $T^{*}$ pode ser impossível. Portanto, para fins práticos, é importante que o sistema conclua a tarefa continuamente, ou seja, o sistema deve iniciar uma nova etapa de sensoriamento de todo o ambiente, sempre que a tarefa é concluída. Assim, quanto menor o tempo entre duas etapas de sensoriamento consecutivas, melhor é o desempenho do sistema.

Antes de iniciar os experimentos, os parâmetros adotados são definidos a seguir:

- Robôs e sensores:

- $R=8.00$ (raio em metros do sensor de obstáculos e de feromônio);

- $\gamma=0.5$ (coeficiente para suavizar o ajuste de direção);

- Velocidade do robô: 0.5 metro por segundo.

- Liberação e evaporação de feromônio:

- $\lambda=0.43 R_{D}$ (raio do semicírculo onde o feromônio é depositado, ver Figura 4.2);

- $\rho=0.01$ (taxa de evaporação);

- $\tau_{q}(0)=0.5$ (quantidade de feromônio no instante $t=0$ na posição $q \in Q)$.

- $\tau_{\max }=1$ (limite máximo de feromônio).

- Mecanismo de ajuste de direção:

- $S=360$ (número de intervalos angulares);

- $\varphi=0.15 S$ (cardinalidade do subconjunto $U$, ver Seção 4.3.2);

- $\omega=0.03 S$ (cardinalidade do subconjunto $V$, ver Seção 4.3.2)

- Parâmetros de simulação: 
- $\eta=0.3$ (distância em metros máxima entre um robô e um obstáculo para ativar o sistema de desvio de obstáculos);

- O tempo de simulação é discreto: $t_{s} \in \mathbb{N}$;

- Número máximo de iterações: 1000.

Os valores atribuídos aos parâmetros são empíricos e correspondem àqueles utilizados no sistema de múltiplos robôs que alcançaram desempenhos significativos, considerando os experimentos realizados em (Calvo et al., 2011 a,c,b). Devido à característica aleatória dos mecanismos de ajuste de direção, os experimentos são executados 10 vezes. Dessa forma, o desempenho é avaliado em termos da média do número de ciclos de vigilância (SE) e de iterações no intervalo de segurança (SI). Os valores de alguns parâmetros podem ser alterados em algum experimento em específico. Neste caso, a alteração será explicitada.

\subsubsection{Comparações entre os Mecanismos de Ajuste de Direção Adotados}

Os mecanismos de ajuste de direção, Amostragem Estocástica (AE) e Amostragem Estocástica Elitista (AEE), possuem características aleatórias, uma vez que o ajuste de direção é determinado de acordo com uma variável aleatória discreta. Para demonstrar que seus respectivos desempenhos não são uma mera consequência do comportamento aleatório, tais mecanismos são comparados com o mecanismo denominado Estratégia Uniforme (EU). De acordo com o mecanismo EU, uma variável aleatória discreta, definida por uma distribuição uniforme no espaço de ângulos $A_{s}$, determina o ajuste de direção a ser realizado. Deste modo, este mecanismo não é capaz de executar as tarefas de exploração e de vigilância. Diferentemente dos mecanismos $\mathrm{AE}$ e $\mathrm{AEE}$, observa-se que não há conexão entre o feromônio e o mecanismo uniforme.

O ambiente projetado para a avaliação é ilustrado na Figura 4.4, onde é possivel identificar seis salas. Três robôs, $r_{1}, r_{2}$ e $r_{3}$, iniciam a navegação a partir da sala 1.

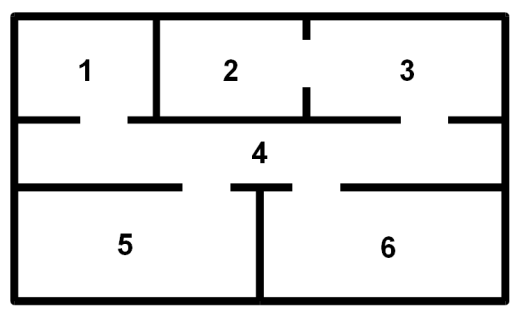

Figura 4.4: Estrutura do ambiente. 
Dois aspectos são considerados para analisar o desempenho da estratégia IAS-SS de acordo com os mecanismos de ajuste de direção: tempo necessário para completar a tarefa de exploração (SE) e o período máximo entre dois sensoriamentos consecutivos do ambiente (SI). Os resultados são apresentados na Tabela 4.1 com os desvios padrão para a média de número de ciclos SE e a média de interações no SI. Uma melhora no desempenho da estratégia IASSS ocorre gradualmente à medida que o mecanismo de ajuste é alterado. A Figura 4.5 ilustra o boxplot da média de iterações do intervalo de segurança para os três mecanismos de ajuste. Os números 1, 2 e 3 (no eixo $x$ ) referem-se aos mecanismos EU, AE e AEE, respectivamente.

Tabela 4.1: Desempenho dos mecanismos de ajuste de direção.

\begin{tabular}{|c|c|c|}
\hline Mecanismo & Média de SE & Média de SI (iterações) \\
\hline $\mathrm{EU}$ & $0.2 \pm 0.4$ & $796 \pm 395.68$ \\
\hline $\mathrm{AE}$ & $4.28 \pm 1.11$ & $233.26 \pm 82.43$ \\
\hline $\mathrm{AEE}$ & $7.25 \pm 1.71$ & $122.13 \pm 24.57$ \\
\hline
\end{tabular}

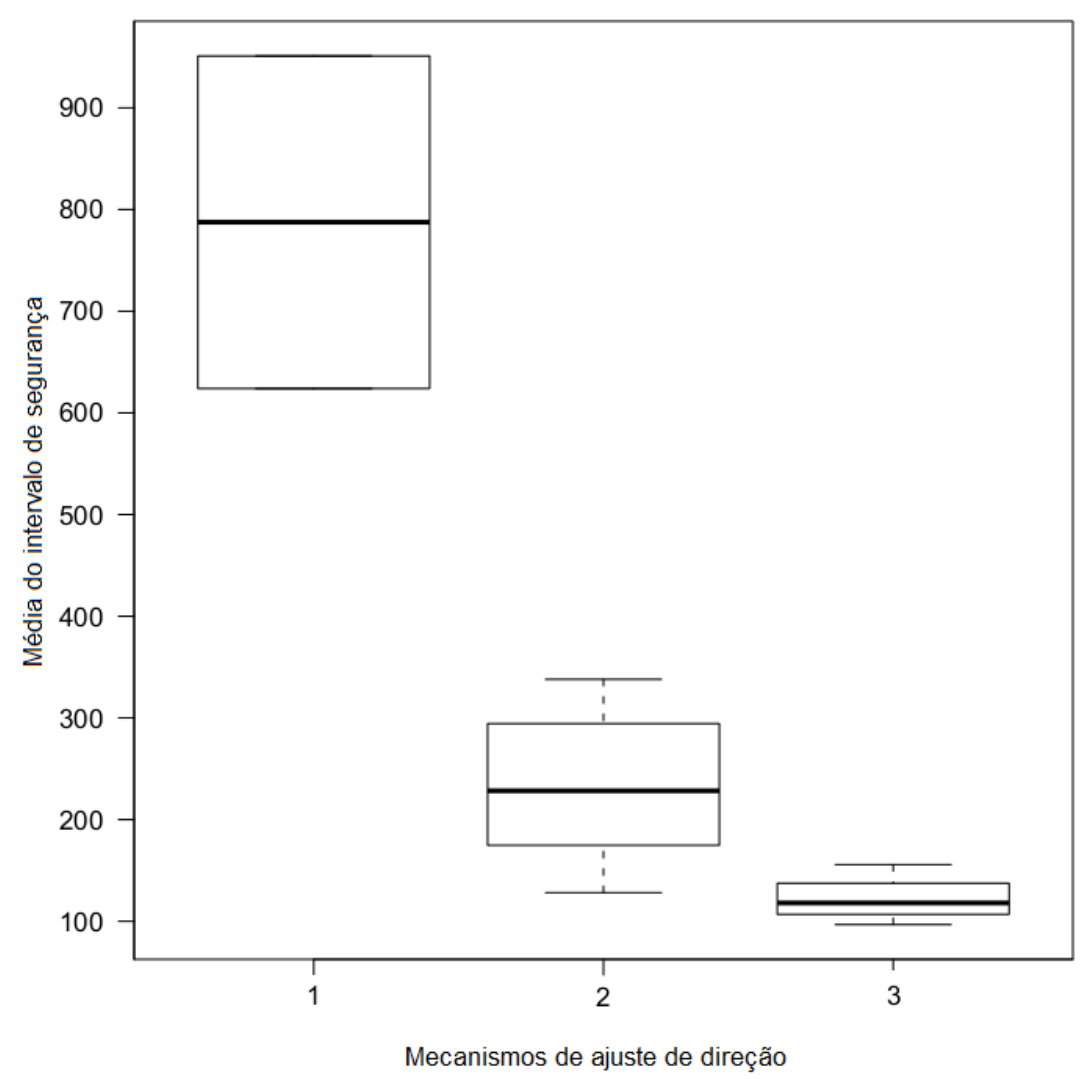

Figura 4.5: Boxplots da distribuição da média do intervalo de segurança para diferentes mecanismos de ajuste de direção.

Informação adicional a respeito do comportamento do sistema pode ser reunida na Figura 4.6 que exibe três conjuntos de grafos que apresentam os 


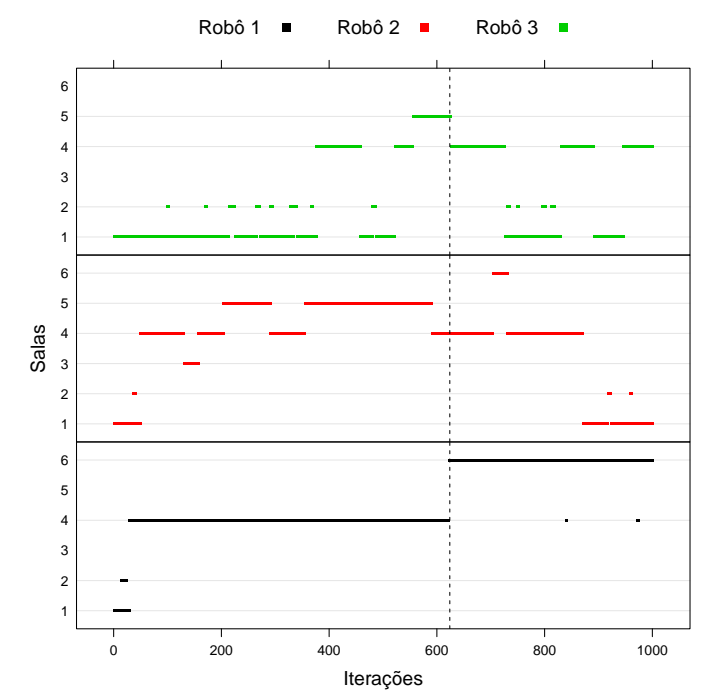

(a)

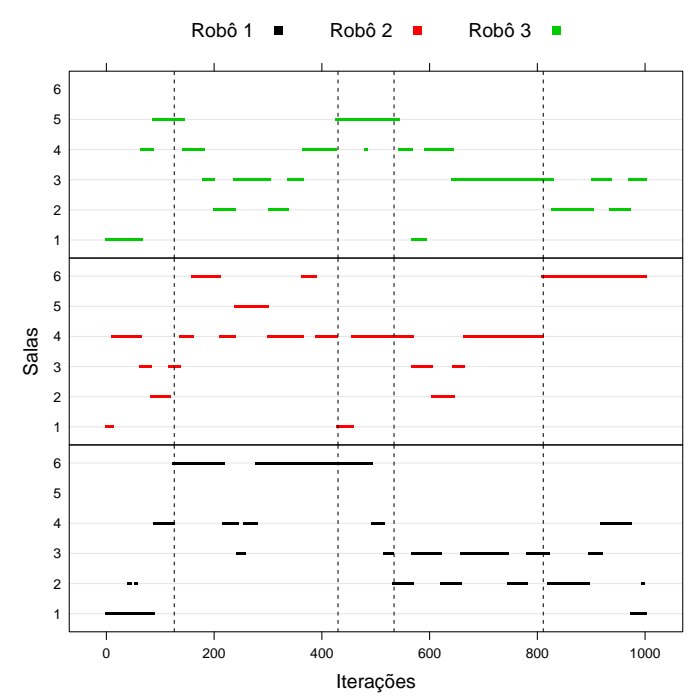

(b)

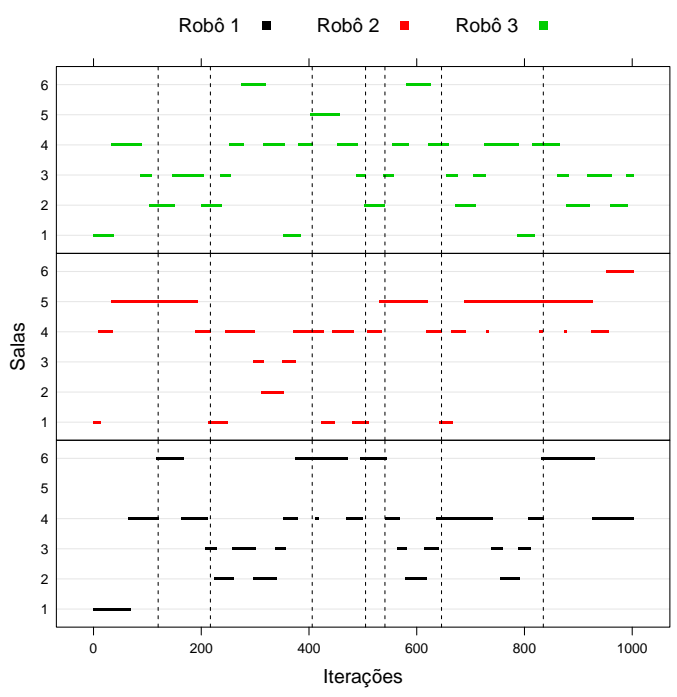

(c)

Figura 4.6: Desempenho da estratégia IAS-SS de acordo com os diferentes mecanismos: (a) EU; (b) AE; (c) AEE.

resultados de simulação, cada um dos quais corresponde a um mecanismo. Os dados utilizados para a exibição dos gráficos (e dos demais resultados) pertencem ao experimento com número mediano de iteração do SI. Para cada mecanismo, registra-se o comportamento dos robôs.

Considerando a tarefa de exploração de ambientes, os gráficos demonstram que a estratégia IAS-SS com o mecanismo EU foi capaz de concluir a tarefa de exploração, contudo, após um longo período, precisamente na iteração 624 . Observa-se que com os mecanismos AE e AEE, o sistema realiza mais eficientemente a tarefa, ou seja, o sistema concluiu num período de tempo menor, nas iterações 126 e 120, respectivamente. A estratégia IAS-SS com o mecanismo EU concluiu a tarefa de vigilância uma vez (há somente um SE), considerando todo o período de simulação. Há um contraste quando o desempenho do EU 


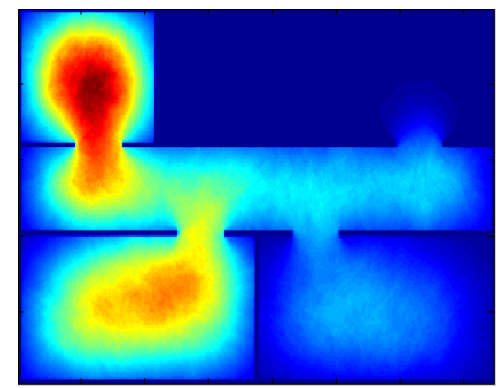

(a)

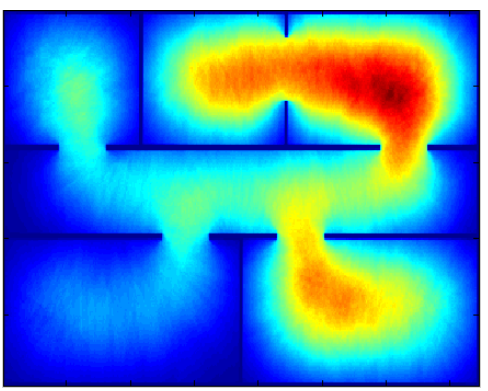

(b)

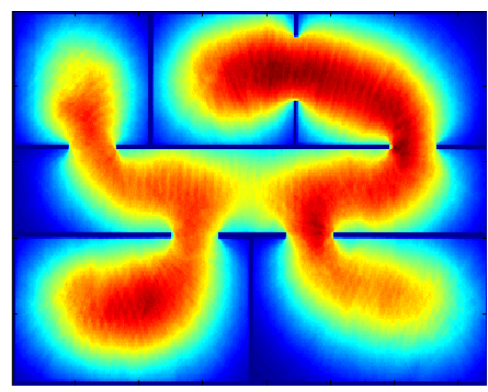

(c)

Figura 4.7: Mapa da média de concentração de feromônio de acordo com os diferentes mecanismos: (a) EU; (b) AE; (c) AEE.

é comparado com aqueles obtidos com os mecanismos AE e AEE. De acordo com o desempenho mostrado na Figura 4.6, observa-se que a tarefa de vigilância é continuamente concluída quando a estratégia utiliza os mecanismos $\mathrm{AE}$ e AEE.

Outra forma de verificar a eficiência do sistema é observar a distribuição do feromônio por todo o ambiente. Os mapas da Figura 4.7 mostram a média de concentração de feromônio para os mecanismos de ajuste de direção, o que complementa a informação mostrada anteriormente nos gráficos. Observase que a distribuição de feromônio se mostrou mais uniforme quando o sistema utiliza o mecanismo AEE (Figura 4.7(c)). Por outro lado, nota-se maior concentração de feromônio somente nas salas 1 e 5 durante a execução do mecanismo EU (Figura 4.7(a)).

As tabelas 4.2 e 4.3 sumarizam os resultados obtidos. O sistema com o mecanismo $\mathrm{AE}$ concluiu a tarefa de vigilância 4 vezes e com o mecanismo AEE 7 vezes. Os intervalos entre dois ciclos consecutivos de sensoriamento são de 304 e 189 iterações, respectivamente. A estratégia IAS-SS com AEE demonstra ter, claramente, um desempenho superior. Os mecanismos $\mathrm{AE}$ e AEE induzem um maior comportamento colaborativo entre os robôs que o mecanismo EU. Observa-se que os robôs, utilizando mecanismos dependentes de feromônio, alternam de salas mais frequentemente que os robôs atuando sob o mecanismo EU.

Tabela 4.2: SE por mecanismo de ajuste de direção.

\begin{tabular}{|c|c|c|c|c|c|c|c|c|}
\hline Mecanismo & Max. SI & \multicolumn{6}{|c|}{ número de iterações em cada SI } \\
\cline { 3 - 9 } & (iterações) & $1^{\circ}$ & $2^{\circ}$ & $3^{\circ}$ & $4^{\circ}$ & $5^{\circ}$ & $6^{\circ}$ & $7^{\circ}$ \\
\hline $\mathrm{EU}$ & 624 & 624 & - & - & - & - & - & - \\
\hline $\mathrm{AE}$ & 304 & 126 & 304 & 104 & 277 & - & - & - \\
\hline $\mathrm{AEE}$ & 189 & 120 & 97 & 189 & 99 & 36 & 105 & 189 \\
\hline
\end{tabular}


Tabela 4.3: Salas monitoradas a cada ciclo SE.

\begin{tabular}{|c|c|c|c|c|c|c|c|c|}
\hline Mecanismo & Robô & \multicolumn{7}{|c|}{ Salas monitoradas nos ciclos SE } \\
\cline { 3 - 9 } & & $1^{\circ}$ & $2^{\circ}$ & $3^{\circ}$ & $4^{\circ}$ & $5^{\circ}$ & $6^{\circ}$ & $7^{\circ}$ \\
\hline \multirow{3}{*}{$\mathrm{EU}$} & $\# 1$ & $1,2,4,6$ & - & - & - & - & - & - \\
\cline { 2 - 9 } & $\# 2$ & $1,2,3,4,5$ & - & - & - & - & - & - \\
\cline { 2 - 10 } & $\# 3$ & $1,2,4,5$ & - & - & - & - & - & - \\
\hline \multirow{3}{*}{$\mathrm{AE}$} & $\# 1$ & $1,2,4,6$ & $6,4,3$ & $6,4,3,2$ & 2,3 & - & - & - \\
\cline { 2 - 9 } & $\# 2$ & $1,2,3,4$ & $3,4,6,5,1$ & 1,4 & $4,3,2,6$ & - & - & - \\
\cline { 2 - 9 } & $\# 3$ & $1,4,5$ & $5,4,3,2$ & 5,4 & $5,4,3,1$ & - & - & - \\
\hline \multirow{3}{*}{$\mathrm{AEE}$} & $\# 1$ & $1,4,6$ & $6,4,3$ & $3,2,4,6$ & 6,4 & 6 & $6,4,3,2$ & $4,3,2,6$ \\
\cline { 2 - 9 } & $\# 2$ & $1,4,5$ & $5,4,1$ & $1,4,3,2$ & 4,1 & $1,4,5$ & $5,4,1$ & $1,4,5$ \\
\cline { 2 - 9 } & $\# 3$ & $1,4,3,2$ & 2,3 & $2,3,4,6,1,5$ & $5,4,3,2$ & 2,3 & $3,4,6$ & $4,3,2,1$ \\
\hline
\end{tabular}

\subsubsection{Posição Inicial dos Robôs}

Este grupo de experimentos avalia a eficiência do sistema IAS-SS para configurações distintas de posicionamento dos robôs. Dois tipos de posicionamento foram projetados: 1) todos os robôs iniciam a navegação na mesma sala, Configuração Agrupado (CA) e 2) os robôs iniciam a navegação em salas distintas, Configuração Separado (CS). Para as tarefas de exploração e vigilância, é óbvio que uma maior eficiência é garantida quando os robôs não estão próximos uns dos outros. Assim, induz que situações em que os robôs iniciam a navegação em salas diferentes apresentam uma pequena vantagem. Contudo, os experimentos demonstram que, depois de um determinado período, os cenários envolvendo o posicionamento CA atingem a mesma eficiência daqueles em que o posicionamento CS é adotado. Isto ocorre, pois os robôs tendem a se manter distantes uns dos outros devido à eficiência da estratégia proposta, como será mostrado mais adiante. Experimentos para analisar o desempenho de acordo com a posição inicial dos robôs são realizados no ambiente da Figura 4.8. Para ambos os posicionamentos, três robôs são utilizados. Para os posicionamentos CA e CS, os robôs iniciam a navegação a partir da sala 6 e salas 2,6 e 7 , respectivamente.

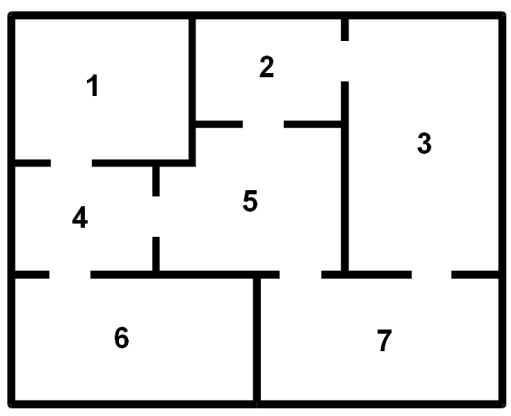

Figura 4.8: Estrutura do ambiente.

A seguir, seis configurações de ambientes são geradas a partir da combinação dos posicionamentos iniciais (CA e CS) e dos mecanismos de ajuste de 
direção (Seção 4.4.1). Analogamente aos experimentos anteriores, dois aspectos são considerados para a análise do desempenho da estratégia IAS-SS. As seguintes abreviações serão usadas nas tabelas de desempenho. A média do número de ciclos de vigilância (SE) será representada por "n. de SE"e a média de iterações nos intervalos de segurança (SI) por "it. de SI".

Conforme o esperado, o desempenho da estratégia com o mecanismo EU para ambos os tipos de posicionamento foi inferior aos mecanismos AE e AEE. É interessante destacar que mesmo com um mecanismo sem alguma relação com feromônio, os robôs completaram em média 1 e 0.3 ciclo SE com o posicionamento $\mathrm{CS}$ e CA, respectivamente. Isto ocorreu devido à característica randômica do mecanismo. Somente para o mecanismo EU, o desempenho da estratégia com a aplicação do posicionamento CS apresenta larga vantagem quando comparado com o posicionamento CA, uma vez que, em CS, os robôs iniciam a navegação já em salas distintas facilitando o cumprimento do ciclo SE. Ao contrário do mecanismo EU, os posicionamentos CS e TP mostram desempenhos semelhantes quando aplicados juntos com os mecanismos $\mathrm{AE}$ e AEE.

Como pode ser visto na Tabela 4.4, para o mecanismo AE, a utilização do posicionamento CS obtém desempenho pouco superior sobre o posicionamento CA tanto para média do número de ciclos SE quanto para a média de iterações no SI. Tal superioridade é ofuscada considerando que em CA, a navegação inicia-se com somente uma sala visitada. No caso do mecanismo AEE, os melhores resultados são obtidos com o posicionamento CA, que, de fato, apresentou o melhor desempenho de forma geral. Isto deixa claro que o posicionamento inicial não causa grandes consequências ao longo da navegação. Os dados da tabela são exibidos na Figura 4.9 que mostra o boxplot da média de iterações de SI para as seis configurações de ambiente. Os números $1, \ldots, 6$ referem-se às configurações de ambiente CS com os mecanismos EU, $\mathrm{AE}$ e AEE e configurações de ambiente CA com os mecanismos EU, AE e AEE, respectivamente.

Embora, teoricamente, o posicionamento CS apresenta uma pequena vantagem sobre o posicionamento $\mathrm{CA}$, uma vez que na iteração $t=0$ os três robôs monitoram simultaneamente três salas distintas, o desempenho de ambas as configurações são similares. Uma das principais características da estratégia IAS-SS é a habilidade dos robôs manterem-se distantes uns dos outros de acordo com o modelo de feromônio baseado na repulsão. Então, mesmo com a configuração CA, os robôs tendem se espalhar pelo ambiente à medida que se locomovem. Assim, após um período de tempo, o desempenho do posicionamento CA torna-se semelhante àquele obtido pelo posicionamento CS. Ou seja, a vantagem do posicionamento CS é diluída durante a navegação dos 
Tabela 4.4: Desempenho da estratégia IAS-SS de acordo com a combinação dos posicionamentos iniciais e os mecanismos de ajuste de direção.

\begin{tabular}{|c|c|c|}
\hline \multirow{2}{*}{ Posicionamento } & \multicolumn{2}{|c|}{ Mecanismo EU } \\
\cline { 2 - 3 } & n. de SE & it. de SI \\
\hline CS & $1 \pm 0.94$ & $512.14 \pm 140.4$ \\
\hline CA & $0.3 \pm 0.5$ & $576 \pm 86.21$ \\
\hline \multicolumn{3}{|c|}{ Mecanismo AE } \\
\hline Posicionamento & n. de SE & it. de SI \\
\hline \multirow{3}{*}{ CS } & $6.66 \pm 1.73$ & $160.04 \pm 85.65$ \\
\hline CA & $6 \pm 2.16$ & $185.03 \pm 122.4$ \\
\hline \multicolumn{3}{|c|}{ Mecanismo AEE } \\
\hline Posicionamento & n. de SE & it. de SI \\
\hline \multirow{3}{*}{ CS } & $6 \pm 2$ & $199.71 \pm 101.62$ \\
\hline CA & $7.85 \pm 2.61$ & $120.51 \pm 44.3$ \\
\hline
\end{tabular}

robôs. Para ilustrar este fato, os gráficos da Figura 4.10 apresentam o comportamento dos robôs e os intervalos de vigilância para as configurações de posicionamento utilizando o mecanismo AEE. Os dados usados nos gráficos são do experimento com as médias de SE e de SI próximas aos valores medianos dentre os demais experimentos realizados. Para o posicionamento CS, o sistema concluiu SE 6 vezes, enquanto que o ciclo SE é concluído 7 para o posicionamento CA.

Com a observação dos gráficos, evidencia-se a influência do posicionamento CS no início da navegação. Nota-se que o primeiro ciclo SE ocorre antes na configuração em que os robôs iniciam a navegação em salas distintas (Figura 4.10(a)). A partir deste instante, entende-se que os robôs já estão dispersos pelo ambiente, o que torna o desempenho de ambos posicionamentos semelhantes.

O conceito chave da tarefa de vigilância de ambientes é a minimização do período (iterações) no qual um ambiente é monitorado. Em outras palavras, a tarefa de vigilância requer a minimização do período no qual as regiões do ambiente permanecem não visitadas, lembrando que a minimização isolada de cada região não garante a solução da vigilância. Portanto, uma alternativa para analisar o desempenho do sistema acontece por meio do período máximo (número máximo de iterações consecutivas) no qual cada sala permanece sem ser visitada. Este periodo é apresentado na Figura 4.11 para as seis configurações do ambiente. Os dados apresentados são os mesmos utilizados nos gráficos de alternância de salas da Figura 4.10. Independentemente do posicionamento inicial dos robôs, são nos experimentos com o mecanismo EU em que aparecem valores para períodos sem visita próximos ao limite superior (1000 iterações) e inferior (nenhuma iteração), o que não surpreende 


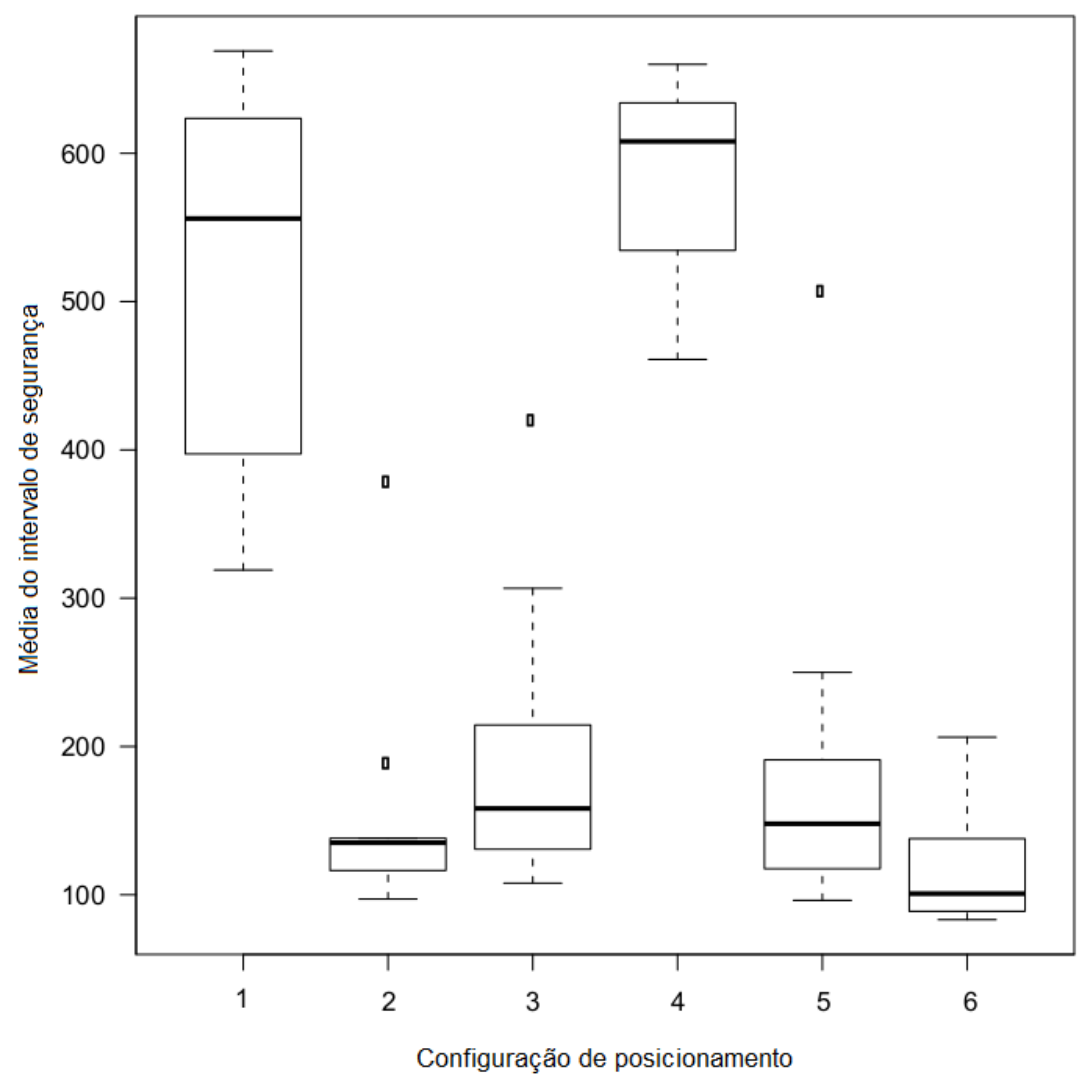

Figura 4.9: Boxplots da distribuição da média do intervalo de segurança para diferentes configurações de posicionamento.

desde que não há uma heurística para realizar a tarefa. Enquanto que para os mecanismos $\mathrm{AE}$ e AEE, a discrepância entre tais períodos é menor. Tendo em vista que o número de robôs é menor que o número de salas, não é objetivo dessa estratégia manter uma sala monitorada a todo instante tal que seu período sem visita seja nulo. A configuração dos ambientes (número de salas e número de robôs) é projetada para forçar os robôs a sairem de sua região monitorada e visitar outras antes de voltar à primeira. Assim, o intuito é distribuir de maneira mais igualitária possível o período em que todas as salas não são visitadas. Neste sentido, percebe-se pelos períodos da Figura 4.11 que a estratégia de coordenação utilizando o mecanismo AEE para o posicionamento CA apresenta melhor desempenho dentre os demais experimentos, confirmando a informação da Tabela 4.4 .

Um problema que surge com a execução desses experimentos está na relação entre o tamanho do ambiente e do raio dos sensores. Da maneira como os ambientes foram configurados juntamente com o modelo de robôs adotado, assim que um robô entra em uma sala, esta é, na maioria das vezes, completamente coberta pela área de alcance dos sensores. Assim, feromônio é depositado em todo o ambiente, o que ocasiona na ausência de locais com baixa quantidade de feromônio para ser visitada. Portanto, os robôs evitam em per- 


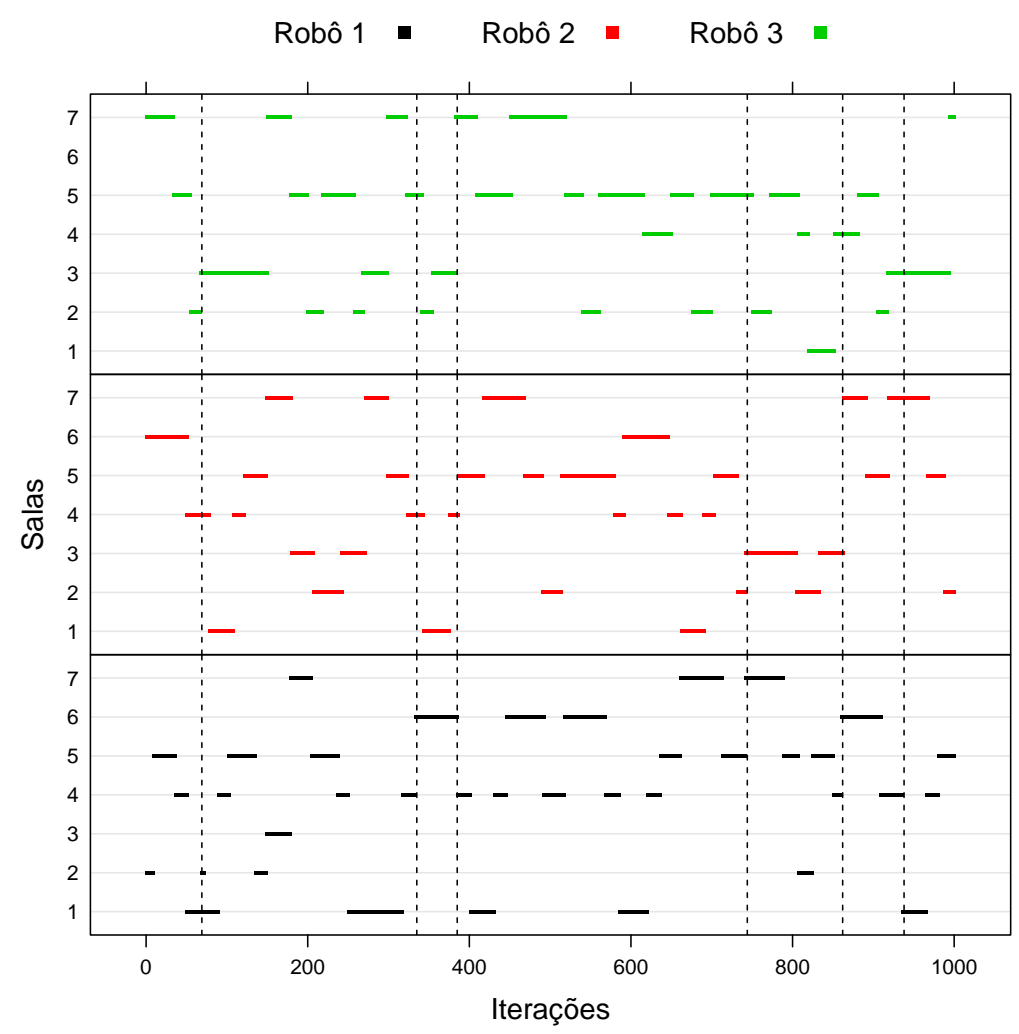

(a)

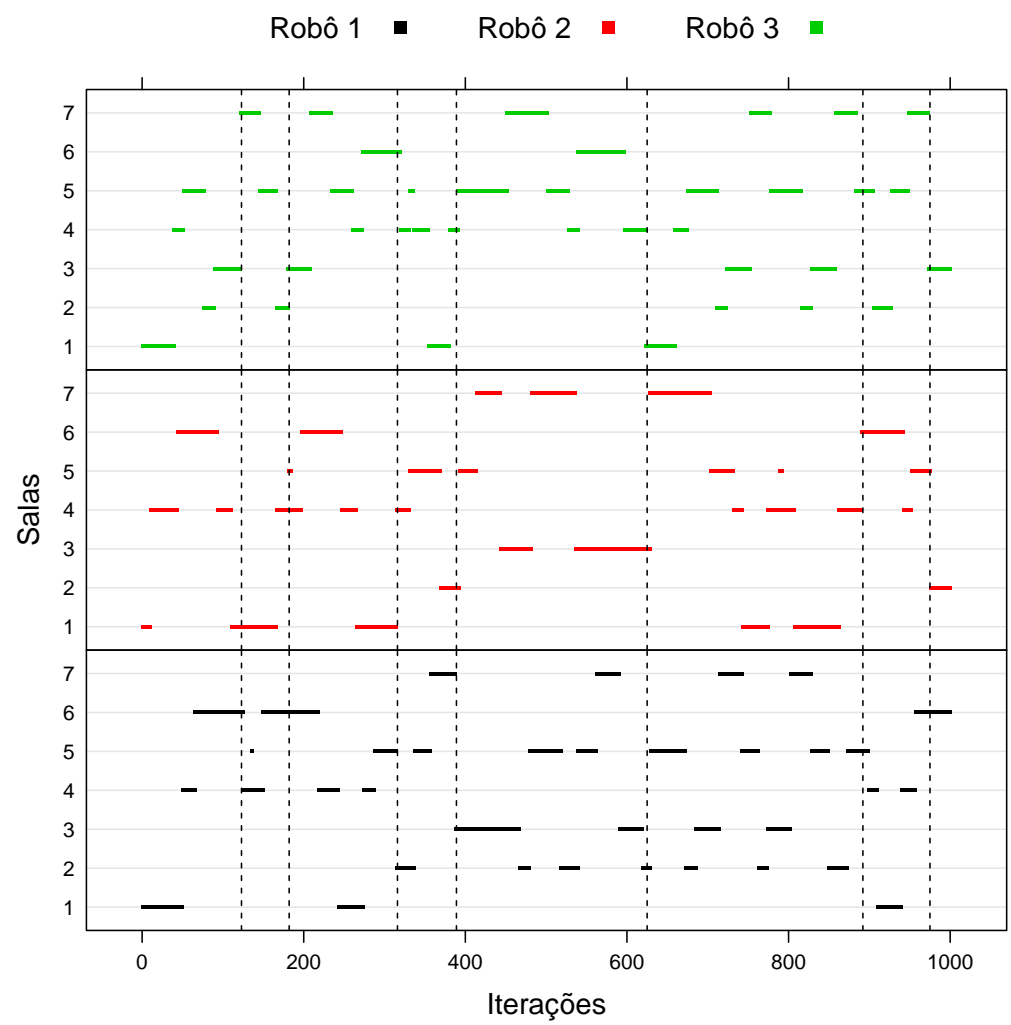

(b)

Figura 4.10: Desempenho da estratégia IAS-SS de acordo com os tipos de posicionamento inicial e o mecanismo AEE: (a) CS; (b) CA. 


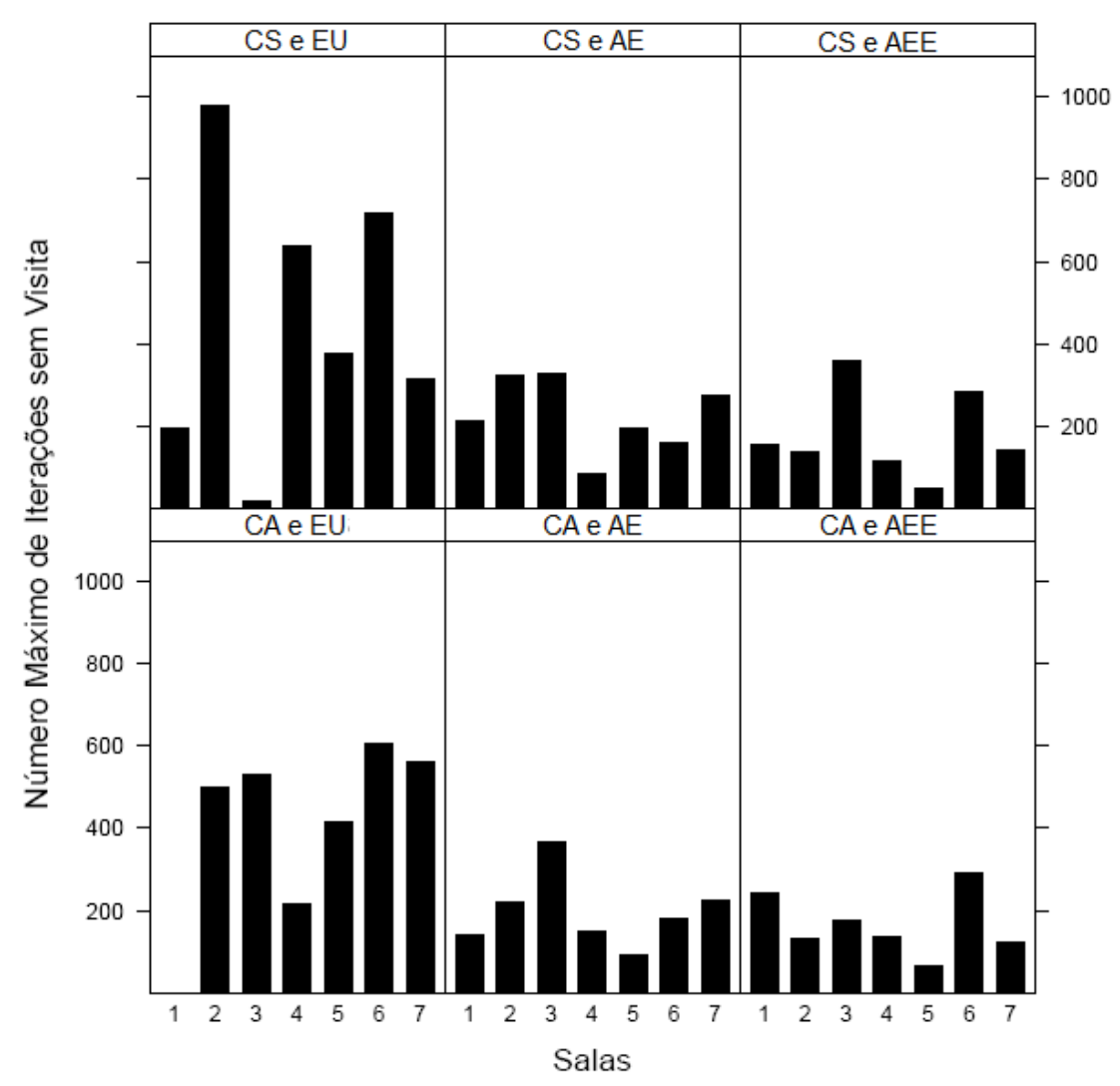

Figura 4.11: Número máximo de iterações sem visita nas salas.

manecer neste ambiente. Neste sentido, os próximos experimentos investigam como a escala do ambiente influencia no desempenho da estratégia IAS-SS. Dois ambientes são considerados com a mesma disposição de obstáculos da Figura 4.8 (que a partir desse ponto será referenciada como ambiente x1), porém com tamanho de escalas diferentes. O primeiro ambiente (ambientes x2) tem sua escala duas vezes maior que o ambiente original e o segundo (ambiente x3) 3 vezes. Dessa forma, as dimensões do ambiente x 2 são $60 \mathrm{~m} \times 40 \mathrm{~m}$ e do ambiente $x 3,90 \mathrm{~m} \times 80 \mathrm{~m}$. A motivação para estender a escala do ambiente reside na validação da adaptabilidade da estratégia na tarefa de vigilância em ambientes com tamanhos distintos. Diferentemente dos experimentos com o ambiente $\mathrm{x} 1$, o número máximo de iterações para os experimentos com os ambientes x2 e x3 são 2000 e 3000, respectivamente.

Analogamente aos experimentos relacionados ao ambiente x1, o desempenho da estratégia em ambos tipos de posicionamentos para os ambientes x2 e x3 são similares. Da mesma forma como justificado anteriormente, a característica repulsiva do feromônio é responsável por manter os robôs distantes um dos outros após um período independentemente do posicionamento inicial adotado (CS ou CA). As Tabelas 4.5 e 4.6 corroboram que não há forte contraste entre os desempenhos das configurações de posicionamentos CS e CA. Destaca nesses experimentos, a superioridade do posicionamento inicial 
CS sobre o CA quando o mecanismo AE é considerado. No entanto, para o mecanismo $\mathrm{AEE}$, a estratégia executa a tarefa de vigilância de forma mais eficiente quando aplicado o posicionamento CA. Portanto, em se tratando de simulações de longa duração, não há como afirmar qual posicionamento inicial é mais adequado. Do ponto vista prático, em que robôs reais seriam aplicados em ambientes reais, o posicionamento inicial mais apropriado é o CA, desde que o conhecimento do ambiente não esteja disponivel.

A respeito do mecanismo de ajuste de direção, o consenso é que o mecanismo AEE resulta no melhor desempenho quando as médias de ciclos SE e de iterações nos intervalos SI são comparados a outros mecanismos. O desempenho da estratégia IAS-SS para as seis configurações nos ambientes x2 e x3 é mostrado no gráfico das Figuras 4.12(a) e 4.12(b), respectivamente. Os números $1, \ldots, 6$ referem-se às configurações CS com os mecanismos EU, AE e AEE; e configurações CA com os mecanismos EU, AE e AEE, respectivamente.

Tabela 4.5: Desempenho da estratégia IAS-SS de acordo com a combinação dos posicionamentos iniciais e os mecanismos de ajuste de direção no ambiente x2.

\begin{tabular}{|c|c|c|}
\hline \multirow{2}{*}{ Posicionamento } & \multicolumn{2}{|c|}{ Mecanismo EU } \\
\cline { 2 - 3 } & n. de SE & it. de SI \\
\hline CS & $2.16 \pm 0.75$ & $892 \pm 517$ \\
\hline CA & $1.75 \pm 0.95$ & $985.75 \pm 576.36$ \\
\hline \multicolumn{3}{|c|}{ Mecanismo AE } \\
\hline Posicionamento & n. de SE & it. de SI \\
\hline \multirow{3}{*}{ CS } & $5.2 \pm 1.62$ & $352.72 \pm 131.96$ \\
\hline CA & $4.6 \pm 2.01$ & $325.11 \pm 94.15$ \\
\hline \multicolumn{3}{|c|}{ Mecanismo AEE } \\
\hline Posicionamento & n. de SE & it. de SI \\
\hline \multirow{3}{*}{ CS } & $8.1 \pm 2.47$ & $246.8 \pm 68.33$ \\
\hline CA & $8.3 \pm 1.88$ & $226.1 \pm 59.48$ \\
\hline
\end{tabular}

O comportamento dos robôs e os intervalos de segurança para ambas configurações de ambiente usando o mecanismo AEE são exibidos nos gráficos das Figuras 4.13 (ambiente x2) e 4.14 (ambiente x3). Os dados usados nos gráficos são referentes aos experimentos com a média de SE e SI próxima aos valores medianos encontrados. Para o ambiente $\mathrm{x} 2$, a estratégia IAS-SS com o posicionamento CS conclui SE 9 vezes e com o CA 8 vezes. Enquanto para o ambiente $\mathrm{x} 3$, SE foi concluído 5 vezes com o posicionamento CS e 6 usando o CA. Da mesma forma que o experimento anterior, o ciclo SE ocorre primeiro no experimento com o posicionamento CS, pois, neste caso, os robôs iniciam a navegação em salas distintas favorecendo a tarefa de vigilância. Após o primeiro ciclo, ou seja, após a dispersão dos robôs, o desempenho para os dois tipos de posicionamento são semelhantes. Para simulações com número 


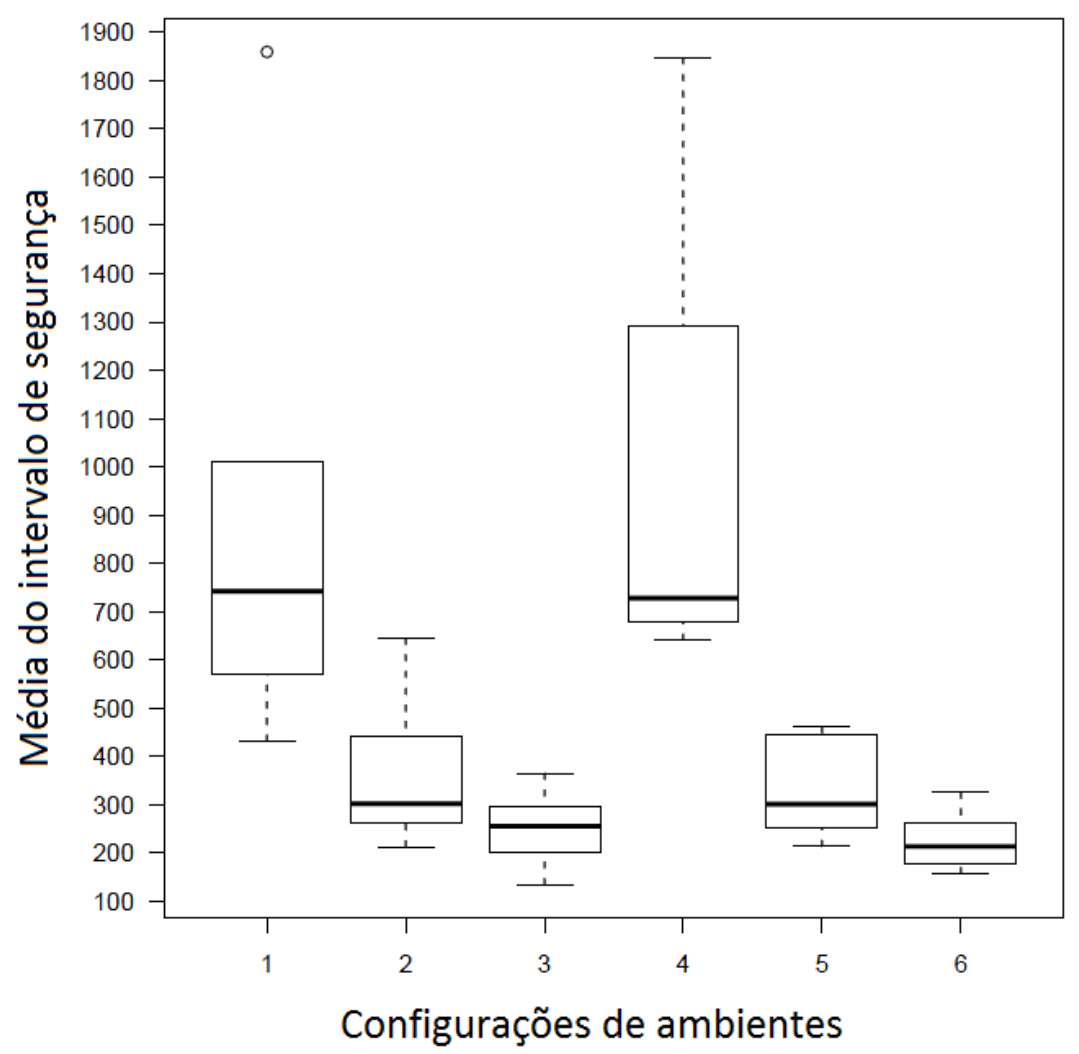

(a)

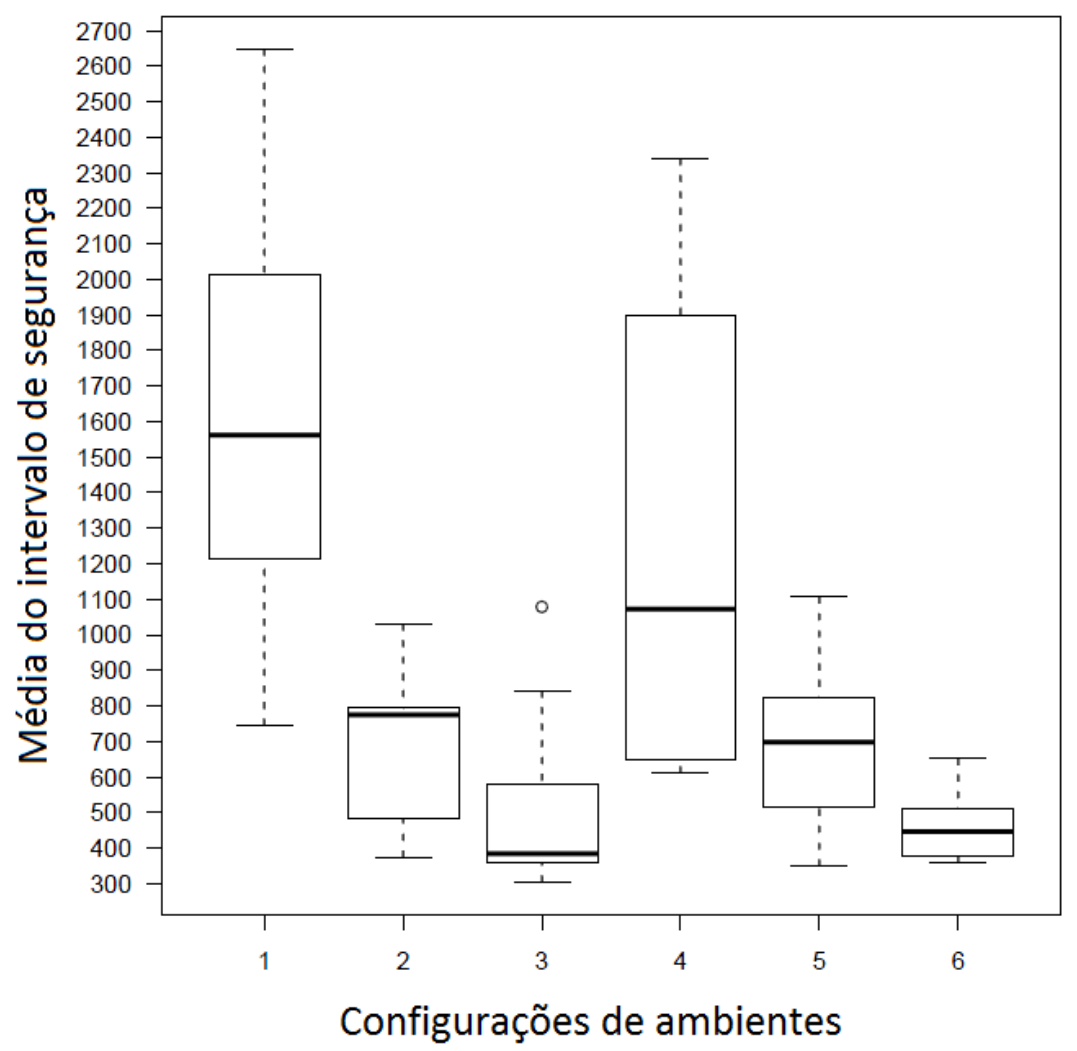

(b)

Figura 4.12: Boxplots da distribuição da média do intervalo de segurança para diferentes configurações de posicionamento: ambientes (a) x2; (b) x3. 
Tabela 4.6: Desempenho da estratégia IAS-SS de acordo com a combinação dos posicionamentos iniciais e os mecanismos de ajuste de direção ambiente x3.

\begin{tabular}{|c|c|c|}
\hline Posicionamento & \multicolumn{2}{|c|}{ Mecanismo EU } \\
\cline { 2 - 3 } & n. de SE & it. de SI \\
\hline CS & $1.37 \pm 0.52$ & $1621.87 \pm 610.53$ \\
\hline CA & $1.5 \pm 0.57$ & $1274.5 \pm 808$ \\
\hline \multicolumn{3}{|c|}{ Mecanismo AE } \\
\hline Posicionamento & n. de SE & it. de SI \\
\hline \multirow{3}{*}{ CS } & $4.33 \pm 1.11$ & $675.8 \pm 211.17$ \\
\hline CA & $3.5 \pm 1.27$ & $685.28 \pm 239.51$ \\
\hline \multicolumn{3}{|c|}{ Mecanismo AEE } \\
\hline Posicionamento & n. de SE & it. de SI \\
\hline \multirow{3}{*}{ CS } & $5.44 \pm 1.51$ & $519.2 \pm 269$ \\
\hline CA & $6.7 \pm 4.47$ & $460.5 \pm 100.11$ \\
\hline
\end{tabular}

elevado de iterações, como é o caso desses experimentos em relação ao anterior com o ambiente $\mathrm{x} 1$, a vantagem inicial do posicionamento CS torna-se insignificante para o resto da simulação.

O período máximo que as salas permanecem sem visita nos experimentos para os ambientes x2 e x3 são apresentados nas Figuras 4.15(a) and 4.15(b), respectivamente. Nota-se que independente da configuração de ambiente adotada, o desempenho da estratégia sofre uma melhora à medida que muda o mecanismo de ajuste de direção de EU para AEE. Além disto, o período sem visitação nas salas dos experimentos com o mecanismo AEE são menores além de melhores distribuídos. Analisando isoladamente cada mecanismo de ajuste, para o mecanismo EU, a distribuição do período sem visitação se mostra menos distribuída, com alta discrepância quando o posicionamento CA é aplicado para ambos os ambientes (x2 e x3). Nos experimentos com o mecanismo AE, a distribuição dos períodos sem visitação é similar para ambos os posicionamentos no ambiente x2. Já no ambiente x3, esta similaridade não é observada. Enquanto, para o posicionamento CS, a oscilação dos períodos é evidente, para o mecanismo AEE, a diferença entre os períodos é menor. Por fim, quando o mecanismo AEE é executado, independente do ambiente utilizado e da posicão inicial dos robôs, os períodos das salas são menores que os períodos das outras configurações além de apresentar uma distribuição mais igualitária.

A característica de auto-adaptação do sistema IAS-SS é visualizada nas trajetórias dos robôs da Figura 4.16. Os dados apresentados são dos experimentos com a média do número de SE próxima ao valor mediano encontrado para cada configuração de ambiente. Somente as trajetórias obtidas das simulações dos experimentos que consideram o mecanismo AEE e configuração CA 


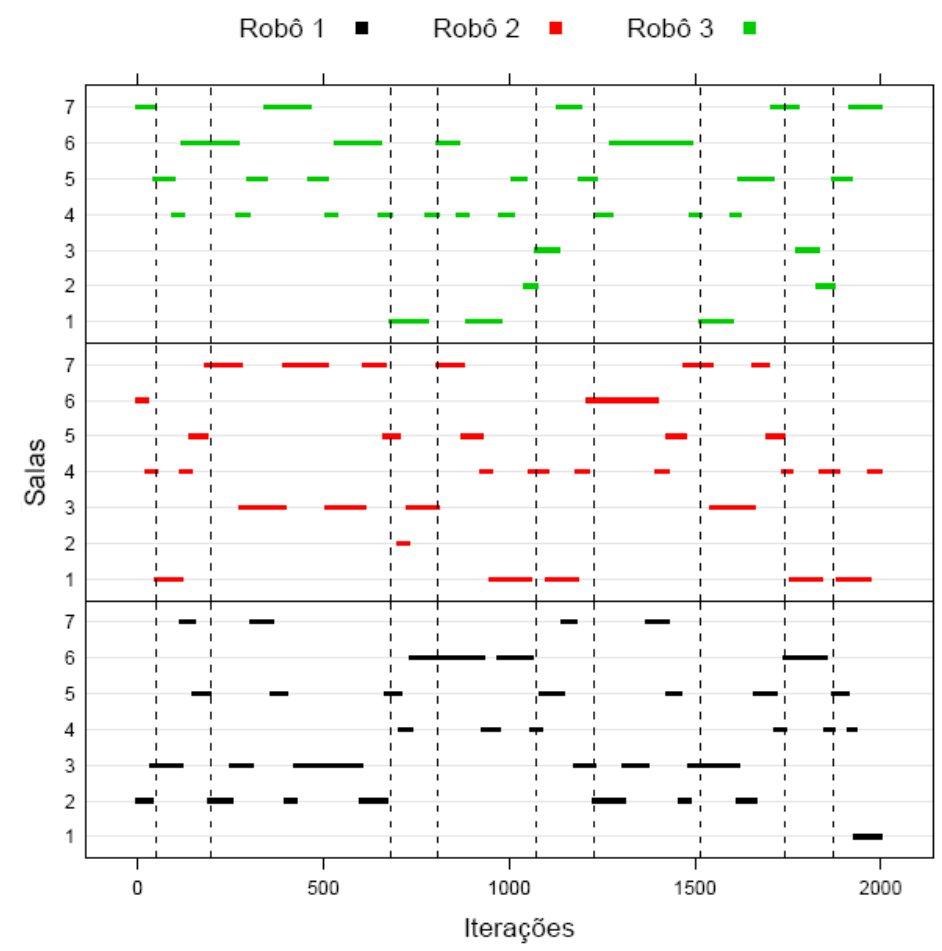

(a)

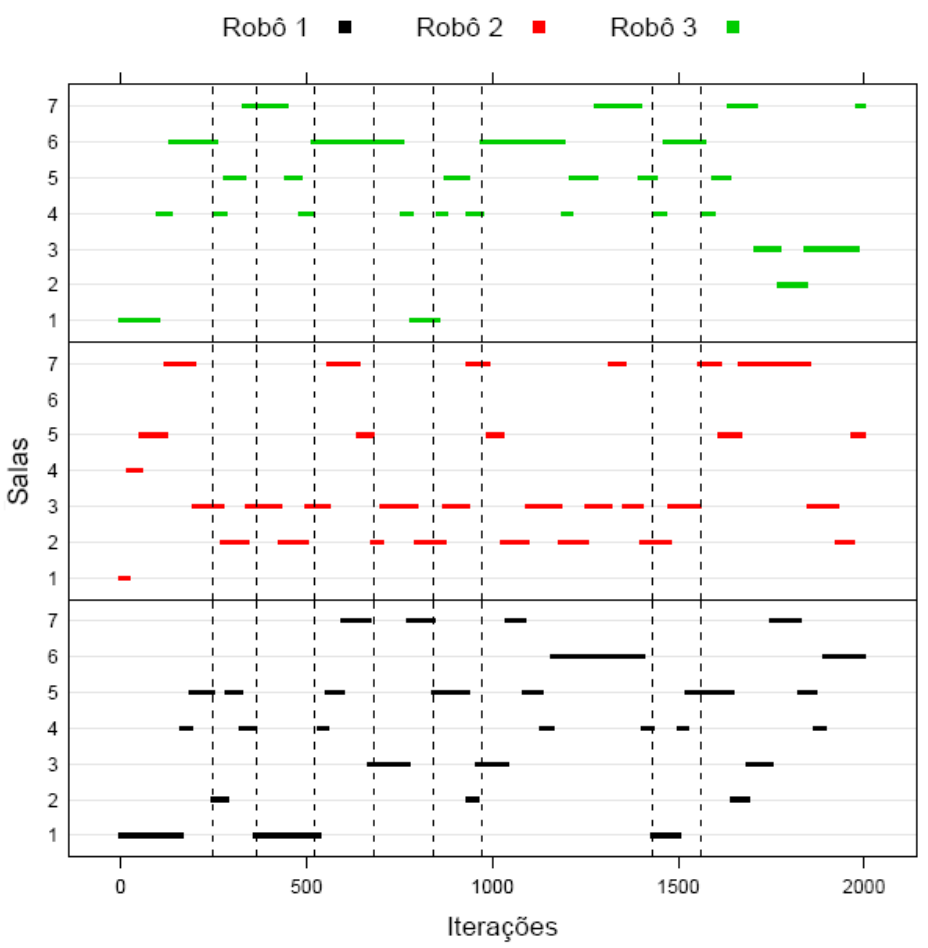

(b)

Figura 4.13: Desempenho da estratégia IAS-SS de acordo com diferentes configurações de posicionamento para o mecanismo AEE no ambiente x2: (a) CS; (b) CA. 


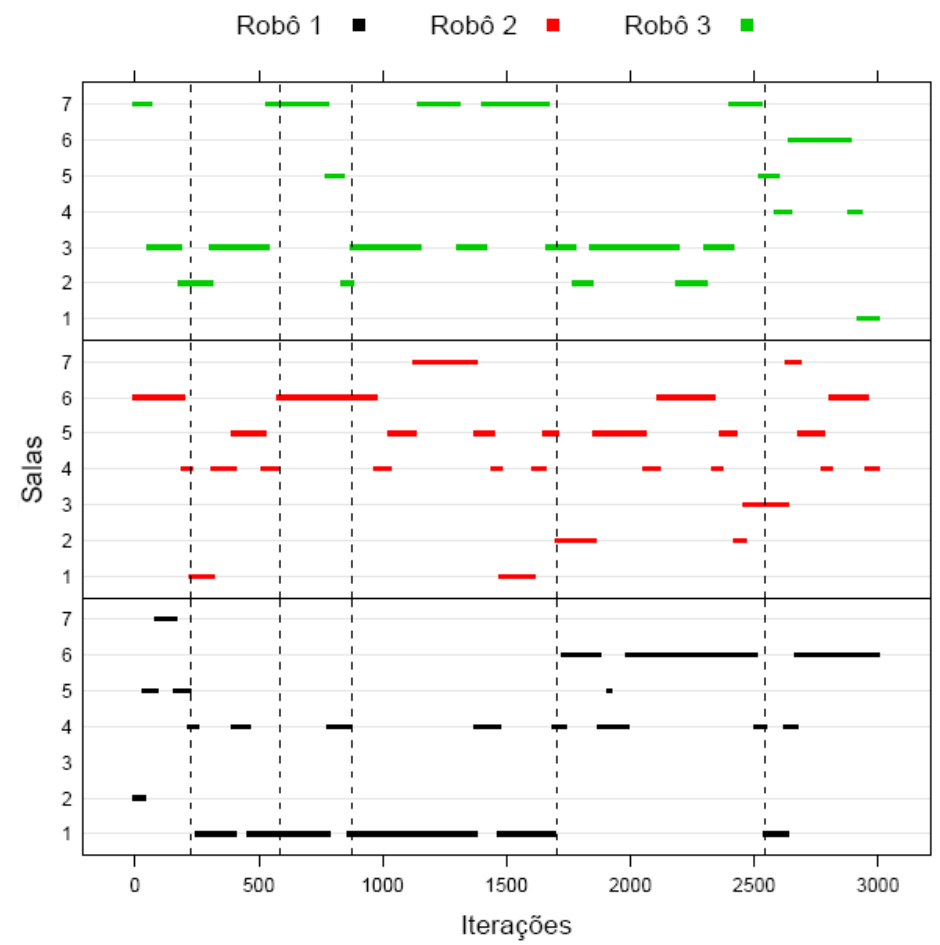

(a)

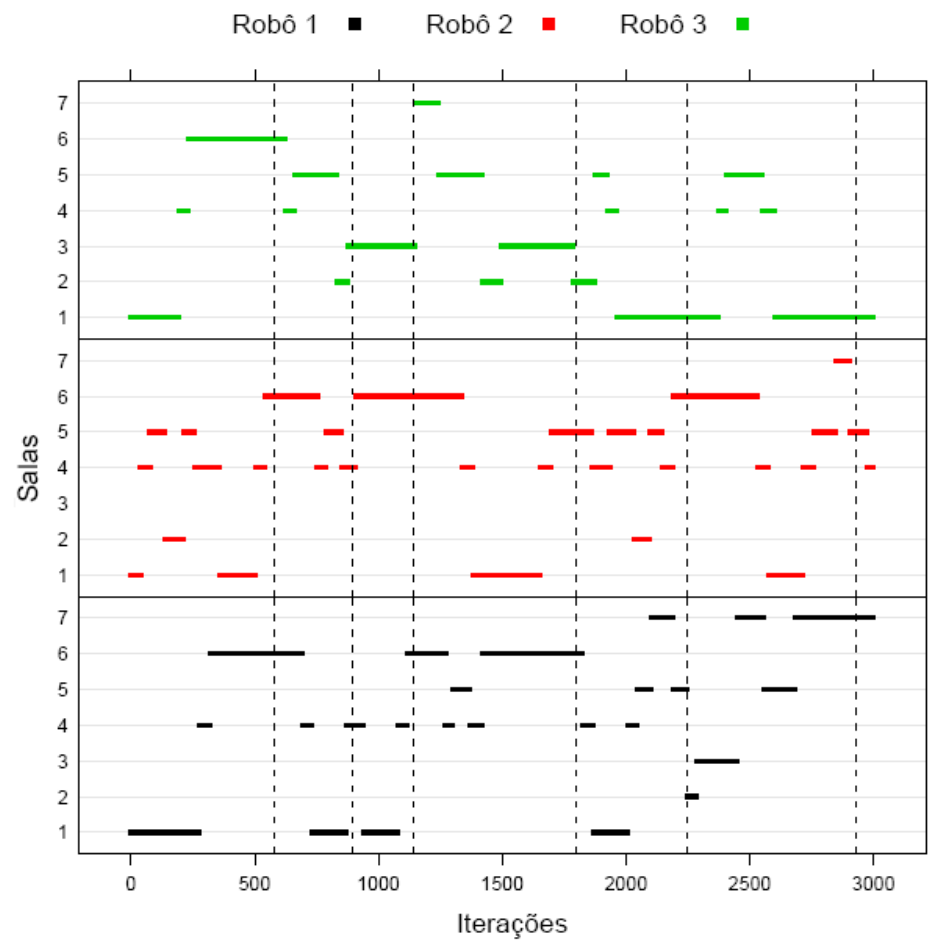

(b)

Figura 4.14: Desempenho da estratégia IAS-SS de acordo com diferentes configurações de posicionamento para o mecanismo AEE no ambiente x3: (a) CS; (b) CA. 


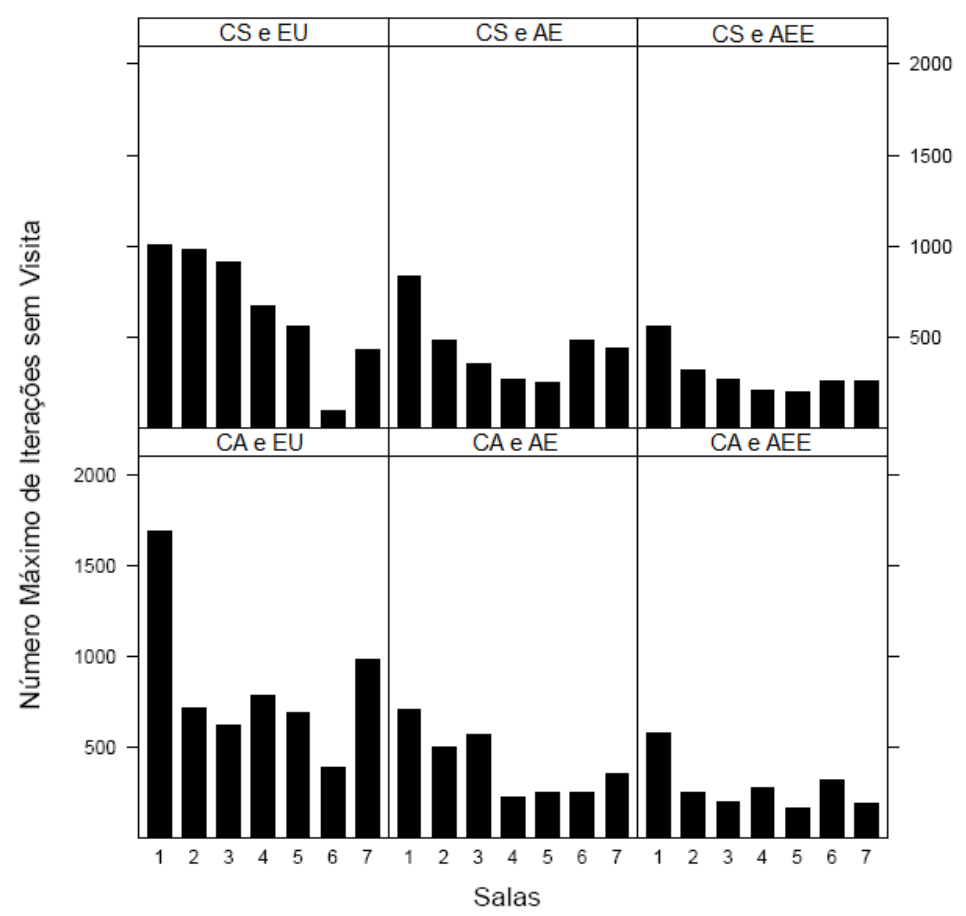

(a)

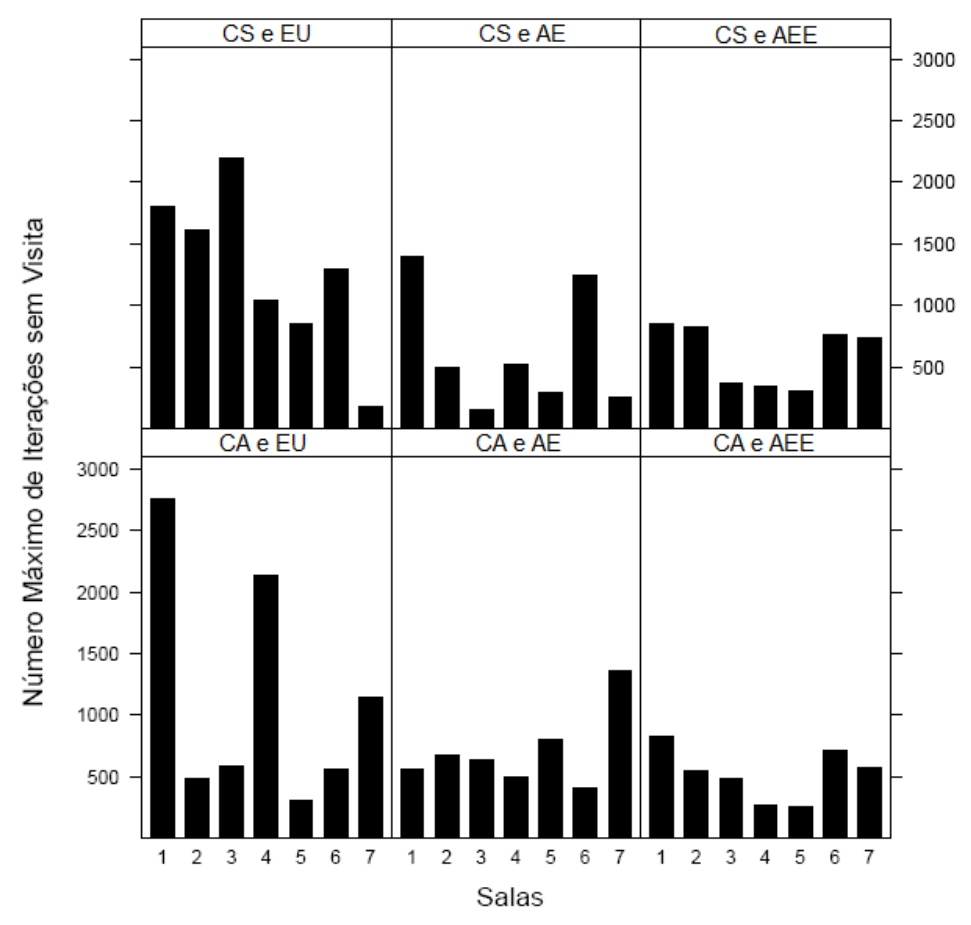

(b)

Figura 4.15: Número máximo de iterações sem visita nas salas: ambientes (a) x2; (b) x3. 


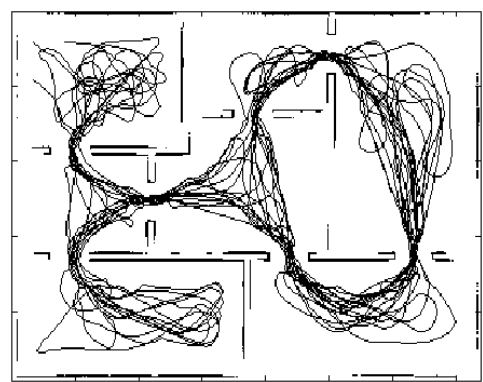

(a)

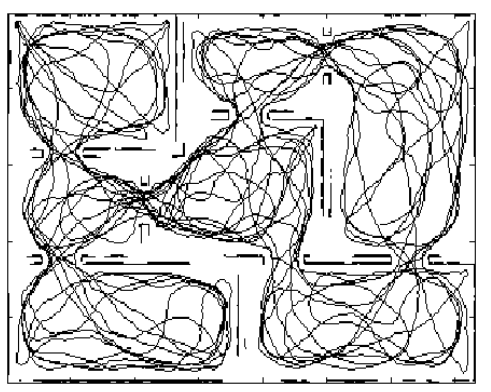

(b)

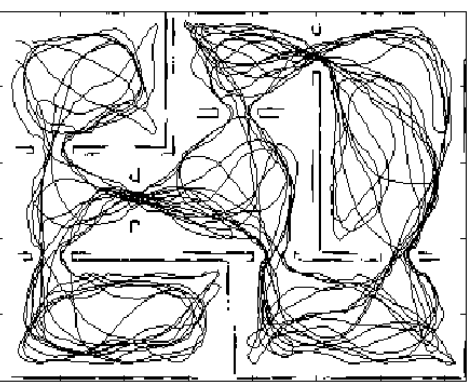

(c)

Figura 4.16: Trajetórias dos robôs durante as tarefas de exploração e vigilância para configuração de ambiente CA com o mecanismo AEE: (a) ambiente x1; (b) ambiente $\mathrm{x} 2$; (c) ambiente $\mathrm{x} 3$.

são mostradas para contrastar a pequena diferença entre os caminhos percorridos. Pode ser observado que as trajetórias estão concentradas em uma trilha quando a dimensão das salas é pequena (Figura 4.16(a)). Com esta configuração de ambiente, ao entrar em uma sala, um robô cobre praticamente toda sua área devido ao alcance de seus sensores. Assim, restam poucos locais na sala nos quais o robô deve se dirigir para depositar feromônio e efetuar a tarefa de vigilância. Se há alguma passagem para outra sala, esta passa a ser a região de interesse uma vez que o alcance dos sensores, geralmente, excede tal passagem. Após entrar em uma sala, a tendência é os robôs se moverem em direção até alguma passagem. Por esta razão, as trajetórias possuem a aparência de trilhas. Nesta breve discussão, não foi considerada a presença de algum robô na sala seguinte após a passagem. Neste caso, tal passagem deixa de ser uma região atrativa forçando o robô a retornar.

Para as situações em que o alcance dos sensores não cobre toda a área de uma sala, como é caso dos ambientes com dimensões duplicadas e triplicadas, os robôs tendem a não gerar trajetórias no formato de trilhas. Em ambientes com estas características, há várias regiões de interesse em uma mesma sala. Dessa forma, os robôs são atraídos para regiões onde o sensor não alcança, ou seja, os robôs se movem para as extremidades (bordas) das salas a fim de cobrir todo o ambiente como mostram as Figuras 4.16(b) e 4.16(c), o que demonstra o poder de cobertura de ambiente que emerge da estratégia proposta.

\subsubsection{Coordenação de Movimento em Função do Número de Robôs}

Os seguintes experimentos abordam a análise do desempenho quanto ao número de robôs utilizados. De fato, quanto maior o número de robôs empregados, mais regiões são exploradas e monitoradas simultaneamente, de modo 
que, poucas ou nenhuma região permanece vazia por um longo período. Uma vez que o comportamento robótico é baseado na modificação da teoria de colônias de formigas artificiais, a probabilidade de somente um robô explorar e monitorar um ambiente (seja amplo ou não) é alta. Contudo, isto demanda um longo período. Para avaliar o desempenho da coordenação de movimento e a eficiência da tarefa de vigilância, experimentos são realizados aumentando o número de robôs no ambiente da Figura 4.17. Como observado nos experimentos descritos anteriormente, o mecanismo AEE apresenta desempenho mais eficiente aos dos mecanismos $\mathrm{EU}$ e $\mathrm{AE}$, portanto, este é adotado para analisar a eficiência das tarefas de exploração e vigilância à medida que o número de robôs é incrementado. Todos os robôs a serem adicionados são alocados na sala 1.

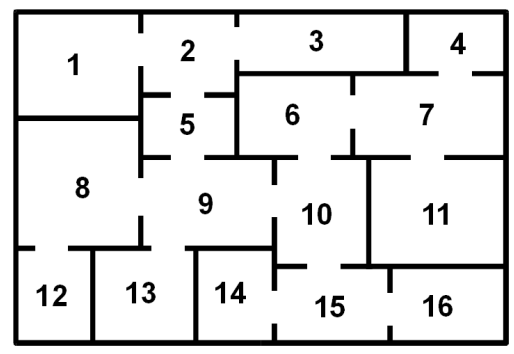

Figura 4.17: Modelo do ambiente.

Embora seja esperado que o tempo para explorar todo o ambiente decaia conforme o número de robôs aumenta, a tarefa de vigilância é realizada mesmo com um número restrito de robôs. Isto enfatiza que o número de robôs não é um fator que limita o tamanho do ambiente a ser explorado. Mesmo considerando poucos robôs, estes são capazes de monitorar áreas amplas. A tarefa de vigilância é completada independentemente do número de robôs. Como comportamento geral do sistema, o tamanho do intervalo SI é reduzido à medida que o número de robôs é incrementado e, por consequência disso, mais ciclos SE se tornam presentes, conforme observado na Tabela 4.7. Observa-se que o aumento do número de robôs ocasiona também no aumento da média de número de ciclos $\mathrm{SE}$ e na redução na média de iterações nos intervalos SI's. Uma visão mais detalhada dos resultados da tabela, em relação à média de iterações nos SI's, é apresentada na Figura 4.18 que mostra o boxplot da distribuição do desempenho da estratégia IAS-SS.

Uma característica interessante da estratégia IAS-SS é extraída desses experimentos. Embora o aumento do número de ciclos SE seja diretamente proporcional ao aumento de número de robôs, é possível observar que o período para completar o primeiro ciclo SE nem sempre obedece esse comportamento. Uma região que conta com a presença de inúmeros robôs recebe alta quantidade de feromônio. Aqueles robôs envoltos por essa quantidade tendem a gerar trajetórias aleatórias, e por esta razão, ficam 'presos' nesta região. O 
Tabela 4.7: Desempenho da configuração de posicionamento CA com o mecanismo de ajuste de direção AEE para o crescente número de robôs.

\begin{tabular}{|c|c|c|}
\hline Número de robôs & Média do número de SE & Média de iterações no SI \\
\hline 2 & $0.5 \pm 0.7$ & $598.25 \pm 196.62$ \\
\hline 3 & $1.1 \pm 0.57$ & $621.44 \pm 179.88$ \\
\hline 4 & $1.5 \pm 0.97$ & $412.56 \pm 190.89$ \\
\hline 5 & $1.5 \pm 0.97$ & $504.77 \pm 239.93$ \\
\hline 6 & $2.4 \pm 0.51$ & $220.60 \pm 65.26$ \\
\hline 7 & $3.2 \pm 0.78$ & $174.01 \pm 58.25$ \\
\hline 8 & $3.4 \pm 0.98$ & $155.97 \pm 59.30$ \\
\hline 9 & $3.9 \pm 1.28$ & $137.94 \pm 61.57$ \\
\hline 10 & $5.3 \pm 1.5$ & $118.75 \pm 20.92$ \\
\hline 11 & $5.7 \pm 2$ & $115.98 \pm 44.14$ \\
\hline 12 & $6.4 \pm 1.89$ & $107 \pm 38$ \\
\hline 13 & $6.9 \pm 2.42$ & $108.4 \pm 46.47$ \\
\hline 14 & $8.2 \pm 1.68$ & $88.04 \pm 21.93$ \\
\hline 15 & $8.3 \pm 2.78$ & $92.02 \pm 40.23$ \\
\hline
\end{tabular}

processo de dispersão dos robôs inicia-se, então, à medida que alguns robôs (talvez, um a um) se distanciam do grupo. Tal processo torna-se mais rápido em regiões amplas sem obstáculos, o que facilita a dispersão dos robôs. No caso da Figura 4.17, o acúmulo de robôs ocorre na sala 1 onde há somente uma passagem para a sala 2. Assim o tempo despendido para a dispersão dos robôs é maior.

Por outro lado, é óbvio que quanto menor o número de robôs, mais rapidamente o grupo se espalha pelo ambiente. Porém, a baixa quantidade de robôs não implica na minimização do período de conclusão do primeiro ciclo SE. Isto depende do tamanho do ambiente como é observado na Tabela 4.7. Uma vez que os robôs já estão dispersos pelo ambiente (independente da quantidade), ou seja, após o primeiro ciclo SE, a frequência com o que o ambiente é sensoriado torna-se proporcional à quantidade de robôs.

Esta característica relacionada à conclusão do primeiro ciclo SE é evidenciada na Figura 4.19. Foram ilustrados o comportamento da estratégia com $2,7,10$ e 15 robôs, considerando o experimento que obteve valores medianos para a média de ciclos SE's e de iterações nos intervalos SI's. Nota-se que o maior período necessário para completar o primeiro ciclo é menor quando 7 robôs atuam na tarefa. Neste caso, o processo de dispersão dos robôs, saindo da sala 1, ocorreu de maneira mais acelarada. Isto mostra que para as dimensões da região denotada como a sala 1 , o número de robôs mais adequado a aglomeração é 7 . O pior caso é assinalado quando somente 2 robôs são empregados. A ineficiência para a conclusão das tarefas, neste caso, justifica-se pelo tamanho do ambiente e da dificuldade de acessar as salas. 


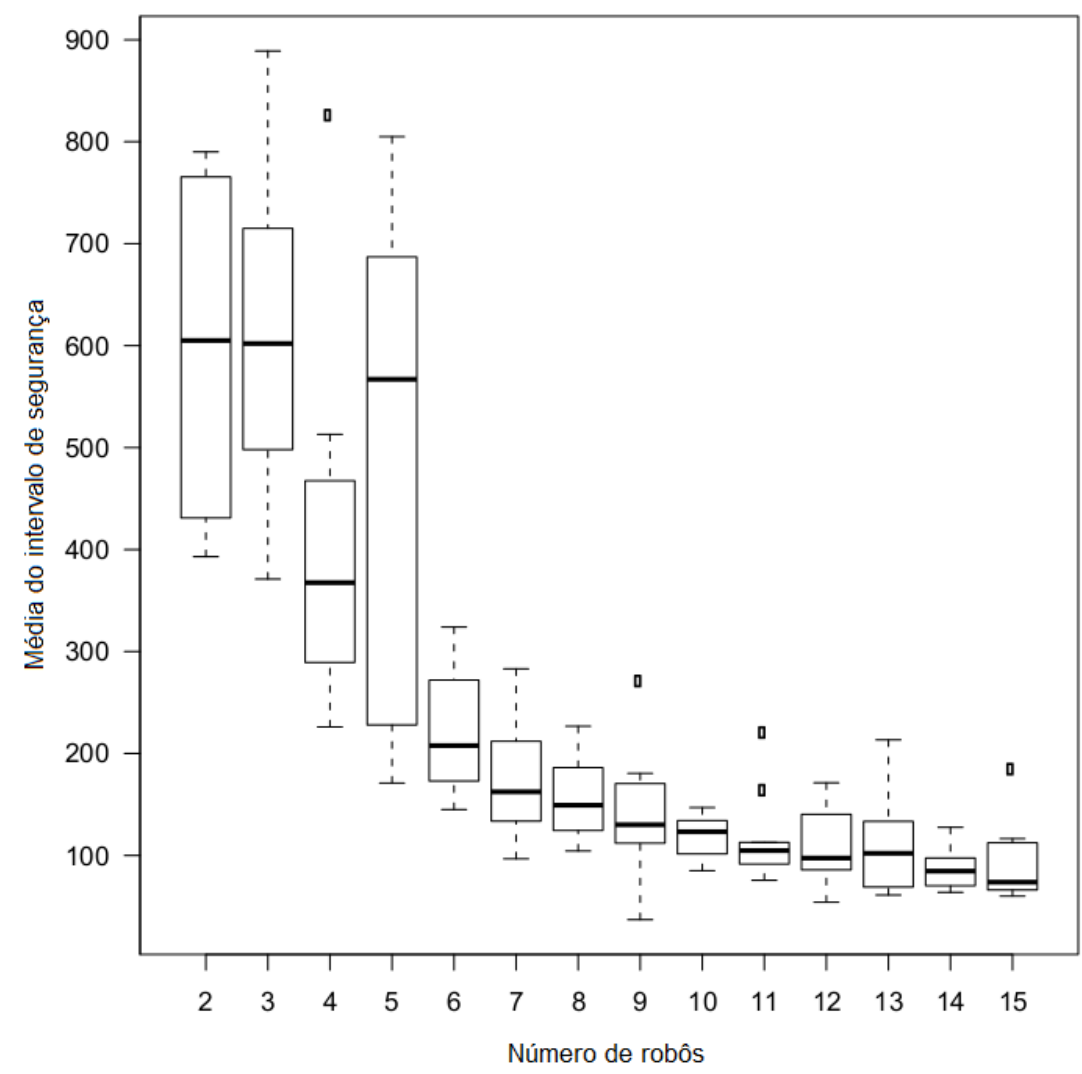

Figura 4.18: Boxplots da distribuição da média do intervalo de segurança para diferentes números de robôs.

\subsubsection{Estrutura dos Ambientes}

A capacidade de adaptação, uma das características da estratégia de coordenação IAS-SS, é destacada nesta seção. O objetivo dos próximos experimentos é mostrar que os robôs desempenham a tarefa de exploração e vigilância independentemente da estrutura do ambiente. Para confirmar esta característica, diferentes estruturas de ambientes são projetadas a partir do espaço retangular dividido em dez pequenas regiões (Figura 4.20(a)), também referenciadas aqui como salas. A divisão é feita sem obstáculos, somente para delimitar as regiões do ambiente. A conectividade entre salas adjacentes é representada pelo grafo da Figura 4.20(b). As passagens que conectam as salas são parcialmente ou totalmente bloqueadas utilizando obstáculos, o que deriva ambientes distintos. Seguindo esse processo, dez modelos de ambientes são considerados, cada qual associado com um grau de complexidade para avaliar a estratégia de coordenação.

Um grau de complexidade é associado a um ambiente de acordo com a quantidade de dificuldades inseridas para alcançar uma sala. Por exemplo, o ambiente mais simples projetado é o da Figura 4.20(c), onde há somente 3 obstáculos, o que possibilita mais liberdade para os robôs em acessar todas as salas, portanto a complexidade deste ambiente é baixa. O ambiente 4.20(d) já 


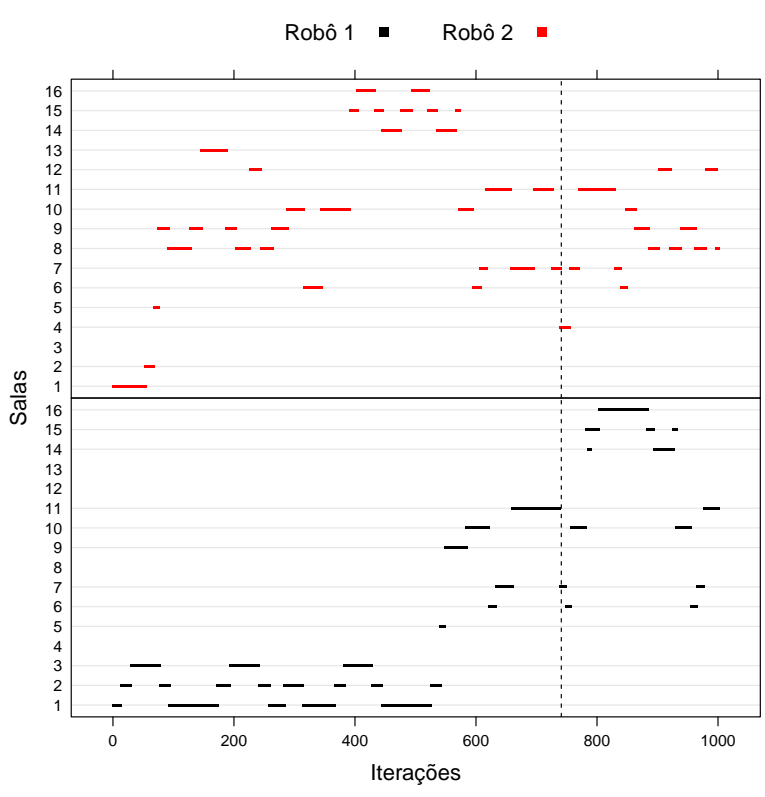

(a)

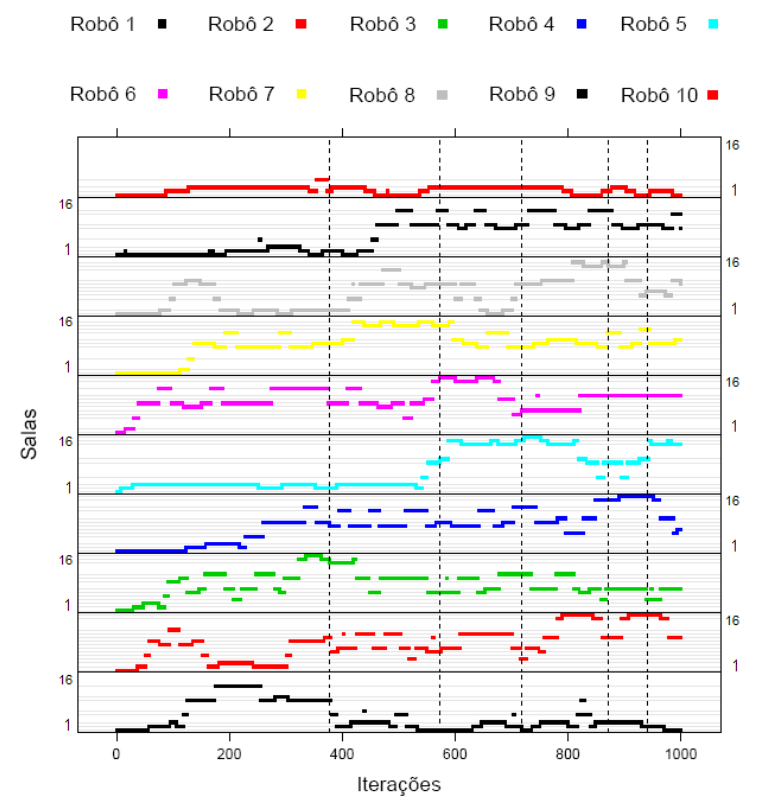

(c)

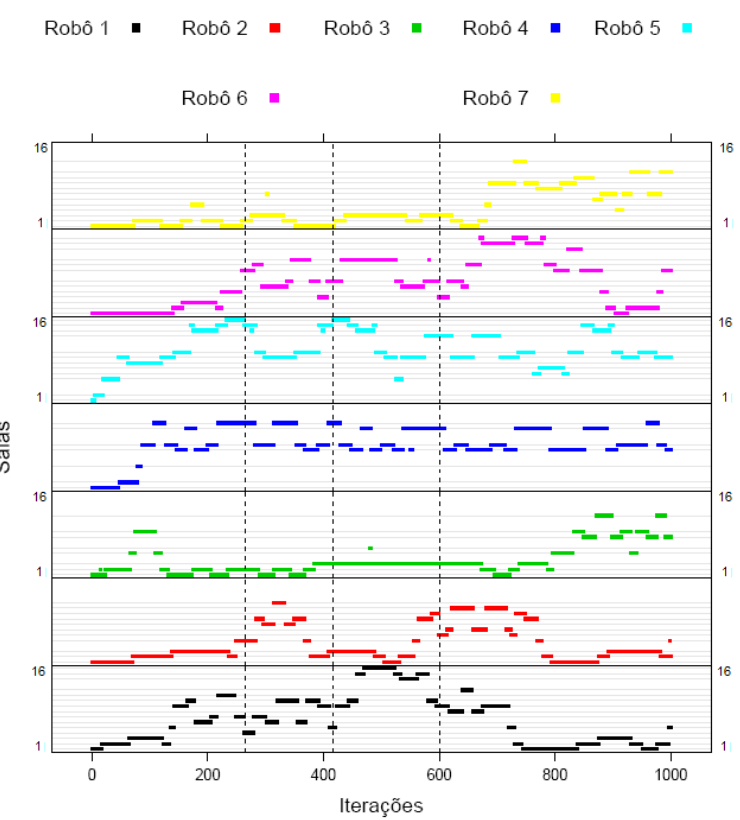

(b)

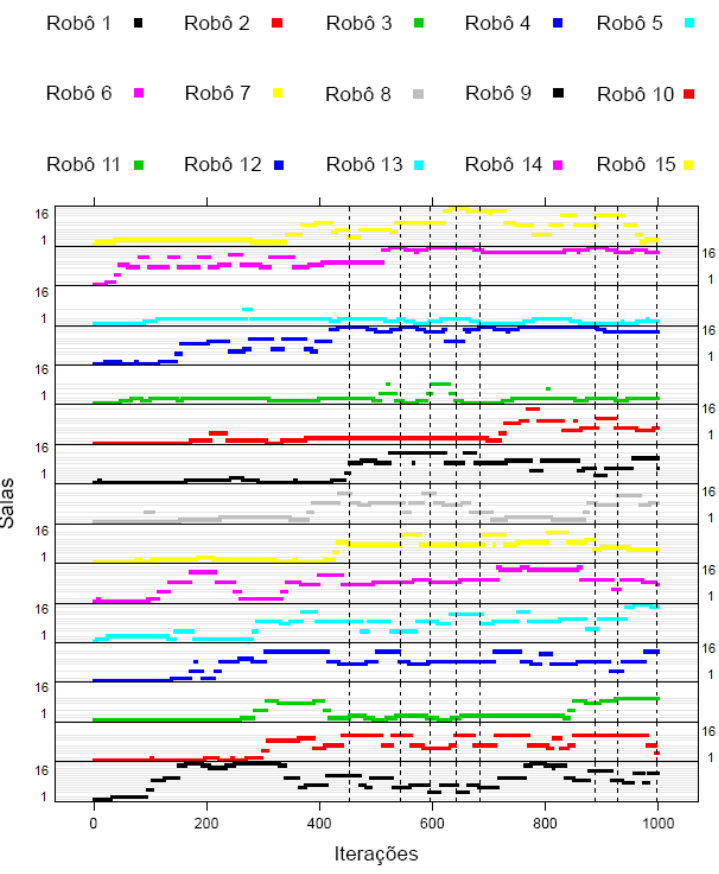

(d)

Figura 4.19: Desempenho do sistema IAS-SS com diferentes números de robôs em um mesmo ambiente: (a) 2; (b) 7; (c) 10; (d) 15 robôs. 


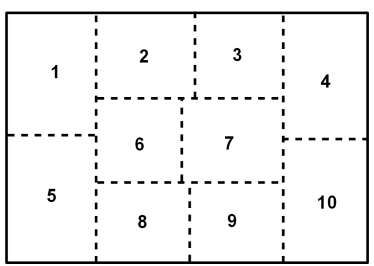

(a)

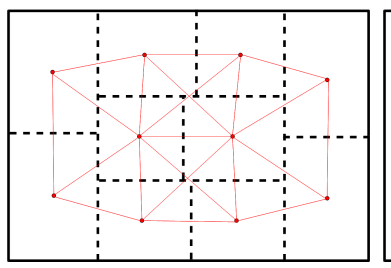

(b)

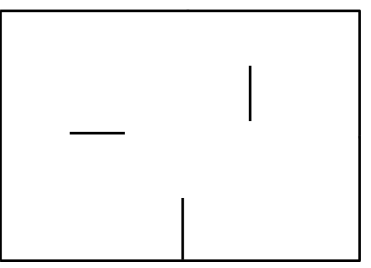

(c)

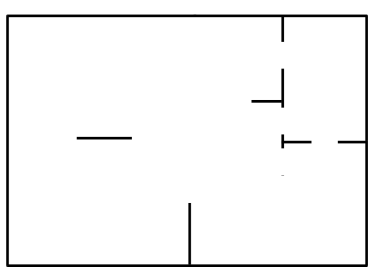

(d)

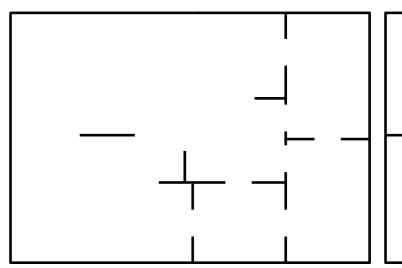

(e)

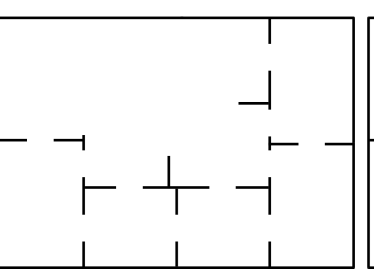

(f)

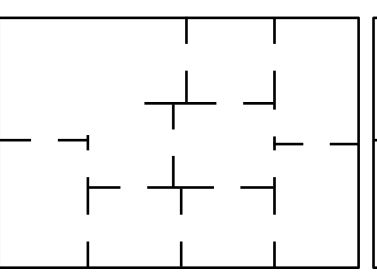

(g)

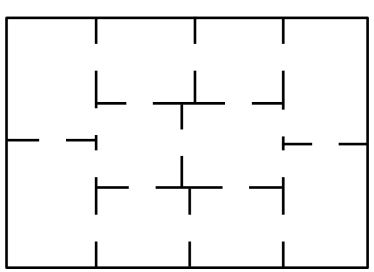

(h)

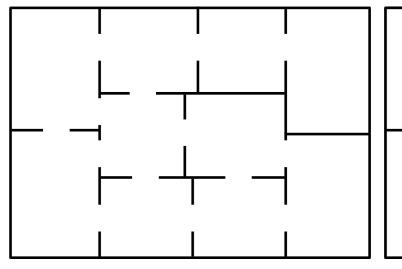

(i)

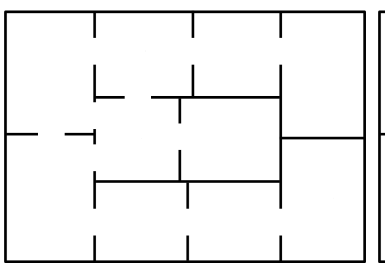

(j)

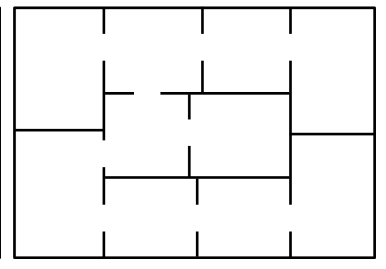

(k)

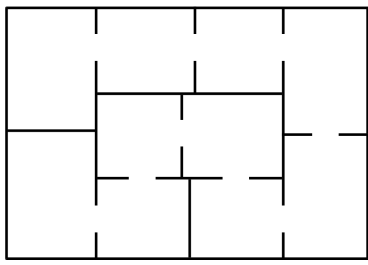

(l)

Figura 4.20: Moldelo de ambientes: (a) ambiente dividido em salas; (b) grafo de conexão entre as salas; (c)-(l) ambientes de \#1 a \#10.

possui complexidade superior ao ambiente anterior, pois os obstáculos inseridos dificultam o acesso à sala 4. A complexidade aumenta para o ambiente da Figura 4.20(e) já que os obstáculos obstruem parcialmente a passagem para as salas 4, 9 e 10. Em particular para este ambiente, a conexão direta entre as salas 6 e 9 é removida do grafo. Na sequência de ambientes das Figuras 4.20(e) - 4.20(1) são inseridos obstáculos aumentando o número de salas cujo acesso seja dificultado ou completamente bloqueado. Obedecendo essa sequência, a complexidade dos ambientes aumenta gradualmente, de maneira que no último, há somente um único caminho (no grafo) para percorrer todas as salas.

O mecanismo de ajuste de direção adotado para os experimentos desta seção é o AEE (ver Seção 4.3.2) por apresentar maior eficiência em relação aos demais mecanismos em experimentos anteriores. Quatro robôs são empregados para monitorar as dez salas, a fim de associar, implicitamente, a cada um pelo menos duas salas. Isto estabelece que os robôs devem se deslocar longas distâncias aumentando a possibilidade de encontrar situações desafiadoras com obstáculos. Para os experimentos, os robôs iniciam a navegação na sala 1 .

Embora esteja claro que o tempo demandado para a exploração do ambi- 
ente aumenta enquanto o grau de complexidade também cresce, a tarefa de vigilância é executada mesmo com um número restrito de opções de caminhos para acessar salas com acesso dificultado. Os experimentos mostram que a estrutura do ambiente influencia no desempenho do sistema, mas não impede que as tarefas sejam executadas. Mesmo atuando em ambientes com alto grau de complexidade, robôs são capazes de executar as tarefas de exploração e vigilância.

O sensoriamento do ambiente (ciclo SE) é completado independentemente da estrutura do ambiente. Como um comportamento do sistema, o tamanho do intervalo SI aumenta à medida que o grau de complexidade também aumenta. Além disso, como consequência da alta complexidade, o número de ciclos SE é menor. Este comportamento é observado na Tabela 4.8. A média do número de ciclos $\mathrm{SE}$ decresce enquanto que a média de iterações no SI apresenta uma tendência crescente, que não é monotônica devido à natureza aleatória dos experimentos.

Tabela 4.8: Desempenho da configurações de ambiente com o mecanismos de ajuste de direção AEE para o crescente grau de complexidade do ambiente.

\begin{tabular}{|c|c|c|}
\hline Ambiente & Média do número de SE & Média de iterações do SI \\
\hline$\# 1$ & $17.5 \pm 1.27$ & $55.36 \pm 4.11$ \\
\hline$\# 2$ & $16.1 \pm 1.6$ & $60.51 \pm 5.3$ \\
\hline$\# 3$ & $14.8 \pm 1.4$ & $65.25 \pm 6.06$ \\
\hline$\# 4$ & $12 ; 8 \pm 1.68$ & $74.93 \pm 10.25$ \\
\hline$\# 5$ & $10.7 \pm 1.7$ & $88.98 \pm 13.79$ \\
\hline$\# 6$ & $11.3 \pm 0.95$ & $86.2 \pm 7.49$ \\
\hline$\# 7$ & $7.8 \pm 1.47$ & $120.49 \pm 29.98$ \\
\hline$\# 8$ & $7 \pm 1.76$ & $138.67 \pm 40.47$ \\
\hline$\# 9$ & $7.2 \pm 1.03$ & $129.67 \pm 18.24$ \\
\hline$\# 10$ & $7.1 \pm 1.19$ & $133.18 \pm 18.02$ \\
\hline
\end{tabular}

Uma visão mais detalhada dos resultados da Tabela 4.8, em função da média de iterações nos SI's, é apresentada na Figura $4.21 \mathrm{com}$ os boxplots da distribuição do desempenho.

Para confirmar a capacidade de auto-adaptação do sistema mediante ambientes com estruturas distintas, a Figura 4.22 mostra as trajetórias dos robôs e o mapa da distribuição da média de feromônio. No ambiente em que os obstáculos delimitam as salas em pequenos espaços, as trajetórias dos robôs se concentram em um rastro (Figuras 4.22 (g) e 4.22(i)). Como explicado anteriormente, a área de cobertura do sensor abrange toda a sala logo que entra, então, não há necessidade do robô se distanciar do rastro. Enquanto que em amplas regiões (ambientes em que há pouco ou nenhum obstáculo), os robôs saem desse rastro em direção às regiões que os sensores não alcançaram. 


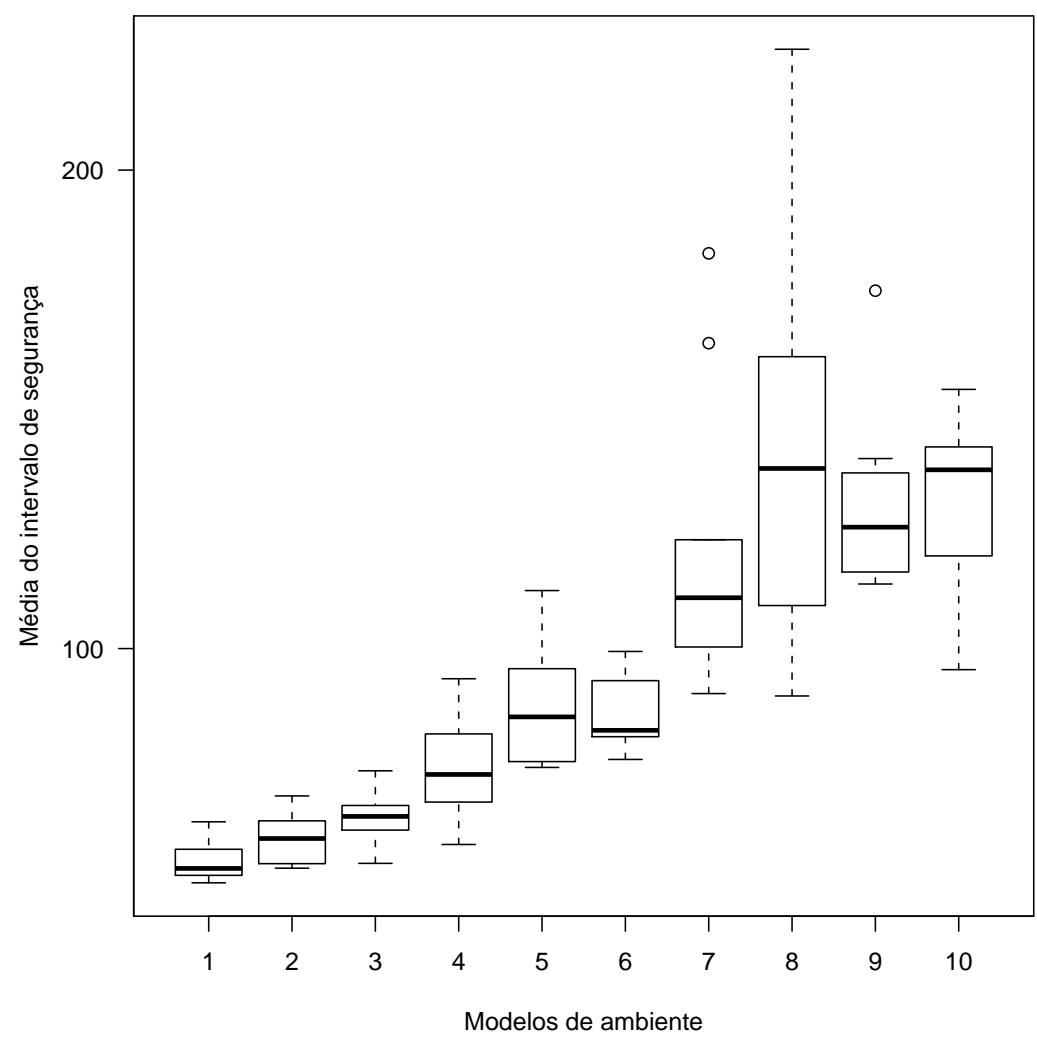

Figura 4.21: Boxplots da distribuição da média do intervalo de segurança para diferentes graus de complexidade do ambiente.

Portanto, os robôs são capazes de monitorar todas as regiões de forma contínua, independentemente do grau de complexidade do ambiente como mostra os mapas da média de feromônio depositado ao longo da navegação. Os dados apresentados na figura se referem aos experimentos com as médias de número de SE e de iterações para o SI próximas ao valor mediano encontrado.

\subsubsection{Métodos de Estigmergia e Influência do Parâmetro $\gamma$}

Em adição ao método de liberação de feromônio descrito na Seção 4.3, o propósito dos experimentos desta seção é apresentar dois métodos de estigmergia a fim de compará-los, são eles: Método de Feromônio para Trás (FT) e Feromônio ao Redor (FR). O método apresentado anteriormente é denominado aqui como Feromônio para Frente (FF). O que diferencia os métodos é a maneira como o feromônio é liberado.

Com relação ao método FT, os robôs deixam uma espécie de rastro marcando os locais monitorados até a iteração anterior. Mesmo com a ideia de rastro, o feromônio continua obedecendo a área de abrangência do sensor de distância a obstáculos. Para melhor entendimento, a Figura 4.23 mostra a área destinada ao depósito de feromônio. A substância é liberada somente nas regiões exploradas em iterações anteriores ao invés da região coberta na iteração corrente como ocorre no método FF. Especificamente, na itera- 


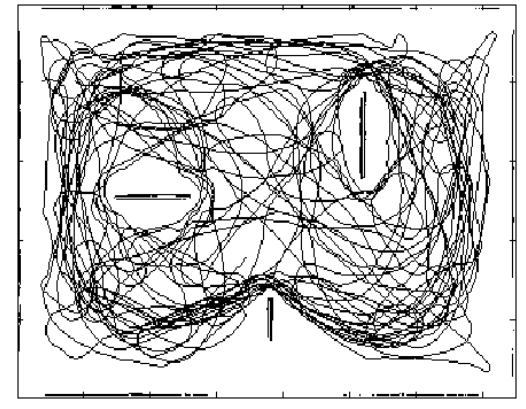

(a)

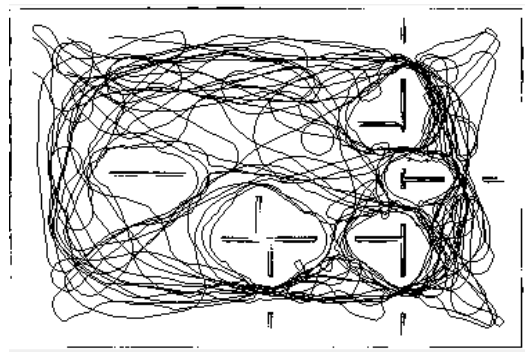

(c)

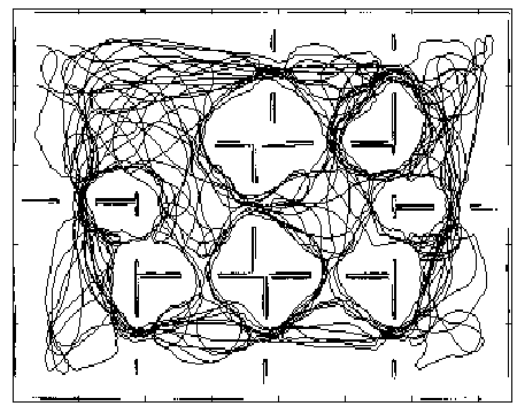

(e)

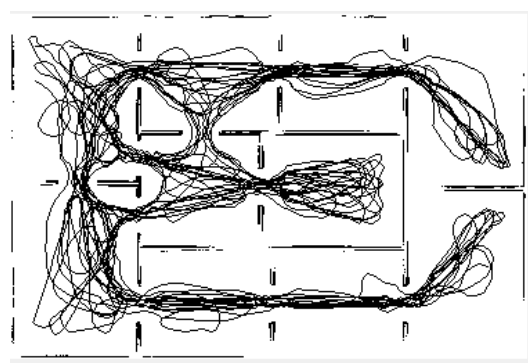

(g)

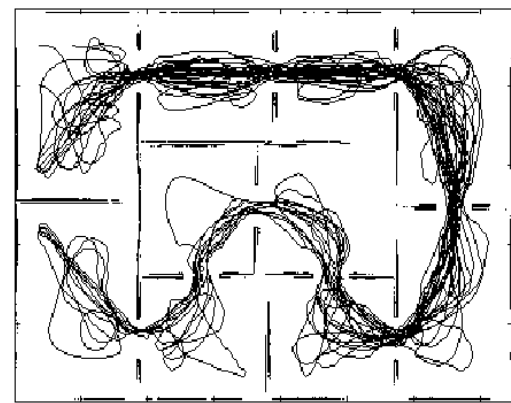

(i)

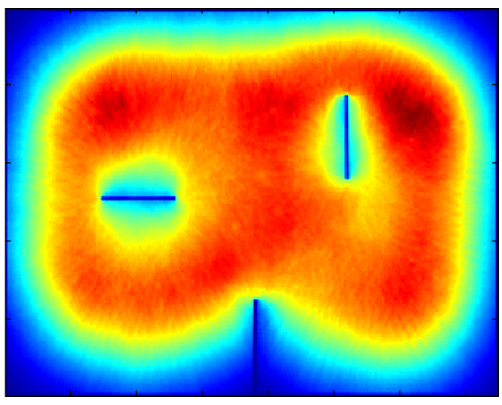

(b)

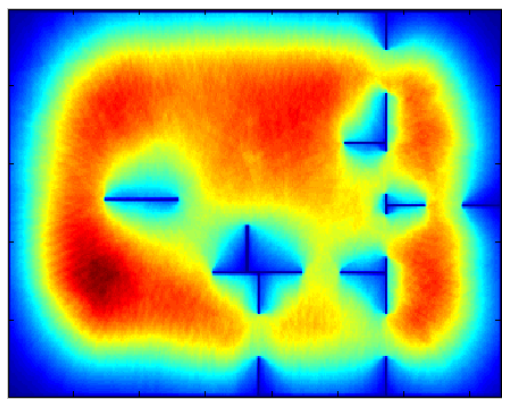

(d)

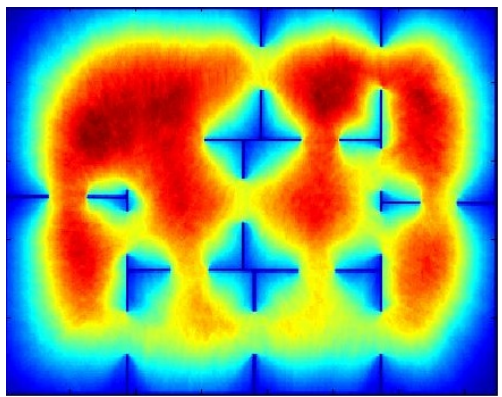

(f)

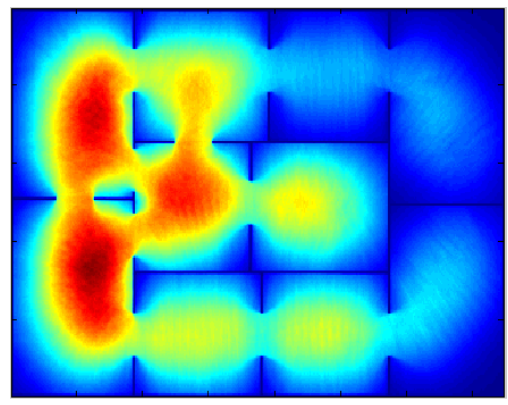

(h)

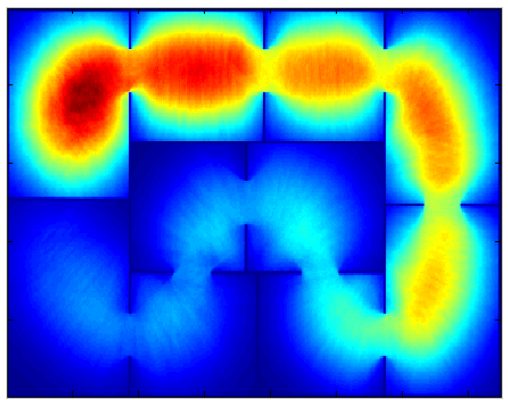

(j)

Figura 4.22: Trajetórias dos robôs e mapa da média de concentração de feromônio de acordo com diferentes estruturas de ambientes: (a)-(b) \#1; (c)-(d) \#3; (e)-(f) \#5; (g)-(h) \#8; (i)-(j) \#10. 
ção $t$, a substância é depositada na área $M$ resultante da diferença entre a área coberta pelo sensor do $k$-ésimo robô nos instantes $t-1$ e $t$, ou seja, $M=L_{t-1}^{k}-L_{t}^{k}$. Da mesma forma que em FF, a liberação de feromônio é modelada de acordo com a equação (4.7), porém com a condição de que $q$ pertença a $M$.

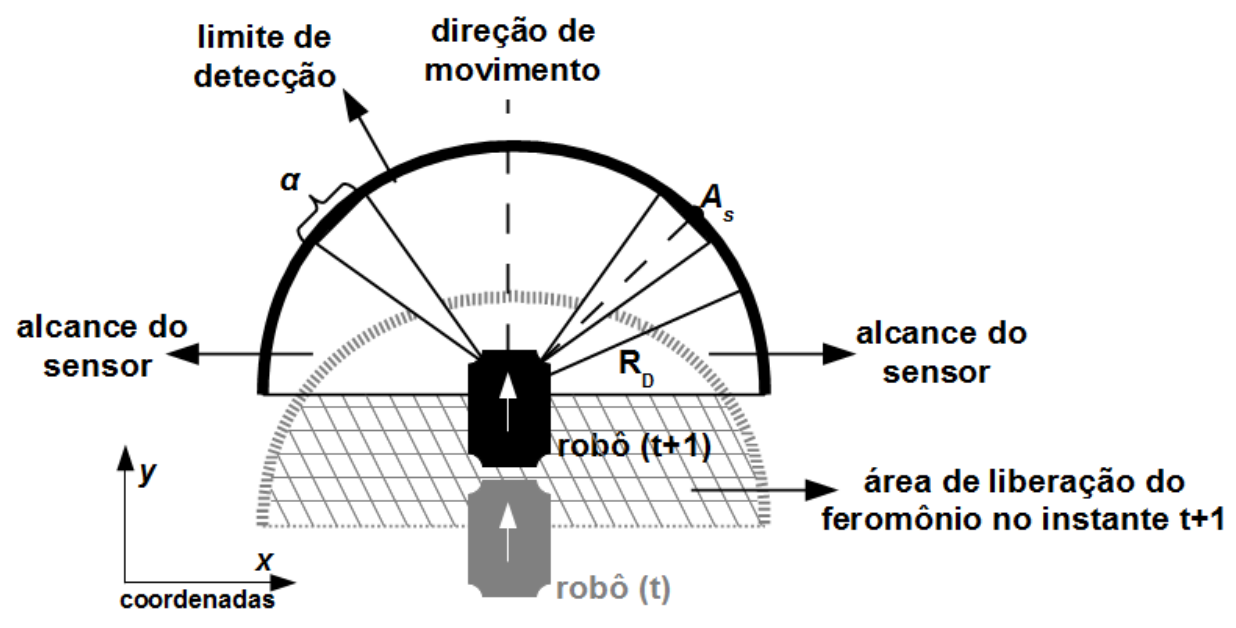

Figura 4.23: Liberação de feromônio para trás.

A motivação para este mecanismo se remete a maneira de liberação de feromônio das formigas biológicas. Estas depositam feromônio deixando um rastro dessa substância no formato de trilha indicando, exatamente, os locais por onde passaram. Estendendo este fato para o sistema IAS-SS, no mecanismo FT, os robôs deixam um rastro de feromônio depositando a substância somente em áreas cobertas em iterações anteriores. Novamente, considerando a tarefa de exploração e vigilância em que as áreas visitadas não devem ser atrativas (por algum período de tempo), as áreas marcadas no método FT como visitadas se referem somente às áreas sensoriadas na interação anterior mas sempre mantendo o formato do sensor de distância de obstáculo. Por isso, em FT, o rastro não representa exatamente as posições nas quais os robôs estiverem, mas sim as áreas que sensoriaram até a iteração corrente.

Em contraste com os métodos apresentados, no método FR, o feromônio é depositado na área do perímetro do robô (Figura 4.24). Além do sensor de feromônio, o modelo do sensor de distância a obstáculos também sofre mudança. Neste caso, estes sensores passam a ter $360^{\circ}$ de abrangência. Assim, a área mapeada corresponde ao círculo de raio $R_{D}$ (raio de detecção de feromônio) com o centro na posição do robô. Na ausência de obstáculos na proximdade do $k$-ésimo robô, a área de abrangência dos sensores no instante $t$ resulta em $M=L_{t}^{k}=\pi R^{2}$. Esta mudança se faz necessária, pois é permitido depositar feromônio somente em locais já mapeados. Mesmo com o aumento da cobertura dos sensores, o modelo da liberação de feromônio segue a equação (4.7). 


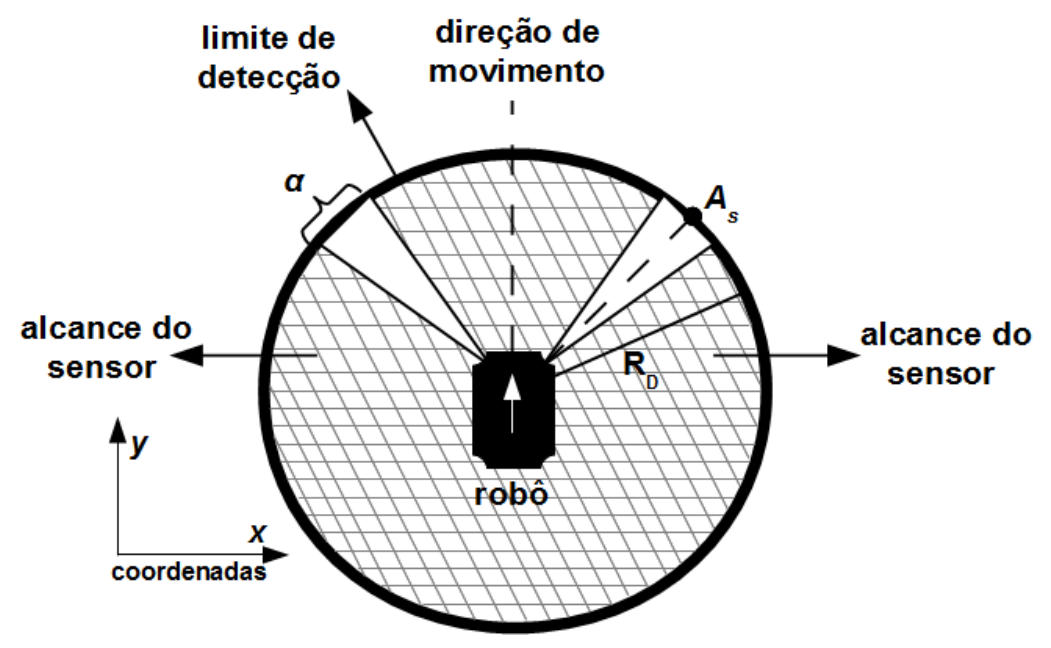

Figura 4.24: Liberação de feromônio no perímetro do robô.

Independente do local onde os métodos liberam feromônio, a detecção de estímulos é limitada a uma circunferência de um círculo de raio $R$ à frente do robô, de $90^{\circ}$ a direita até $90^{\circ}$ a esquerda como visto na Seção 4.3.2. Enquanto que para o método $\mathrm{FF}$, o feromônio é liberado na área frontal do robô, no método FT, a área considerada para o depósito da substância é a área de abrangência do sensor no instante anterior e que não é coberta no instante atual e, no método FR, os robôs depositam feromônio em toda a área circular que os envolve. A quantidade de feromônio depositada em $q \in L_{t}^{k}$ decresce à medida que a distância entre $q$ e a posição do robô $q_{k}$ aumenta. Os modelos de acúmulo dessa substância e de evaporação são definidos de forma análoga aos modelos apresentados na Seção 4.3.2.

Para uma análise mais efetiva, cada método de estigmergia é combinado com os de ajuste de direção. O ambiente utilizado é mostrado na Figura 4.25 com sete salas. Três robôs $k \in\{1,2,3\}$ são empregados inciando a navegação na sala 1.

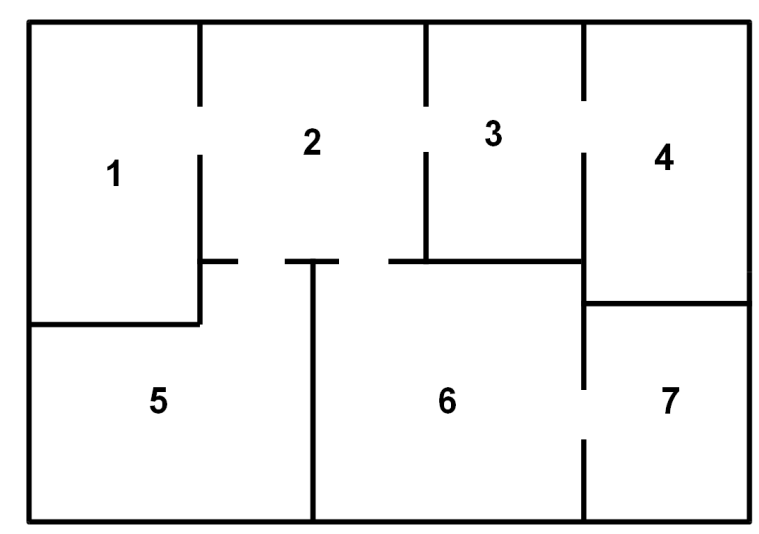

Figura 4.25: Modelo do ambiente.

Outro propósito dos experimentos apresentados a seguir está no foco do parâmetro $\gamma$ (ver equação (4.5)). Com a intenção de evitar mudanças abrup- 
tas de direção em robôs do porte do Pioneer $2 D X$, o valor para $\gamma$ foi fixado em 0.4 nos experimentos anteriores. Nesta seção, realizou-se estudos empíricos a fim de verificar se a utilização de outro valor seria benéfico. Assim, a fim de realizar uma análise mais profunda da suavização do ajuste de direção, $\gamma$ assume valores do conjunto $\Gamma=\{0.2,0.4,0.6,0.8,1\}$. Os experimentos são organizados de acordo com a escolha do método de liberação de feromônio, mecanismos de ajuste de direção e coeficiente de suavização do ajuste de direção. Assim, define-se uma configuração de estratégia como uma tripla $C=\{z, w, \gamma\}$, tal que $z \in\{F T, F A, F F\}, w \in\{A E, A E E\}$ e $\gamma \in \Gamma$. A Tabela 4.9 reúne os resultados obtidos de experimentos que, combinando os elementos da tripla, formam 30 configurações. O desempenho é avaliado pela média do número de SE's e iterações no SI's.

Tabela 4.9: Períodos de intervalos de segurança.

\begin{tabular}{|c|c|c|c|c|}
\hline \multirow[t]{3}{*}{$\Gamma$} & \multicolumn{4}{|c|}{ Feromônio para trás } \\
\hline & \multicolumn{2}{|c|}{ mecanismo AE } & \multicolumn{2}{|c|}{ mecanismo AEE } \\
\hline & $\mathrm{n}^{\circ} \mathrm{SE}$ & it. SI & $\mathrm{n}^{\circ} \mathrm{SE}$ & it. SI \\
\hline 0.2 & $0.3 \pm 0.48$ & $824 \pm 156.88$ & $0.5 \pm 0.53$ & $776 \pm 124.28$ \\
\hline 0.4 & $0.6 \pm 0.52$ & $658.17 \pm 193.81$ & $1.3 \pm 0.95$ & $549.02 \pm 160.16$ \\
\hline 0.6 & $0.8 \pm 0.63$ & $613.21 \pm 242.69$ & $\mathbf{1 . 5} \pm \mathbf{0 . 8 5}$ & $440.13 \pm 165.91$ \\
\hline 0.8 & $1.2 \pm 1.13$ & $472.45 \pm 259.21$ & $1.4 \pm 0.7$ & $430.39 \pm 200.6$ \\
\hline 1.0 & $1.1 \pm 0.57$ & $531.5 \pm 198.12$ & $1.4 \pm 0.7$ & $526.35 \pm 186.69$ \\
\hline \multirow[t]{3}{*}{$\Gamma$} & \multicolumn{4}{|c|}{ Feromônio ao redor } \\
\hline & \multicolumn{2}{|c|}{ mecanismo AE } & \multicolumn{2}{|c|}{ mecanismo AEE } \\
\hline & $\mathrm{n}^{\circ} \mathrm{SE}$ & it. SI & $\mathrm{n}^{\circ} \mathrm{SE}$ & it. SI \\
\hline 0.2 & $0.6 \pm 0.84$ & $553.37 \pm 180.4$ & $1.7 \pm 1.16$ & $386.54 \pm 172.17$ \\
\hline 0.4 & $2.1 \pm 0.99$ & $374.04 \pm 135$ & $4.2 \pm 1.4$ & $204.56 \pm 64.09$ \\
\hline 0.6 & $2 \pm 1.15$ & $374.3 \pm 153.43$ & $4.5 \pm 1.71$ & $232.87 \pm 173.73$ \\
\hline 0.8 & $2.7 \pm 0.95$ & $316.85 \pm 97.77$ & $\mathbf{7} \pm \mathbf{1 . 1 5}$ & $132.22 \pm 25.5$ \\
\hline 1.0 & $2.7 \pm 1.49$ & $426.75 \pm 254.59$ & $6.2 \pm 1.93$ & $151.78 \pm 53.24$ \\
\hline \multirow[t]{3}{*}{$\Gamma$} & \multicolumn{4}{|c|}{ Feromônio para frente } \\
\hline & \multicolumn{2}{|c|}{ mecanismo AE } & \multicolumn{2}{|c|}{ mecanismo AEE } \\
\hline & $\mathrm{n}^{\circ} \mathrm{SE}$ & it. SI & $\mathrm{n}^{\circ} \mathrm{SE}$ & it. SI \\
\hline 0.2 & $0.6 \pm 0.84$ & $591.12 \pm 284.71$ & $2.1 \pm 1.2$ & $351.42 \pm 129.41$ \\
\hline 0.4 & $3.3 \pm 1.25$ & $326.03 \pm 225.34$ & $5.4 \pm 1.58$ & $199.35 \pm 109.42$ \\
\hline 0.6 & $2.5 \pm 1.27$ & $304.44 \pm 193.17$ & $4.3 \pm 1.77$ & $245.02 \pm 126.71$ \\
\hline 0.8 & $2.4 \pm 0.7$ & $371.73 \pm 119.75$ & $7.2 \pm 1.23$ & $124.31 \pm 15.06$ \\
\hline 1.0 & $2.6 \pm 1.07$ & $316.37 \pm 73.02$ & $7.2 \pm 1.55$ & $131.36 \pm 32.26$ \\
\hline
\end{tabular}

De acordo com a tabela, observa-se a tendência das configurações de estratégia com altos valores para o coeficiente de suavização, $\gamma=\{0.8,1\}$, apresentarem melhor desempenho. Isto mostra o comportamento dos robôs em se orientarem exatamente na direção de regiões com pouca quantidade de fero- 
mônio. De maneira geral, outro comportamento que pode ser observado é o fraco desempenho quando o coeficiente assume baixo valor, $\gamma=\{0.2\}$. Uma explicação é o ajuste da direção dos robôs que, às vezes, é irrelevante para atingir a orientação desejável.

Além disso, pode ser notado que os experimentos com o mecanismo AEE apresentam desempenho superior àqueles com o mecanismo $\mathrm{AE}$ independente da configuração de estratégia adotada, devido ao seu menor nível de aleatoriedade como descrito na Seção 4.3.2. Para o método FT, duas configurações de estratégia com o mecanismo AE, $\{F T, A E, 0.8\}$ e $\{F T, A E, 1\}$ completaram, em média, uma tarefa de vigilância. Aplicando o mecanismo AEE, houve uma melhora significativa quando $\gamma$ assume valores medianos, $\gamma=\{0.4,0.6\}$, concluindo, em média, 1.3 e 1.5 vezes a tarefa de vigilância, respectivamente. Porém, com altos valores para o coeficiente de suavização, o desempenho mostra resultados semelhantes àqueles obtidos com o mecanismo AE. Para o método FA, dentre as configurações que utilizaram o mecanismo AE, o sistema obteve melhor desempenho com as duas configurações $\{F A, A E, 0.8\} \mathrm{e}$ $\{F A, A E, 1\}$. Entretanto, a média de iterações entre dois sensoriamentos consecutivos na configuração $\{F A, A E, 0.8\}$ é 316.85 iterações, menos que a média obtida pela configuração $\{F A, A E, 1\}$. Com o mecanismo AEE, observouse também que o melhor desempenho apresentado pelo sistema foi atingido quando $\gamma=0.8$, com 7 ciclos $\mathrm{SE}$ completados em média. Desempenho pouco inferior, mas satisfatório perante as demais configurações, é obtido com a configuração $\{F A, A E, 1\}$, quando o sistema conclui 6.2 ciclos SE. Finalmente, considerando o método $\mathrm{FF}$, o melhor desempenho é alcançado com $\gamma=0.4$ quando o mecanismo AE é adotado e os robôs completam o ciclo SE, em média, 3.3 vezes com média de 326.03 iterações em cada SI. No caso do mecanismo AEE, o sistema conclui a tarefa de vigilância mais eficientemente com rin $0.8,1\}$, resultando, na média, em 7.2 ciclos $\mathrm{SE}$ para ambas as configurações. No entanto, a primeira configuração, $\{F F, A E E, 0.8\}$, obteve melhor desempenho devido à sua baixa média de iterações nos SI's, computado em 124.31 .

Em relação aos resultados do mecanismo AEE, é facilmente observado que o método FF é superior. Para todos os métodos de liberação de feromônio, esta substância é depositada na área de cobertura do sensor com baixas intensidades nas bordas (veja equação 4.8). No entanto, a área considerada no método FF é maior, desde que o raio do semicírculo que define a área onde o feromônio é depositado é maior que a distância percorrida por um robô em uma iteração. Desta forma, mais áreas são sensoriadas em um período de tempo reduzido. O fato da área de depósito de feromônio ser menor em FT, torna a probabilidade dos robôs estarem próximos, o que deprecia o desempenho do 
sistema IAS-SS.

Considerando o método de liberação de feromônio FA, o modelo do sensor abrange todo o perímetro do robô o que consiste numa área maior que as áreas definidas para os demais métodos. Se por um lado, a característica de manter os robôs dispersos é mais evidente, por outro, em ambientes com escalas reduzidas, um robô está sujeito a estar ocioso pelo motivo de alta quantidade de feromônio o circundar, ou seja, uma vez que o robô está cercado por quantidades semelhantes de feromônio, a possibilidade de escolher uma direção desfavorável para executar as tarefas de exploração e vigilância é maior. Neste sentido, o desempenho obtido para os experimentos com o método AP se mostra inferior.

Embora o valor sugerido, nos experimentos das seções anteriores, para o ajuste de direção tenha fornecido resultados convincentes, constatou-se, a partir dos experimentos apresentados nesta seção, que tal valor não é ótimo. Considerando o mecanismo AEE, observou-se que as configurações que obtiveram melhor desempenho eram compostas por $\gamma=0.8$ em qualquer método de liberação de feromônio.

\subsection{Considerações Finais}

Neste capítulo foi apresentada uma estratégia de coordenação bioinspirada e distribuída, denominado IAS-SS, para múltiplos robôs aplicada para as tarefas de exploração e vigilância. Desde uma visão geral até detalhes dos componentes do sistema foram descritos. Tal estratégia fundamenta-se na teoria de inteligência coletiva, mais especificamente na teoria clássica de sistemas baseados em colônias de formigas. De acordo com essa estratégia, os agentes são capazes de realizar comunicação indireta assim como os agentes biológicos o fazem, porém a reação dos agentes em relação ao feromônio é distinta. O detalhe está na natureza do feromônio. Na estratégia proposta, o feromônio provoca comportamento repulsivo dos robôs. Assim, os mecanismos que definem o ajuste de direção dos robôs, os guiam preferencialmente para regiões com baixa quantidade de feromônio. Um conjunto de experimentos foi proposto para investigar diversos aspectos da estratégia. Eles consideraram dois critérios para avaliar o desempenho: a média do número de ciclos de vigilância e a média de iterações nos intervalos de segurança. Os resultados obtidos forneceram detalhes para observar os pontos positivos e negativos de cada aspecto envolvido nas simulações.

No primeiro conjunto de experimentos, duas versões da estratégia IAS-SS foram consideradas e comparadas com uma estratégia totalmente randômica. Tais versões são construídas utilizando os mecanismos de ajuste de direção 
$\mathrm{AE}$ e AEE. Enquanto o mecanismo AE considera todos os pontos na extensão da borda da área de cobertura do sensor, o mecanismo AEE destaca, dentre eles, aqueles pontos com menor concentração de feromônio. Independente do mecanismo adotado, utiliza-se a mesma política para definir a nova orientação dos robôs, ou seja, pra cada ponto, associa-se um valor de probabilidade inversamente proporcional à quantidade de feromônio detectada. Devido às características randômicas dos mecanismos, ambos foram confrontados com um terceiro totalmente randômico para demonstrar que o desempenho destes não é resultado de uma coincidência. As estratégias propostas apresentaram desempenho consideralmente superior. Constata-se, no entanto, que mesmo com a utilização do terceiro mecanismo, as tarefas de exploração e vigilância são concluídas. Este fato é admissível desde que, em sucessivas escolhas randômicas de direção e por um longo período de tempo, a possibilidade dos robôs cobrirem todo o ambiente existe. Entretanto, o contraste de desempenho perantes os mecanismos propostos é notório.

Ainda considerando os mecanismos de ajuste de direção, o segundo conjunto de experimentos teve como objetivo a análise da influência causada pela posição inicial dos robôs. Para tanto, foram propostos, dois tipos de configuração das posições inicais: CA e CS. Os robôs realizaram as tarefas de exploração e vigilância em três tipos de ambientes, os quais diferem somente em suas dimensões. Simulações mostraram que desempenho das tarefas quando utilizadas ambas as configurações são semelhantes a longo prazo. Referindose aos mecanismos de ajuste $\mathrm{AE}$ e $\mathrm{AEE}$, foi possivel observar que, para todos os ambientes, o primeiro ciclo SE ocorre antes nas configurações CS, pois os robôs já iniciam a navegação em salas distintas. Porém, devido ao comportamento repulsivo resultante da detecção de feromônio, os robôs tendem a se afastar um dos outros. A partir da análise dos resultados, notou-se que, após o primeiro ciclo, a frequência com o que outros são concluídos é semelhante quando as duas configurações, em cada mecanismo, são comparadas. $\mathrm{O}$ fato de elevar as dimensões de um ambiente consiste em aumentar a área das salas do ambiente de maneira que a região de abrangência dos sensores não seja suficiente para cobrir uma sala assim que o robô a adentra. Neste caso, aplicando a configuração CS, os robôs iniciam mais afastados uns dos outros. Mesmo assim, com a utilização de CA, o desempenho do sistema foi satisfatório.

Diante dos melhores desempenhos apresentados pelo mecanismo AEE nos experimentos anteriores, somente este foi utilizado nas simulações do terceiro conjunto. Visando avaliar a robustez do sistema em termos do número de robôs, siimulações foram realizadas, cada qual com uma quantidade de robôs distinta. Em um ambiente com diversas salas, o sistema se mostrou mais 
eficiente à medida que o número de robôs é incrementado, como o esperado. No entanto, a principal intenção desse experimento é validar a hipótese de que as tarefas de exploração e vigilância não estão restritas à quantidade de robôs. De acordo com os resultados exibidos, observa-se que a eficiência da estratégia IAS-SS na realização das tarefas mesmo com poucos robôs atuantes. Embora não foram feitos experimentos simulando a falha de um algum robô, fica evidente que este problema é contornado pela estratégia proposta. A partir do momento em um robô passa a estar fora de operação, o feromônio depositado em suas proximidades tende a evaporar, o que atrai a aproximação de outros robôs. Este raciocínio é semelhante ao que é observado através dos resultados quando o número de robôs é subtraído.

A robustez do sistema também é verificada nos experimentos do quarto conjunto, em que o número de robôs é fixado e obstáculos são inseridos em cada simulação. Assim, foi possível comprovar a capacidade da estratégia IAS-SS em promover a exploração e vigilância em ambientes com qualquer disposição de obstáculos. O comportamento apresentado pelos robôs nesta fase se assemelha ao segundo conjunto de experimentos onde os ambientes são ampliados. Em ambientes com poucos obstáculos, a trajetória dos robôs são geradas de maneira que todas as regiões sejam coberta. À medida que obstáculos são inseridos, aumentando o grau de complexidade do ambiente, o caminho percorrido pelos robôs se resume em uma trilha, pois as salas são cobertas sem a necessidade do robô se desalinhar desta. Com os experimentos, observou-se a capacidade do sistema em se adaptar à diferentes configurações de ambientes, destacando sua habilidade em desempenhar as tarefas em ambientes desconhecidos.

Outro aspecto analisado neste capítulo foi a maneira pela qual os robôs liberam feromônio. Diferentemente dos agentes biológicos, os robôs adotados para a estratégia IAS-SS depositam feromônio em sua região frontal (método FP). Para fins de exploração, este método de liberação tornou o desempenho do sistema mais eficiente quando comparado com os demais métodos propostos (FT e FA). A região de depósito de feromônio corresponde à região de abrangência do sensor, o que é totalmente aceitável, desde que a região coberta por um robô não deve ser coberta por outro em um instante próximo. Seguindo o modelo que, talvez, se aproxime mais dos modelos tradicionais de colônia de formigas, quando o feromônio é depositado para trás (FT), os robôs são repelidos somente nas regiões de rastro, o que não evita colisões entre os robôs e entre os robôs e obstáculos. Além disso, observa-se também maior densidade de robôs em locais próximos (ou na mesma sala). Efeito contrário é provado pela liberação de feromônio em todo o perímetro do robô (FA). Neste caso, os robôs são afastados um dos outros, porém, há a ocorrência em que 
os robôs permanecem cercados pela alta concentração do próprio feromônio. Devido à essas adversidades, o método de liberação para frente se mostrou mais adequado para a objetivo em questão. Além do método de liberação de feromônio, também foi investigado a influência do parâmetro que suaviza o ajuste de direção dos robôs. Com o auxílio dos resultados, o melhor observado para tal parâmetro é distindo daquele definido nos experimentos iniciais, mesmo que este último tenha apresentado resultados satisfatórios. Sendo assim, vislumbra-se potenciais ganhos de desempenho caso $\gamma=0.8$ seja utilizado. 


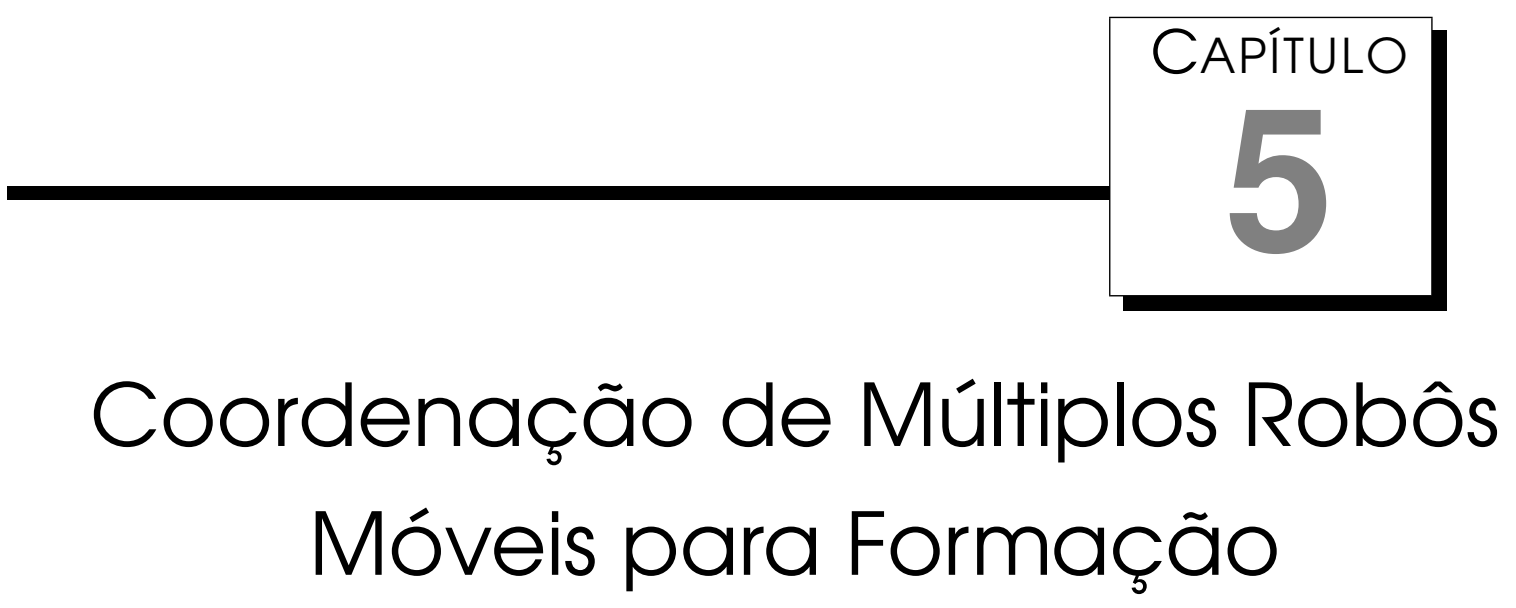

\subsection{Considerações Iniciais}

Recentemente, tem-se observado grande interesse no desenvolvimento e emprego de sistemas de múltiplos robôs (Zhu and Yang, 2010; Parker, 2003; Iocchi et al., 2001). A fim de que o potencial de tais empreendimentos possa ser satisfatoriamente realizado, é desejável que o grupo apresente características de alinhamento, coesão e não-colisão, conforme sugerido por Reynolds (1987). Para tanto, cinco métodos de controle de formação são conhecidos, a saber: comportamental, consenso, líder-seguidor, estrutura virtual e função potencial com líder virtual.

Conforme descrito no Capítulo 2, a abordagem de estrutura virtual define o comportamento dos robôs em uma formação fixa desde o início da navegação. Por outro lado, no método baseado em função potencial, embora os robôs não iniciem em uma formação determinada, eles convergem para tal. Em ambos os casos, tal rigidez de formação limita sua aplicação. Assim, essas abordagens não são apropriadas caso a configuração do ambiente não seja conhecida a priori.

Com o objetivo de apresentar uma solução adequada a tais cenários, neste capítulo propõe-se uma estratégia de formação que reúne características das abordagens comportamental, líder-seguidor e de consenso. Assim, pretendese beneficiar das qualidades apresentadas por cada uma delas, assim como superar suas deficiências. Nesse contexto, a formação do grupo é resultado 
da combinação dos comportamentos (de repulsão e atração) derivados da interação dos agentes. Para promover o deslocamento do grupo, um dos agentes é definido como líder, cujo papel é determinar a hierarquia entre os agentes e indicar aos seguidores as regiões por onde esteve e a direção de movimento. Caso o líder falhe, o novo líder é eleito por consenso.

Este capítulo está organizado como segue. Na Seção 5.2, são descritos alguns conceitos básicos necessários para a compreensão do sistema de formação proposto. Na Seção 5.3, é apresentado o sistema de formação autoadaptativo proposto nesta tese. Na Seção 5.3.1, os sensores utilizados nos robôs são especificados. Na Seção 5.4, os resultados e o desempenho da estrátegia proposta são analisados. Por fim, na Seção 5.5, são apresentadas as considerações finais deste capítulo.

\subsection{Conceitos Básicos}

Nesta seção, são apresentados alguns conceitos básicos para melhor compreensão do sistema de formação proposto. Tais conceitos estão relacionados tanto à comunicação indireta quanto à direta. Esta última, por sua vez, exige que os robôs estejam conectados e organizados na forma de grafo, o que favorece a definição de vizinhança dos mesmos. O modelo distribuído adotado para representar a topologia e promover a cooperação entre os agentes define um relacionamento entre eles baseado na localização relativa. Tal modelo é fundamentado nos grafos de Diagrama de Voronoi e Triangulação de Delaunay (Balch and Akin, 1998; Bulusu et al., 2003; Meguerdichian et al., 2001; Cortes et al., 2002).

\section{Feromônio Repulsivo e Atrativo}

Dentre as caracteríticas relacionadas às formigas, apresentadas no Capítulo 4, a comunicação indireta é um dos pontos enfatizados nesta proposta. Segundo Caetano et al. (2002), algumas espécies de formigas podem liberar até 20 tipos de feromônio, cada um representando um cenário distinto. Por exemplo, em situações em que formigas não encontram alimento, o caminho utilizado para a busca pode ser marcado com um tipo de feromônio que possua propriedade de repelir as demais formigas, indicando que este caminho não é recomendável para a busca de alimentos. Por outro lado, ao atingir seu objetvo (o alimento foi encontrado), as formigas liberam outro tipo de feromônio que ao ser detectado por outras formigas, as atraí para tais locais. Tendo em vista esta habilidade, as formigas artificiais (robôs) considerados neste capítulo são capazes de liberar dois tipos de feromônio, são eles: feromônio repulsivo e atrativo. A funcionalidade para a liberação do feromônio repulsivo segue os 
conceitos apresentados no capítulo anterior. Relembrando, esta substância é depositada no ambiente para demarcar regiões visitadas e evitar que outros robôs as visitem em um curto período de tempo. A propriedade de repulsão favorece as tarefas de exploração e vigilância uma vez que os robôs tendem a não ocupar regiões próximas, distribuindo as tarefas entre eles. Além disso, devido ao fenômeno de evaporação, regiões anteriormente visitadas voltam a ser buscadas após o desaparecimento da substância.

Outro tipo de feromônio introduzido neste capítulo, agora relacionado exclusivamente à tarefa de formação, é o feromônio atrativo. Esta substância tem a capacidade de atrair robôs para locais onde foi depositada. Desde que a tarefa de formação exige a coesão do grupo de robôs (estes devem se deslocar na mesma direção, mantendo uma distância constante entre eles), o depósito de feromônio atrativo é um meio para evitar que os robôs se dispersem do grupo. Tendo em vista que a abordagem líder-seguidor é uma das adotadas para estabelecer a formação, o feromônio atrativo é liberado somente pelo líder, a fim de indicar a trajetória a ser seguida pelos demais robôs do grupo.

Embora o foco do capítulo seja dedicado somente ao mecanismo de formação, o sistema proposto apresenta duas habilidades que beneficiam a tarefa de exploração e vigilância, são elas: mudança e adição de líder. Tais eventos ocorrem segundo a necessidade do sistema. A mudança de líder ocorre com o intuito de mudar a direção de movimento do grupo. Tal mudança é necessária, para evitar que os robôs se movam para áreas recentemente visitadas, prejudicando o desempenho da tarefa. Como é o líder que guia o movimento do grupo, é a partir de seu comportamento que o processo de mudança de líder é disparado. Ao detectar muita quantidade de feromônio repulsivo por longo período, é dito que o líder está saturado positivamente. Então um novo líder deve ser definido na tentativa de mudar a direção de movimento do grupo. Ao contrário, a saturação negativa está relacionada à detecção de pouca quantidade de feromônio pelo mesmo período de tempo. Neste caso, um líder é adicionado, possibilitando a divisão do grupo e a distribuição das tarefas.

\section{Grafos}

Para estabelecer uma formação, é necessário que os agentes de um grupo tenha conhecimento a respeito de infomações dos vizinhos que estão na proximidade, por exemplo, posição, direção e velocidade. A troca de mensagens entre um agente e outro é feita somente se ambos estiverem conectados. Tal conexão entre os agentes é definida pela topologia do grupo, que é representada por um grafo. Considerando $N$ agentes, o grafo $G=\{P, E\}$ é um conjunto $P$ de $N$ vértices conectados por um conjunto de arestas $E$. Dois agentes são ditos conectados, ou seja, eles são passíveis de troca de informação, se existir 
uma aresta entre eles. Matematicamente, dados os agentes $i$ e $j \in P$, a comunicação entre eles é possível se a aresta $(i, j) \in E$. Um grafo é não direcionado se não há orientação nas arestas, ou seja, $(i, j)=(j, i) \in E$. Isto implica que é permitido o envio de mensagens do agente $i$ para o $j$ e vice-versa. No sistema proposto, cada agente $i$ possui um conjunto $N_{i}$ contendo os agentes que formam sua vizinhança, e somente com eles, a troca de informação é realizada.

\section{Diagrama de Voronoi}

Durante a formação, os robôs do grupo mantêm uma região ao seu redor para estabelecer uma distância entre eles, evitando assim, colisões. As regiões são associadas a pontos geradores (McKerrow, 1991) (posições dos robôs) e delimitadas por quaisquer pontos do ambiente equidistantes dos geradores. Em outras palavras, quando qualquer ponto do ambiente pertence à região de um gerador se a distância entre eles for menor que a distância entre este ponto e qualquer outro gerador. Para modelar tais regiões, considere um conjunto $\Omega \subseteq \mathbb{R}^{d}(d>0$ e $d \in \mathbb{N})$ e um conjunto de pontos $P=\left\{p_{1}, p_{2}, \ldots, p_{n}\right\}^{T} \subset \Omega(n \in \mathbb{N})$, a partição Voronoi de $\Omega$ gerada por $P$ é a coleção dos conjuntos $\left\{V^{1}, V^{2}, \ldots, V^{n}\right\}$ definida por:

$$
V^{i}(P)=\left\{q \in \Omega \mid\left\|q-p_{i}\right\| \leq\left\|q-p_{j}\right\|, \forall p_{j} \in P, j \neq i\right\}
$$

em que a $V^{i}(P)$ é a região de Voronoi do ponto $p_{i}$.

Ocasionalmente, como resultado da partição Voronoi, a região $V^{i}(P)$ pode não ser totalmente fechada, o que é chamada de região infinita. Esta região é limitada com o auxílio de um círculo $O\left(p_{i}, r\right)$, denominado círculo de Voronoi, em $\mathbb{R}^{2}$ com centro em $p_{i}$ e raio $r$ de maneira que a região Voronoi limitada pelo raio $r$ seja definida como:

$$
V^{i}(P)=V^{i}(P) \cap O\left(p_{i}, r\right)
$$

\section{Tringulação de Delaunay}

A relação de vizinhança entre os agentes é definida pela Triangulação de Delaunay. De uma forma geral, para a construção dos triângulos de Delaunay, sobre o conjunto $P$, utiliza-se o critério de maximização dos ângulos mínimos dos triângulos. Ou seja, todos os triângulos resultantes devem ser o mais próximo possível de triângulos equiláteros, evitando ângulos internos agudos. Uma outra maneira utiliza o critério de circuncírculo: três pontos $p_{i}, p_{j}$ e $p_{k} \in P$ são vértices de um triângulo de Delaunay, se e somente se, existir um círculo $c$ sobre os três pontos e não incluir nenhum outro ponto de $P$ ( $c$ é denominado círculo vazio). Existem diversos algoritmos para cons- 
trução de triangulações de Delaunay: divisão-e-conquista (Guibas and Stolfi, 1985), incremental (de Berg et al., 2008), sweepline (Shewchuck, 1997) e com restrições (Kallmann et al., 2003).

Em diversas abordagens, a triangulação de Delaunay é definida como um grafo dual do diagrama de Voronoi, de forma que dois nós $p_{i}$ e $p_{j} \in P$ são conectados por uma aresta $e_{i, j}$, se suas respectivas regiões de Voronoi são vizinhas (Figura 5.1). Assim, qualquer aresta (conexão) adicionada ao grafo deve interceder ortogonalmente uma aresta resultante do diagrama de Voronoi. A triangulação de Delaunay define propriedades entre dois nós conectados, como por exemplo a distância entre eles, que pode ser estimada pela distância euclediana entre os nós conectados usando um sistema de coordenada global.

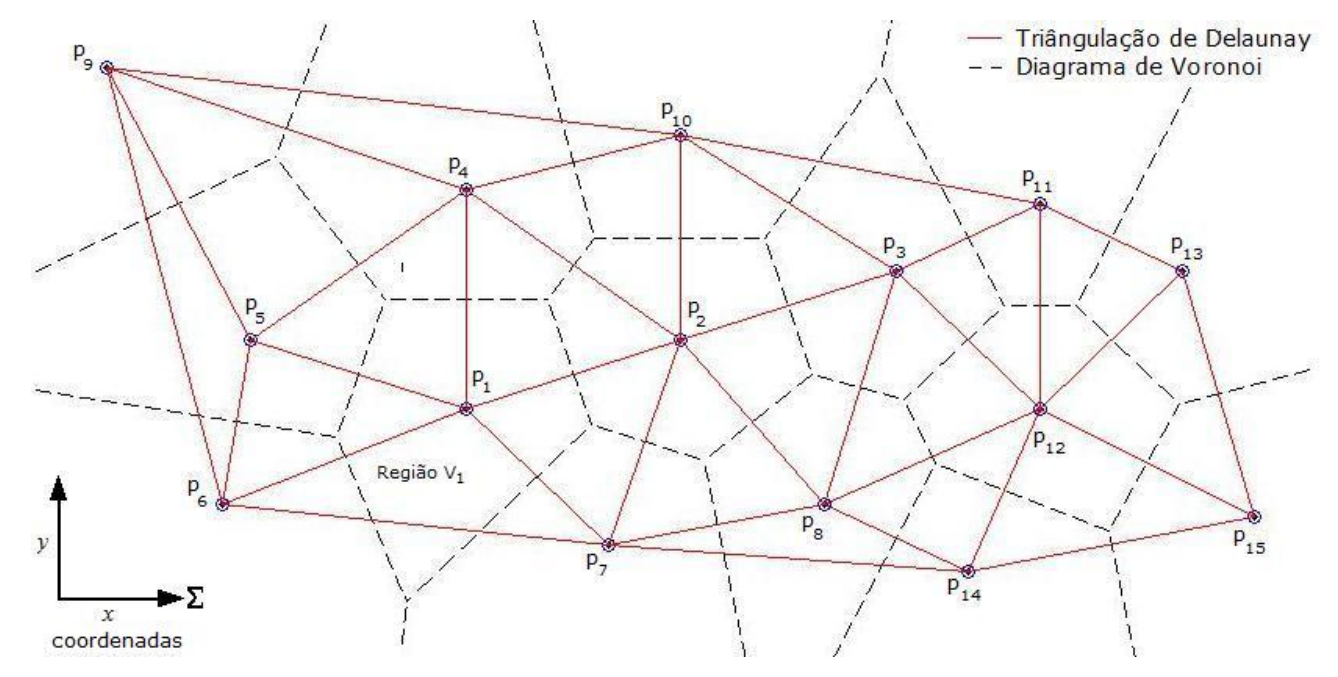

Figura 5.1: Modelo matemático da Triangulação de Delaunay e Diagrama de Voronoi.

No contexto da presente proposta, os elementos de $P$ estão associados às posições dos robôs. Dessa maneira, a topologia é alterada dinamicamente devido à movimentação do grupo, o que modifica o conjunto de vizinhos de um robô. A relação de vizinhança entre os robôs é definida por ambos os grafos (Voronoi e Delaunay) e noções de grafos de proximidade (vindos da geometria computacional) auxiliando na definição de robôs vizinhos.

Um grafo de proximidade $G$ é uma função que associa um conjunto finito de pontos no plano cartesiano a um grafo cujo os vértices são esses pontos e as arestas dependem das posições relativas destes. Mais precisamente, dado um conjunto $P=\left\{p_{1}, \ldots, p_{n}\right\} \subset \mathbb{R}^{d}$ de $n$ pontos distintos, o grafo de proximidade $G$ em $P$, denotado por $G(P)$, é um grafo não direcionado com conjunto de vértices $P$ e conjunto de arestas $E_{G}(P)$, em que $E_{G}(P) \subseteq\{\{p, q\} \in P \times P \mid p \neq q\}$, tal que arestas com a origem e destino idênticos não são permitidas. Grafos de proximidade fornecem um significado natural para modelar a topologia de interconexão de um grupo de robôs. Em geral, esta topologia pode ser modelada de acordo com a localização dos agentes, assim como as capacidades senso- 
riais e de comunicação de cada um dos robôs. A seguir, são mencionadas alternativas para modelar a topologia do grafo discutidas em (Cortes et al., 2004; Jaromczyk and Toussaint, 1992; de Berg et al., 2000; Martinez et al., 2007):

- Grafo r-disk $G_{d i s k}(r)$, onde $r>0$, em que dois robôs são vizinhos se a distância entre eles é no máximo $r$, ou seja, $\left\{p_{i}, p_{j}\right\} \in E_{G d i s k}(P)$ se $\| p_{i}-$ $p_{j} \| \leq r$

- Grafo de Delaunay $G_{D}$, em que dois robôs são vizinhos se suas correspondentes células de Voronoi se interceptam, ou seja, $\left\{p_{i}, p_{j}\right\} \in E_{G D}(P)$ se $V_{i}(P) \cap V_{j}(P) \neq \emptyset$. Aqui a intersecção de duas células de Voronoi pode incluir somente partes do contorno de cada célula;

- Grafo Delaunay r-limitado $G_{L D}(r)$, onde $r>0$, em que dois robôs são vizinhos se suas correspondentes células de Voronoi se interseccionam e a distância entre eles é no máximo $r$, ou seja, $\left\{p_{i}, p_{j}\right\} \in E_{G L D}(P)$ se $V_{i, r}(P) \cap V_{j, r}(P) \neq \emptyset \mathrm{e}\left\|p_{i}-p_{j}\right\| \leq r ;$

- Grafo de visibilidade $G_{v i s, Q}$, onde $Q$ é um conjunto em $\mathbb{R}^{d}$, em que dois robôs são ditos vizinhos se um estiver no campo de visão do outro, ou seja, $\left\{p_{i}, p_{j}\right\} \in E_{G v i s, Q}(P)$ se o segmento $\left\{p_{i}, p_{j}\right\} \subset Q$;

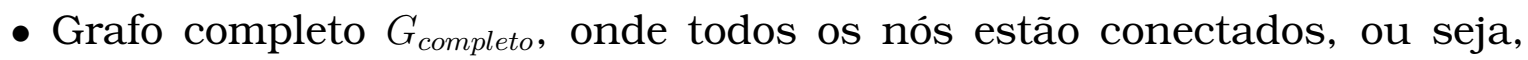
todos os pares de robôs são vizinhos.

Independente do grafo de proximidade $G(P)$ sobre o conjunto finito de pontos $P$, define-se o conjunto de vizinhos do vértice $p_{i} \in P$ como:

$$
N^{p} i_{G, p_{i}}(P)=\left\{q \in P \mid\left\{p_{i}, q\right\} \in E_{G}(P)\right\}
$$

\subsection{Sistema de Formação Auto-Adaptativo}

Motivado pelas vantagens e desvantagens das abordagens de formação discutidas no Capítulo 2, nesta seção é proposta uma estratégia de formação confiável e de fácil implementação que possui as seguintes características:

- Descentralização: a fim de distribuir a tarefa de formação e não sobrecarregar um único robô ou agente externo, a estratégia deve ser descentralizada, mesmo que uma grande quantidade de robôs seja empregada. Duas vantagens são evidentes quando ocorre a distribuição da tarefa. Primeiro, os agentes passam a ser independentes de qualquer influência externa ou interna de outros agentes. Dessa maneira, eles tomam uma 
decisão baseado-se apenas em informações locais, ou seja, somente o estado do ambiente na região de percepção do agente é considerado para a realização de tal tarefa. Segundo, a formação não é prejudicada em caso de falha de um agente do grupo. Ao contrário, em sistemas onde um único agente concentra todas as operações, a execução da tarefa pode ser comprometida se este sofrer algum dano e se tornar inutilizável.

- Livre de colisão: além de manter o grupo em constante formação, a estratégia deve garantir movimentos livres de colisão entre os agentes e os obstáculos do ambiente e entre eles próprios. O ato de evitar colisões é um comportamento extremamente importante. Em aplicações com veículos aéreos, por exemplo, a colisão, provavelmente, ocasionaria o término da execução da tarefa. Com robôs terrestres e de pequeno porte, a colisão pode não causar grandes danos materiais, mas inúmeras colisões podem retardar o cumprimento de uma tarefa. Portanto, evitar colisões é necessário para manter a integridade dos agentes e a formação e eficiência do grupo.

- Adaptação: a estratégia deve ser capaz de manter a formação em qualquer configuração de ambiente. Uma característica interessante da proposta apresentada é a habilidade do grupo em atuar em cenários cujo mapa não está disponível. Isto permite a sua utilização em ambientes hostis e desconhecidos, onde a presença de um ser humano não é segura, como em situações de resgate, monitoramento e escolta de materiais nocivos. Muitos modelos de formação, no entanto, consideram somente ambientes favoráveis às suas características. Portanto, a estratégia de formação deve ser adaptável a diferentes ambientes, com ou sem obstáculos.

- Topologia dinâmica: esta característica está diretamente relacionada com a adaptação do grupo em ambientes desconhecidos. Dependendo da tarefa a ser executada ou da configuração do ambiente, a topologia da formação pode sofrer altereções. Em alguns modelos, um conjunto de formatos específicos para a topologia é definido de maneira que o grupo assuma um deles de acordo a situação encontrada. Este não é o caso da estratégia apresentada nesta tese. O que fundamenta esta característica é a capacidade de ajuste da formação que melhor se adeque a uma determinada situação, descartando quaisquer formações previamente definidas. Logo, a formação obtida não é do conhecimento do projetista. Na estratégia proposta, a topologia se adapta ao estado do ambiente. Ou seja, o formato do grupo é dependente da disposição dos obstáculos. Assim, fica claro que a configuração do ambiente não é uma 
dificuldade para estabelecer a formação. Com a mudança da topologia, a conexão (que possibilita a comunicação) entre os agentes também é alterada. Entretanto, seguindo o comportamento independente dos agentes (como mencionado na característica de descentralização), novos vizinhos são definidos de acordo com informações locais para a troca de informação, condição essencial para a manutenção da formação.

- Estabilidade: a garantia de que a formação é mantida sob quaisquer circunstâncias é essencial para o cumprimento de uma determinada tarefa. Por exemplo, em escolta e transporte de objetos, é de extrema importância que a formação seja mantida e que nenhum robô se afaste por completo do grupo. Independentemente da configuração do ambiente, da topologia adotada para a formação e da quantidade de robôs no grupo, a dinâmica do sistema deve assegurar que o grupo se mantenha coeso. Em alguns casos, os robôs podem sofrer perturbações, como sair do alinhamento do grupo devido à eminência de colisão ou à mudança repentina de direção deles. Nestas situações, para qualquer estado assumido pelas variantes envolvidas na dinâmica do movimento, o sistema deve se mostrar confiável a fim de que a estabiliade da formação seja mantida.

A Tabela 5.1 compara as características entre os trabalhos encontrados na literatura e a estratégia de formação proposta neste estudo. Para melhor visualização da tabela, os termos são abreviados como: Descentralização (Desc.); Livre de colisão (Liv. Col.); Adaptação (Adapt.); Topologia dinâmica (Top. Din.) e Estabilidade (Est.).

Tabela 5.1: Tabela comparativa de características.

\begin{tabular}{|c|c|c|c|c|c|}
\hline Autor & Desc. & Liv. Col. & Adapt. & Top. Din. & Est. \\
\hline (De La Cruz and Carelli, 2006) & & & $\mathrm{X}$ & $\mathrm{X}$ & $\mathrm{X}$ \\
\hline (Consolini et al., 2009) & $\mathrm{X}$ & & $\mathrm{X}$ & $\mathrm{X}$ & $\mathrm{X}$ \\
\hline (Dong and Farrell, 2008) & $\mathrm{X}$ & & $\mathrm{X}$ & & $\mathrm{X}$ \\
\hline (Mastellone et al., 2011) & & $\mathrm{X}$ & & & $\mathrm{X}$ \\
\hline (Tan et al., 2004) & & $\mathrm{X}$ & $\mathrm{X}$ & & $\mathrm{X}$ \\
\hline (Alboul et al., 2010) & $\mathrm{X}$ & $\mathrm{X}$ & & & $\mathrm{X}$ \\
\hline (Lewis and Tan, 1997) & & $\mathrm{X}$ & & & $\mathrm{X}$ \\
\hline (Kaliappan et al., 2011) & $\mathrm{X}$ & $\mathrm{X}$ & $\mathrm{X}$ & $\mathrm{X}$ & \\
\hline Esta tese & $\mathrm{X}$ & $\mathrm{X}$ & $\mathrm{X}$ & $\mathrm{X}$ & $\mathrm{X}$ \\
\hline
\end{tabular}

A ideia fundamental da estratégia proposta é promover a descentralização, reduzindo o custo computacional de alguma entidade máxima que governe o movimento dos agentes, dotando o sistema de capacidade de ajuste da topologia para a aplicação da estratégia em diversos tipos de ambientes. Em outras 
palavras, a proposta é desenvolver uma estratégia de formação distribuída, onde todos os agentes têm sua parcela de participação, que proporcione flexibilidade ao grupo independentemente da estrutura do ambiente, assegurando a estabilidade da formação. Para tanto, na busca por alcançar tais características, o sistema de formação é uma combinação das abordagens comportamental, líder-seguidor e de consenso.

O processo de formação ocorre à medida que os robôs se locomovem, isto é, o ajuste da topologia ocorre gradualmente. Para o movimento do grupo, é considerada a estratégia de exploração baseada na versão modificada do sistema de colônias de formigas apresentado no Capítulo 4. Logo, os conceitos básicos da teoria clássica do sistema de colônias de formigas foram trazidos para a concepção do sistema de formação, denominado Sistema de Formação AutoOrganizável (Self-Adaptative Formation System - SAFS). O papel da estratégia de exploração é simplesmente manter o grupo em movimento. No entanto, este capítulo não entra no mérito da avaliação de sua eficiência, tampouco a eficiência da tarefa de vigilância. O foco está unicamente no estabelecimento da formação propriamente dita.

A formação é organizada por uma topologia em que cada robô está associado a um nivel hierárquico. O líder sempre está no nível 0 e os vizinhos que possuem uma conexão com ele estão no nível 1. Os robôs conectados àqueles do nível 1 e que não estão ligados ao líder, estão no nível 2 e assim por diante. Partindo-se do líder, o nível de hierarquia é incrementado de acordo com o percurso em amplitude. A Figura 5.2 exemplifica a distribuição do nível em um caso de formação para um conjunto $R$ de 10 robôs $R=\left\{R_{1}, R_{2}, \ldots, R_{10}\right\}$. O nivel dos robôs tem um papel importante para a manutenção da formação. Um robô, em particular, no nível $l$ busca seguir o trajeto de seus vizinhos que estão no nível $l-1$. A tendência é que robôs com nível baixo estejam mais próximos do líder. Portanto, seguindo estes robôs, a consequência é que o grupo se movimente em direção ao líder.

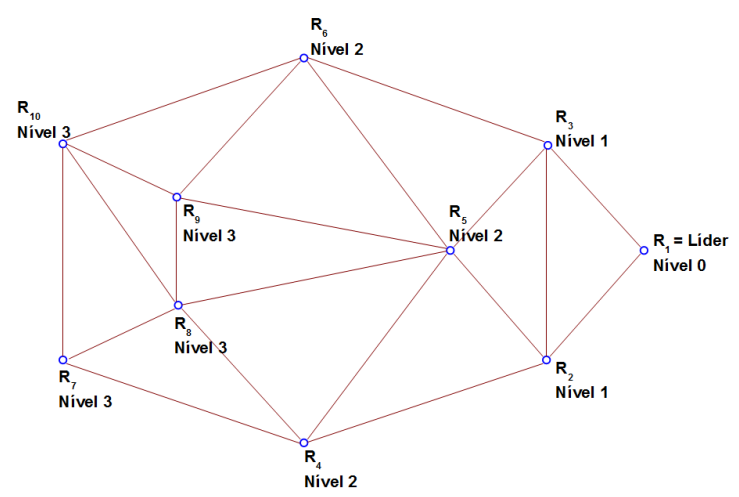

Figura 5.2: Nivel dos robôs em formação. 
Em contraste com os robôs atuando de forma isolada na estratéga IAS-SS, em que a única forma de interação entre os agentes é através do ambiente devido à liberação de feromônio, há diversas maneiras de interações quando o problema de formação é considerado. Os novos meios de interação entre os agentes torna a estrutura dos robôs mais complexa em relação àqueles utilizados anteriormente, como mostrada na Figura 5.3.

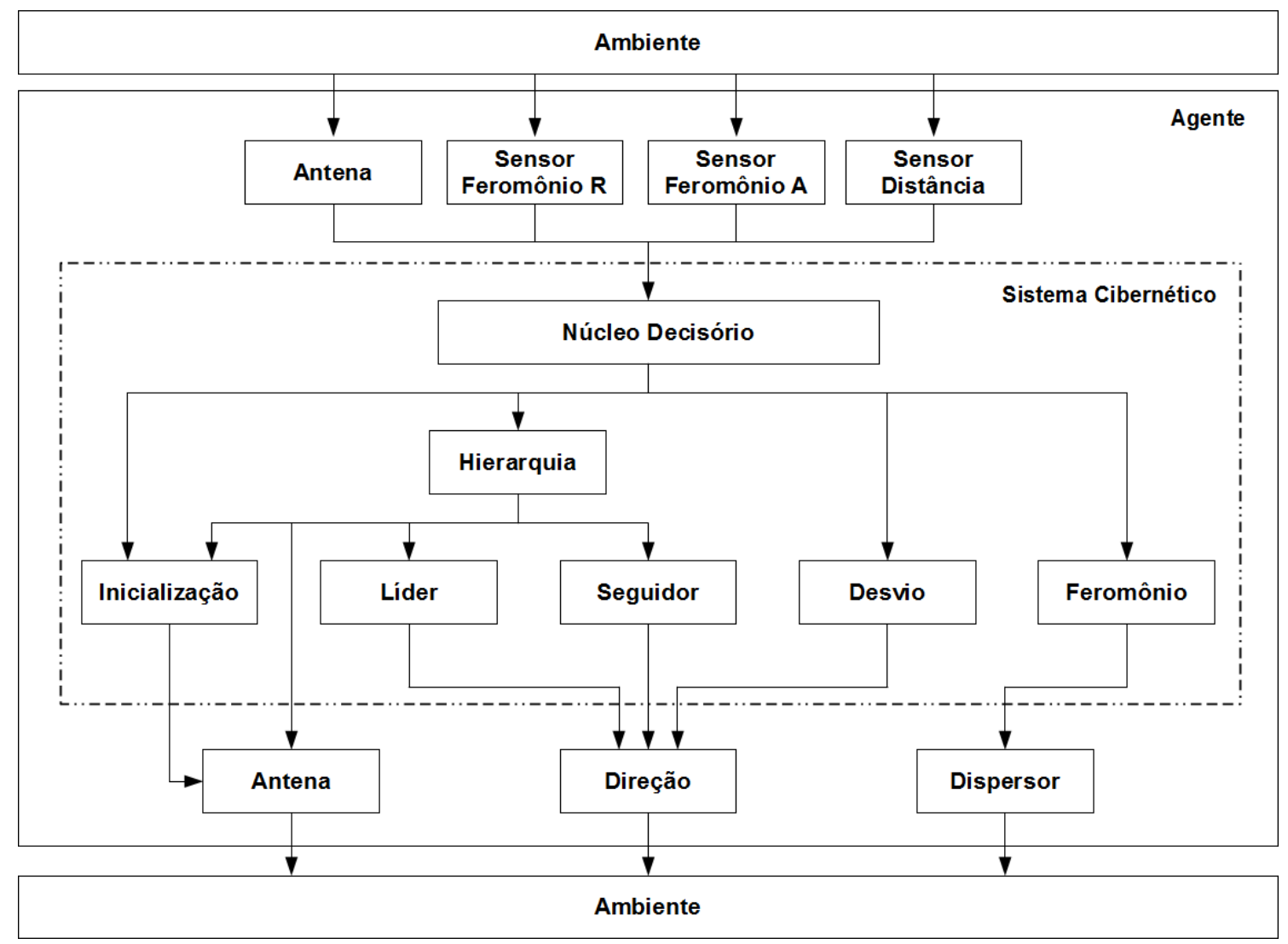

Figura 5.3: Diagrama arquitetural do sistema cibernético para um único robô no SAFS.

A diferença já é notória ao observar a quantidade de atuadores e sensores. Adicionalmente à estratégia IAS-SS, os robôs são capazes de perceber e liberar feromônio de natureza atrativa. O robô na condição de líder é o único que libera feromônio atrativo com o intuito de mostrar o caminho aos seguidores. No entanto, é o único a não perceber este tipo de feromônio. Ao contrário disto, os seguidores liberam somente feromônio repulsivo (para marcar regiões exploradas) mas detectam feromônio atrativo (para seguir o líder). Enquanto um dos fatores que influencia na tomada de decisão dos seguidores é a quantidade de feromônio depositado pelo líder, este, por sua vez, é guiado pela estratégia de exploração. O sistema cibernético de cada robô consiste de 7 componentes: Núcleo Decisório e os módulos de Hierarquia, Inicialização, Líder, Seguidor, Desvio e Feromônio. Tais módulos estão em um mesmo nível hierárquico e são subordinados ao Núcleo Decisório. 
Resumidamente, a função do núcleo decisório é ativar e desativar os módulos que compõem o sistema cibernético. Mediante os sinais provenientes do ambiente, o Núcleo Decisório identifica o estado atual do agente e direciona sua ação dentre os módulos. Tais ações diferem em selecionar um líder (Módulo de Inicialização), agir como um líder e guiar o grupo (Módulo Líder), seguir o líder (Módulo Seguidor), desviar de obstáculos (Módulo de Desvio) e depositar feromônio repulsivo/atrativo (Módulo de Feromônio). O único módulo constantemente ativado, independente do robô ser identificado como líder ou seguidor, é o Módulo de Hierarquia. Este módulo tem a função de associar o nível de hierarquia do robô perante a formação estabelecida, desde que o nível seja incrementado gradualmente a partir do líder.

De modo distinto ao apresentado em IAS-SS, o módulo responsável por depositar feromônio está conectado (por meio do núcleo decisório) com as entradas sensoriais do sistema cibernético. Se por um lado, o feromônio repulsivo é liberado independente da condição do robô (líder ou seguidor), por outro, o feromônio atrativo é depositado somente se o robô for identificado como líder. E para que tal substância seja liberada, a informação sobre a condição de líder do robô deve ser transmitida ao módulo de feromônio pelo núcleo decisório. Somente os módulos de Líder, Seguidor e Desvio influeciam diretamente na escolha da nova direção a ser seguida pelo robô, enviando sinais para o atuador responsável pela orientação do veículo, enquanto os sinais gerados pelos módulos de Inicialização e Feromônio são transmitidos para os demais robôs da vizinhança através do atuador do tipo antena e um dispositivo mecânico que dispersa o feromônio.

Em ambas as tarefas de exploração e formação, a estigmergia se faz presente. Embora somente o líder seja condicionado a depositar feromônio atrativo, os seguidores detectam a substância no ambiente, pelo sensor de feromônio atrativo, para alinhar seu movimento com a trajetória do grupo. Para a tarefa de exploração, o feromônio repulsivo, liberado por todos os robôs (inclusive o líder), marca tais regiões como visitadas, as quais tornam-se regiões menos atrativas para uma nova visita. Com a estratégia de exploração adotada, é natural que a tarefa de vigilância seja desempenhada uma vez que a evaporação do feromônio torna a região atrativa novamente após um período. Porém, como dito antes, a execução de tais tarefas não serão avaliadas aqui. Além da estigmergia, a comunicação direta ocorre com o uso da antena para transmitir de robô para robô informações como sua identificação e quantidade de feromônio detectada no instante corrente. 


\subsubsection{Sensores do Robô}

Similar ao modelo descrito no capítulo anterior, robôs $r_{k}, k=1, \ldots, N, N \in \mathbb{N}$ se deslocam em um plano $Q \subset \mathbb{R}^{2}$, denota-se um ponto arbitrário $\in Q$ por $q \mathrm{e}$ assume que o tempo é discreto. Em adição, os robôs utilizados na estratégia SAFS são equipados pelas seguintes classes de sensores: sensores de feromônio repulsivo e atrativo, sensores de distância e antena. O mecanismo de detecção de obstáculo é semelhante àquele apresentado na estratégia IAS-SS. Por esse motivo, detalhes dos sensores de distância a obstáculos não são discutidos nesta seção.

Os sensores de feromônio repulsivo e atrativo apresentam a mesma estrutura descrita no Capítulo 4. A área de raio $R_{D}$ coberta por ambos corresponde à área frontal do robô $\left[-90^{\circ}, 90^{\circ}\right]$. Porém, a maneira pela qual a substância é detectada difere nos dois casos. Em relação ao sensor de feromônio repulsivo, o robô líder é o único a utilizá-lo. Como sua principal função é dotar o grupo de capacidade de exploração em busca de regiões com baixa quantidade de feromônio repulsivo, o mecanismo de detecção é idêntico àquele apresentado na Seção 4.3.1. O feromônio é detectado em todos os ângulos $A_{s r}, s r=\left\{-S_{r}, \ldots,-1,0,1, \ldots, S_{r}\right\}$, tal que: $\left(2 S_{r}+1\right) \alpha=180$ localizados na borda do sensor.

No modelo adotado para o sensor de feromônio atrativo, tal substância é detectada em toda área frontal, e não somente na borda do sensor. O ângulo de abrangência $\left(180^{\circ}\right)$ é dividido em seções angulares idênticas, medindo $\alpha^{\circ}$ no qual sua sensibilidade é mais acentuada (Figura 5.4). Cada seção angular é representada pela sua bissetriz $B_{s a}, s a=\left\{-S_{a}, \ldots,-1,0,1, \ldots, S_{a}\right\}$, tal que: $\left(2 S_{a}+1\right) \alpha=180$. A informação detectada na região da bissetriz $B_{s a}$ responde pela informação de sua seção angular, denotada por $\sec _{B s a}$ (a partir desse ponto, $B_{s a}$ é referenciado como um ângulo). Tal informação, enviada para o sistema cibernético do robô, equivale à média da quantidade de feromônio detectada na região que coincide com a bissetriz. Assim, a quantidade média de feromônio atrativo no ângulo $B_{s a}$ no instante $t$ é representada por $\overline{\tau_{B s a}^{a}(t)}$.

Para gerar a informação emitida pelo sensor de feromônio atrativo, alguns locais de detecção da bissetriz podem não ser considerados para o cálculo da média da quantidade de feromônio. Somente aqueles locais com quantidade superior a uma constante $\psi$ são considerados para encontrar o valor indicado por $B_{s a}$. Desde que, o feromônio atrativo é liberado pelo líder, os seguidores se direcionam para regiões com maior quantidade de feromônio a fim de realizar a mesma trajetória do líder. Mesmo que uma pequena região (poucos locais da bissetriz) seja detectada com alta concentração de feromônio atrativo, a possibilidade do líder estar posicionado próximo a esta região é elevada. Ao contrário, se a mesma quantidade de feromônio é detectada de forma mais 


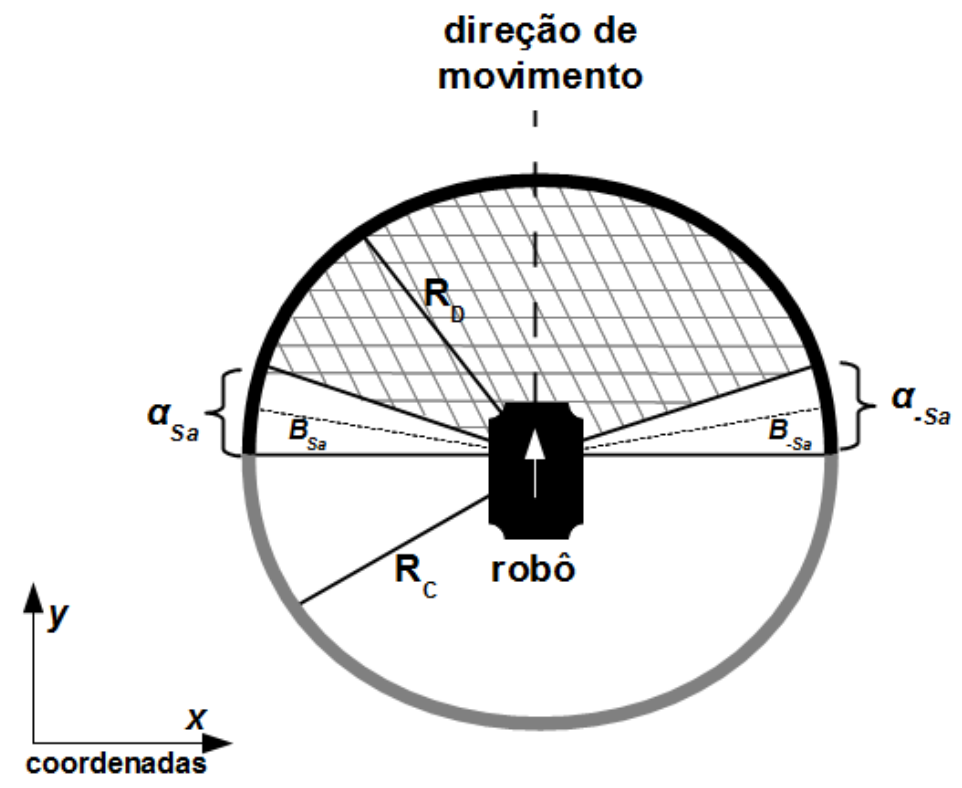

Figura 5.4: Modelo do sensor de feromônio atrativo.

dispersa, ou seja, em uma região maior (muitos locais da bissetriz), significa que a concentração está distribuída e não é intensa, indicando que o líder não está próximo dessa região. Neste caso, a quantidade média de feromônio atrativo no ângulo $B_{s a}$ no instante $t$ é dada por:

$$
\begin{aligned}
& \overline{\tau_{B s a}^{a}(t)}=\frac{1}{n_{a}} \sum_{q \in \sec _{B s a}(t)} \tau_{q}^{a *}(t), \quad \mathrm{e} \\
& \tau_{q}^{a *}(t)=\left\{\begin{array}{l}
\tau_{q}^{a}(t), \text { se } \tau_{q}^{a}(t)>\psi \\
0, \text { caso contrário }
\end{array}\right.
\end{aligned}
$$

em que $\tau_{q}^{a}(t)$ é a quantidade de feromônio atrativo na posição $q \in Q$ no instante $t$ e $n_{a}$ é a quantidade de locais $q$ com concentração maior que $\psi$.

A última classe de sensores, a única que estabelece a comunicação direta entre os robôs, é representada por um dispositivo que detecta informações (ou mensagens) emitidas por estes em área circular de raio $R_{C}$ (raio de comunicação). A mensagem detectada e interpretada pelo sistema cibernético consiste em dois modelos de pares ordenados, são eles: (identificação do robô, quantidade de feromônio repulsivo) e (identificação do robô, nível de hierarquia), representados como ( $\left.m s g \_i d, m s g \_f e r o m o n i o\right)$ e ( $\left.m s g \_i d, m s g \_n i v e l\right)$, respectivamente. O tratamento das mensagens difere de acordo com o modelo detectado. O primeiro modelo está associado aos instantes em que a definição de um líder é solicitada. O segundo é transmitido pelos robôs constantemente para atualizar seu nível na hierarquia do grupo. O conteúdo destas mensagens será discutido nas próximas seções. A entidade responsável pela troca de informação é mencionada nesta tese como antena, mas qualquer dispo- 
sitivo capaz de enviar e receber mensagens (rádio ou tecnologias de comunicação por rede sem fio, como zigbee) é adaptável à estrutura do robô.

\subsubsection{Núcleo Decisório}

A cada movimento do robô, a antena, os sensores de feromônios repulsivo, atrativo e de distância a obstáculos capturam estímulos do ambiente na forma de vetores, $D_{A}, D_{F R}, D_{F A}$ e $D_{D}$, respectivamente. A estrutura dos vetores é definida da seguinte maneira: os estímulos capturados pela antena são organizados em pares ordenados e devido à sua capacidade de detectar informações de mais de um robô, o vetor pode assumir dois modelos, $D_{A} \in$ $\left\{D_{A 1}, D_{A 2}\right\}$, tal que $D_{A 1}=\left\{\left(m s g \_i d_{1}, m s g \_n i v e l_{1}\right), \ldots,\left(m s g \_i d_{n_{v}}, m s g \_n i v e l_{n_{v}}\right)\right\}$ e $D_{A 2}=\left\{\left(m s g_{-} i d_{1}, m s g_{-} f_{\text {eromonio }}\right), \ldots,\left(m s g_{-} i d_{n_{v}}, m s g_{-} f\right.\right.$ eromonio $\left.\left._{n_{v}}\right)\right\}$. O tamanho desses vetores é igual ao número de robôs identificados por meio da antena $\left(n_{v}\right)$, ou seja, os robôs que estão na vizinhança. A informação a respeito do nível hierárquico dos robôs da vizinhança é essencial para a manutenção da formação, portanto os sinais do vetor $D_{A 1}$ são requisitados a todo instante, enquanto que os sinais em $D_{A 2}$ são capturados somente em ocasiões onde um líder precisa ser definido, uma vez que a quantidade de feromônio repulsivo é o critério para tal definição.

A modelagem vetorial dos sensores de feromônio repulsivo e atrativo seguem a estrutura $D_{F R}=\left\{A_{s r} \mid s_{r} \in\left\{-S_{r}, \ldots,-1,0,1, \ldots, S_{r}\right\}\right\}$ e $D_{F A}=$ $\left\{B_{s a} \mid s_{a} \in\left\{-S_{a}, \ldots,-1,0,1, \ldots, S_{a}\right\}\right\}$, respectivamente. O sensor de obstáculos é modelado como $D_{D}=\left\{d_{1}, d_{2}, \ldots, d_{n_{s}}\right\}$, em que $n_{s}$ é o número de leituras sensorias com o valor de distância.

De posse desses sinais, o papel do núcleo decisório é conduzir as ações de um robô. Para tanto, com a disponibilidade de uma base de regras, os sinais dos sensores são interpretados de maneira que o estado atual do robô seja detectado. A partir deste estado, algumas ações passam a ser inoperadas até que o estado seja alterado posteriormente. Além da base de regras, o núcleo decisório é composto por 4 módulos (Figura 5.5): Detecção de Vizinhança, Definição de Líder, Energia do Líder e Distância a Obstáculos.

\section{Módulo de Detecção de Vizinhança}

No problema de formação, a interação entre os robôs é um requisito essencial. Para a manutenção da formação, um robô se locomove a partir da observação dos demais, como orientação, posição e velocidade e, então, ajustar sua direção de movimento e sua velocidade com o intuito de manter o grupo coeso. Nesta tese, os atributos detectados são a orientação em relação à sua direção de movimento e a distância que o vizinho está do robô. A vizinhança do $k$-ésimo, contudo, é definida pelo conjunto $N^{k}$ de robôs que estão na área 


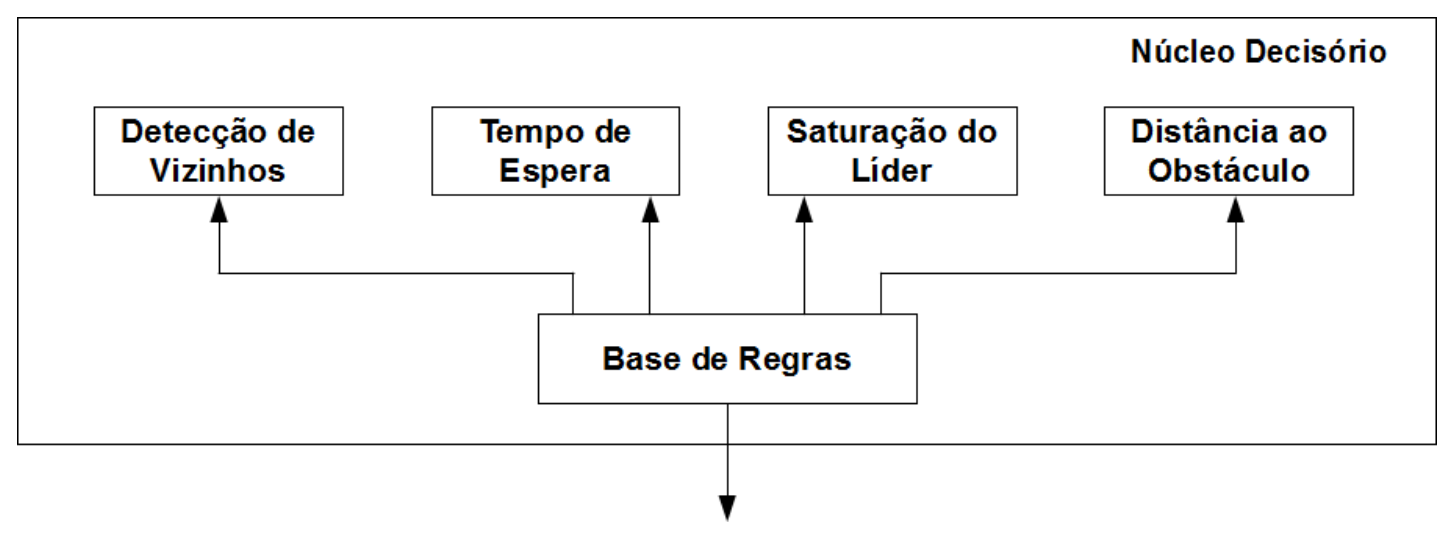

Figura 5.5: Diagrama arquitetural do Núcleo Decisório.

de cobertura da antena (Figura 5.4). Portanto, os robôs que estão a uma distância menor que $R_{C}$ têm suas informações (distância e direção relativa) detectadas pelo robô $k$. A partir destas informações, é possível inferir a distância dos vizinhos de um robô.

De maneira constante, o $k$-ésimo robô transmite informação referente à sua identificação $\left(m s g \_i d_{k}\right)$ e seu nível na hierarquia do grupo ( $\left.m s g_{-} n i v e l_{k}\right)$, organizada no par ordenado $\left(m s g_{-} i d_{k}, m s g_{-} n i v e l_{k}\right)$, para $k<n_{v}^{k}$. Ao detectar os robôs em sua vizinhança, o robô $k$ agrupa os pares ordenados em um único vetor $D_{A 1}$. Em seguida, são encontradas a distância e a direção dos vizinhos, o que possibilita o cálculo da posição destes. O vetor $N^{k}$ resultante do processo de detecção contém o par ordenado $\left(m s g_{-} i d_{i}, m s g_{-} q_{i}\right)$, em que $q_{i} \in Q$ é a posição do $i$-ésimo vizinho do robô $k$. O Algoritmo 2 define os passos do processo de detecção de vizinhança.

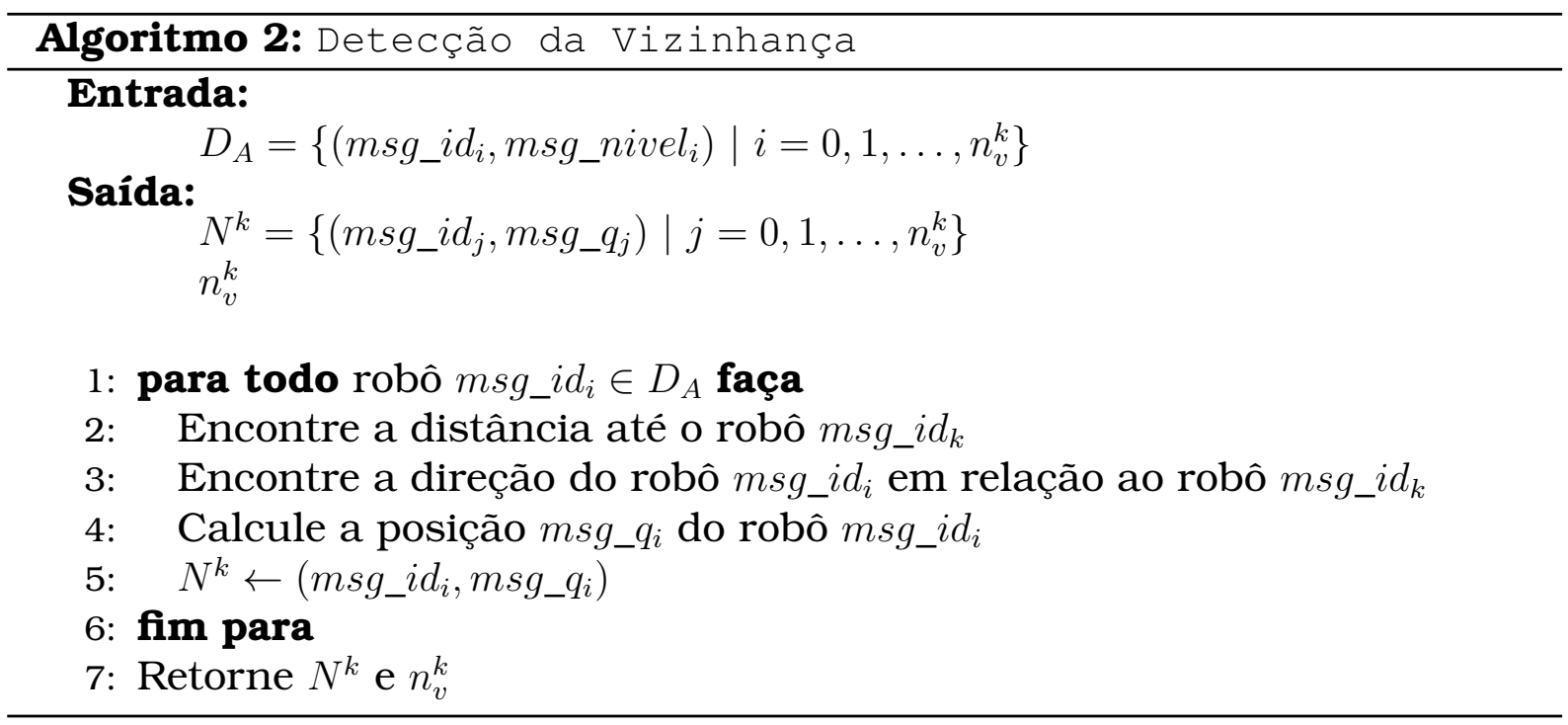

Módulo de Tempo de Espera

Conforme mencionado na Seção 5.3, a cada robô é associado um valor que define seu nível na hierarquia do grupo. Como a topologia do grupo pode ser 
alterada devido à movimentação do mesmo, o nível dos robôs deve apresentar comportamento dinâmico. Para que tal valor seja atualizado, é necessário que o robô receba a informação do nível de vizinhos situados em níveis inferiores. Uma vez que o nível é atualizado, este é propagado para aqueles vizinhos que estão em níveis superiores. Logo, percebe-se que a execução do processo de definição de nível é em efeito cascata e que o líder é responsável por iniciá-lo, desde que seu nível é zero.

$\mathrm{Na}$ ausência de um líder, este processo é interrompido, ou seja, nenhum robô receberá a informação de nível zero. Como consequência, nenhum robô envia o valor de seu nível aos seus vizinhos, o que afeta a formação. A fim de evitar que o grupo permaneça sem líder por um período de tempo indefinido, o Módulo de Tempo de Espera determina o período (tempo_esper $a_{k}$ ) pelo qual um robô $k$ não recebe informações do nível de seus vizinhos. Se este período for longo, é induzido que uma falha ocorreu no líder ou este, por situações raras, desconectou-se do grupo. Assim, é necessário que um novo líder seja definido. Para tanto, o $k$-ésimo robô requer informações provenientes da antena segundo o modelo do par ordenado ( $m s g_{-} i d_{i}, m s g_{-}$nivel $_{i}$ ), para $i<n_{v}^{k}$. Os passos do processo são mostrados no Algoritmo 3. Vale ressaltar que o incremento do período tempo_esper $a_{k}$ ocorre somente se o robô não é líder (mode_lider l $_{k}=0$ ) e quando este não receber nenhuma informação de outros robôs. Portanto, para fins de modelagem, a ausência de informação é representada por $N U L L$.

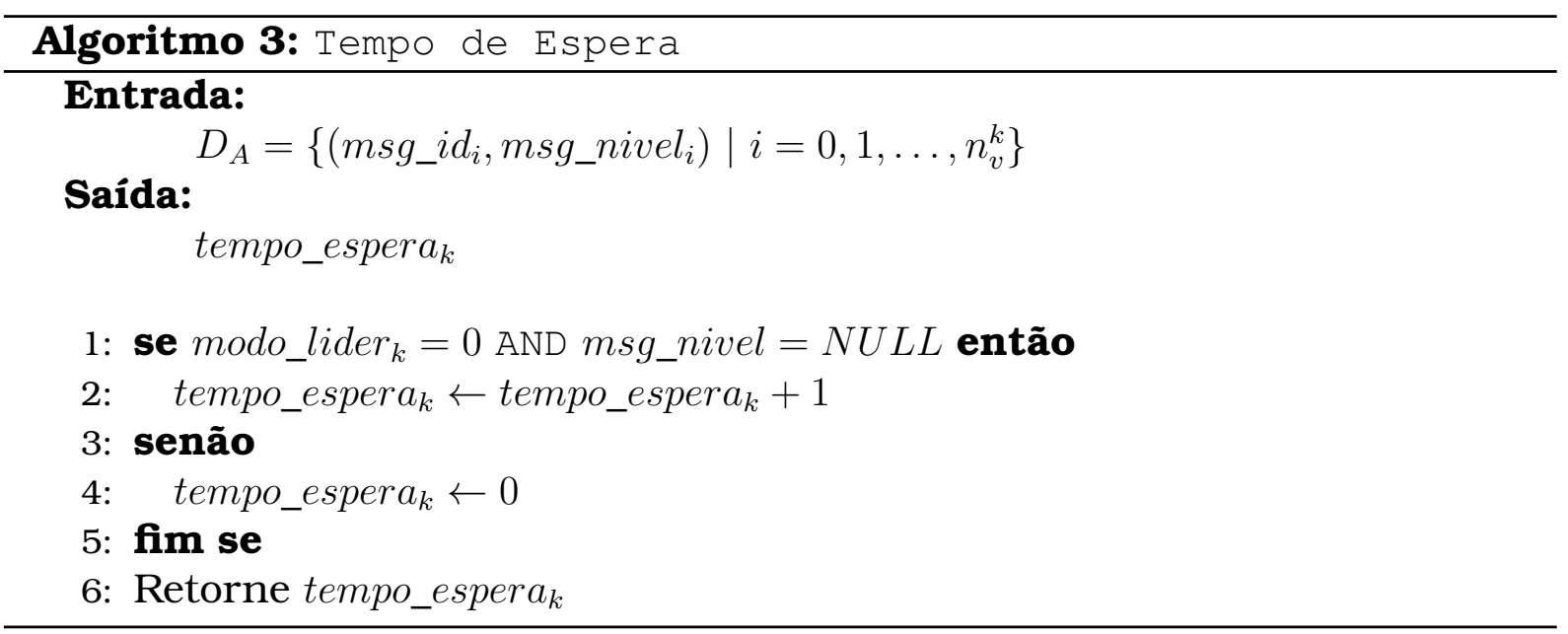

\section{Módulo de Saturação do Líder}

Este módulo está relacionado à habilidade do sistema em adicionar um líder no grupo ou substituí-lo. De forma sucinta, um líder é definido com base na quantidade de feromônio repulsivo disperso no ambiente, ou seja, o líder é aquele que detecta menor quantidade da substância em um determinado instante. Como o líder é o robô que guia os demais, a ideia é deslocar o grupo para regiões com pouca quantidade de feromônio que, portanto, não 
foram recentemente visitadas. A fim de evitar a troca ou adição constante de líderes, o conceito de saturação, conforme explicado na Seção 5.2 é aqui considerado. Assim, quando o líder detecta muita quantidade de feromônio por um longo período de tempo (saturação positiva), induz-se que o grupo está visitando muitas regiões há pouco exploradas. Sendo assim, a mudança de líder é desejável, permitindo que outras rotas sejam exploradas. Em situação oposta, ao detectar pouco feromônio (saturação negativa), o sistema percebe que há uma ampla área a ser explorada e que a divisão do grupo seria benéfica para tal tarefa. Desse modo, um novo líder é adicionado.

Em termos práticos, a saturação é definida pelo nível de energia do líder. Partindo-se da condição inicial de energia máxima do robô líder $k$ (energia ( $_{k}=$ MAXIMO_ENERGIA), o decaimento desta ocorre de acordo com a percepção consecutiva de alta ou baixa quantidade de feromônio. Se o nível mínimo de energia for atingido com alta quantidade de feromônio, tem-se saturacao $_{k}=+1$. Por outro lado, se a quantidade for baixa, então saturacao $k=-1$. A quantidade de feromônio é dita alta se esta ultrapassar o valor indicado em LIMITE_FEROMONIO e dita baixa se não atingir tal valor. Porém, havendo alternância na detecção com alta e baixa quantidade de feromônio antes da energia atingir seu nível mínimo, esta retorna ao seu valor máximo.

Considerando os sinais do sensor de feromônio repulsivo, o processo de saturação do líder é descrito no Algoritmo 4.

\section{Módulo de Distância a Obstáculo}

Embora a característica de estabilidade do sistema de formação garanta robustez em relação à colisão entre os robôs e entre os robôs e obstáculos, restrições de cunho prático demandam tratamento especial. Para o sistema proposto, os robôs são considerados entidades pontuais, porém as dimensões físicas dos robôs utilizados nos experimentos tornam possível a ocorrência de colisões. Por esta razão, o desenvolvimento do Módulo de Distância a Obstáculo faz-se necessário. Dada a leitura dos sensores de obstáculo de um robô $k$, este módulo visa obter a menor distância a um obstáculo ( min_dist $_{k}$ ) e sua direção $\left(m_{i n} \_d i r_{k}\right)$. Este procedimento é descrito no Algoritmo 5, em que min e qual min calculam o valor mínimo de um conjunto e sua posição do mesmo, respectivamente.

Base de Regras

Os sinais gerados pelos módulos do Núcleo Decisório são, na verdade, requisitos para a definição do estado do robô. A Base de Regras, munida de informações de referência como o limite máximo de espera por uma mensagem e a distância mínima de aproximação de um robô a um obstáculo (LI- 

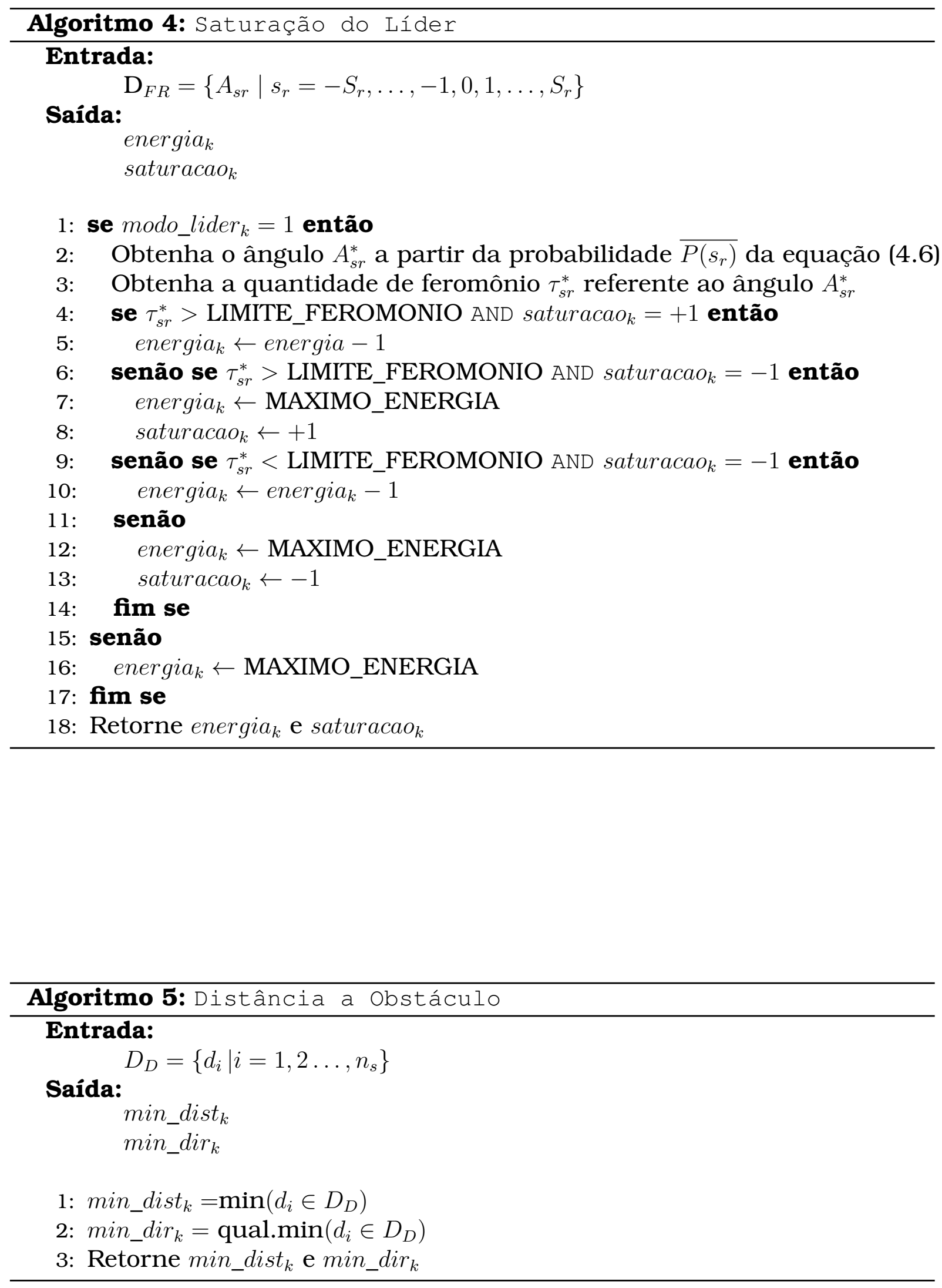
MITE_TOLERANCIA e LIMITE_PROXIMIDADE, respectivamente), tem o objetivo de atualizar o estado do robô e, como consequência disto, predizer quais módulos do sistema cibernético são operados e de que maneira executá-los. Este procedimento se repete toda vez que os módulos do Núcleo Decisório recebem estímulos capturados pelos sensores. O Algoritmo 6 exibe as condições que compõem a Base de Regras.

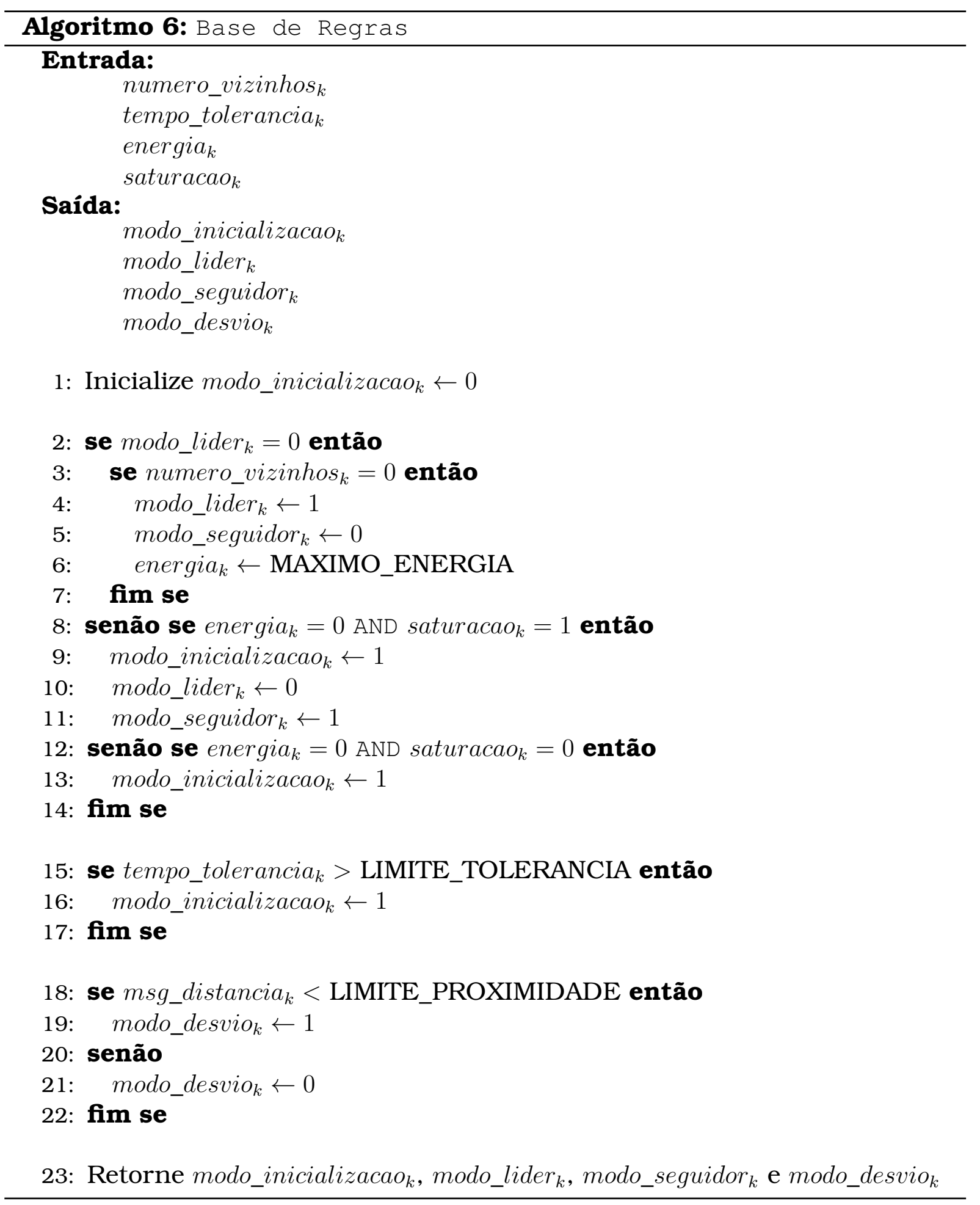

A primeira delas diz respeito ao número de vizinhos detectados na área de comunicação do $k$-ésimo robô $\left(n_{v}^{k}\right)$. Situações em que o robô $k$ não possui 
vizinhos (linha 3), este torna-se imediatamente um líder (linhas 4 e 5) e seu nível de energia é máximo (linha 6). Este caso implica que o robô $k$ está distante do grupo e conclui-se, então, que não há meio de interagir diretamente com qualquer robô. Portanto, o robô $k$ passa a ser líder do grupo que contém somente ele próprio como membro. Obviamente, a possibilidade da condição de um robô ser alterada para líder é real somente se este for um seguidor (modo_seguidor $\left._{k}=1\right)$. Caso contrário, a quantidade nula de vizinhos detectada não influencia na mudança de condição de líder para seguidor. Da mesma forma, sendo que o robô $k$ possua pelo menos um vizinho, sua condição não é alterada.

A partir do momento que o robô $k$ é líder (modo_lider ${ }_{k}=1$ ), a única maneira de deixar este posto é por meio da saturação positiva. Ao atingir o nível mínimo de energia, se o histórico do líder corresponde à detecção de muita quantidade de feromônio (linha 8), este torna-se um seguidor (linhas 10 e 11). No caso do histórico apresentar somente quantidades muito baixas de feromônio, este robô permanece líder (linha 12). Em ambos os casos, a busca por um novo líder é requisitada (modo_inicializacao $k=1$ ) tanto para substituir o líder atual (saturação positiva) quanto para adicionar um novo líder ao grupo (saturação negativa) (linhas 9 e 13).

Outra regra que implica diretamente na ativação ou desativação da busca de um novo líder está relacionada ao período de tempo pelo qual o robô $k$ aguarda por uma mensagem do nível de algum vizinho. No instante em que o limite máximo de tolerância é atingido (linha 15), a tarefa de busca de um novo líder é invocada (linha 16). Em outras palavras, o fato de um robô não ter conhecimento do nível de seus vizinhos por um longo período sugere que seu grupo não possui um líder. Portanto, um novo líder deve ser definido para continuar o movimento do grupo.

Por fim, a distância mínima entre um robô e um obstáculo é constantemente monitorada a fim de evitar colisões. Desde que a tarefa de exploração e formação exibam, naturalmente, comportamento de desvio de obstáculos, esta regra é necessária para tratar eventuais exceções já mencionadas. Assim, para casos em que a distância mínima observada for inferior à distância mínima permitida para o robô se aproximar de um obstáculo sem a necessidade de evitá-lo (linha 18), a tarefa de desvio deve ser executada (linha 19). Em situação contrária, a presença do obstáculo é ignorada (linha 21).

\subsubsection{Módulo de Hierarquia}

A comunicação entre dois robôs por meio da antena deve ocorrer somente se estes estiverem conectados. Havendo tal conexão, considera-se que estes robôs interagem entre si. Neste sentido, a definição da topologia e a associação 
de um nível aos robôs são extremamente importantes para a manutenção da formação. Um dos fatores que auxilia na coesão do grupo é a atração que os vizinhos aplicam sobre um robô. Porém, nem todos os vizinhos são capazes de atraí-lo, mas somente aqueles conectados ao robô. Mesmo assim, não é garantido que tais vizinhos conectados estejam aptos para tal função. É por meio da topologia (conexões) que os níveis de hierarquia são propagados do líder até os robôs mais distantes (topologicamente). Um robô envia a informação de seu nível a outro somente se ambos estiverem conectados. Dado que todos os robôs estejam associados a um nível, um robô $k$ é atraído pelos seus vizinhos conectados e que estejam em nível inferior. Como já mencionado, isto justifica-se pela tendência dos robôs com valores baixos para o nível hierárquico estarem mais próximos do líder.

A topologia, portanto, estabelece um relacionamento entre os robôs baseado em sua posição relativa. O modelo adotado está fundamentado na Triangulação de Delaunay (ver Seção 5.2). Para o problema de formação considerado aqui, os elementos em $P$ estão associados aos robôs. Considerando o robô $k$, o método de Triangulação de Delaunay é aplicado nos vizinhos do conjunto $N^{k}$ (definido no Módulo de Detecção de Vizinhos), resultando no grafo $G_{k}\left(N^{k}\right)$. Dependendo do posicionamento dos vizinhos, há a possibilidade de alguns não estarem conectados com o robô $k$. Ou seja, embora um robô esteja na área de comunicação do robô $k$, ambos podem não interagir diretamente.

Os vizinhos diretamente conectados ao robô $k$ são denominados por vizinhos adjacentes e denotados pelo conjunto $N_{A D J}^{k}=$ $\left\{\left(m s g_{\_} i d_{i}, m s g_{-} q_{i}\right) \mid\left(m s g_{-} i d_{i}, m s g_{-} q_{i}\right) \in E_{G_{k}}\left(N^{k}\right)\right\}$. A Figura 5.6 ilustra um exemplo em que o robô $3\left(R_{3}\right)$ detecta sete vizinhos em sua área de comunicação, portanto, $N^{3}=\left\{R_{1}, R_{2}, R_{4}, R_{5}, R_{6}, R_{7}, R_{8}\right\}$. Considerando somente os vizinhos conectados ao robô 3 , têm-se $N_{A D J}^{3}=\left\{R_{1}, R_{2}, R_{4}, R_{7}\right\}$. São estes robôs que influenciam no deslocamento do robô 3 .

Tendo conhecimento dos vizinhos adjacentes, o robô $k$ torna-se capaz de atualizar o seu nível na hierarquia do grupo de maneira correta. Ao receber a mensagem de nivel $\left(m s g_{-} i d_{i}, m s g \_n i v e l_{i}\right)$ de algum vizinho (inclusive os vizinhos não adjacentes), a conectividade deste com o robô $k$ é verificada. Se não for um vizinho adjacente, a mensagem é ignorada. Caso contrário, o nível do robô $k$ é ajustado, incrementando em 1 unidade o valor do nível recebido. Desde que haja a possibilidade do robô possuir mais de um vizinho adjacente, dentre as mensagens de nível recebidas, ele seleciona aquela de menor valor e incrementa seu nível em 1 unidade em relação ao valor selecionado. O motivo para tal seleção está na necessidade dos robôs estarem mais próximos possiveis do líder (esta proximidade refere-se à quantidade de conexões até o líder). $\mathrm{O}$ Algoritmo 7 mostra os passos do processo descrito tanto para a definição da 


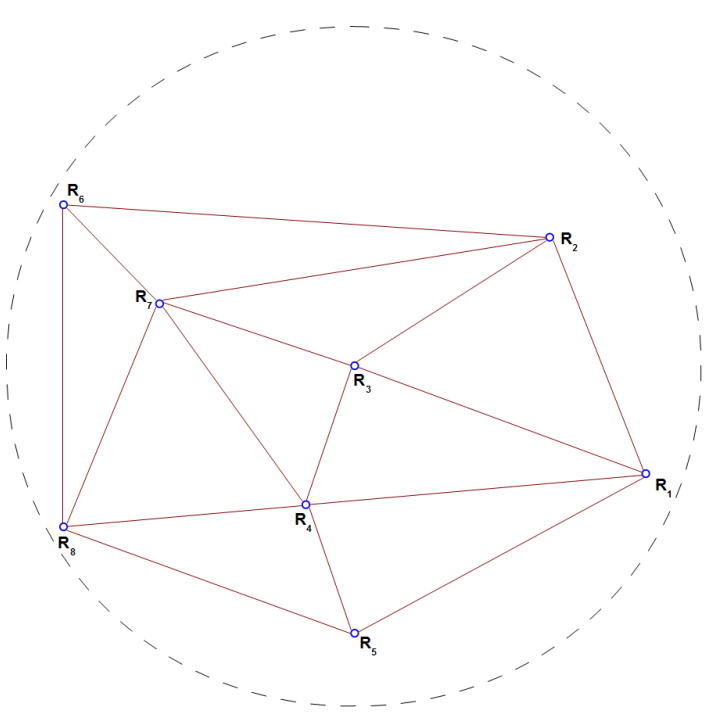

(a)

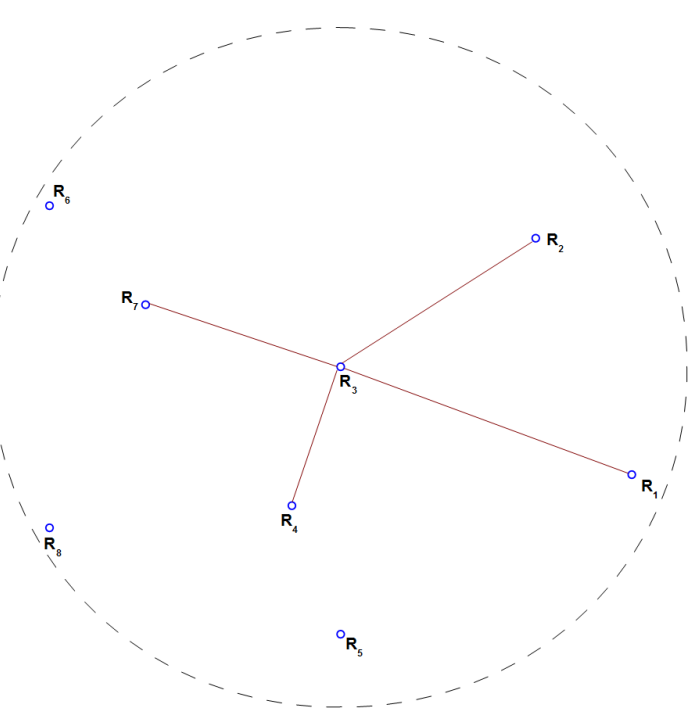

(b)

Figura 5.6: Topologia da vizinhança de um robô definida pela Triangulação de Delaunay: (a) vizinhos detectados pelo raio de comunicação $R_{C}$; (b) vizinhos adjacentes.

topologia e a atuaização do nível do robô $k$ (nivel $l_{k}$ ), em que min calcula o valor mínimo de um conjunto que é atribuído à variável temporária min_nivel $l_{k}$.

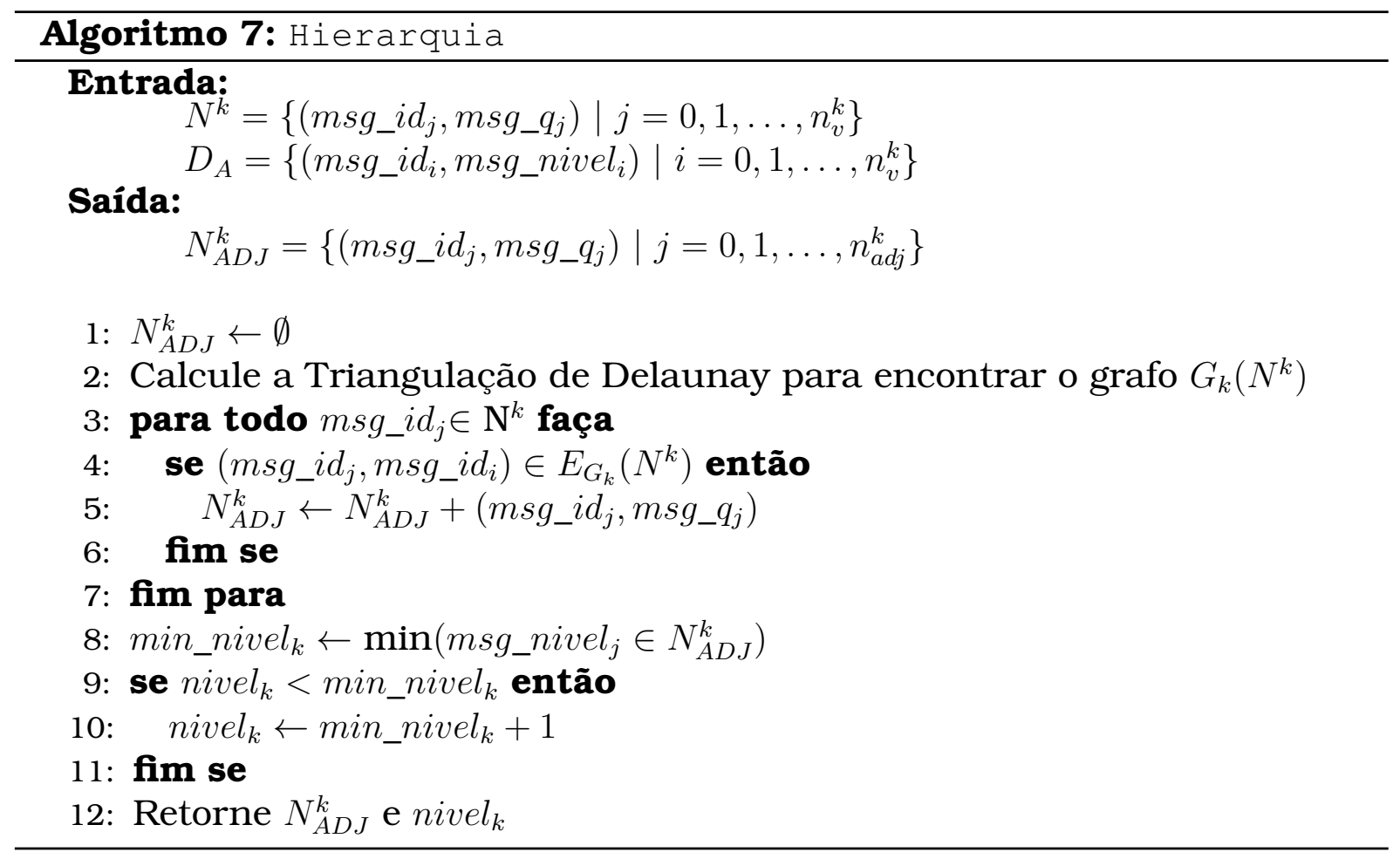

\subsubsection{Módulo de Inicialização}

Este módulo serve de suporte para a definição de líder do grupo realizada pelo Núcleo Decisório. Em termos gerais, ele é ativado nos instantes em que o grupo requisita um líder. Estes instantes se resumem em três casos: 1) não 
há líder no grupo; 2) o líder saturou positivamente e; 3) o líder saturou negativamente. O primeiro caso ocorre, basicamente, quando os robôs são lançados no ambiente e não há um líder para guiar o grupo. No segundo caso, a saturação positiva sugere que outro robô assuma a liderança do grupo. Esta troca favorece a tarefa de exploração, possibilitando a mudança de direção do grupo a fim de reduzir a frequência de visitação de regiões recentemente exploradas. Para o terceiro caso, um novo líder deve ser definido para auxiliar o atual na exploração de amplas áreas desconhecidas ou recentemente não exploradas. A adição de líder passa a falsa ideia de que o grupo possui dois líderes. Na verdade, há dois grupos formados pelos mesmos membros, cada qual estruturado por uma topologia e guiado por um líder. Com a presença de dois líderes, a concentração de feromônio atrativo é disposta em direções distintas e, como não há meio de associar a cada líder o feromônio depositado, ambas as direções são atrativas para os seguidores. A nova direção do seguidor é definida de maneira a se aproximar daquela com maior quantidade de feromônio atrativo. Em relação ao comportamento de atração que os vizinhos adjacentes geram, ora o seguidor tende a se deslocar na direção da trajetória de um líder, ora na direção da trajetória do outro. Assim, por exemplo, considere os robôs seguidores $i, k$ e $j$ em duas topologias. Na primeira, o nível dos seguidores é definido como $l-1, l$ e $l+1$, respectivamente, sendo o robô $k$ atraído pelo seu vizinho $i$, pois o nível deste é inferior. Na segunda topologia, os níveis são definidos como $l+1, l$ e $l-1$, respectivamente. Agora, a atração aplicada sobre o robô $k$ é influenciada pela posição do robô $j$. Dependendo da intensidade da atração exercida por $i$ e $j$, o robô $k$ opta por seguir um deles, afastando-se do outro. Desta forma, grupos disjuntos tendem a ser formados.

A necessidade de definir um líder, para qualquer uma das situações descritas, é detectada pelo Núcleo Decisório quando um robô permanece por um longo período sem receber a informação do nível de seus vizinhos. Ao atingir este período (LIMITE_TOLERANCIA), o robô interrompe o envio da mensagem referente ao seu nível (par ordenado ( $\left.m s g_{-} i d_{k}, m s g \_n i v e l_{k}\right)$ ) e passa a enviar, aos seus vizinhos adjacentes, a informação sobre a quantidade de feromônio repulsivo detectada no momento atual (par ordenado ( $m s g_{-} i d_{k}, m s g_{-}$feromonio f $)$). É importante lembrar que o líder detecta somente feromônio repulsivo e se movimenta para regiões com baixa quantidade dessa substância. Portanto, um novo líder é aquele robô, dentre os demais do grupo, que percebe menor quantidade de feromônio. Assim, aumenta-se a possibilidade de explorar áreas promissoras.

Durante o processo de definição de um líder, este módulo é invocado sucessivas vezes. Na primeira, o robô $k$ compara sua quantidade de feromônio ( feromonio $_{k}$ ) com a informação recebida (par ordenado 
$\left.\left(m s g_{-} i d_{i}, m s g_{-} f e r o m o n i o_{i}\right)\right)$ neste instante, relativa ao vizinho $i$, e armazena no par ordenado (id_feromonio, , qtde_feromonio ${ }_{k}$ ) aquela com menor valor. Esta informação é então enviada por meio da antena. Nas iterações subsequentes, os valores de feromônio nas mensagens recebidas $\left(m s g_{-} i d_{i}, m s g_{-} f e r o m o n i o_{i}\right)$ são confrontadas com aquela armazenada, e o menor valor é mantido pelo robô $k$ e trasmitido aos seus vizinhos. Com a evolução do processo, a informação armazenada tende a estabilizar-se, convergindo para a menor quantidade de feromônio detectada pelos robôs do grupo. Se tal informação permanecer constante por um período definido (TEMPO_SINCRONIA), significa que esta corresponde ao robô com menor leitura de feromônio repulsivo. Mesmo que cada robô execute este processo de forma independente, espera-se que todos encontrem a mesma resposta. Neste caso, diz-se que a definição do novo líder deu-se por consenso. O Algoritmo 8 descreve este procedimento a partir da segunda iteração.

Uma vez que o líder é escolhido, qualquer robô $k$ deve definir seu modo de operação (líder ou seguidor), alterando seus estados modo_lider $_{k}$ e modo_seguidor $_{k}$. Assim, se um robô $k$ qualquer for o líder, então modo_lider $_{k}=1$ e modo_seguidor $_{k}=0$, caso contrário, têm-se modo_seguidor $_{k}=1$ e modo_lider $_{k}=$ 0 .

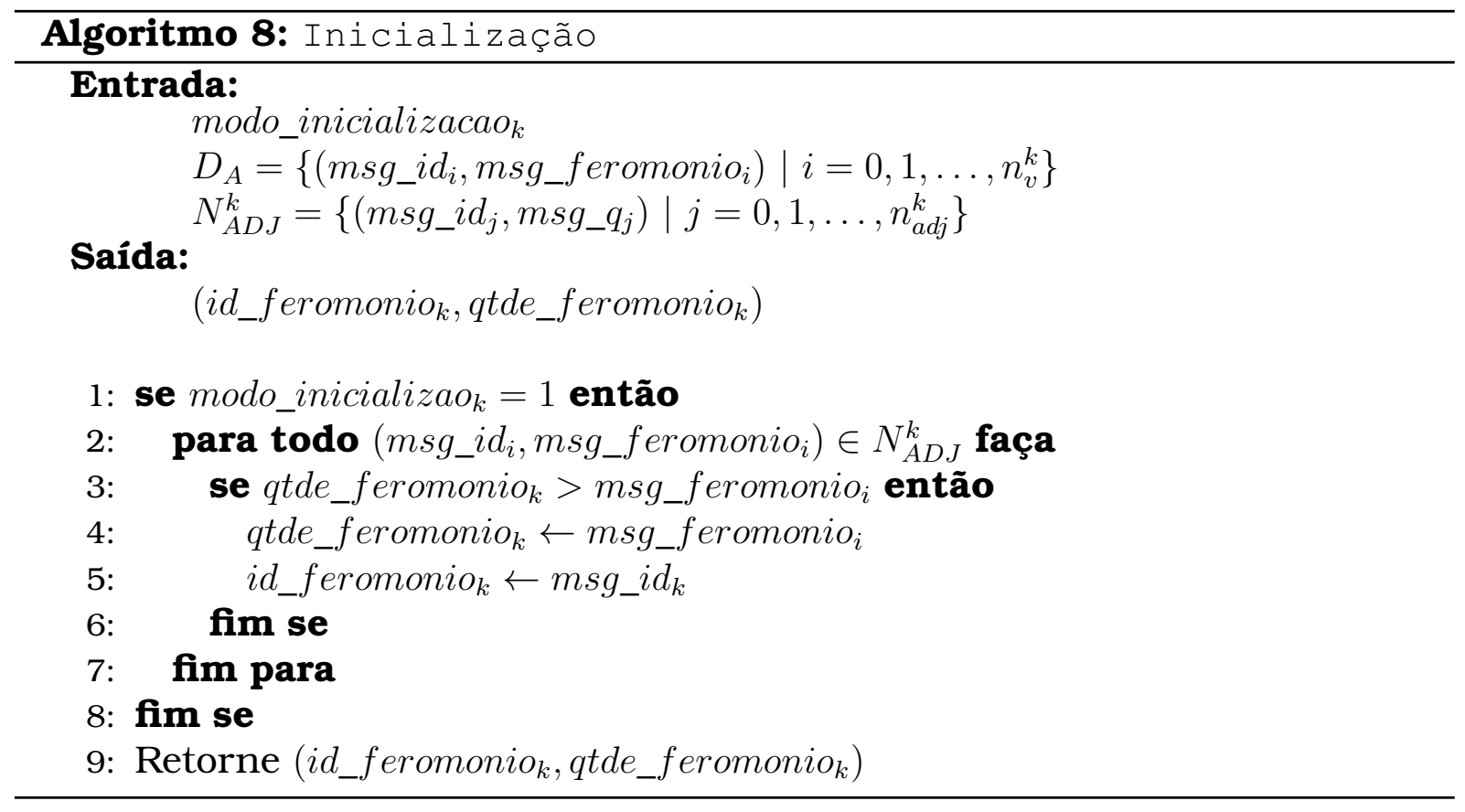

\subsubsection{Módulo Líder}

Uma vez que o Módulo de Inicialização associou a condição de líder a um robô, este passa a desempenhar três funções básicas: 1) atrair o grupo; 2) definir nível de hierarquia e; 3) promover o deslocamento do grupo. A primeira 
tarefa é realizada por meio de feromônio atrativo. Ao coordenar (junto com o Módulo de Feromônio) o depósito de tal substância no ambiente, o líder deixa um rastro de feromônio que fornece aos demais agentes do grupo indicativo da trajetória a ser seguida. Como efeito deste comportamento, observa-se que os seguidores tendem a manter uma proximidade entre si e com o líder. Desde que os seguidores detectem somente feromônio atrativos, estes se orientam em regiões com alta quantidade de feromônio. Ao detectar o rastro deixado, torna-se inevitável (desconsiderando outros comportamentos) a aproximação dos seguidores ao líder, mesmo em situações de quantidade reduzida de feromônio devido ao fenômeno de evaporação.

A segunda tarefa está relacionada à topologia do grupo. Cabe ao líder iniciar o processo de definição de nivel dos seguidores. Estando por definição no nível zero, ele coordena o envio (junto com o Módulo de hierarquia) de tal informação para seus vizinhos adjacentes, de forma contínua. Estes, por sua vez, atualizam seu nível através da informação recebida e o transmitem a seus vizinhos. O processo em cascata é finalizado quando os robôs localizados no último nível recebem a informação de seus vizinhos. Nota-se, portanto, que o líder é o responsável por estabelecer a hierarquia do grupo. Tal habilidade é fundamental para manter a coesão da formação, uma vez que um seguidor deve se locomover na direção dos vizinhos que estão em um nível hierárquico inferior.

Por fim, o objetivo da terceira tarefa é somente guiar o grupo. Sem qualquer intenção de manter a formação, nesta atividade, o líder tem o papel de visitar regiões desconhecidas ou recentemente não visitadas. O deslocamento do líder é gerado pela estratégia de exploração descrita no Capítulo 4. Com a capacidade de detectar feromônio repulsivo, o líder é atraído por regiões com pouca (ou nenhuma) quantidade dessa substância. Esta tarefa é atribuída ao líder com a intenção de mostrar a robustez e a estabilidade da formação enquanto o grupo se desloca pelo ambiente. Do exposto, percebe-se que as tarefas do líder são complementares para prover o deslocamento do grupo. Utilizando o mecanismo de ajuste de direção BRSS, os passos que descrevem a tarefa de exploração do líder são mostrados no Algoritmo 1.

\subsubsection{Módulo Seguidor}

Ativado somente quando um robô $k$ é seguidor ( modo_seguidor $_{k}=1$ ), este módulo é a peça chave para a formação do grupo. Como discutido na Seção 5.3.5, uma das tarefas do líder é explorar o ambiente, deixando o rastro de feromônio atrativo para prover o deslocamento do grupo em regiões favoráveis à exploração. Em relação à formação dos robôs, a única colaboração do líder é fornecer ao grupo condições para que os seguidores definam seu nivel de hi- 
erarquia. Como uma das deficiências da estratégia líder-seguidor, o líder não recebe retorno a respeito da posição e orientação dos seguidores. Portanto, os responsáveis pela manutenção da formação são os próprios seguidores. De uma forma descentralizada, cada seguidor, por meio de informações locais, são capazes de ajustar sua direção de movimento. Baseado na abordagem comportamental, os seguidores se apoiam em 3 comportamentos para manter a coesão do grupo: seguir o rastro do líder, seguir os vizinhos e distanciar-se deles. Dependendo da situação encontrada pelo seguidor, a ponderação dos comportamentos indica aquele com maior relevância para o momento atual. Cada comportamento gera uma força que é aplicada sobre o seguidor $k$, posicionado em $q_{k}=\left(x_{k}, y_{k}\right)$, e representada na forma vetorial $F_{\Lambda}=q_{\Lambda}$, em que $q_{\Lambda}=\left(x_{\Lambda}, y_{\Lambda}\right)$ e $\Lambda$ é uma generalização dos índices tanto para as forças isoladas quanto para a força resultante. De maneira análoga, $F^{k}$ representa a direção do robô $k$. Pelo fato dos robôs se movimentarem em velocidade constante, o módulo das forças (também referenciado no texto como intensidade) é considerado para ajustar a orientação do seguidor.

A composição da força resultante, gerada pela combinação das forças oriundas dos comportamentos, é responsável por manter a coesão da formação e alcançar algumas das características mencionadas na Seção 5.3, como será discutido ao final desta seção.

\section{Comportamento de Atração do Líder}

Um dos comportamentos que resulta em uma maior proximidade entre os robôs advém da força de atração do líder ( $F_{L}^{k}$, quando o robô é considerado). Com a capacidade de detectar feromônio atrativo, os seguidores são atraídos para regiões com maior concentração da substância. Para encontrar esta região, a extensão do sensor de feromônio atrativo é dividida em intervalos angulares $I n t_{i}, i=1, \ldots, n_{i}, n_{i}>0$ formados por diversos ângulos $B_{s a}$. Cada intervalo é definido de maneira que a quantidade média de feromônio em seus ângulos sejam similares. Contudo a quantidade de feromônio detectada em um intervalo $I n t_{i}$ é obtida pela média de feromônio detectado nos ângulos $B_{s a}$, denotada por:

$$
\overline{\tau_{\text {Int }_{i}}^{a}}=\frac{1}{b_{i}} \sum_{B_{s a} \in \text { Int }_{i}} \overline{\tau_{B s a}^{a}}
$$

em que $\tau_{\text {Int }_{i}}^{a}$ é a quantidade média de feromônio atrativo no intervalo angular $I n t_{i}$ e $b_{i}$ é a quantidade de ângulos $B_{s a}$ no mesmo intervalo.

Definido os intervalos angulares, a direção da força $F_{L}^{k}$ assume um dos ângulos do intervalo Int* que obteve maior quantidade de feromônio modelado como: 


$$
\overline{\tau_{\text {Int }}^{a *}}=\max \left\{\overline{\tau_{\text {Int }}^{a}}\right\}_{i=1, \ldots, n_{i}}
$$

Considerando somente o intervalo angular $I n t^{*}$, a direção da força $F_{L}^{k}$, em relação à direção de movimento do robô, corresponde à média ponderada da concentração detectada nos ângulos $B_{s a}$ pertencentes a este intervalo (equação (5.8)). Diferentemente dos mecanismos de ajuste de direção descritos no Capítulo 4, o ajuste baseado na percepção do feromônio atrativo não apresenta característica aleatória com o intuito de minimizar o risco de um robô seguidor sair do trajeto estabelecido pelo líder.

$$
\alpha_{F L}^{k}=\left\{\begin{array}{l}
0, \text { se } I n t_{i}=\{0\} \\
\frac{\sum_{s a} \in \sum_{\text {Int }} \overline{\tau_{B s a}^{a}} \cdot s a}{s a \in \sum_{\text {Int }} s a}, \text { caso contrário }
\end{array}\right.
$$

em que $\alpha_{F L}^{k}$ é uma aproximação da direção onde a maior concentração de feromônio atrativo foi detectada pelo robô $k$.

A intensidade da força passa a ser, portanto, a maior quantidade média de feromônio $\overline{\tau_{I n t}^{a *}}$ e, juntamente com a direção obtida na equação (5.8), a posição $q_{l}=\left(x_{l}, y_{l}\right)$ que define a força $F_{L}^{k}$ é calculada segundo as seguintes equações:

$$
\begin{aligned}
& x_{l}=\cos \left(\alpha_{F L}^{k}\right) \cdot \overline{\tau_{I n t}^{a *}} \\
& y_{l}=\operatorname{sen}\left(\alpha_{F L}^{k}\right) \cdot \overline{\tau_{I n t}^{a *}}
\end{aligned}
$$

\section{Comportamento de Atração dos Vizinhos}

Outro comportamento responsável por manter os robôs próximos está diretamente relacionado à região de vizinhança. Dentre os vizinhos adjacentes $N_{A D J}^{k}$, um robô $k$ no nível $l$ é atraído somente por aqueles que apresentam nível $l-1$. Como já mencionado, robôs em níveis inferiores tendem a estar mais próximos do líder (mas isto nem sempre ocorre). Portanto, para manter a direção de movimento na mesma direção da trajetória, é óbvio que um robô deve considerar os vizinhos mais adiantados na formação, ou seja, aqueles com valores para o nível inferiores ao seu. Outra razão que justifica a implantação da força de atração dos vizinhos $\left(F_{V}^{k}\right)$ é a necessidade em suprir a falta de detecção do feromônio atrativo (liberado pelo líder). Em casos onde o nível do robô é alto, é razoalmente admissivel que este esteja distante do líder. Portanto, a possibilidade deste robô detectar feromônio atrativo é baixa. O único modo de ainda permanecer no grupo é sob a influência dos vizinhos adjacentes.

A força $F_{V}^{k}$ é resultante das forças individuais que cada vizinho adjacente 
aplica sobre o robô $k$, o qual sofre maior influência dos vizinhos mais próximos. Sendo assim, a força de atração individual, $f_{i}$, de cada vizinho é inversamente proporcional à distância entre o robô $k$ e seu vizinho. Uma vez próximos, a dispersão dos robôs torna-se dificultada, o que favorece a coesão do grupo. Portanto, a intensidade $I_{i}^{k}$ da força de atração do vizinho $i$ é modelada em função da distância $\operatorname{dist}_{k, i}$ até o robô $k$ :

$$
I_{i}^{k}=e^{-\left(\frac{d i s t_{k, i}}{\sigma_{v}}\right)}
$$

onde $\sigma_{v}$ é dispersão.

A partir da intensidade $I_{i}^{k}$, constrói-se a força $f_{i}$ correspondente ao vizinho adjacente $i$, da seguinte forma:

$$
f_{i}=\frac{q_{i}-q_{k}}{\operatorname{dist}_{k, i}} \cdot I_{i}^{k}
$$

Devido à atuação conjunta de vários vizinhos, a força $F_{V}^{k}$ é definida na equação a seguir:

$$
\begin{gathered}
F_{V}^{k}=\sum_{\left(m s g_{-} i d_{i}, m s g_{-} q_{i}\right)} \in N_{A D J}^{k} f_{i}^{*} \\
f_{i}^{*}=\left\{\begin{array}{l}
f_{i}, \text { se } \text { nivel }_{i}=l-1 \\
0, \text { caso contrário }
\end{array}\right.
\end{gathered}
$$

\section{Comportamento de Atração do Centroide}

Até o momento, nenhum comportamento trata a tarefa de colisão. Com a aplicação de ambas as forças, há a possibilidade da aglomeração dos robôs nas proximidades do líder, tornando inevitável colisões entre os agentes. O único comportamento relacionado à repulsão dos robôs é modelado de acordo com a construção do Diagrama de Voronoi. A motivação se deve pela observação do comportamento dos animais solitários. Estes buscam locais distantes dos demais de sua espécie e demarca seu território a fim de evitar que rivais disputem a mesma presa. Seguindo o princípio de delimitar uma região para cada robô, dado um conjunto de geradores, o mecanismo baseado em Voronoi associa locais do ambiente ao ponto mais próximo. No caso da definição da região de Voronoi do robô $k$, os geradores são sua posição $\left(q_{k}\right)$ e de seus vizinhos adjacentes denotados pelo conjunto $P=\left\{q_{k}\right\} \cup\left\{m s g_{q} q_{i}\right\}$, para todo $\left(m s g_{\_} i d_{i}, m s g_{-} q_{i}\right) \in N_{A D J}^{k}$. Considerando a região planar $Q \subset \mathbb{R}^{2}$ por onde os robôs se deslocam e $M_{t}^{k} \subset Q$ a área de comunicação do $k$-ésimo robô no instante $t$, a região de Voronoi do robô $k$ é definida por: 


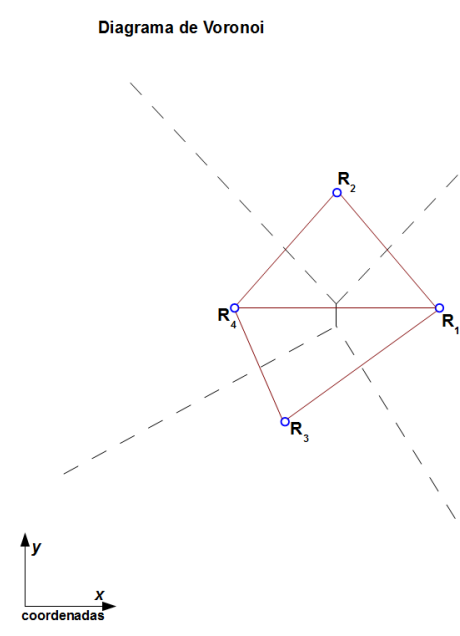

Diagrama de Voronoi

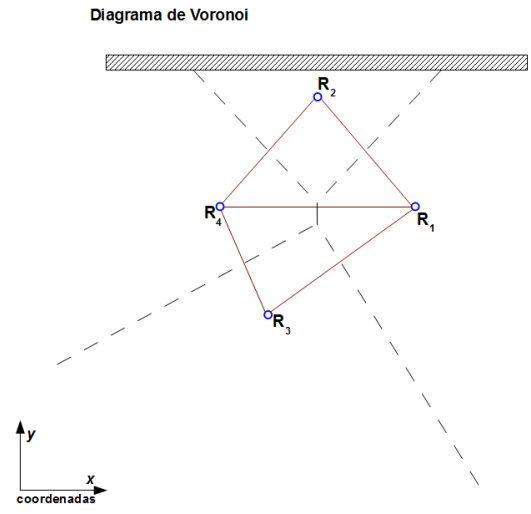

(a)
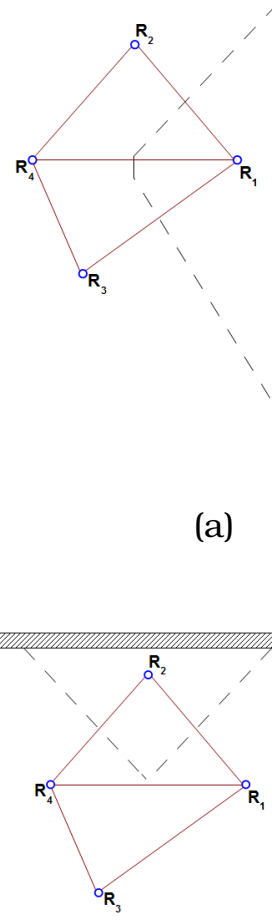

(b)

Figura 5.7: Truncamento da região de Voronoi infinita para um robô que: (a) não detecta obstáculo; (b) que detecta um obstáculo.

$$
V^{k}(P, t)=\left\{q \in L_{t}^{k} \mid\left\|q-q_{k}\right\| \leq\left\|q-m s g_{\_} q_{i}\right\|, \forall\left(m s g \_i d_{i}, m s g_{-} q_{i}\right) \in N_{A D J}^{k}\right\}
$$

em que $V^{k}(P, t)$ é a região de Voronoi do robô $k$ gerada pelo conjunto $P$ no instante $t$. Ou seja, gerada pela posição dos vizinhos adjacentes e dele mesmo.

Ocasionalmente, como resultado da partição Voronoi, a região $V_{k}(P, t)$ pode não ser totalmente fechada, o que é chamada de região infinita. Esta região é limitada com o auxílio de um círculo $O\left(q_{k}, R_{V}\right)$, denominado círculo de Voronoi, em $Q$, com centro em $q_{k}$ e raio $R_{V}<<R_{C}$, de maneira que a nova região de Voronoi limitada seja definida de acordo com (5.15). A Figura 5.7 ilustra duas situações em que a região infinita é truncada. Na primeira, não há obstáculo para influenciar na definição da região de Voronoi limitada. Na segunda, há obstáculo.

$$
V_{R_{V}}^{k}(P, t)=V^{k}(P, t) \cap M_{t}^{k} \cap O\left(q_{k}, R_{V}\right)
$$




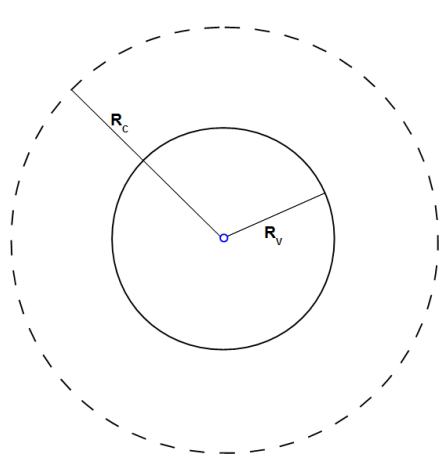

(a)

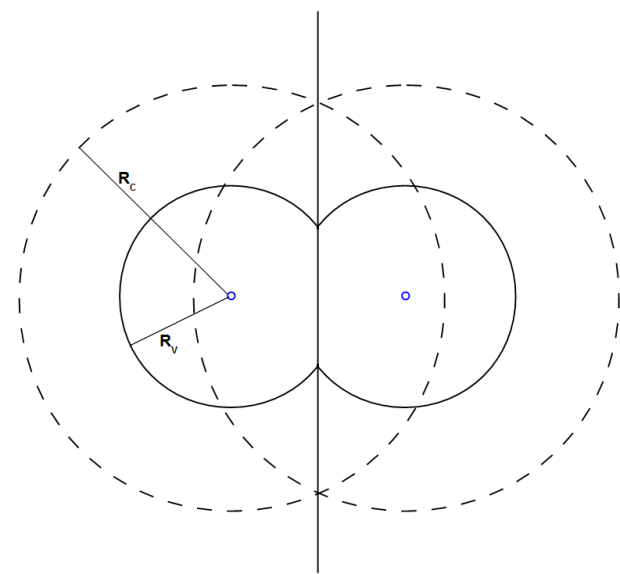

(b)

Figura 5.8: Truncamento da região de Voronoi infinita para um robô: (a) sem vizinho; (b) com um vizinho.

Nos casos que não é possível encontrar a região de Voronoi, duas heurísticas, baseadas na quantidade de vizinhos adjacentes, são citadas para truncar as regiões infinitas:

- Sem vizinho: o robô $k$ encontra-se isolado do grupo e nenhum outro está em sua área de comunicação, assim, sua região de Voronoi é resultado da intersecção entre a área de comunicação e o círculo de Voronoi, definida como $V_{R_{V}}^{k}(P, t)=M_{t}^{k} \cap O\left(q_{k}, R_{V}\right)$ (Figura 5.8(a));

- Com um vizinho $r_{i}$ : com o segmento de reta definido como a conexão entre os dois robôs na (Módulo de Hierarquia), estabelece-se, perpendicularmente, uma aresta $e$ no ponto médio deste segmento resultando em duas regiões infinitas $V^{k}(P, t)$ e $V^{i}(P, t)$. Assim, limita-se as regiões de forma análoga à equação (5.15) em que o robô possui dois ou mais vizinhos adjacentes (Figura 5.8(b)).

Com o objetivo de reduzir o risco de colisões, é desejável que os robôs permaneçam em suas regiões de Voronoi limitadas evitando invadir a região do vizinho. Seguindo este raciocínio, os robôs devem ser atraídos para o interior de suas regiões enquanto seguem o movimento do grupo. Para tanto, calcula-se o centroide $C_{V k}$ (posicionado na posição $q_{c}$ ) da regiao de Voronoi limitada do $k$-ésimo robô. Portanto, a terceira força aplicada sobre os robôs é de atração ao centroide de sua região $\left(F_{C}^{k}\right)$. Ao mesmo tempo, esta força tende a distanciar os robôs uns dos outros. Geralmente, com a força de atração do centroide, aqueles robôs situados na borda (ou fronteira) do grupo tendem a se direcionar para regiões externas a este, se distanciando dos demais. Esta repulsão gera a expansão do grupo uma vez que a ação dos robôs de fronteira ocasiona o aumento da região de Voronoi daqueles robôs posicionados 


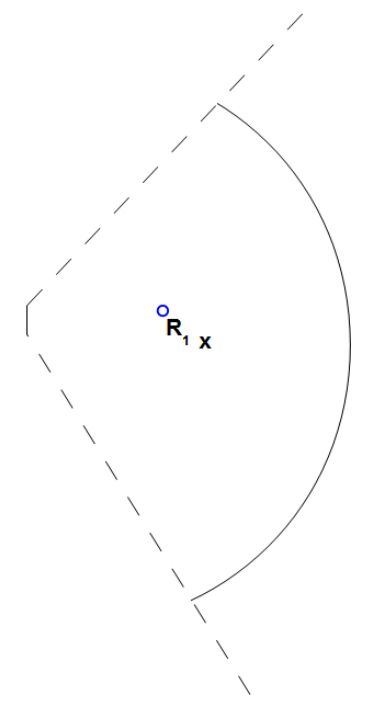

(a)

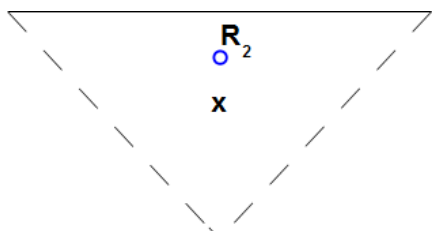

(b)

Figura 5.9: Posicionamento do centroide em uma região de Voronoi limitada: (a) pelo círculo de Voronoi; (b) por um obstáculo.

no centro do grupo ('cercado' por outros robôs). Além de evitar colisões entre os robôs, este mecanismo possui ainda a capacidade de evitar colisões entre os robôs e obstáculos. Outra particularidade observada aqui refere-se a habilidade de conter a dispersão, mesmo quando o robô se distancia do grupo. A Figura 5.9 mostra o posicionamento do centróide quando a região é limitada pelo círculo de Voronoi e pela presença de um obstáculo. Como consequência desse comportamento, a área de cobertura do grupo é maximizada, reduzindo, portanto, a sobreposição de sensores dos robôs.

À medida que o robô se aproxima de seu centróide, a intensidade de $F_{C}^{k}$ é enfraquecida. O caso ótimo ocorre quando a posição do robô coincide com a do centroide. Nesta situação, a intensidade é nula. Logo, o principal propósito desse comportamento é alcançado. Com o robô em seu centróide, não há a possibilidade de colisão. Por outro lado, quanto maior a distância entre o centroide e o robô maior é intensidade da força. Longas distâncias implicam que o robô está próximo a seus vizinhos ou a um obstáculo. Portanto, a força deve ser intensificada, a fim de evitar situações de risco de colisão. Conclui-se, então, que a intensidade $I_{c}^{k}$ da força $F_{C}^{k}$ é diretamente proporcional à distância dist $_{k, c}$ entre o robô $k$ e seu centróide $C_{V k}$, definida por:

$$
I_{c}^{k}=e^{\frac{-\left(1-d i s t_{k, c}\right)}{\sigma_{c}}}
$$

De forma análoga à força de atração dos vizinhos, a força $F_{C}^{k}$ é obtida como:

$$
F_{C}^{k}=\frac{q_{c}-q_{k}}{\text { dist }_{k, c}} \cdot I_{c}^{k}
$$




\section{Composição de Forças}

Visando manter a coesão da formação, as três forças supracitadas são utilizadas para determinar a orientação do movimento do robô seguidor $k$. Enquanto as forças de atração $F_{L}^{k}$ e $F_{V}^{k}$ estimulam o deslocamento de maneira a reduzir a proximidade entre os robôs, a força $F_{C}^{k}$ tem o objetivo de dispersá-los, mantendo uma distância significativa entre os mesmos. Assim, percebe-se a importância da atuação conjunta das três forças. Em termos práticos, a composição das mesmas dá origem à força resultante $F_{R}^{k}=\left(x_{r}, y_{r}\right)$ aplicada sobre o robô $k$ de acordo com a equação:

$$
F_{R}^{k}=F_{L}^{k}+F_{V}^{k}+F_{C}^{k}
$$

Ao combinar as três forças, busca-se o equilíbrio entre a dispersão e atração entre os robôs. O primeiro caso é realizado pela força de atração ao centróide. Ao construir sua região de Voronoi, os robôs são atraídos pelo centróide da mesma. Sabendo que o centróide indica uma posição segura contra colisões, a força de atração $F_{C}^{k}$ causa o afastamento dos robôs. Ou seja, com a aproximação dos robôs, é possível que estes estejam posicionados próximos a uma das arestas de suas regiões. O deslocamento deles em direção ao centróide minimiza o risco de colisão. A dispersão máxima ocorre no instante em que o robô atinge seu centróide, garantindo uma distância segura entre os robôs. O segundo caso é tratado pelas forças $F_{L}^{k}$ e $F_{V}^{k}$. A força $F_{L}^{k}$ permite o robô seguir o rastro de feromônio deixado pelo líder. Como os demais robôs do grupo também desempenham o mesmo comportamento, o risco de colisão se eleva. De uma maneira indireta, a força $F_{V}^{k}$ também orienta o robô na direção do líder, pois os vizinhos responsáveis por gerar tal força são atraídos pelo feromônio e também por outros vizinhos, com nível hierárquico inferior, que se encontram na mesma situação. Assim, ambas as forças promovem o comportamento de atração entre os robôs de maneira que a aplicação de uma força repulsiva faz-se necessária para evitar colisões enquanto o grupo se desloca mantendo a coesão da formação.

Empregando a força $F_{R}^{k}$ descrita na equação (5.18), a nova direção $F_{k}^{\prime}=$ $\left(x_{k}, y_{k}\right)$, associada ao robô $k$, é dada segundo a equação:

$$
F^{k \prime}=F^{k}+F_{R}^{k}
$$

O processo de composição das forças é descrito no Algoritmo 9, dado como entrada a percepção de feromônio atrativo, $D_{F A}$ do robô $k$, o conjunto de seus vizinhos adjacentes, $N_{A D J}^{k}$, e a informação de nível dos vizinhos proveniente da antena, $D_{A}=D_{A 1}$.

As características livre de colisão, adaptação, topologia dinâmica e esta- 


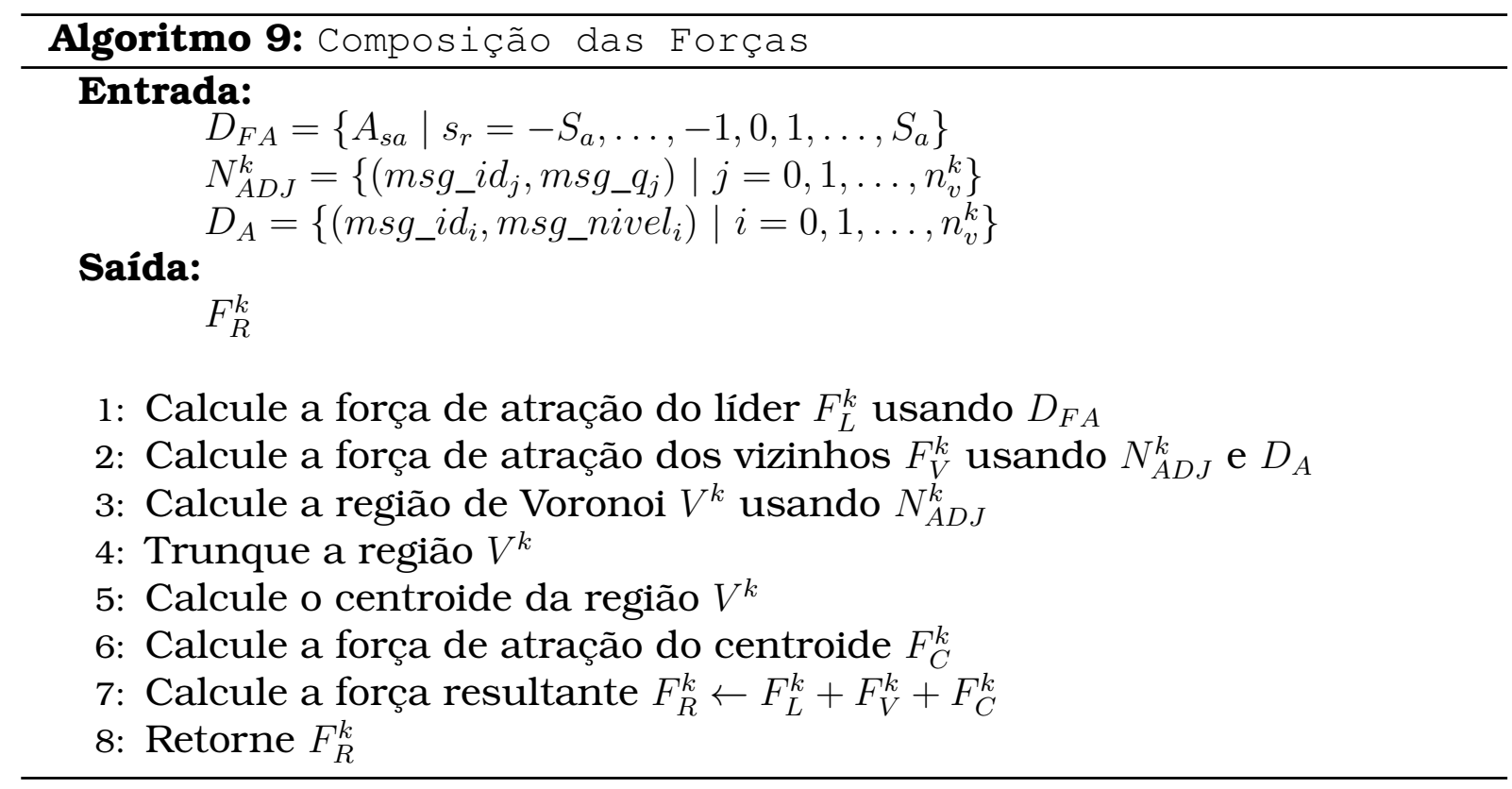

bilidade (ver Seção 5.3), desejáveis para a estratégia de formação SAFS, são alcançadas por meio da combinação das forças de atração que dão origem à força resultante. A estratégia é livre de colisão, pois ao se aproximar de um obstáculo ou de um membro do grupo, um robô é atraído para o centroide de sua região de Voronoi com intensidade maior que as forças de atração do líder e dos vizinhos. Neste caso, o robô se encontra em uma das bordas da região de Voronoi, e portanto, em um dos locais mais distantes do centroide da região. Assim, a instensidade da força de atração do centroide é elevada, o que direciona o robô a esta posição, reduzindo o risco de colisão. As características de adaptação e topologia dinâmica são decorrentes das forças de atração. À medida que os robôs se deslocam em direção ao líder e ao mesmo tempo evitam colisões, os robôs não obedecem a uma formação geométrica fixa. A maneira pela qual a ponderação dos comportamentos de atração atuam nos robôs, permite a flexibilidade da formação. Assim, o grupo torna-se capaz de navegar em qualquer configuração de ambientes. A habilidade do grupo em evitar obstáculos e perseguir a trajetória do líder (e dos vizinhos) possibilita a adaptação da formação ao formato do ambiente em que atua e, consequentemente, a topologia da formação é alterada. Para manter a estabilidade da formação, é necessário que nenhum robô se desconecte do grupo. Esta característica é alcançada graças a relação entre o raio de comunicação e o de Voronoi, definida como $R_{C}>>R_{V}$. A única força de dispersão dos robôs do grupo corresponde à força de atração do centroide. A intensidade dessa força é nula (ou próxima de nula) quando um robô está extamente na posição (ou próximo) do centroide de sua região de Voronoi. Assim, as forças de atração do líder e dos vizinhos se sobressaem, aproximando o robô aos demais do grupo. A aproximação dos robôs ocorre até que a distância entre 
cada um deles e seus respectivos centroides seja elevada para que a força de atração do centroide passe a ter, novamente, intensidade suficiente para dispersá-los. A intensidade de tal força é enfraquecida à medida que os robôs se aproximam dos centroides. Neste instante, as forças de atração do líder e dos vizinhos atuam, novamente, com mais ênfase. A aproximação dos robôs e a dispersão dos mesmos tendem a ocorrer alternadamente sem que qualquer robô se desconecte do grupo. Isto é possivel porque, mesmo que o grupo atinja a dispersão máxima, ou seja, todos os robôs estão em seus centroides, o grupo ainda permanece conectado devido a relação entre os raios de comunicação e de Voronoi.

\subsubsection{Módulo de Desvio}

Este módulo é requisitado em eventuais exceções quando um robô está extremamente próximo a um obstáculo ou a outro robô (modo_desvio $=1$ ). Conforme discutido no Módulo de Distância a Obstáculos, a estratégia de formação proposta logra estabelecer trajetórias livres de colisão. Entretanto, ajustes de direção podem ser requeridos devido às características físicas dos robôs. Neste sentido utilizou-se aqui um mecanismo baseado em lógica nebulosa (Zadeh, 1965) para a tarefa de desvio de obstáculo. Com base nas informações provenientes do Núcleo Decisório (i.e. distância e direção do obstáculo mais próximo), tal mecanismo redireciona os robôs com intensidade variável de acordo com a proximidade ao obstáculo. Pelo fato do foco desta tese se concentrar na manutenção da formação de robôs, os detalhes desta abordagem não são mencionados. O leitor interessado pode encontrá-la em (Calvo, 2007). Para fins de compreensão do diagrama arquitetural do sistema cibernético (Figura 5.3), o sinal gerado pelo Módulo de Desvio é direcionado para o atuador que ajusta a direção do robô.

\subsubsection{Módulo de Feromônio}

Independente do sistema cibernético operar o robô no modo líder ou seguidor, este módulo é requerido para o depósito de feromônio. No caso do seguidor, feromônio repulsivo é depositado no ambiente para marcar regiões visitadas, o que auxilia na tarefa de exploração executada pelo líder. Este, por sua vez, libera tanto o feromônio repulsivo, para fins de exploração, quanto atrativo, para atrair o grupo e prover o deslocamento do mesmo. Para o feromônio repulsivo, a área de liberação corresponde àquela apresentada no Capítulo 4. De forma distinta, o feromônio atrativo é depositado na área representada pela circunferência de raio $R_{D}$ (raio de detecção de feromônio, ver Seção 5.3.1). Nestas áreas, a liberação de ambos os tipos de feromônio segue o 
mesmo comportamento exibido pela estratégia IAS-SS, com dispersões $\lambda_{r}$ e $\lambda_{a}$, respectivamente, assim como o fenômeno de evaporação. Este módulo opera segundo o procedimento descrito no Algoritmo 10.

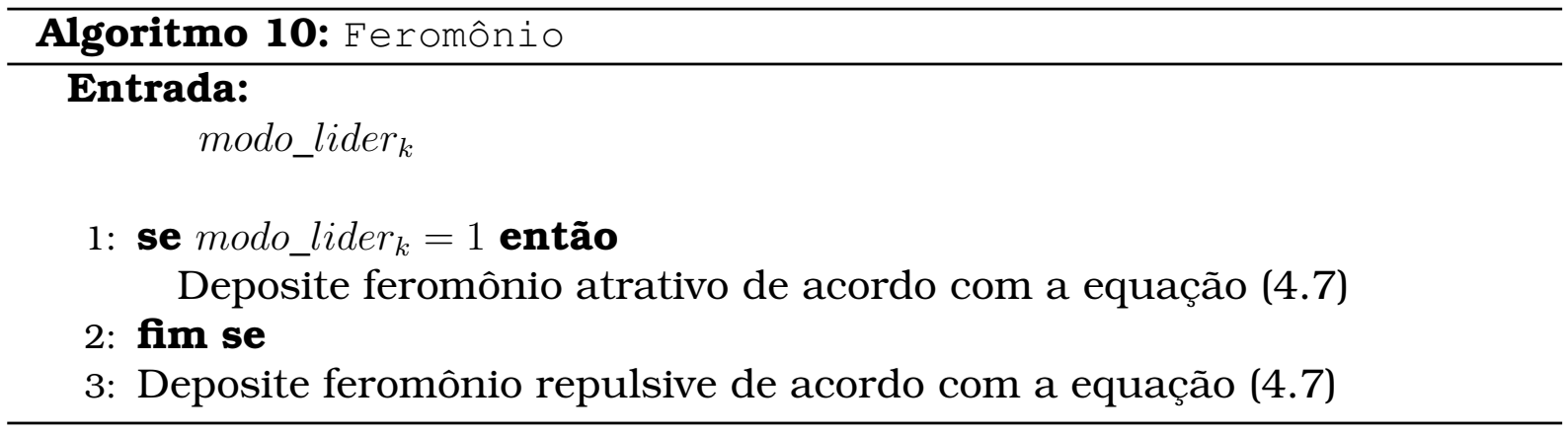

\subsection{Resultados experimentais}

Esta seção relata experimentos com o intuito de investigar o sistema de formação auto-adaptativo (SAFS) e também analisar o desempenho em relação aos resultados esperados. A expectativa é que o sistema promova a um conjunto de robôs em formação, a capacidade em satisfazer os critérios definidos por Reynolds (1987): separação, alinhamento e coesão. Para estabelecer a formação, é necessário que os robôs permaneçam próximos, porém, colisões devem ser evitadas. Além disso, à medida que os robôs se locomovem, estes devem seguir a mesma trajetória, ou seja, todos devem estar orientados na mesma (ou similar) orientação. Além de cumprir os critérios estabelecidos, o sistema como um todo visa atingir as características definidas na Seção 5.1 a fim de contrapor as abordagens propostas na literatura e apresentar um sistema simples, porém, robusto para a concepção da formação.

Assim como a tarefa de vigilância e exploração, a estratégia de formação é validada a partir de experimentos simulados pelas mesmas razões apresentadas no capítulo anterior. Para tanto, a plataforma Player/Stage também é utilizada juntamente com os modelos do robô e sensor de distância a obstáculos: Pioneer 2DX e o sensor laser SICK LMS 200 adotados, respectivamente. Nota-se que somente um tipo de sensor é simulado pela plataforma. Os sensores de feromônio são simulados pelo autor desta tese e não pela plataforma. Com a mesma região de abrangência do sensor de distância (região frontal com extensão de $180^{\circ}$ ), o sensor de feromônio repulsivo é modelado. Ampliando a área de abrangência para uma extensão de $360^{\circ}$, modela-se o sensor de feromônio atrativo e a região de comunicação da antena. Os sinais gerados pelo sensor de distância são utilizados tanto para detectar objetos próximos ao robô quanto para construir o mapa explorado. Embora a segunda tarefa não seja enfatizada no trabalho pelo fato de que este tema se distancia do propósi- 
tos da pesquisa, o mapa gerado é empregado para simular a quantidade de feromônio. Utilizando a abordagem de grades de ocupação (Elfes, 1989), o valor que representa a concentração da substância é inserido nas células da grade que correspondem as regiões nas quais os robôs visitaram.

A estratégia de formação é resultado da agregação das abordagens líderseguidor, de consenso e comportamental. Enquanto as duas primeiras são responsáveis pelo deslocamento do grupo e pelo mecanismo de definição do líder, respectivamente, a única abordagem que trata da formação em si é a comportamental. Por este motivo, o foco dos experimentos está nesta abordagem que envolve as forças de atração do líder, dos vizinhos e do centróide da região de Voronoi. Dentre estas forças, o primeiro grupo de experimentos se concentra na análise da aplicação da força de atração do centróide de maneira isolada. Nos demais experimentos, o desempenho é avaliado quando estas forças são combinadas e, juntamente, com as abordagens líder-seguidor e de consenso, a formação é observada durante a navegação do grupo. O comportamento da formação é observado em diferentes configurações de ambientes, quantidades de robôs e mediante as habilidades de mudança e adição de líder.

A estabilidade da formação é verificada por meio de conjunto de gráficos formados por subgráficos referentes a cada robô. Cada subgráfico exibe o comportamento de um robô durante o processo de formação. Um dos requisitos básicos da formação é a coesão, isto é, os robôs devem se manter próximos enquanto se movimentam na mesma orientação. Portanto, um dos parâmetros que merece atenção na avaliação do desempenho é a distância entre os robôs. Para verificar a constante formação, considera-se a distância entre um robô e seu vizinho mais próximo. Situações em que esta distância não se altera ou sofre pequenas oscilações mostram que a formação é mantida. Outro paramêtro utilizado na análise do desempenho é a intensidade gerada pela força de atração do centroide de sua região de Voronoi. A manutenção da formação ocorre quando os robôs permanecem próximos aos respectivos centróides. Isto significa que a força de repulsão evita a aglomeração dos robôs e ao mesmo tempo indica que estes permanecem em uma posição segura, ou seja, livre de colisão. Os gráficos são marcados por linhas verticais para facilitar a compreensão do funcionamento do sistema e destacar momentos relevantes do processo de formação. Além dos gráficos, a formação é observada visualmente em quadros que exibem o processo. Com o objetivo de identificar o líder, a concentração de feromônio atrativo é ilustrada, o que permite identificar os robôs que sofrem maior influência da força de atração do líder. Neste sentido, a escala de cores da Figura 5.10 será utilizada para indicar locais com maior e menor concentração de feromônio atrativo.

Alguns parâmetros são definidos em seguida para a realização dos experi- 


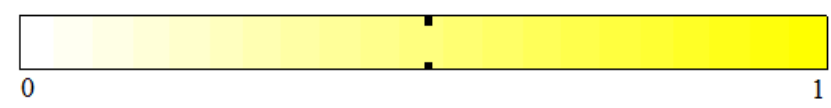

Figura 5.10: Escala de cores para a distribuição da concentração de feromônio atrativo.

mentos. Aqueles que não influenciam no desempenho dos testes são omitidos desta lista. Para facilitar a leitura, outros são repetições dos parâmetros apresentados no capítulo anterior.

- Robôs e sensores:

- $R=8.00$ (raio em metros do sensor de obstáculos e de feromônio);

- $R_{D}=8.00$ (raio em metros do sensores de feromônio repulsivo e atrativo);

- $R_{C}=8.00$ (raio em metros do alcance da antena);

- $R_{V}=0.3 R$ (raio de Voronoi para limitar a região infinita);

- $\gamma=0.4$ (coeficiente para suavizar o ajuste de direção);

- Velocidade do robô: 0.5 metro por segundo.

- Liberação e evaporação de feromônio:

- $\lambda_{r}=0.43 R$ (raio do semicírculo onde o feromônio repulsivo é depositado, ver Figura 4.2);

- $\lambda_{a}=0.3 R$ (raio do semicírculo onde o feromônio atrativo é depositado, ver Figura 4.2);

- $\rho=0.01$ (taxa de evaporação);

- $\tau_{q}(0)=0.5$ (quantidade de feromônio repulsivo e atrativo no instante $t=0$ na posição $q \in Q$ ).

- $\tau_{\max }=1$ (limite máximo de feromônio repulsivo e atrativo ).

- Mecanismo de ajuste de direção:

- $S_{a}=180$ (constante que define a quantidade de intervalos angulares para a detecção de feromônio repulsivo);

- $S_{r}=180$ (constante que define a quantidade de seções angulares para a detecção de feromônio atrativo);

- $\varphi=0.15 .\left(2+S_{a}+1\right)$ (cardinalidade do subconjunto $U$, ver Seção 4.3.2);

- $\omega=0.03 .\left(2+S_{a}+1\right)$ (cardinalidade do subconjunto $V$, ver Seção 4.3.2)

- Parâmetros de simulação: 
- LIMITE_PROXIMIDADE $=0.3$ (distância em metros máxima entre um robô e um obstáculo para ativar o sistema de desvio de obstáculos);

- O tempo é discreto pela iterações de simulação: $t_{s} \in \mathbb{N}$;

\subsection{Dispersão dos Robôs}

Primeiramente, é analisada a eficiência do comportamento de atração do centróide. Conforme dito na Seção 5.3.7, a única força de dispersão exercida sobre o grupo advém da relação entre os robôs e os seus respectivos centróides. Tal força é intensificada à medida que aqueles se distanciam destes. Sendo assim, robôs muito distantes do centróide apresentam alta intensidade de atração ao mesmo. De maneira inversa, não é necessário que seja aplicada força de atração acentuada aos robôs próximos ao centróide, pois, nestes casos, eles já se encontram em locais mais seguros contra colisão. Aplicando somente esta força, a dispersão máxima entre os robôs ocorre quando estes atingirem seus centróides. Nesta situação, o posicionamento dos robôs permanece praticamente inalterado, pois, a força de atração é próxima a nula. Em particular quando aplica-se a força de atração no centróide para o problema de exploração em particular, uma consequência é o aumento da área de cobertura dos robôs, já que a redundância de leituras sensorias é reduzida.

A fim de mostrar o comportamento desta força na tarefa de formação, conduziu-se experimentos em que ela é aplicada isoladamente a um grupo de robôs. O objetivo é verificar se, dados agentes inicialmente próximos um dos outros, estes são capazes de se dispersarem mantendo as características de grupo. Para tanto, impõe-se que a distância entre os robôs permaneça constante ao atingirem a dispersão máxima, evitando assim, que estes se afastem de maneira desordenada. O primeiro experimento ilustra tal cenário utilizando 10 robôs, identificado por cores na Tabela 5.2. Na Figura 5.11(a) têm-se os robôs em sua configuração inicial. A cada iteração do sistema, um robô detecta sua vizinhança, constrói a sua região de Voronoi a partir de seus vizinhos adjacentes e por fim, direciona-se para o centroide da região. A expansão dos robôs ocorre até que o centroide seja alcançado. A partir deste ponto a configuração do grupo permanece inalterada. A Figura 5.11(b) mostra o posicionamento dos robôs quando a dispersão máxima é atingida. Os diagramas de Voronoi correspondentes a ambas configurações são representados nas Figuras 5.11(c) e 5.11(d), respectivamente.

Informação complementar da evolução do comportamento dispersivo do sistema é fornecida na Figura 5.12. Ela exibe a intensidade da força de atração ao centróide (ver equação (5.16)) aplicada em cada robô, no decorrer das iterações. De forma geral, pode-se notar que, para todos os robôs, a intensidade da força apresenta tendência decrescente. Como no início os robôs se encon- 


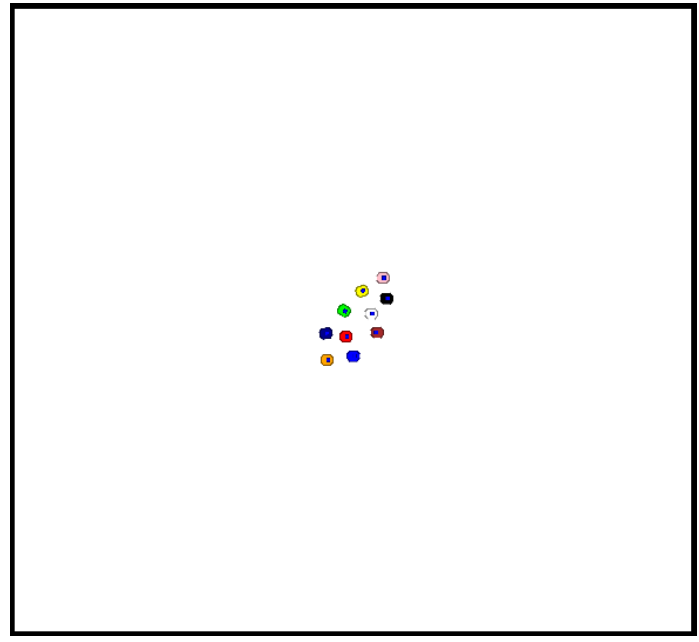

(a)

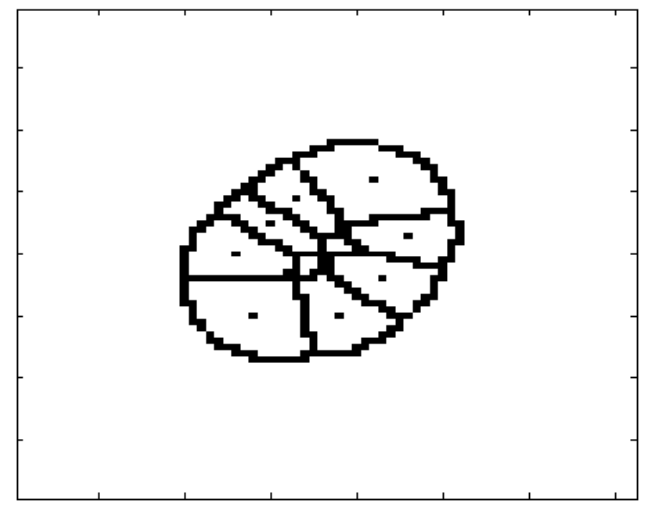

(c)

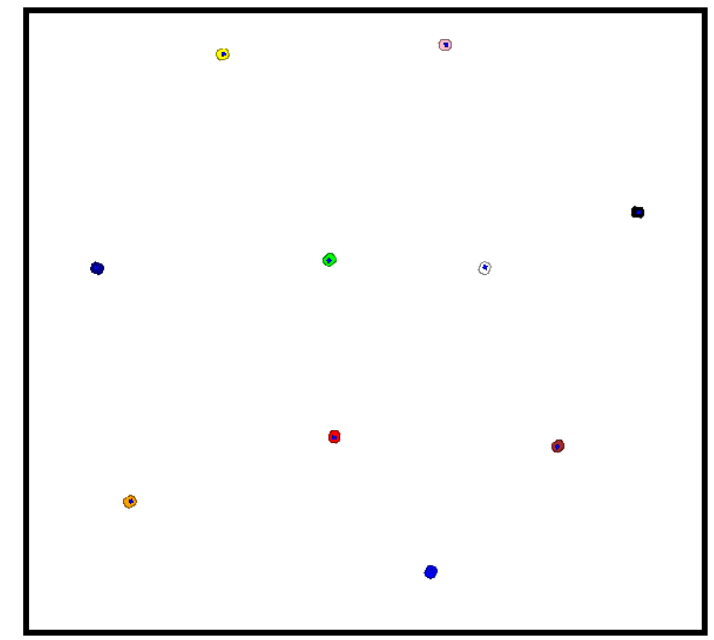

(b)

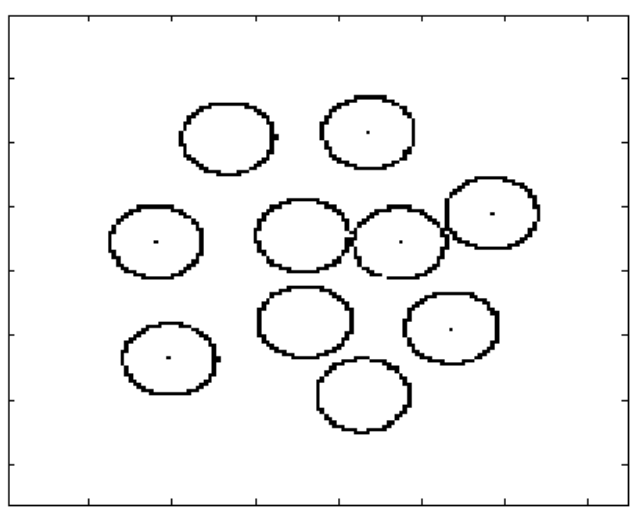

(d)

Figura 5.11: Processo de dispersão dos robôs com a utilização da força de atração do centroide e 10 robôs: (a) configuração inicial (robôs compactados); (b) configuração final (robôs dispersos); (c) diagrama de Voronoi na configuração inicial; (d) diagrama de Voronoi na configuração final. 
Tabela 5.2: Identificação dos robôs

\begin{tabular}{|c|c|}
\hline Robôs & Cores \\
\hline 1 & vermelho \\
\hline 2 & branco \\
\hline 3 & verde \\
\hline 4 & amarelo \\
\hline 5 & azul escuro \\
\hline 6 & azul claro \\
\hline 7 & marrom \\
\hline 8 & preto \\
\hline 9 & laranja \\
\hline 10 & rosa \\
\hline
\end{tabular}

tram muito próximos, as regiões de Voronoi localizadas na borda do grupo são maiores do que aquelas internas. Sendo assim, é mais provável que o centróide dessas regiões estejam distantes do respectivo robô e, consequentemente, a intensidade da força é maior, como visto durante as primeiras iterações na figura. Portanto, quem promove a expansão do grupo são os robôs das regiões de borda (robôs de 3, 4, 5-10). Dentre estes, os robôs 3 e 4 já se encontram próximos ao seu centróide devido ao formato de suas regiões. Neste caso, a força de atração é próxima de zero. De maneira similar, os centroides das regiões internas já estão muito próximos da posição dos robôs (robôs de 1 e 2). Por este motivo, a intensidade da força nestas regiões é baixa. Analisando o gráfico da Figura 5.12, observa-se que, a partir da iteração 35, todos os robôs já se encontram em seu respectivo centroide. Esta situação perdura até o fim da simulação.

A atuação da força atrativa do centróide foi avaliada também em um grupo com números reduzido e aumentado de robôs. Na Figura 5.13, o processo de dispersão é realizado com 5 robôs e na Figura 5.14 com 20. Em ambos os casos, pode ser observado desempenho semelhante à configuração com 10 robôs, evidenciando a escalabilidade e robustez do mecanismo.

\subsubsection{Agregação das Forças de Atração}

Embora a força de atração do centróide seja capaz de promover uma formação entre os robôs, tal comportamento dispersivo não é suficiente para estimular o deslocamento do grupo na realização de uma determinada tarefa. Para este fim, a agregação de forças faz-se necessária. Neste conjunto de experimentos, o sistema como um todo é avaliado combinando as três forças apresentadas na Seção 5.3.7. Assim, incluiu-se, na dinâmica do movimento do grupo, a atração do líder e dos vizinhos. Elas, ao contrário da atração do centróide, são responsáveis por aproximar os robôs a seus pares favorecendo 


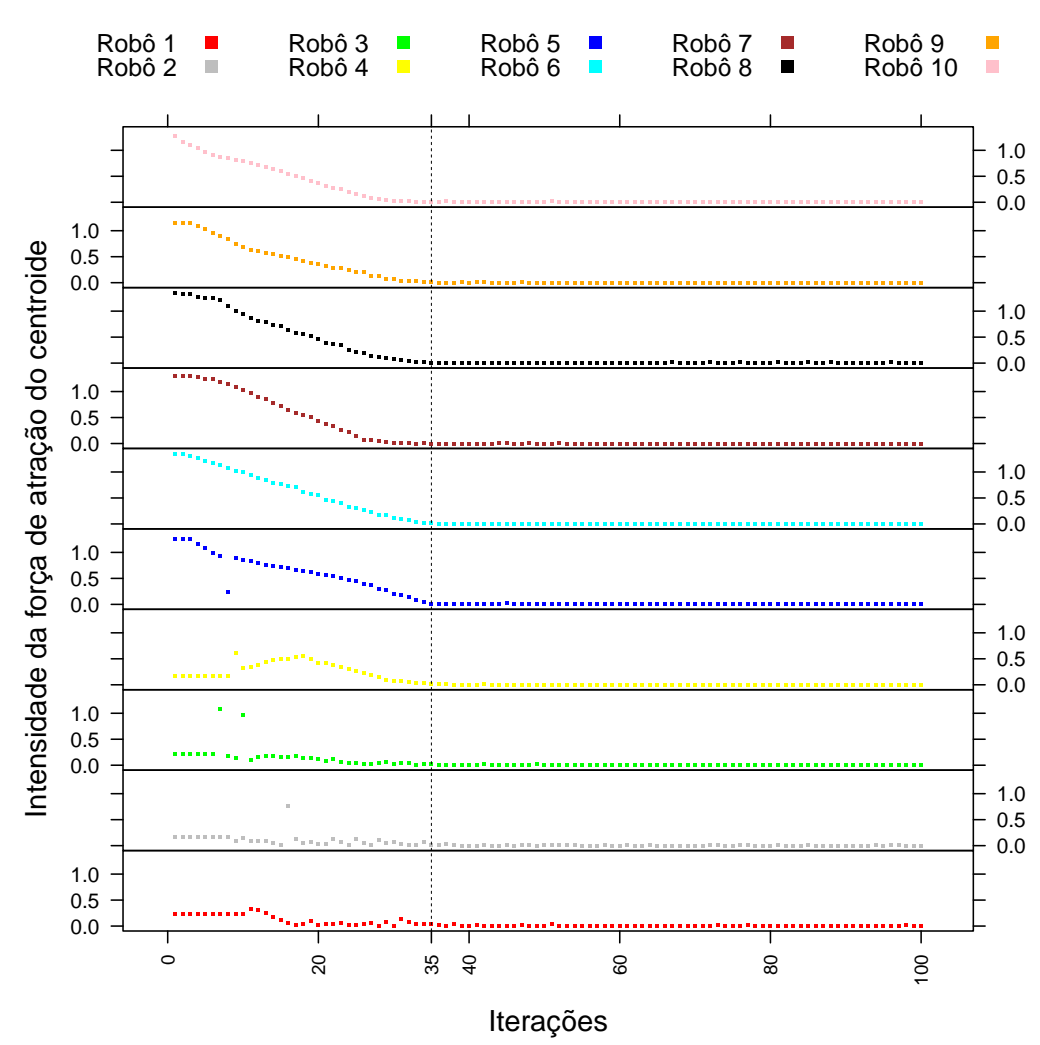

Figura 5.12: Intensidade da força de atração do centroide.

a movimentação do grupo. Enquanto a primeira atrai os robôs para a direção do líder, guiando-os na trajetória do mesmo, a segunda tem o objetivo de manter a coesão de movimento entre os vizinhos, além de permitir o deslocamento em grupo nas situações em que o robô se encontra muito distante do líder e sua força de atração torna-se nula. Portanto, o equilibrio dessas forças possibilita a manutenção da formação durante a navegação dos robôs. Para avaliar isto, robôs são lançados no ambiente com o objetivo de cobri-lo, mantendo sua formação.

No experimento exibido na Figura 5.15, 10 robôs são utilizados (com a mesma identificação por cores da Tabela 5.2) para navegar em um ambiente composto por duas amplas áreas interligadas por uma estreita passagem, denominada aqui como corredor. Como o propósito desse experimento é analisar a característica de adaptabilidade da formação, o módulo que define um líder (Módulo de Inicialização) é desativado. Sem comprometer a validade do experimento, fixou-se tal papel logo no início da simulação. Como consequência, não há troca nem adição de líder. A fim de verificar o desempenho do sistema, observa-se o deslocamento do grupo nos quadros extraídos da simulação com 1000 iterações. Ao iniciar a navegação, os robôs são expandidos pelo ambiente sem perder a comunicação, como é visto nas Figura 5.15(b). Devido a maior prioridade dada ao comportamento de repulsão (ver Seção 5.4), nota-se que a área de cobertura do grupo é aumentada com maior intensidade nas 


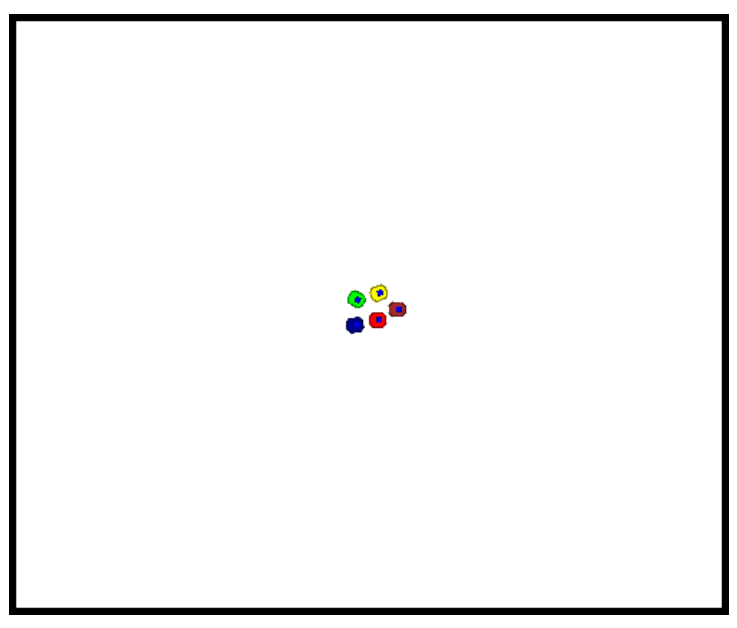

(a)

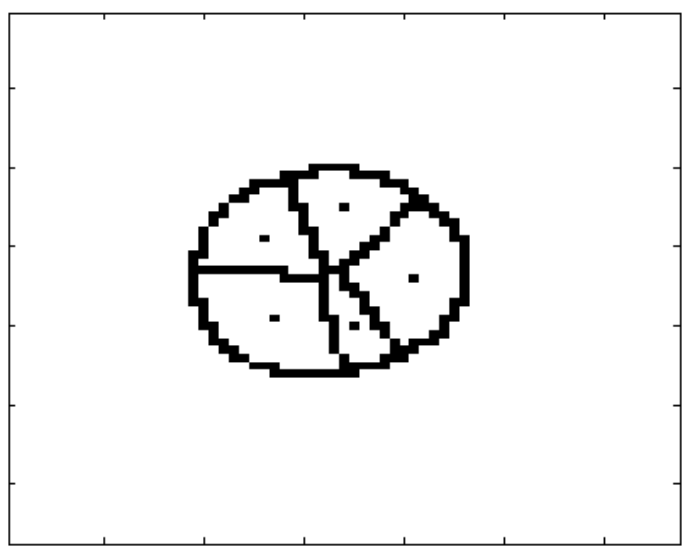

(c)

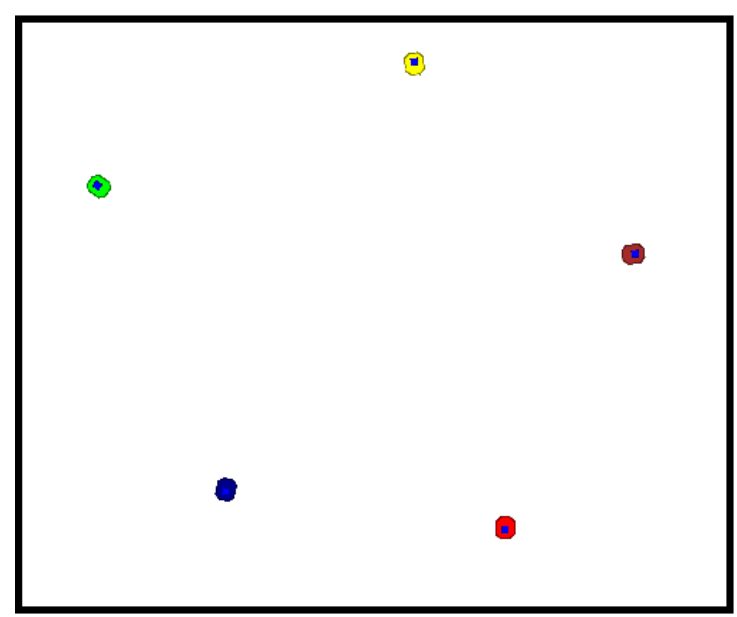

(b)

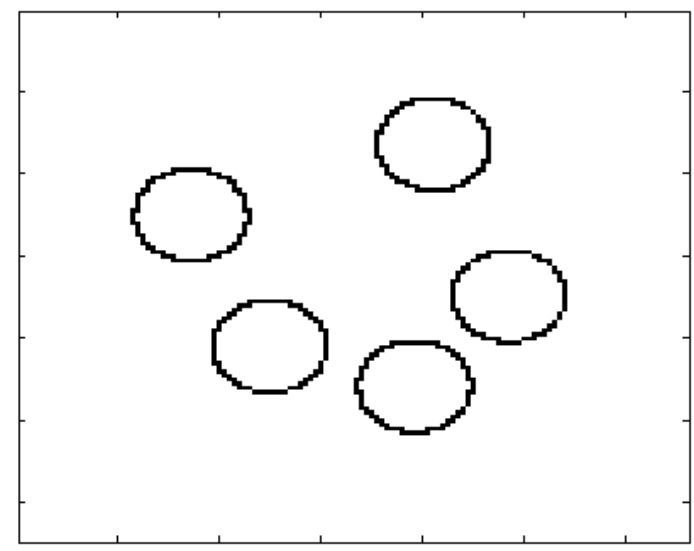

(d)

Figura 5.13: Processo de dispersão dos robôs com a utilização da força de atração do centroide e 5 robôs: (a) configuração inicial (robôs compactados); (b) configuração final (robôs dispersos); (c) diagrama de Voronoi na configuração inicial; (d) diagrama de Voronoi na configuração final. 


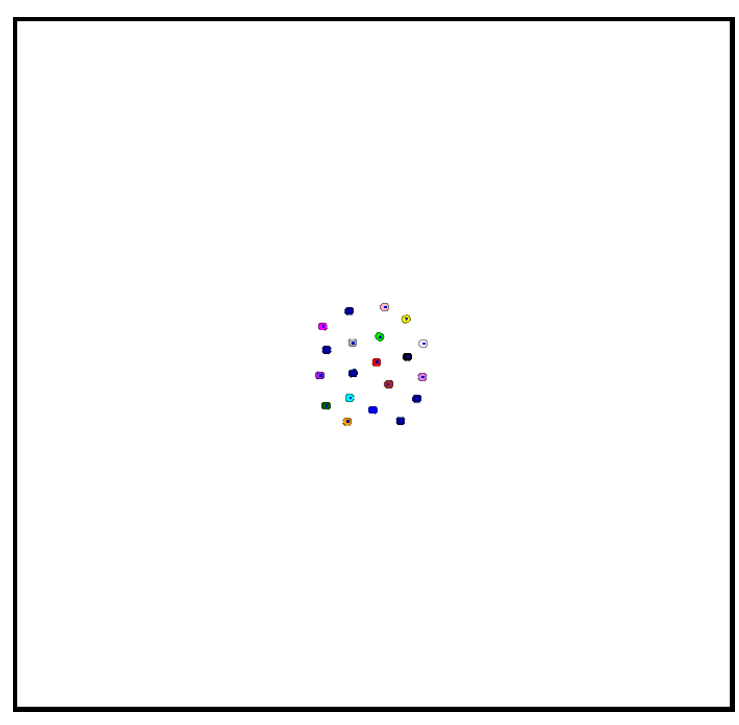

(a)

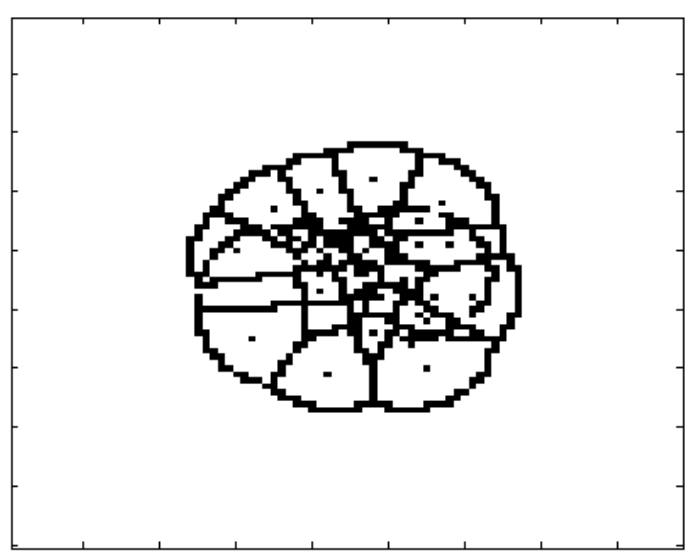

(c)

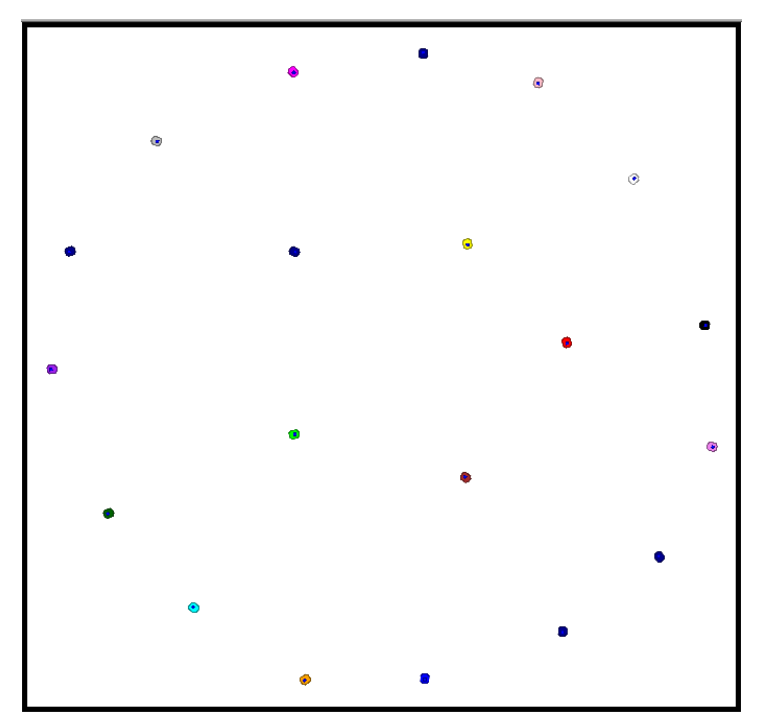

(b)

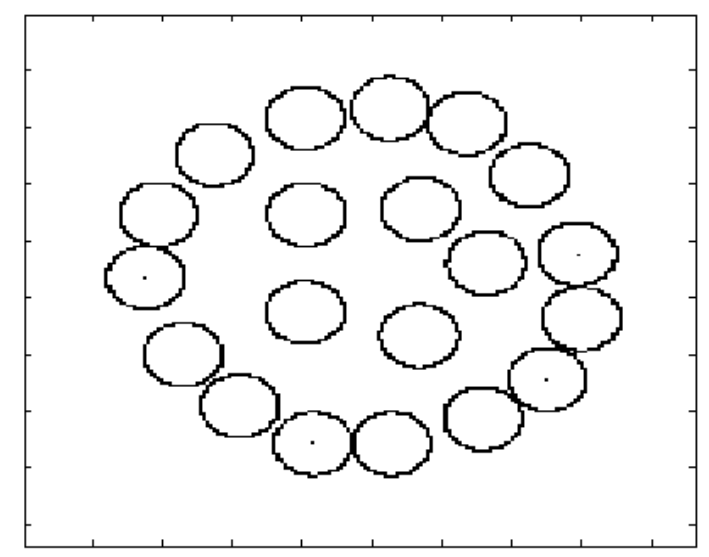

(d)

Figura 5.14: Processo de dispersão dos robôs com a utilização da força de atração do centroide e 20 robôs: (a) configuração inicial (robôs compactados); (b) configuração final (robôs dispersos); (c) diagrama de Voronoi na configuração inicial; (d) diagrama de Voronoi na configuração final. 
primeiras iterações. Após atingir o estágio em que a intensidade da força de repulsão seja nula (ou quase nula), os robôs mantêm constante a distância aos seus vizinhos durante a movimentação, o que enfatiza a característica de coesão do grupo. Isto é ilustrado nas Figuras 5.15(b) - 5.15(c).

Outra característica destacada do processo de formação é a capacidade do grupo em adaptar seu formato de acordo com sua localização no ambiente. Ao se deparar com o corredor, a formação torna-se mais alongada (Figuras 5.15(e) - Figura 5.15(h)). O primeiro robô a atingir o corredor é o líder. À medida que este avança, seus vizinhos imediatos também o fazem, pois detectam alta concentração de feromônio atrativo. Robôs distantes do líder, incapazes de sentir tal feromônio, orientam-se segundo seus vizinhos adjacentes. Isto ocasiona no afunilamento da formação dos robôs. No entanto, esta aproximação faz com que a posição do centróide das regiões de borda seja ajustada de modo a atrair o respectivo robô para regiões externas do grupo (ou repelido do grupo). Por este motivo, colisões entre os robôs são evitadas. Este comportamento é extendido mesmo quando o grupo está dentro do corredor. Neste caso, as bordas do corredor são utilizadas para formar a região de Voronoi de cada robô. Assim, é evidente que o centróide nunca estará posicionado próximo às paredes. Assim, nota-se a capacidade dos robôs em evitar colisões contra obstáculos. O formato alongado do grupo é mantido até que os robôs saiam do corredor. Neste instante, ocorre, novamente, a expansão dos robôs em outro ambiente (Figuras 5.15(i) - Figura 5.15(1)). Os robôs que antes tinham sua região de Voronoi limitada pelas paredes do corredor, ao sair deste, agora tem sua área de região também expandida, o que resulta no posicionamento do centróide em locais mais distantes da concentração de robôs. As regiões de Voronoi geradas durante a simulação são mostradas na Figura 5.16, em consonância com as iterações anteriormente exibidas. As porções amarelas do gráfico correspondem ao feromônio atrativo depositado pelo líder no instante da iteração indicada. Sendo o feromônio utilizado na comunicação indireta no processo de formação, os robôs mais próximos do líder sofrem maior influência atrativa.

A evolução e manutenção da formação também pode ser verificada através do gráfico da Figura 5.17. Ela ilustra a relação entre cada robô e seu vizinho, com nível inferior, mais próximo no decorrer das iterações. É de consenso que a distância entre os robôs é suficiente para validar a formação. Uma vez que esta distância se mostre constante, é possivel afirmar que o grupo está em formação. Porém, dentre os vizinhos de cada robô, aquele que apresenta maior risco de colisão é o que está mais próximo. Por tal motivo, a distância em relação a este vizinho é utilizada no gráfico. É importante ressaltar que o robô 1 indicado no gráfico é designado como o líder do grupo. Assim, 


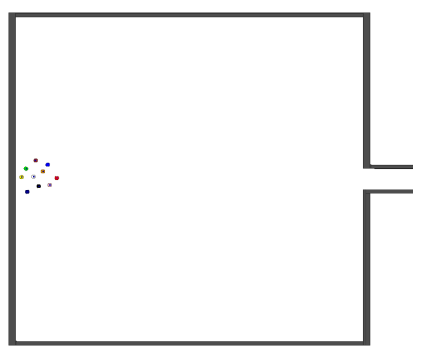

(a)

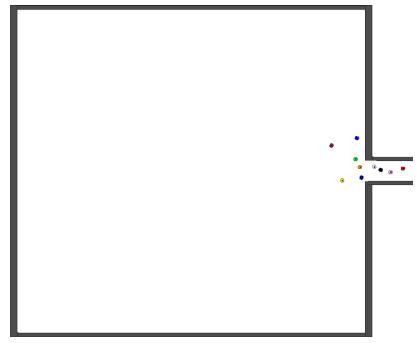

(d)

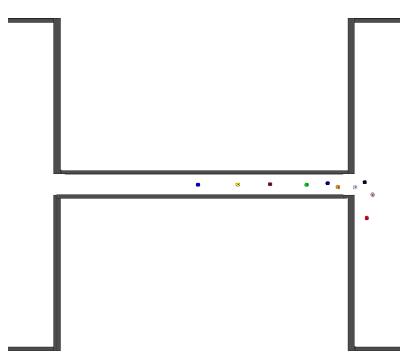

(g)

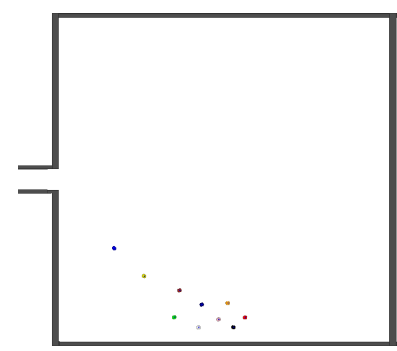

(j)

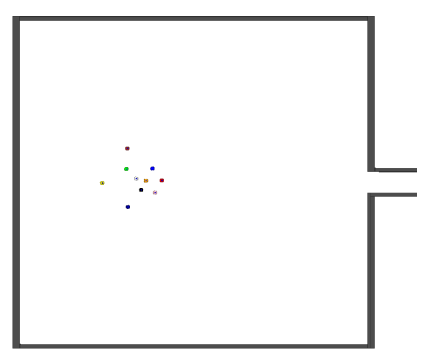

(b)

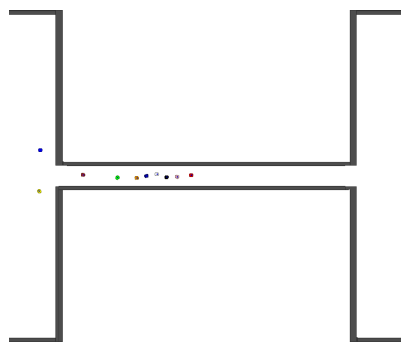

(e)

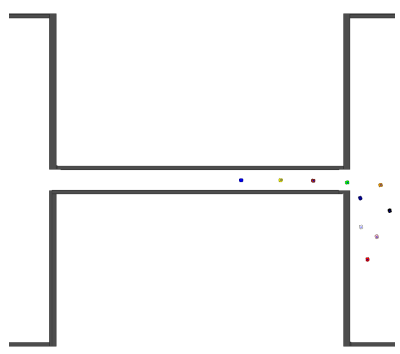

(h)

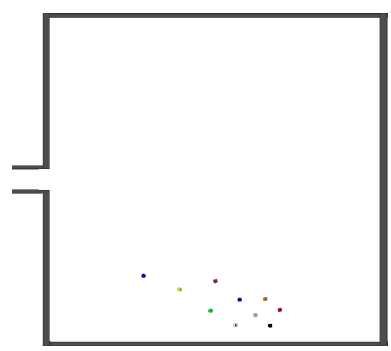

(k)

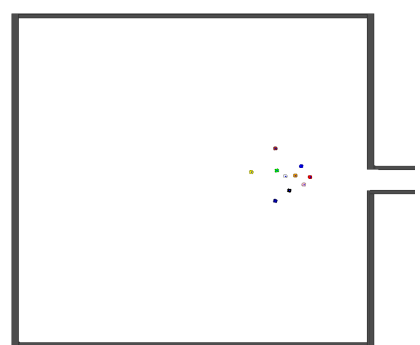

(c)

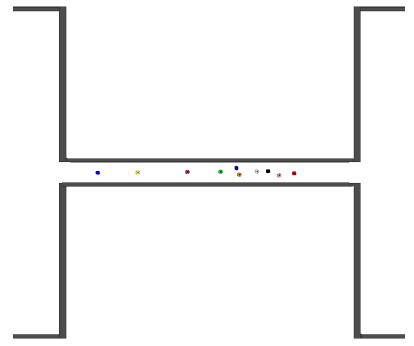

(f)

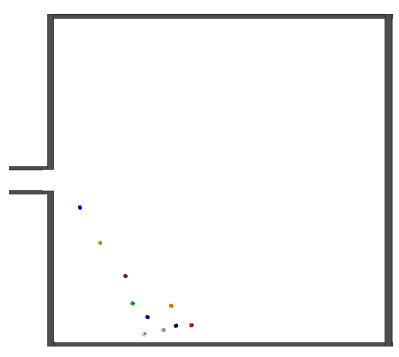

(i)

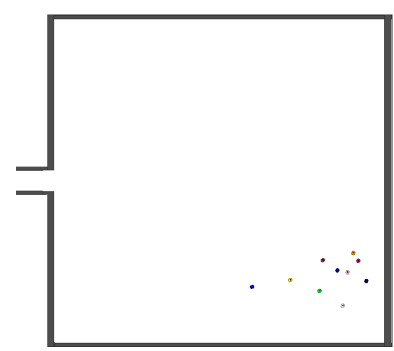

(l)

Figura 5.15: Sequência de quadros da simulação em que o grupo de 10 robôs passa por um corredor nas iterações: (a) 0; (b) 60; (c) 150; (d) 210; (e) 270; (f) 330; (g) 390; (h) 420; (i) 510; (j) 540; (k) 570; (l) 630. 


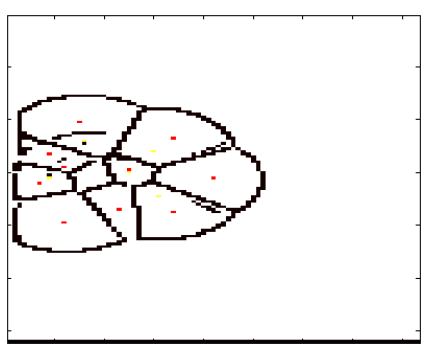

(a)

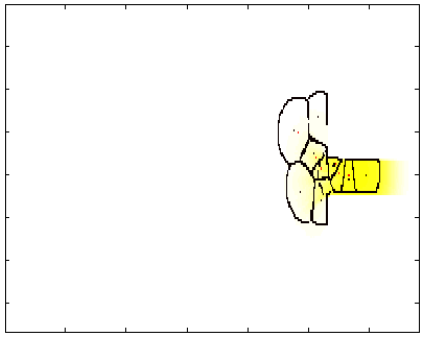

(d)

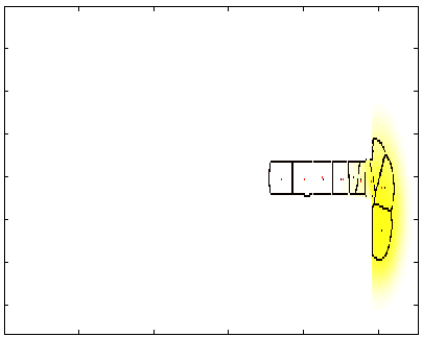

(g)

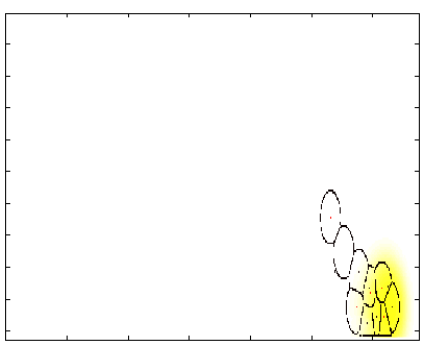

(j)

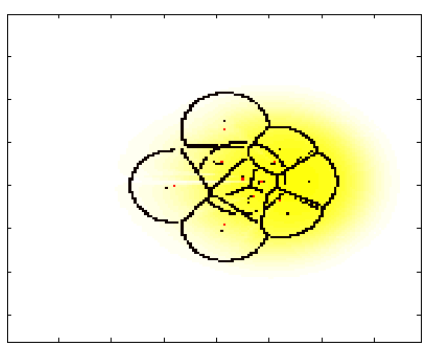

(b)

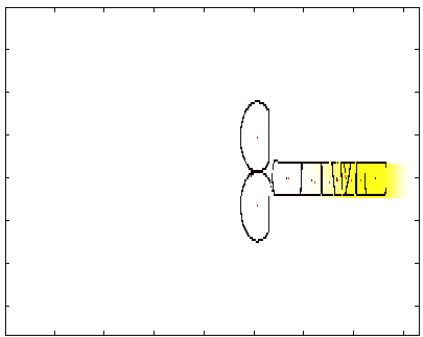

(e)

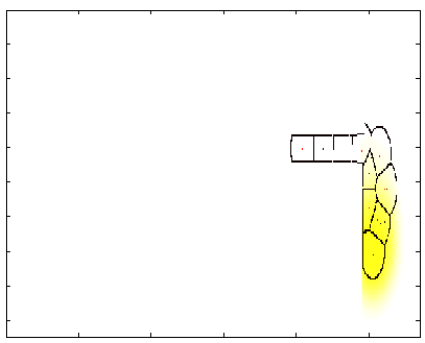

(h)

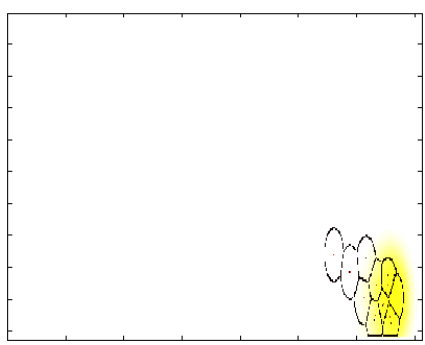

(k)

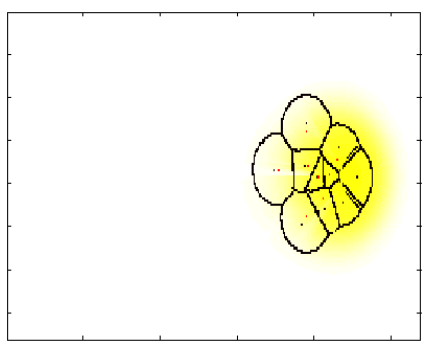

(c)

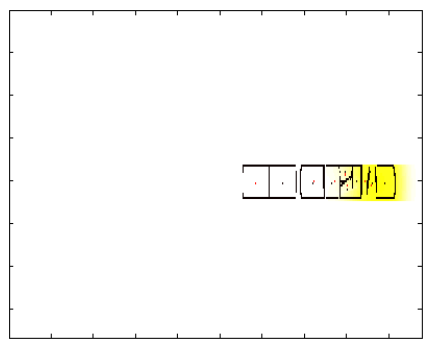

(f)

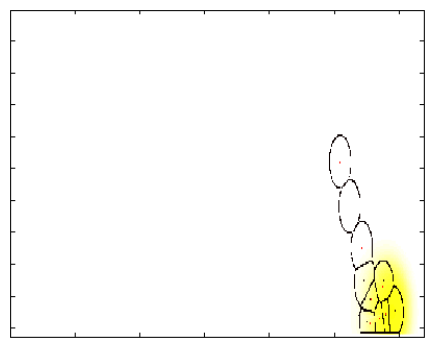

(i)

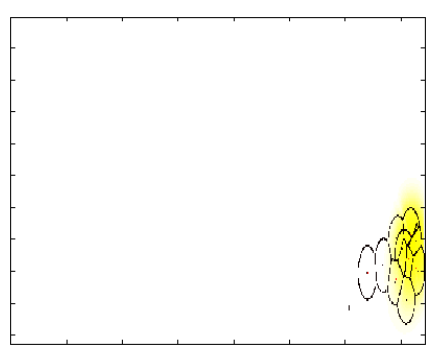

(l)

Figura 5.16: Sequência de quadros do diagrama de Voronoi da simulação em que o grupo de 10 robôs passa por um corredor nas iterações: (a) 0; (b) 60; (c) 150; (d) 120; (e) 270; (f) 330; (g) 390; (h) 420; (i) 510; (j) 540; (k) 570; (l) 630. 
sua curva se mostra constante em zero, pois estando no nível mais baixo da topologia, não há vizinhos aos quais se possa calcular a distância. A partir do gráfico, observa-se pequenas oscilações da curva da distância dos robôs nas primeiras iterações devido ao comportamento repulsivo inicial (aproximadamente até a iteração 60). Ao estabelecer a formação, tal distância flutua em torno de um valor constante até o grupo alcançar a entrada do corredor, o que mostra a estabilidade da formação. Neste instante, caracterizado pelo afunilamento dos robôs, a curva de distância sofre novas oscilações. Para evitar colisões nesta situação em que os robôs se aproximam, a força de atração do centroide atua expandindo o grupo. Como consequência, a tendência é que os robôs se distanciem um dos outros, como pode ser visto em torno da iteração 270. No período em que o grupo está no corredor (aproxidamente entre as iterações 270 e 420), por ser um ambiente estreito, espera-se que a variação da distância seja mínima, entretanto, esta situação não se verifica plenamente. Mesmo no corredor, as forças de atração nem sempre definem as mesmas direções. Assim, o robô apresenta movimento oscilatório. Sendo assim, devido ao método de triangulação de Delaunay, um robô imediatamente atrás de outro pode estar em nivel diferente deste (e portanto a distância é pequena), e em outro momento, no mesmo nível. Neste último caso, um robô mais adiante é quem define seu nível e, portanto, sua distância aumenta, como é refletido no gráfico. É interessante notar ainda que existe uma clara correspondência entre as distâncias observadas para os robôs 3, 4 e 7 (verde, amarelo e marrom, respectivamente) e suas posições nas Figuras 5.16(e) - 5.16(h). Tão logo os robôs saem do corredor a distância entre os vizinhos aumenta devido à expansão do grupo ao encontrar um ambiente amplo. A variação da distância é suave até que a curva apresente comportamento estável, o que indica uma nova formação. O comportamento errático é observado a partir da iteração 630, quando o líder se depara com os limites do ambiente e na tentativa de sair desta situação, há uma grande variação na topologia do grupo.

Comportamento do grupo semelhante ao observado durante o processo de formação, assim como sua característica de topologia flexível, também é verificado em experimentos utilizando 5 e 20 robôs e mostrados nas Figuras 5.18 e; Figuras 5.19, respectivamente. Nota-se nos experimentos a característica emergente de adaptação da formação ao ambiente ao encontrar o corredor.

\subsubsection{Mudança de Líder}

Nesta seção, é discutido o comportamento do grupo diante da habilidade do sistema em alterar o líder. Conforme mencionado na Seção 5.3.4, o líder deve ser substituído quando detecta muita quantidade de feromônio atrativo por um longo período de tempo (saturação positiva). A troca de líder permite 


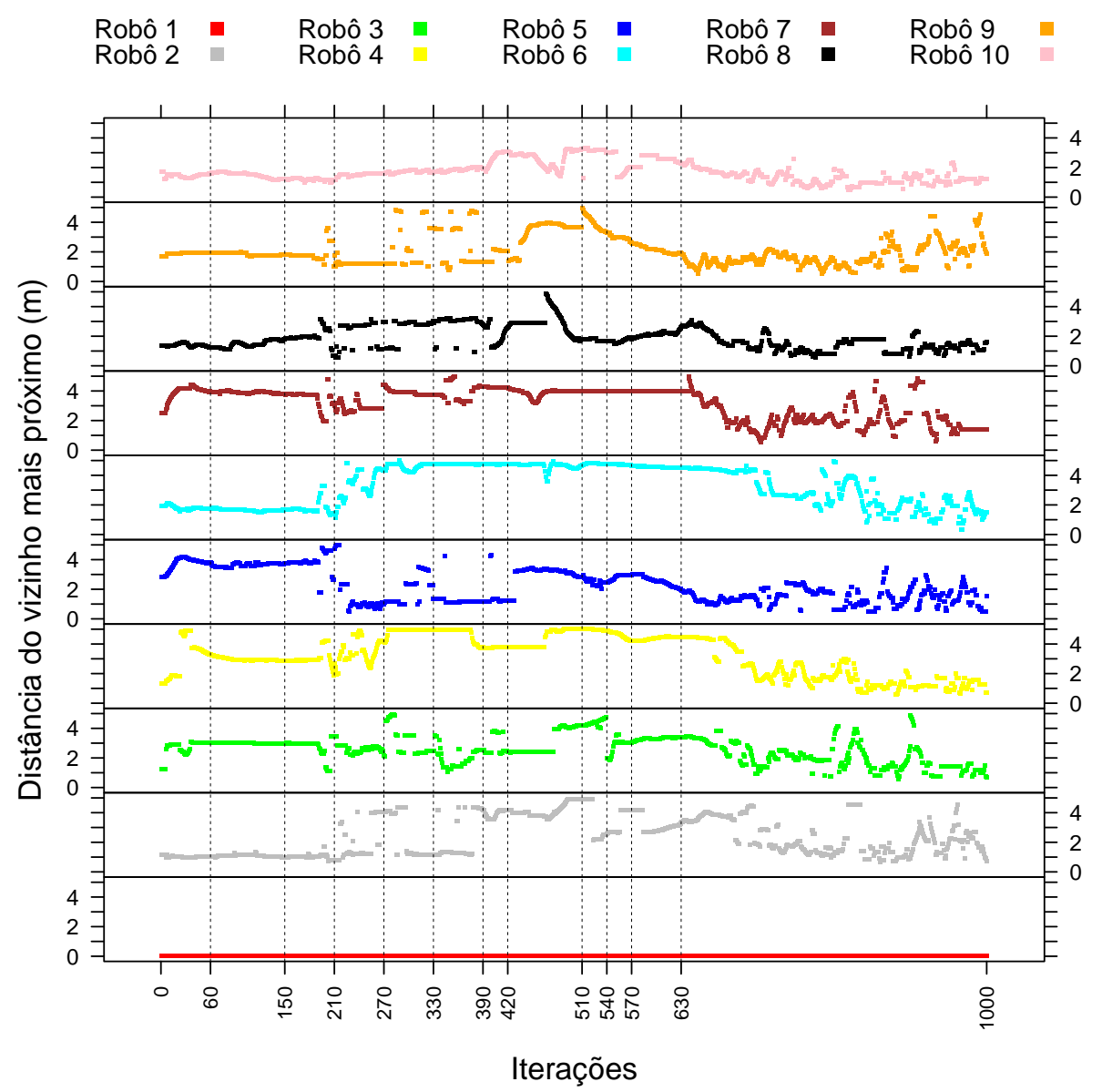

Figura 5.17: Distância do vizinho mais próximo. 


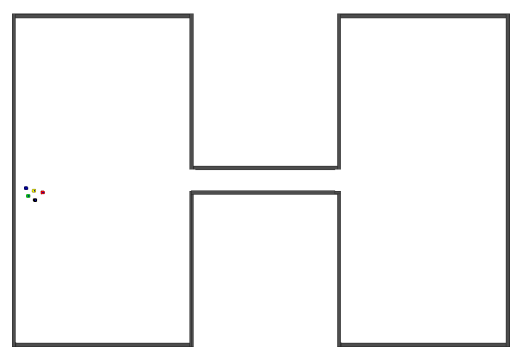

(a)

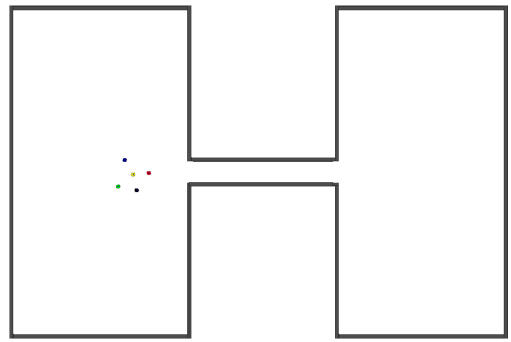

(d)

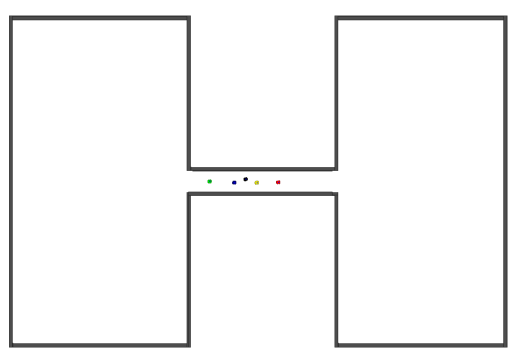

(g)

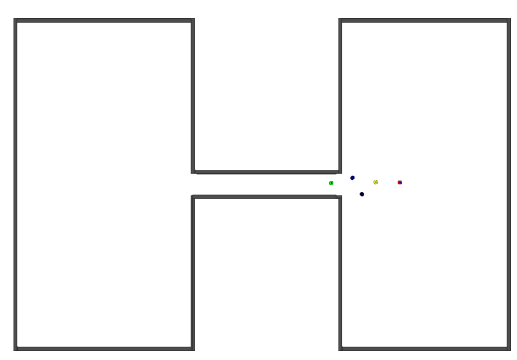

(j)

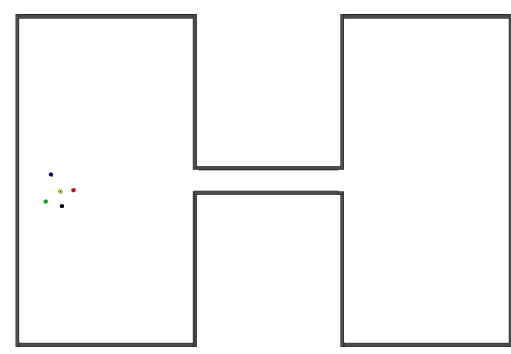

(b)

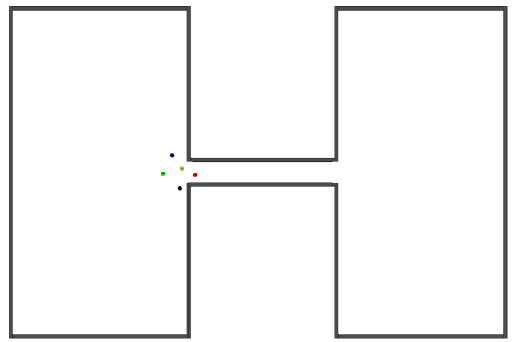

(e)

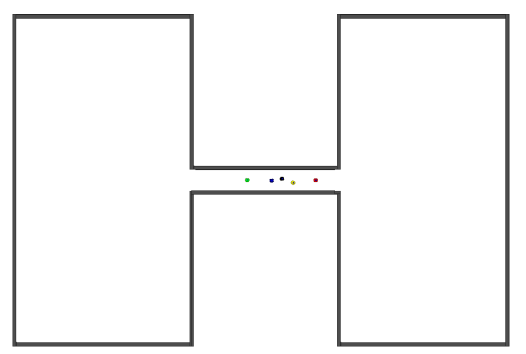

(h)
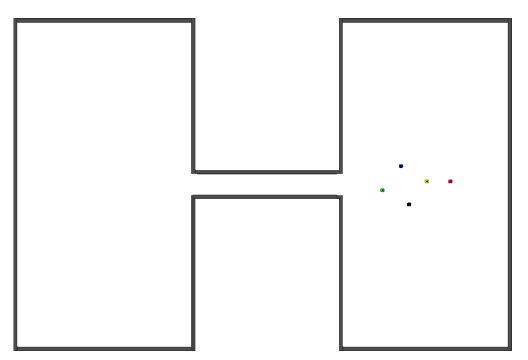

(k)

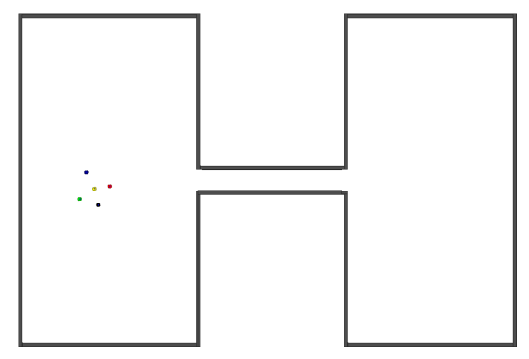

(c)

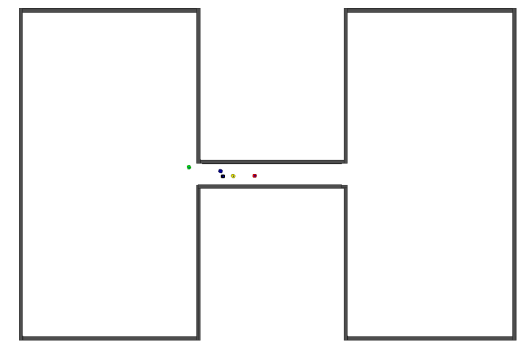

(f)

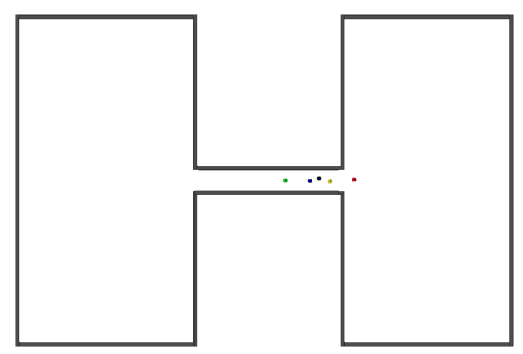

(i)

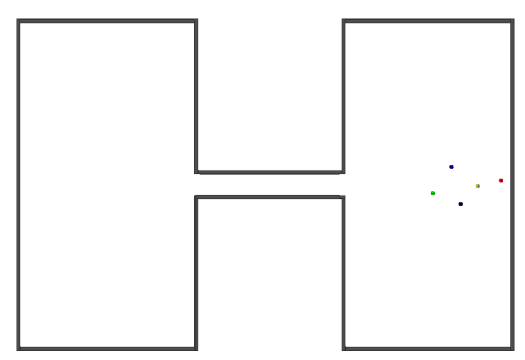

(l)

Figura 5.18: Sequência de quadros da simulação em que o grupo de 5 robôs passa por um corredor nas iterações: (a) 0; (b) 10; (c) 30; (d) 60; (e) 90; (f) 120; (g) 140; (h) 160; (i) 180; (j) 210; (k) 240; (l) 270. 


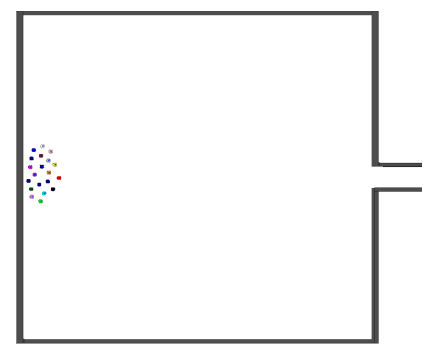

(a)

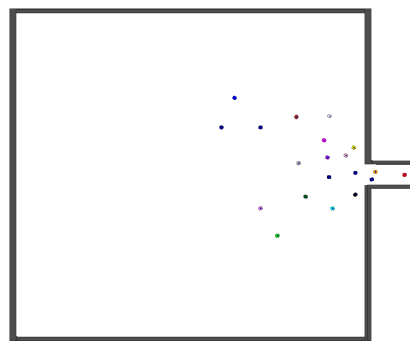

(d)

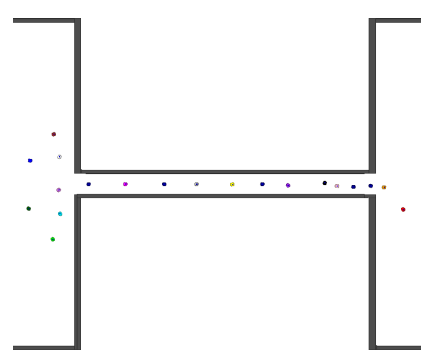

(g)

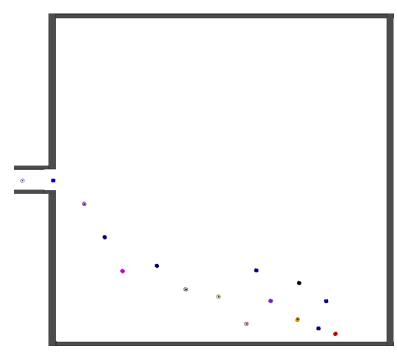

(j)

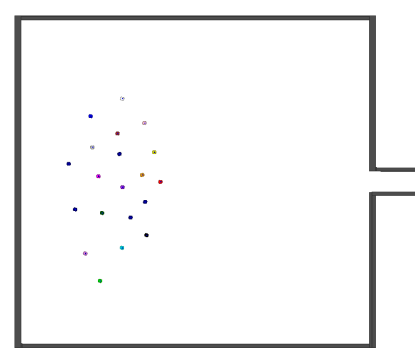

(b)

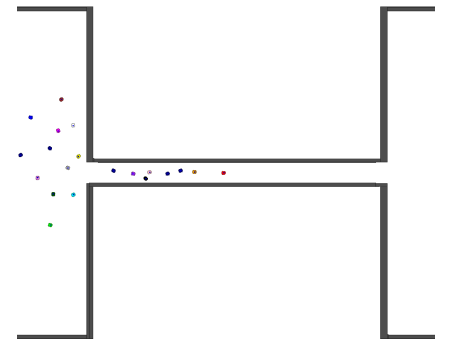

(e)

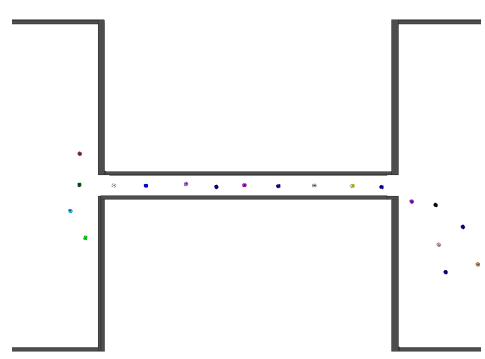

(h)

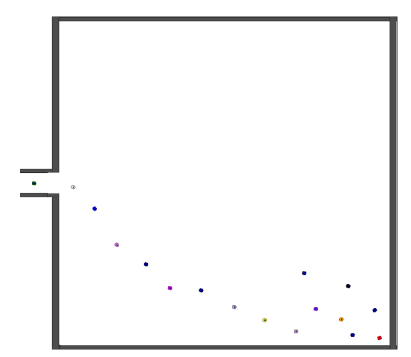

(k)

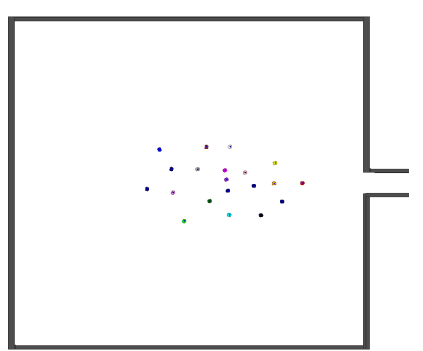

(c)

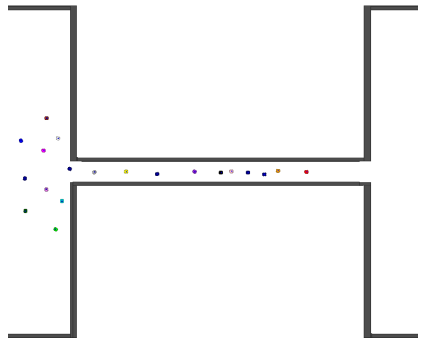

(f)

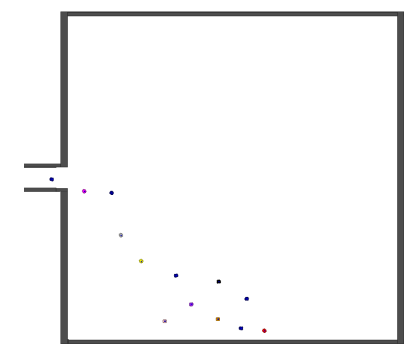

(i)

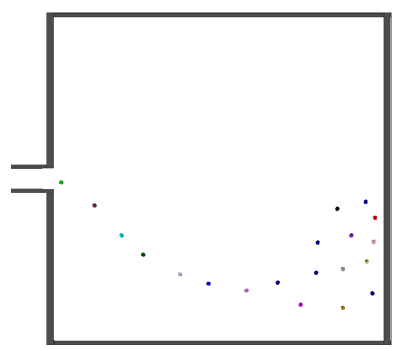

(l)

Figura 5.19: Sequência de quadros da simulação em que o grupo de 20 robôs passa por um corredor nas iterações: (a) 0; (b) 60; (c) 150; (d) 210; (e) 270; (f) 330; (g) 390; (h) 450; (i) 570; (j) 630; (k) 660; (l) 750. 
melhorias no desempenho da exploração no sentido de que a direção de movimento do grupo seja alterada. Dado que o grupo vem explorando áreas com alta concentração de feromônio, a mudança de orientação do grupo possibilita que áreas distintas sejam exploradas. Para auxiliar na tarefa, o novo líder é escolhido dentre os seguidores, o robô que está detectando menor quantidade de feromônio no instante em que a troca é requisitada. Assim, evita-se que o grupo altere sua trajetória em direção à regiões tão exploradas quanto aquela detectada pelo antigo líder.

De maneira distinta ao que foi explicitado no modelo do sistema cibernético, a troca de líder é requisitada num instante pré-determinado. Segundo o modelo, este instante é definido quando o líder detecta muita quantidade de feromônio num período igual à TEMPO_ESPERA. Dessa forma, ao fim desse período o Módulo de Inicialização é ativado para que um novo líder seja escolhido. Realizar uma simulação de um experimento na tentativa que ocorra a troca de líder pode tornar-se uma tarefa tediosa. Para tanto, devese estabelecer valores exatos para TEMPO_ESPERA, LIMITE_FEROMONIO e taxas de dispersão e evaporação do feromônio repulsivo. Devido à dificuldade encontrada, determinou-se um instante para que tal evento aconteça. Independentemente do modo adotado para indicar a necessidade da mudança de líder, o experimento é analisado em relação ao comportamento do grupo, ou seja, como o grupo adapta sua topologia quando a orientação da trajetória é alterada.

No experimento apresentado a seguir, são utilizados 10 robôs em um ambiente amplo e retangular, sem a presença de obstáculos. Na Figura 5.20 exibe-se a evolução do sistema com essa configuração. Para melhor compreender seu comportamento, os robôs são numerados e indicados por cores conforme a Tabela 5.3. De maneira a contornar a dificuldade supracitada, o evento de mudança de líder é fixado na iteração 200 em uma simulação com total de 400 para que o comportamento seja observado antes, durante e depois da realização da troca. Com a definição inicial de um líder (robô roxo indicado por uma flecha na Figura 5.20(a)), o grupo mantém-se em formação devido à combinação das forças de atração e ao deslocamento provocado pelo líder até que o processo de mudança seja iniciado. Neste instante, o Módulo de Inicialização é ativado, e após inúmeras repetições da execução deste, um novo líder é definido. Em particular para o experimento em questão, a quantidade de feromônio repulsivo detectada por cada robô no momento em que a mudança é requisitada é mostrada na Tabela 5.6. Na primeira execução do Módulo de Inicialização, cada robô envia aos vizinhos adjacentes a sua própria leitura da quantidade de feromônio. Nas próximas execuções, o robô seleciona, dentre as informações recebidas, aquela que corresponde à menor quantidade de 
feromônio e a repassa para seus vizinhos. Seguindo este processo, a informação selecionada converge para a menor quantidade de feromônio obtida dentre os robôs. No caso do experimento, o robô 5, indicado pela flecha na Figura 5.20(e), foi nomeado como novo líder do grupo.

Tabela 5.3: Identificação dos robôs.

\begin{tabular}{|c|c|}
\hline Robôs & Cores \\
\hline 1 & vermelho \\
\hline 2 & roxo \\
\hline 3 & verde \\
\hline 4 & amarelo \\
\hline 5 & azul \\
\hline 6 & cinza \\
\hline 7 & marrom \\
\hline 8 & preto \\
\hline 9 & laranja \\
\hline 10 & rosa \\
\hline
\end{tabular}

Tabela 5.4: Quantidade de feromônio repulsivo no instante da mudança de líder.

\begin{tabular}{|c|c|}
\hline Robôs & Quantidade Feromônio \\
\hline 1 & 0.99968 \\
\hline 2 & 0.999799 \\
\hline 3 & 0.9999 \\
\hline 4 & 0.999554 \\
\hline 5 & 0.999527 \\
\hline 6 & 0.99966 \\
\hline 7 & 0.999845 \\
\hline 8 & 0.999806 \\
\hline 9 & 0.999756 \\
\hline 10 & 0.999686 \\
\hline
\end{tabular}

Na condição de líder, o robô 5 passa a depositar feromônio, pois, agora, os demais robôs devem seguir a sua trajetória. Além disso, o novo líder recebe a atribuição de disparar o processo de definição de nível. A topologia do grupo antes e depois da mudança de líder pode ser observada na Tabela 5.7. Embora os vizinhos de um robô sejam os mesmos após a mudança de líder, o nível na hierarquia do grupo é alterado. Com o novo líder no nível zero, a hierarquia dos demais é ajustada conforme a conexão entre os vizinhos adjacentes. Em adição, com o comportamento mostrado na Figura 5.20, nota-se a capacidade do sistema em ajustar o formato do grupo quando da mudança brusca de direção. Além deste fator, o feromônio depositado pelo líder antigo (robô 1) também influência na direção de movimento do grupo. Mesmo após deixar a condição de líder, a concentração de feromônio liberado pelo robô 1 


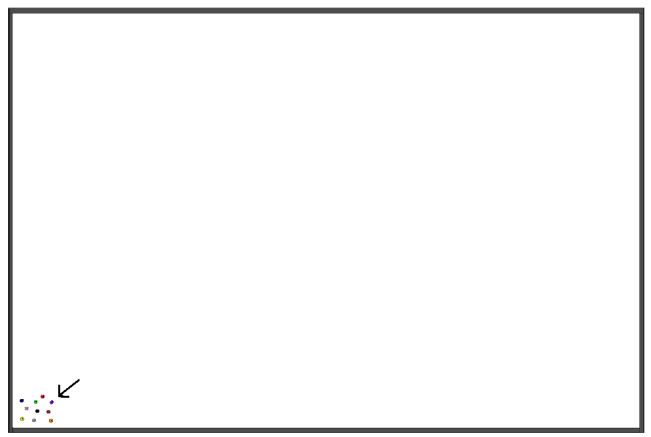

(a)

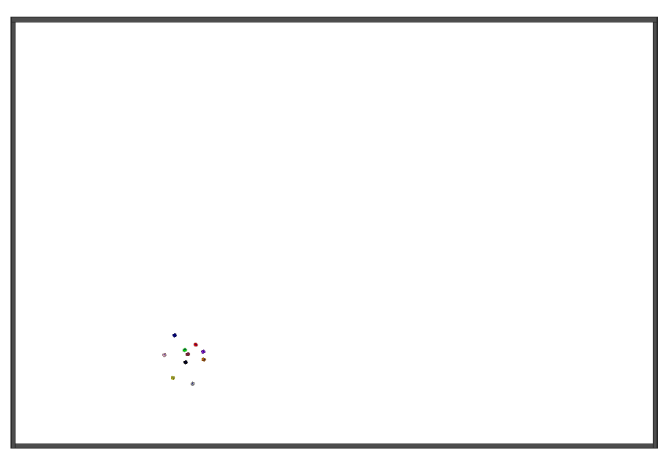

(c)

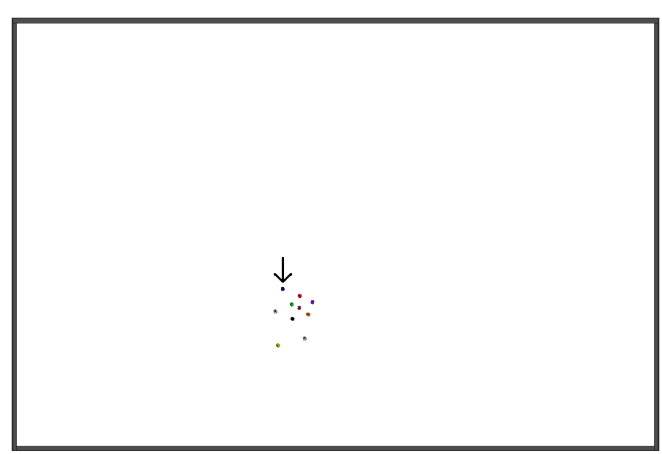

(e)

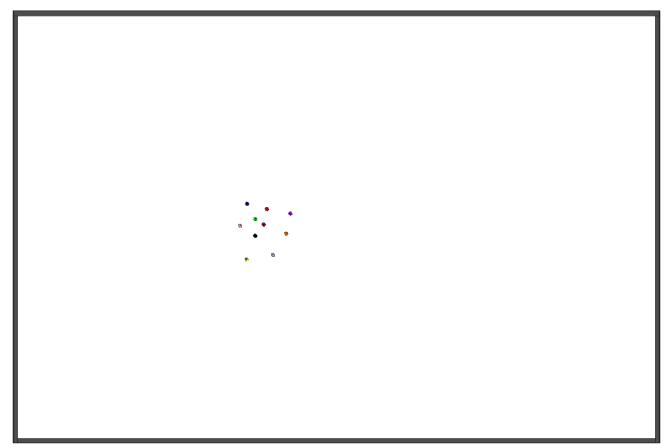

(g)

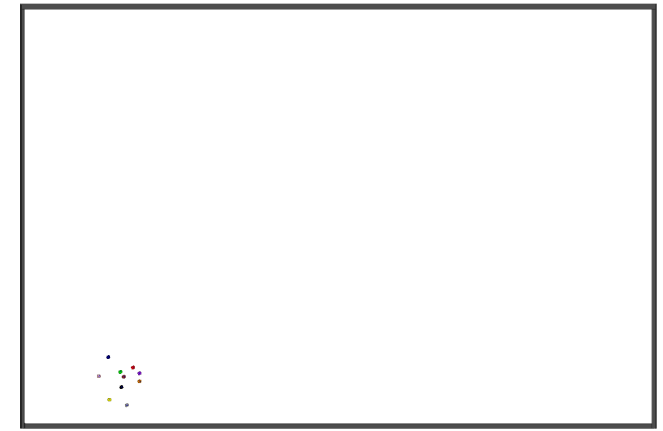

(b)

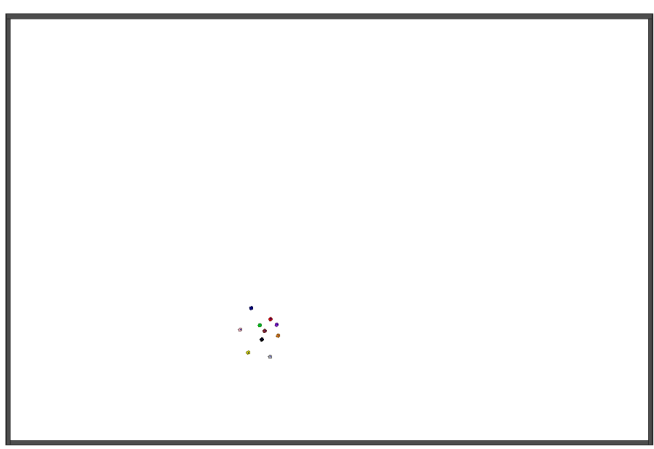

(d)

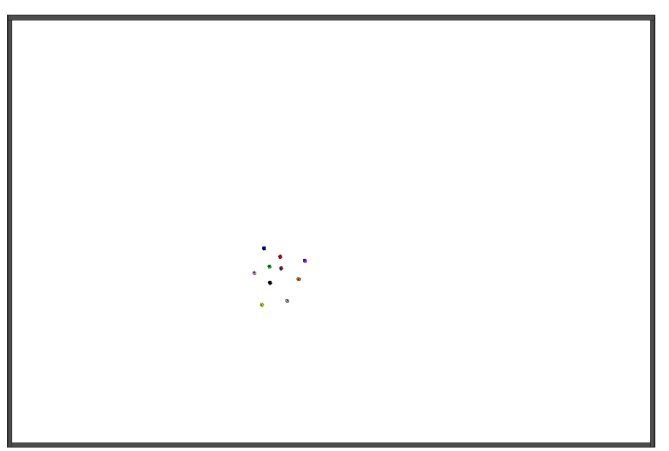

(f)

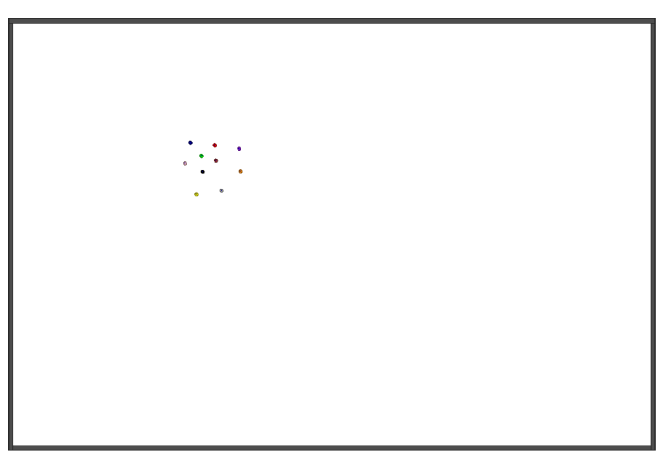

(h)

Figura 5.20: Sequência de quadros da simulação para um grupo de 10 robôs quando há a mudança de líder: (a) 0; (b) 60; (c) 120; (d) 180; (e) 210; (f) 240; (g) 270; (h) 330. 


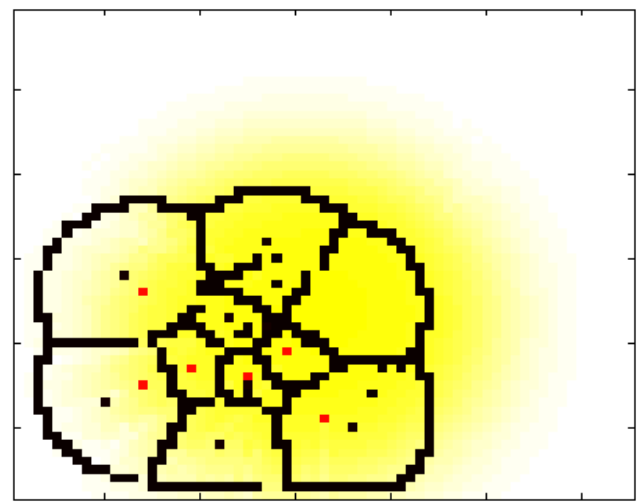

(a)

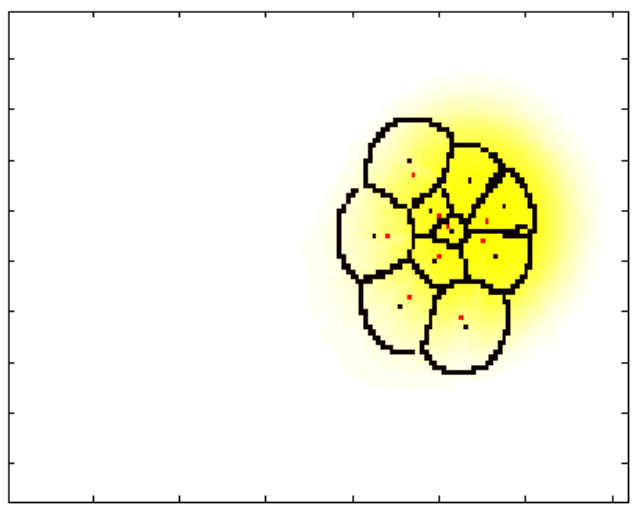

(c)

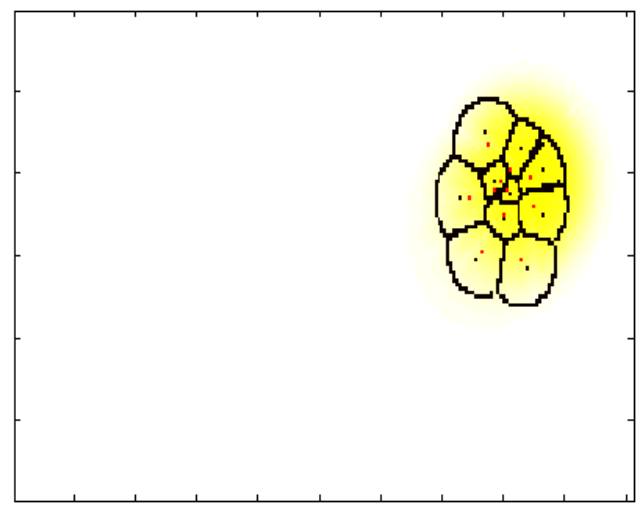

(e)

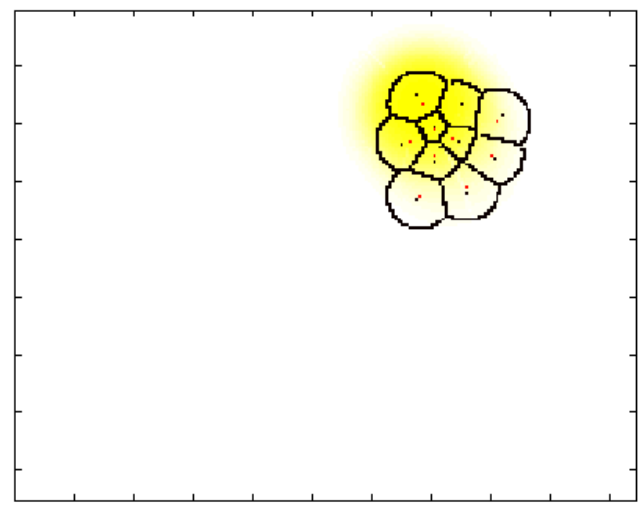

(g)

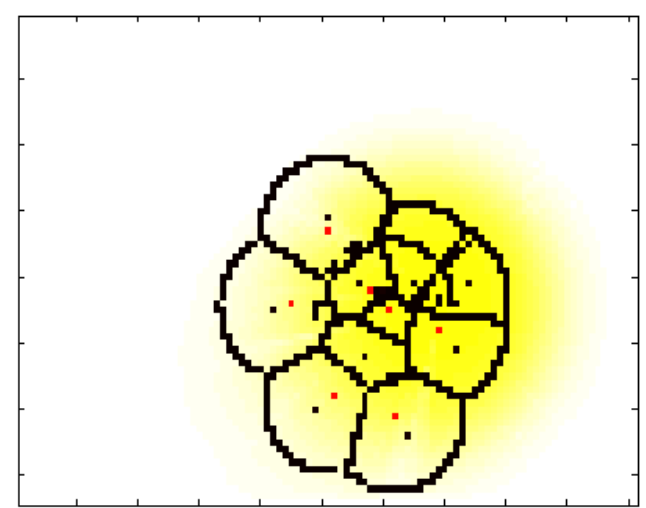

(b)

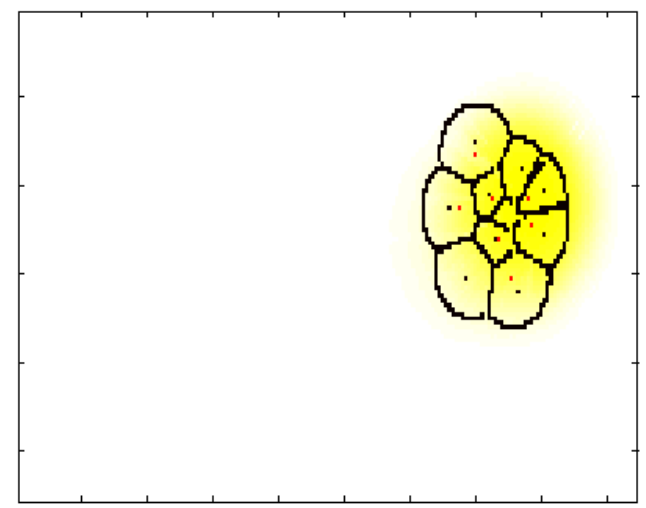

(d)

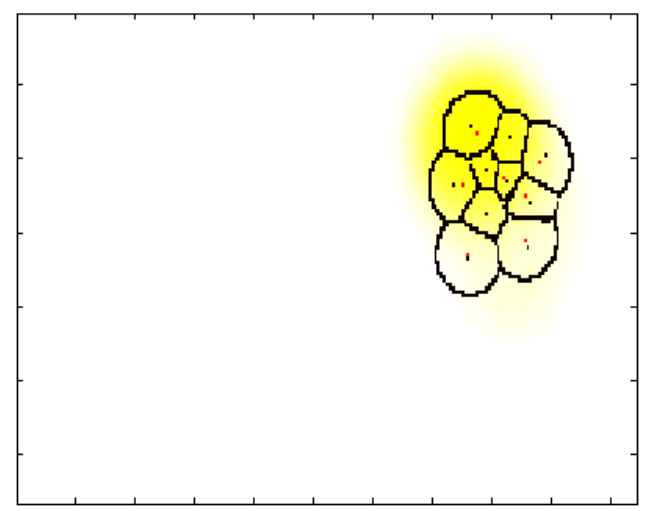

(f)

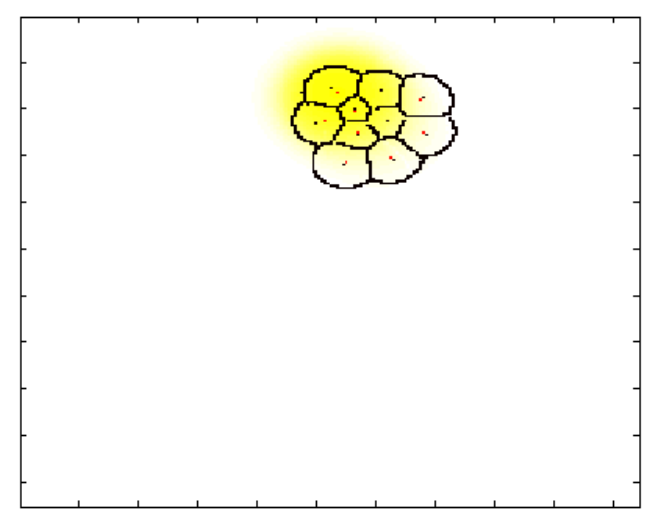

(h)

Figura 5.21: Sequência de quadros do diagrama de Voronoi da simulação para um grupo de 10 robôs quando há a mudança de líder: (a) 0; (b) 60; (c) 120; (d) 180; (e) 210; (f) 240; (g) 270; (h) 330. 
permanece no ambiente até ser totalmente liberado. Enquanto os robôs detectam tal concentração, as regiões da trajetória demarcadas pelo antigo líder ainda atraem os robôs (inclusive o robô 1 que passa a ser seguidor). Porém, como tais regiões não recebem mais feromônio, a tendência é que o deslocamento dos seguidores sejam em direção à região ocupada pelo novo líder, já que em suas proximidades a concentração da substância será constantemente reforçada.

Tabela 5.5: Identificação dos robôs

\begin{tabular}{|c|c|c|c|c|c|c|c|c|c|c|}
\hline Robôs & 1 & 2 & 3 & 4 & 5 & 6 & 7 & 8 & 9 & 10 \\
\hline Níveis antes & 1 & 0 & 2 & 3 & 2 & 2 & 1 & 2 & 1 & 3 \\
\hline Níveis depois & 3 & 2 & 2 & 1 & 3 & 0 & 2 & 1 & 1 & 2 \\
\hline
\end{tabular}

O comportamento de formação também é observado por meio do gráfico da Figura 5.22, que exibe a distância de cada robô ao seu vizinho mais próximo durante a simulação. Nas primeiras iterações (aproximadamente até a iteração 60), a dispersão dos robôs causa a perturbação das curvas. Após o grupo estabelecer uma formação, a tendência é que a distância entre os robôs permaneça constante. Tal situação é verificada entre as iterações 60 e 200, quando há mudança de líder. Em decorrência disto, nota-se, entre as iterações 200 e 220, um período de transição de formação. A partir de então, o grupo mantém, novamente, uma formação estável, o que é observado pela constância das curvas até o término da simulação.

\subsubsection{Adição de Líder}

Além da habilidade de mudança de líder mostrada na seção anterior, o sistema é capaz de adicionar um outro quando necessário. A necessidade de adição é detectada pelo Núcleo Decisório quando o líder do grupo percebe pouca quantidade de feromônio por um longo período de tempo (saturação negativa). Nesta situação, é provável que o grupo esteja explorando regiões não recentemente visitadas. Neste caso, a distribuição de tarefas reduziria o tempo necessário para explorar tais regiões. Considerando esta hipótese e na tentativa de tornar a exploração mais eficiente, um segundo líder é definido para o grupo. A tendência é que o robô escolhido para assumir tal condição atraia os demais de maneira que estes se desvinculem do grupo, formando outro. Com a divisão do grupo, espera-se, então, beneficiar a tarefa de exploração.

Para fins de modelagem, o número de grupos atuando em um ambiente é igual ao número de líderes existentes. No caso descrito em que um segundo líder foi adicionado ao grupo, têm-se, na verdade, dois grupos idênticos 


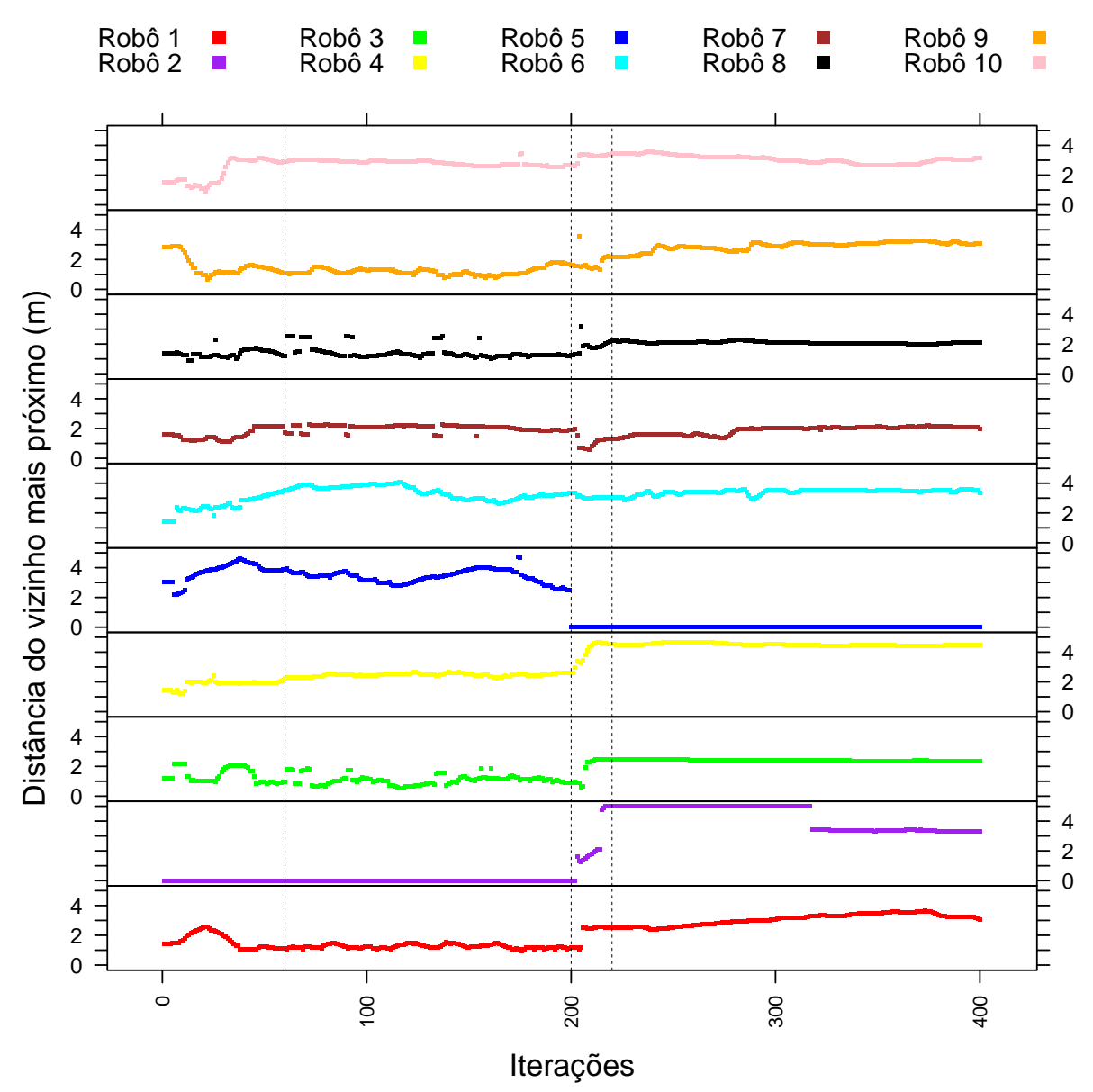

Figura 5.22: Distância do vizinho mais próximo quando há a mudança de líder. 
(mesmo membros), cada qual guiado por um líder. Sendo assim, os seguidores são atraídos pela concentração de feromônio deixada por ambos os líderes e ao mesmo tempo em direção aos seus centroides. A única força que tem sua ação diferenciada para cada um dos seguidores, é a de atração aos vizinhos. Nesta situação, vizinhos adjacentes a um seguidor com nível inferior a ele são distintos entre os grupos. Desta forma, o seguidor é atraído, alternadamente, pelos seus vizinhos adjacentes em relação a um grupo, e depois, a outro. Como o líder é guiado somente pela estratégia de exploração, é inevitável que este se afaste do grupo em busca de regiões com baixa quantidade de feromônio repulsivo. Porém, para que um seguidor, permaneça em um grupo ou em outro, algumas variantes são consideradas em cada um, são elas: a quantidade de vizinhos adjacentes com nível inferior, a distância entre tais vizinhos e o seguidor e a proximidade com o líder (o que define a quantidade de substância detectada).

O experimento conduzido aqui segue configuração semelhante àquela considerada na seção anterior. Assim, 10 robôs (identificados por cores segundo a Tabela 5.3) dispostos em um ambiente amplo sem presença de obstáculos são utilizados para avaliar a tarefa de adição de líder em uma simulação com 400 iterações. Na Figura 5.23, é mostrada a sequência do processo de formação quando essa configuração é adotada. Num primeiro momento, o robô 1 (roxo) (assinalado com uma flecha na Figura 5.23(a)) desempenha a função de líder. Enquanto não ocorre a adição, o grupo estabelece uma formação e a mantém. Na iteração 200, o Módulo de Inicialização é ativado, dando início ao processo de definição de líder. Como já mencionado, o novo líder é escolhido por meio do consenso entre os robôs a respeito da informação da quantidade de feromônio repulsivo detectado por cada um na iteração 200. Utilizando a informação mostrada na Tabela 5.6, o novo líder escolhido é o robô 5 (azul), indicado pela flecha na Figura 5.23(e).

Tabela 5.6: Quantidade de feromônio repulsivo no instante da adição de líder

\begin{tabular}{|c|c|}
\hline Robôs & Quantidade Feromônio \\
\hline 1 & 0.999835 \\
\hline 2 & 0.99977 \\
\hline 3 & 0.999701 \\
\hline 4 & 0.999779 \\
\hline 5 & 0.999526 \\
\hline 6 & 0.999841 \\
\hline 7 & 0.999766 \\
\hline 8 & 0.999895 \\
\hline 9 & 0.999895 \\
\hline 10 & 0.999919 \\
\hline
\end{tabular}




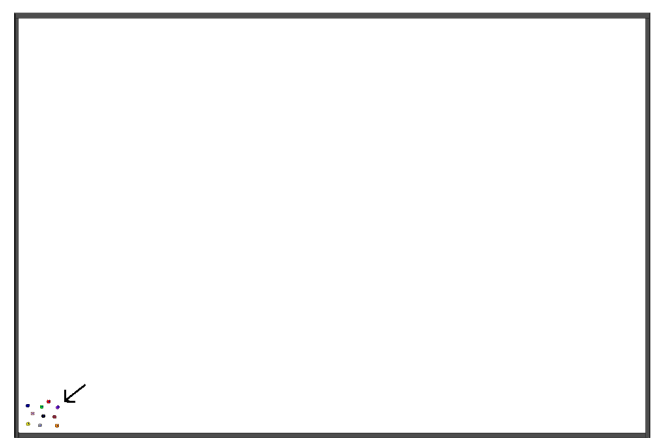

(a)

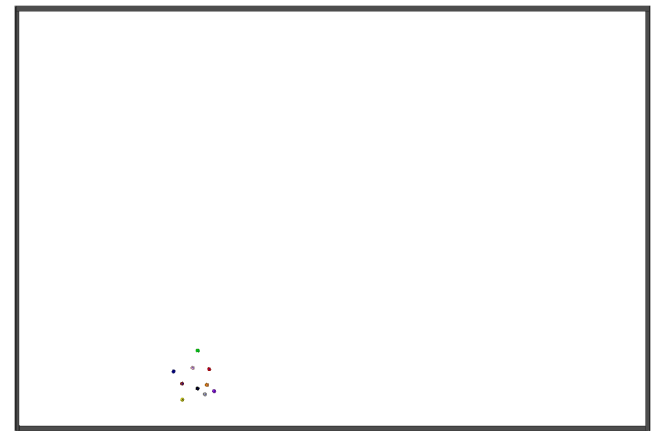

(c)

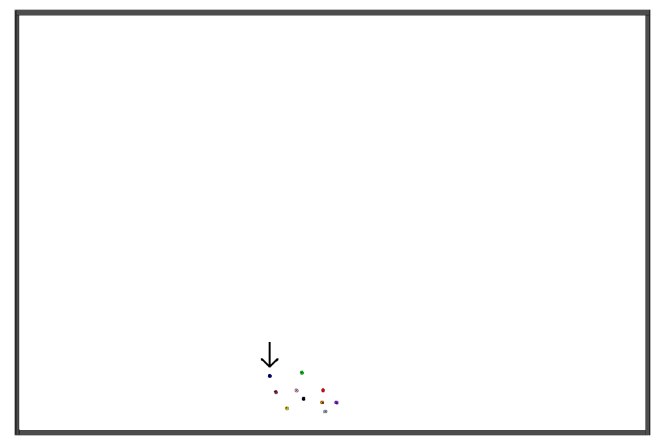

(e)

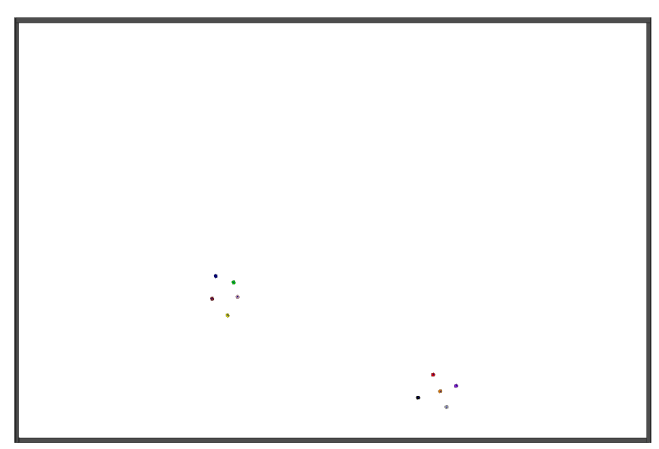

(g)

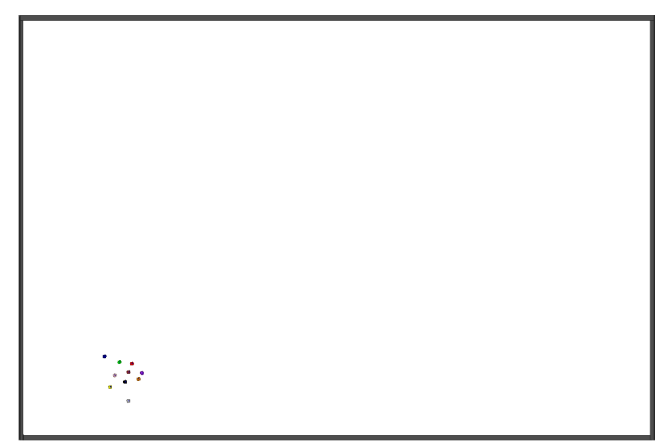

(b)

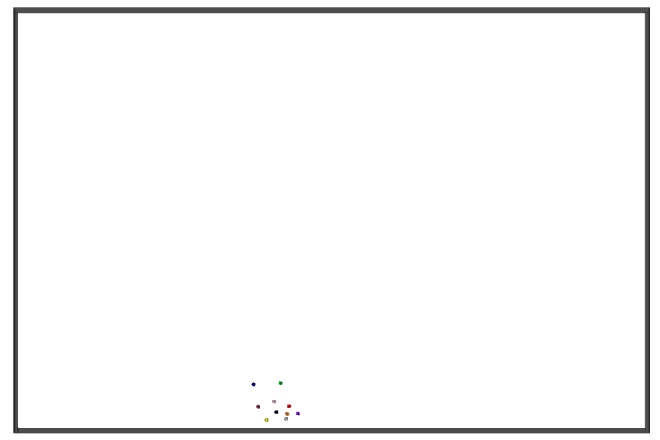

(d)

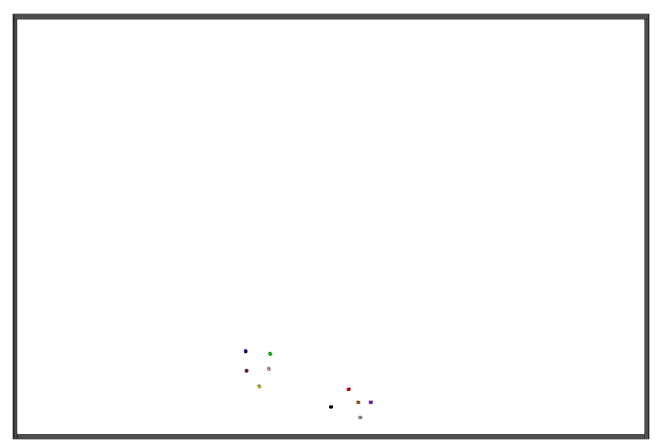

(f)

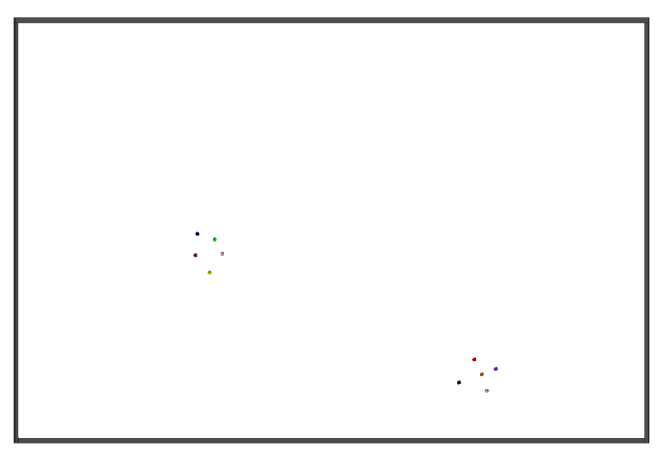

(h)

Figura 5.23: Sequência de quadros da simulação para um grupo de 10 robôs quando há a adição de líder: (a) 0; (b) 60; (c) 120; (d) 180; (e) 210; (f) 240; (g) 300; (h) 330. 


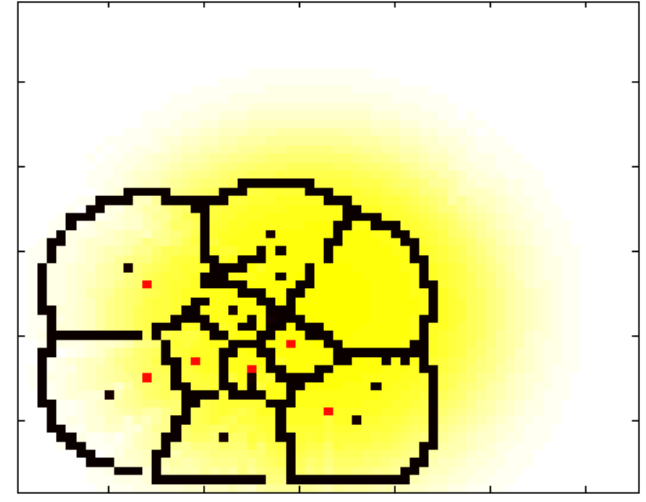

(a)

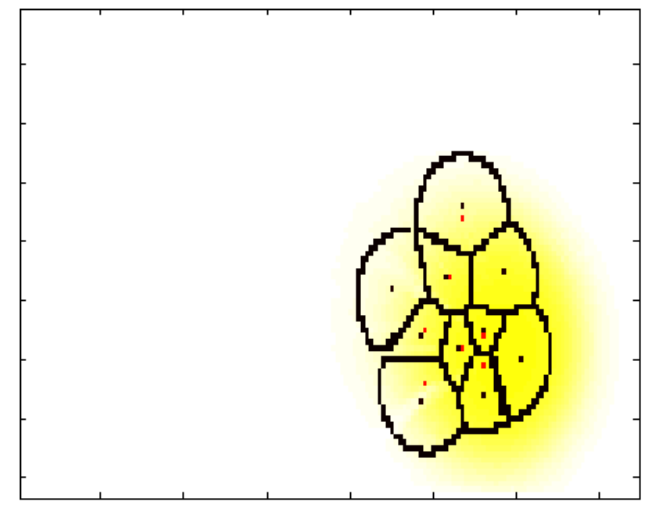

(c)

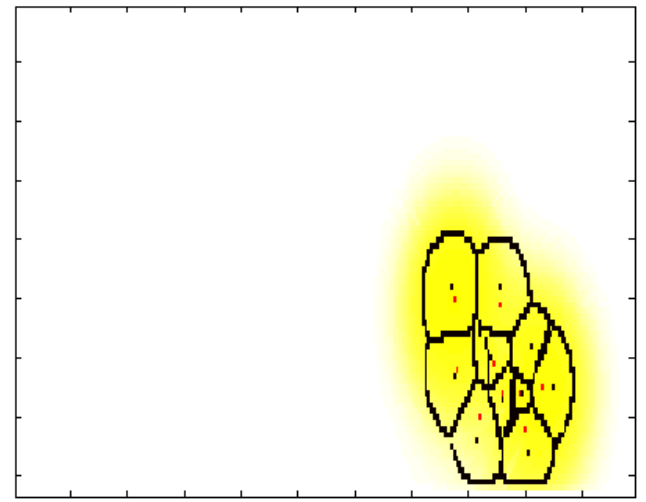

(e)

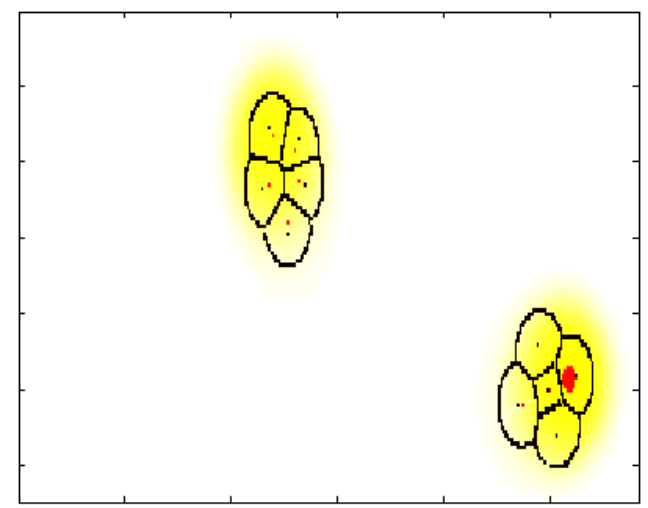

(g)

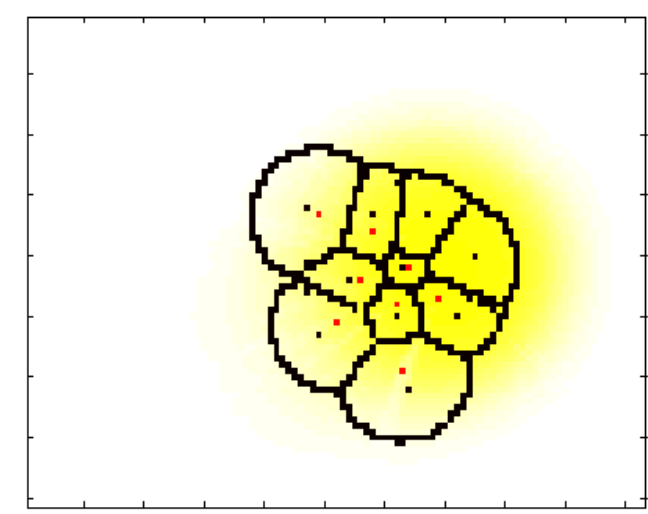

(b)

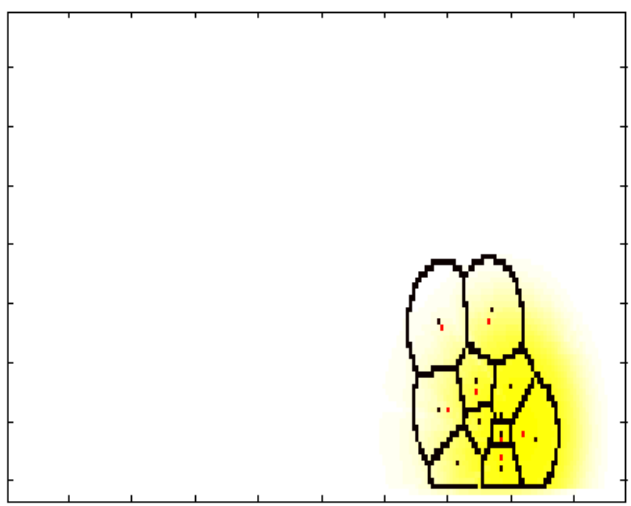

(d)

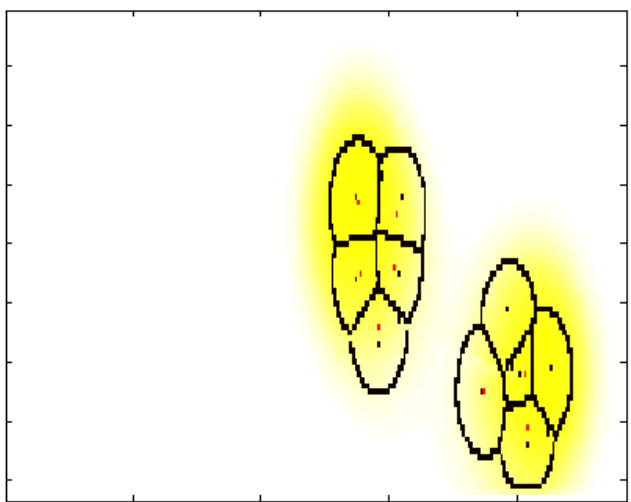

(f)

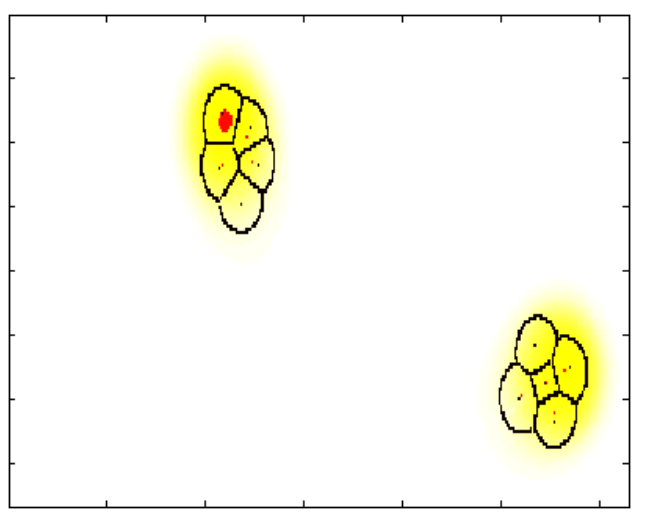

(h)

Figura 5.24: Sequência de quadros da simulação para um grupo de 10 robôs quando há adição de líder: (a) 0; (b) 60; (c) 120; (d) 180; (e) 210; (f) 240; (g) 300; (h) 330. 
A adição de um líder implica na geração de um novo grupo, mesmo que este contenha os mesmos membros do grupo original. Sendo assim, cada seguidor possui dois niveis de hierarquia, cada qual correspondendo a um grupo. Conforme dito anteriormente, os seguidores são atraídos, intercaladamente, pelos vizinhos adjacentes de um grupo e de outro. As forças de atração do líder e do centroide são independentes do grupo considerado para fornecer a orientação do seguidor. À medida que os dois líderes se deslocam, um comportamento observado é a decisão tomada pelos seguidores em se moverem na direção de um dos líderes até que os grupos tornam-se disjuntos. A partir de então, tais grupos se deslocam pelo ambiente de forma independente.

Tal comportamento tem impacto na hierarquia de grupo, conforme pode ser visto na Tabela 5.7. Nela são apresentados os níveis dos robôs em 3 situações: antes da adição, imediatamente após a adição e quando da separação dos grupos. No primeiro caso, há apenas um grupo no ambiente e a definição de nível de hierarquia dos robôs depende de um único líder. Ao ser adicionado um líder, um novo grupo surge, com todos os robôs pertencendo a ambos, exigindo que cada robô tenha dois níveis. No último caso, a separação dos grupos é completa e cada robô retorna a ter apenas um nível. É importante ressaltar que um líder não é seguidor em outro. Entretanto, para manter comunicação entre os robôs, o nível do líder obedece a hierarquia deste outro grupo.

Tabela 5.7: Níveis dos robôs.

\begin{tabular}{|c|c|c|c|c|c|c|c|c|c|c|}
\hline Robôs & 1 & 2 & 3 & 4 & 5 & 6 & 7 & 8 & 9 & 10 \\
\hline Níveis antes & 1 & 0 & 1 & 2 & 2 & 1 & 3 & 2 & 1 & 2 \\
\hline Níveis imediatamente após & 1 & 0 & 1 & 2 & 2 & 1 & 3 & 2 & 1 & 2 \\
\hline Níveis imediatamente após & 2 & 2 & 1 & 2 & 0 & 3 & 1 & 2 & 3 & 1 \\
\hline \multicolumn{10}{|c|}{} \\
\hline Níveis após & 1 & 0 & - & - & - & 1 & - & 2 & 1 & - \\
\hline Níveis após & - & - & 1 & 2 & 0 & - & 1 & - & - & 2 \\
\hline
\end{tabular}

Análise adicional do comportamento do grupo durante a adição de líder é realizada através da informação da distância entre cada robô e seu vizinho mais próximo, mostrada no gráfico da Figura 5.25. Pelo fato dos robôs iniciarem muito próximos uns dos outros, a força de atração do centroide atua com mais intensidade, resultando na expansão do grupo logo nas primeiras iterações (por volta da iteração 60). Deste ponto até a iteração 200, as curvas das distâncias apresentam leves perturbações. Ocorre então a adição de um novo líder (robô 5). Deste instante até a iteração 240, os seguidores se orientam ,de forma intercalada, em direção aos seus vizinhos adjacentes de ambos os grupos, gerando as oscilações observadas naquele intervalo. Quando os grupos 
estão completamente disjuntos (a partir da iteração 240), a distância entre os vizinhos tende, novamente, a ser constante. O comportamento apresentado mostra a capacidade do sistema em fragmentar um grupo de robôs, gerando grupos coesos que cooperaram para realizar a tarefa de exploração.

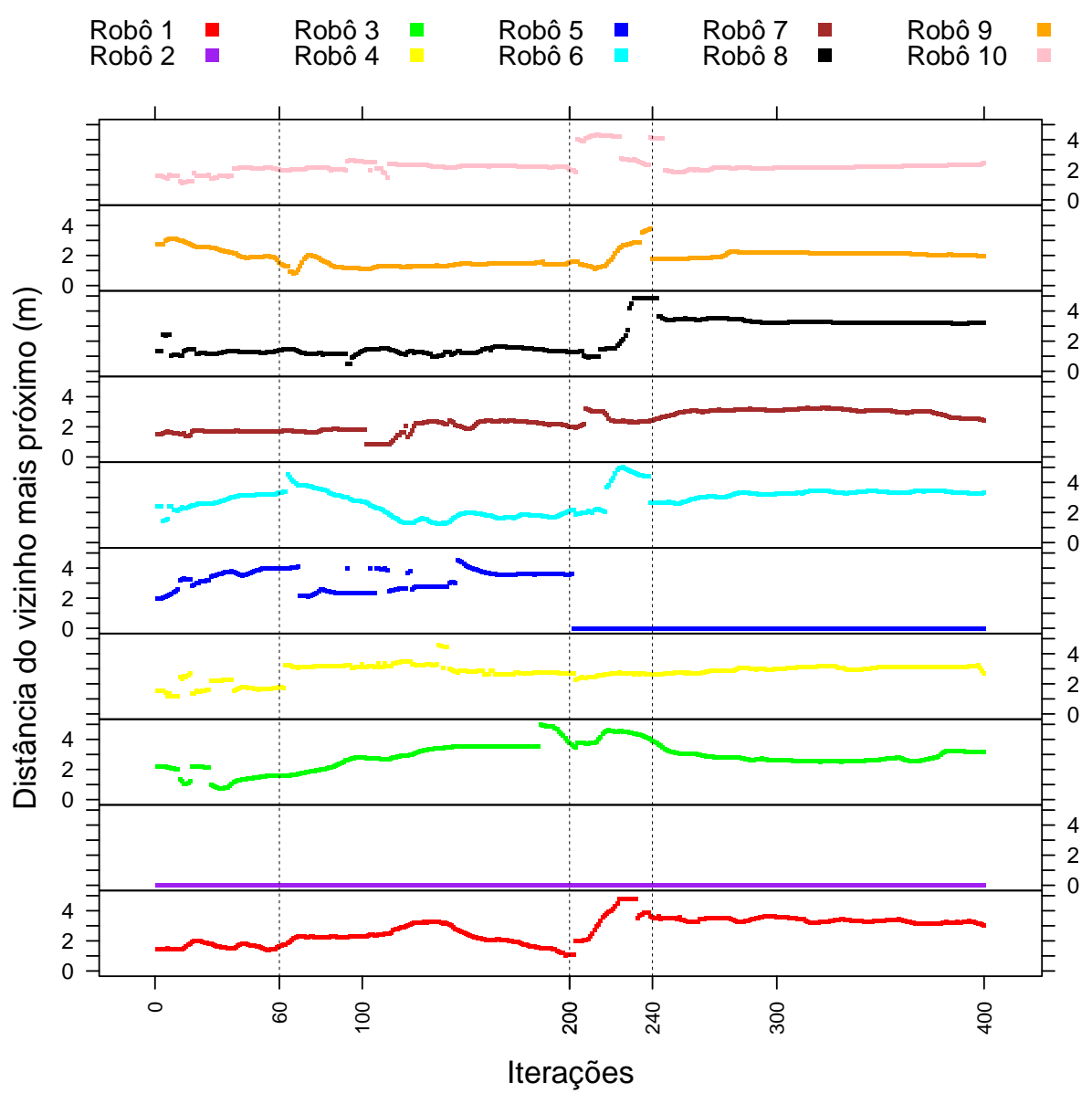

Figura 5.25: Distância do vizinho mais próximo quando há a mudança de líder.

\subsection{Considerações Finais}

O sistema de formação proposto neste capítulo combinou conceitos das abordagens comportamental, líder-seguidor e de consenso, logrando aproveitar as vantagens individuais de cada uma delas e ao mesmo tempo mitigar suas desvantagens. Com isso, conseguiu-se desenvolver um sistema descentralizado, robusto a colisão, adaptável a qualquer ambiente, capaz de ajustar sua topologia e de estabilidade garantida. Basicamente ele é composto por um conjunto de robôs que interagem de forma direta e indireta, cada qual desempenha funções atribuídas a seu papel no grupo. Cada robô é dotado de uma estrutura formada por diversos módulos que são ativados e desativados de acordo com seu estado atual. A partir de informações provenientes do campo sensorial, o núcleo decisório é o responsável por atualizar o estado do 
robô atribuindo a este a condição de líder ou seguidor. Além disso, o núcleo é capaz de detectar situações em que o grupo ao qual o robô pertence não possui líder e também identificar uma situação eminente de colisão.

Dentre os módulos da estrutura dos robôs, três se destacam por estar relacionados intrinsicamente com as abordagens citadas no parágrafo anterior. $\mathrm{O}$ primeiro deles é o Módulo de Inicialização, que por meio do consenso entre os robôs, auxilia no processo de definição de líder. O segundo, Módulo Líder, associado à abordagem líder-seguidor, influencia diretamente no deslocamento do grupo, uma vez que o líder é guiado pela estratégia de exploração. O terceiro, com papel fundamental para a manutenção da formação, é o principal responsável pela coesão do grupo. Associado à abordagem comportamental, o Módulo Seguidor agrega as forças de atração a fim de aproximar os robôs, evitar que estes colidam (e ao mesmo tempo uma dispersão desordenada) e prover o deslocamento em direção à trajetória do líder.

Com o objetivo de avaliar o comportamento deste sistema, simulações computacionais foram realizadas. Elas abrangeram diversos aspectos que um sistema real deve considerar. No primeiro experimento, a capacidade dos robôs em se dispersar foi avaliada, considerando somente a força de atração do centroide. Nesta situação, observou-se que os robôs se dispersaram apenas até certo ponto. A distância estabelecida entre eles ao atingirem seu centroide foi definida de acordo com o tamanho do raio de Voronoi. A escolha correta deste raio tanto evita que os robôs se afastem completamente do grupo quanto que eles colidam entre si. Como consequência, a área de cobertura do grupo é maximizada, favorecendo a tarefa de exploração.

Num segundo momento, os experimentos foram realizados em um ambiente de maior complexidade, exercitando diversas características do sistema. Na simulação, o movimento dos robôs foi regido pela combinação das diversas forças de atração, em um ambiente com duas áreas amplas interligadas por um corredor estreito. Nesta configuração, constatou-se a capacidade dos robôs em estabelecer uma formação e mantê-la estável enquanto obstáculo algum for encontrado. Ao se deparar com o corredor, o sistema mostrouse robusto, ajustando sua topologia e adaptando-se à sua nova percepção de ambiente. Durante a passagem no corredor, o grupo assumiu disposição alongada respeitando os limites da região explorada. A expansão do grupo é novamente observada ao entrar na segunda área ampla do ambiente. Estes resultados confirmaram a eficiência em deslocar os robôs de maneira conjunta e coesa, sugerindo a adequação do sistema em tarefas de navegação em ambientes desconhecidos.

Por fim, as habilidades do sistema em alterar e adicionar um líder foram analisadas. Embora esses eventos tenham sido provocados, o foco estava em 
observar o comportamento do grupo durante e após a ocorrência de tais eventos. Inicialmente, o comportamento exibido pelo grupo é semelhante àquele apresentado no experimento mencionado no parágrafo anterior, ou seja, notase que o grupo se expande nas primeiras iterações até que uma formação seja estabelecida. Nos instantes em que um novo líder é requisitado, observa-se a capacidade do grupo em adaptar sua topologia. Porém, tal adaptação é distinta àquela causada pelo formato do ambiente. Com a presença de um novo líder, o nível hierárquico dos robôs também são alterados. Mesmo assim, pode-se perceber a habilidade do grupo em manter a formação coesa. No evento de mudança de líder, a direção de movimento do grupo como um todo foi alterada bruscamente devido também à atualização de nível dos robôs. Para o evento de adição de líder, um grupo adicional foi originado com os mesmos membros do grupo antigo. No processo de separação dos grupos, houve uma pequena oscilação no comportamento dos seguidores que passaram a seguir os dois grupos de maneira alternada, como era esperado. Após a separação total, ambos os grupos voltam a ajustar sua topologia em busca da estabilidade da formação. Isto enfatiza a robustez do sistema a distúrbios. 


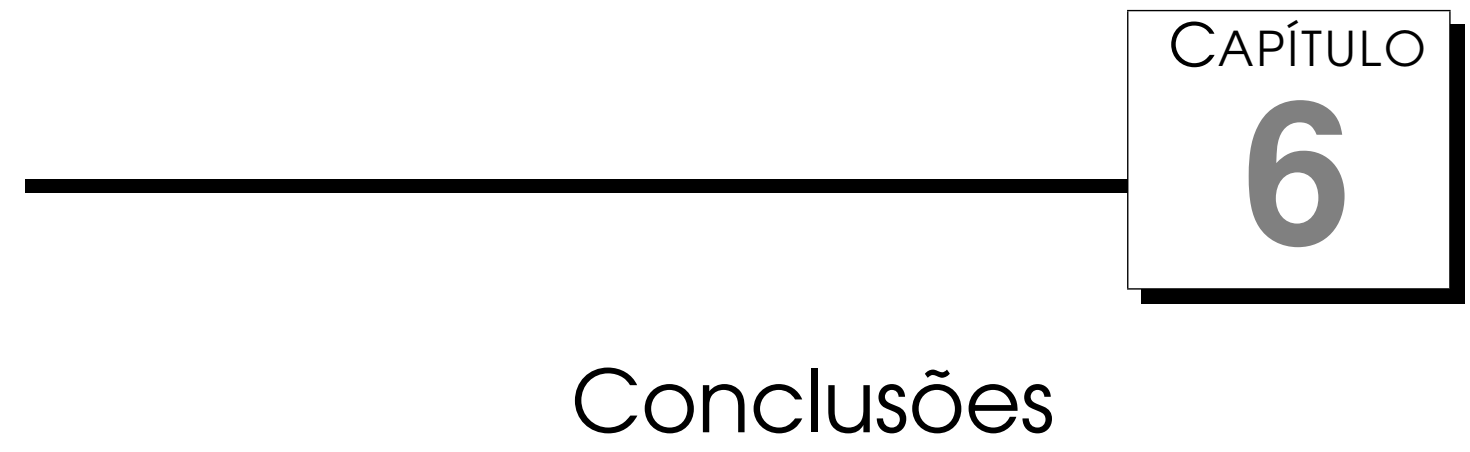

O foco da pesquisa desenvolvida durante este doutorado foi a investigação de estratégias bioinspiradas para a coordenação de robôs móveis em sistemas de múltiplos agentes atuando em ambientes desconhecidos. Nos cenários aqui considerados, o comportamento social de formigas ofereceu uma analogia natural adequada à concepção de soluções algorítmicas atuantes em duas frentes: coordenação de robôs para fins de vigilância e coordenação de robôs visando a manutenção da formação do grupo. As contribuições originais oriundas deste trabalho são destacadas a seguir, estratificadas pela aplicação.

\subsection{Contribuições}

No primeiro momento, o enfoque foi no desenvolvimento da estratégia de coordenação IAS-SS (Inverse Ant System-Based Surveillance System), que, embora compartilhe das principais características do sistema artificial de colônias de formigas proposto por Dorigo (1992), apresenta como diferencial marcante a utilização de feromônio repulsivo para determinar a dinâmica comportamental dos agentes. Isto estimula que o grupo de robôs dispersos no ambiente a ser vigiado busque, continuamente, explorar regiões não visitadas recentemente. Desta forma, logrou-se desenvolver um sistema de vigilância reativo, adaptativo e distribuído, em que cada robô move-se de maneira independente e se orienta, através de comunicação indireta com seu pares, segundo as informações que percebe do ambiente.

O conjunto abrangente de simulações conduzido no Capítulo 4 forneceu evidências positivas acerca do desempenho do IAS-SS em diversos aspectos. Inicialmente, as duas variantes da estratégia, designadas $\mathrm{AE}$ (Amostragem 
Estocástica) e AEE (Amostragem Estocástica Elitista) foram avaliadas tendo como critério a média do número de ciclos de vigilância e a média de iterações nos intervalos de segurança. A comparação entre as variantes evidenciou a superioridade da posterior, o que era esperado, dada sua natureza elitista. Além disso, ambas foram melhores que uma estratégia totalmente randômica. Em seguida, foi investigada a robustez do IAS-SS quanto à disposição inicial dos robôs na área vistoriada. Neste sentido, duas situação foram testadas: CS (Configuração Separado) e CA (Configuração Agrupado), em três tamanhos de ambientes. Os resultados obtidos tornaram patente que, no decorrer das iterações, comportamento repulsivo do feromônio depositado é capaz de espaçar os agentes do grupo, permitindo uma cobertura adequada tanto para CS quanto para CA, embora a primeira seja superior. Em relação ao número de robôs, a expectativa em relação às vantagens de se considerar grupos maiores foi confirmada. Outrossim, verificou-se que mesmo um número reduzido de robôs foi capaz de realizar a tarefa de vigilância. Este resultado sugere a capacidade do sistema em lidar com eventuais falhas nos robôs. Posteriormente, experimentos envolvendo remodelagem do ambiente permitiram observar a maleabilidade do IAS-SS em relação à disposição dos obstáculos. Nesse ponto, ressalta-se que, mesmo com menos opções de rotas disponíveis aos robôs, devido à maior complexidade do ambiente, o monitoramento foi realizado a contento. Por fim, a forma de liberação de feromônio pelos robôs foi investigada. Três métodos foram comparados: FT (Feromônio para Trás), FR (Feromônio ao Redor) e FF (Feromônio para Frente) Nesse ponto, a solução biológica foi subjugada por considerações práticas, uma vez que a liberação de feromônio segundo o método FF mostrou-se o mais adequado para a exploração do ambiente considerado.

Do aprendido pelos resultados experimentais com o IAS-SS, pode-se salientar que tanto a faceta exploratória quanto a de vigilância do IAS-SS foram satisfatoriamente verificadas. Em relação à primeira, como os robôs são direcionados para regiões com pouca quantidade de feromônio, o que significa que tais áreas ou são desconhecidas ou não foram recentemente exploradas, a tarefa é completada. Quanto à segunda, destaca-se o comportamento emergente de manter os robôs distantes uns dos outros, possibilitando que cada um monitore regiões distintas do ambiente. O êxito dessa estratégia simples e eficiente foi publicado em fóruns nacionais e internationais por meio de artigos científicos:

- CAlvo, R. ; OliveirA, J. R. ; Figueiredo, M. ; ROMERO, R. A. F. - A Distributed, Bio-Inspired Coordination Strategy for Multiple Agent Systems Applied to Surveillance Tasks in Unknown Environments. In: International Joint Conference on Neural Networks, 2011, San Jose, CA, 
USA. Proceedings of IJCNN'2011. Los Alamos : IEEE Press, 2011. p. 3248-3255.

- CAlvo, R. ; OliveirA, J. R. ; Figueiredo, M. ; ROMERO, R. A. F. - Inverse ACO Applied for Unknown Environment Exploration. In: The Third International Conference on Advanced Cognitive Technologies and Applications, 2011, Rome, Italy. Proceedings of COGNITIVE'2011, 2011. p. $142-147$.

- CAlVO, R. ; OlIVEIRA, J. R. ; FIGUEIREDO, M. ; ROMERO, R. A. F. . Bioinspired coordination of multiple robots systems and stigmergy mechanims to cooperative exploration and surveillance tasks. Cybernetics and Intelligent Systems (CIS), 2011 IEEE 5th International Conference on , vol., no., pp.223-228, 17-19 Sept. 2011.

- CAlvo, R. ; OliveirA, J. R. ; Figueiredo, M. ; ROMERO, R. A. F. - Uma Estratégia de Coordenação Distribuída e Bio-Inspirada para Sistema Multiagentes Aplicada à Tarefa de Vigilância em Ambientes Desconhecidos. In: X Congresso Brasileiro de Inteligência Computacional (CBIC), 2011, Fortaleza - CE. Anais do X CBIC, 2011. p. 1-9.

- CAlvo, R. ; OliveirA, J. R. ; Figueiredo, M. ; ROMERO, R. A. F. . A Bio-Inspired Coordination Strategy for Controlling of Multiple Robots in Surveillance Tasks. Special issue on Applied Swarm Intelligence, 2011 (submetido).

No segundo momento, dedicou-se ao desenvolvimento da estratégia de coordenação de múltiplos robôs para formação. Ela foi denominada SAFS (SelfAdaptative Formation System). Sua concepção foi baseada em três abordagems de formação: comportamental, líder-seguidor e de consenso. Da primeira, o sistema utiliza uma combinação dos comportamentos repulsivos e atrativos dos agentes a fim de determinar a formação. Da segunda, tem-se o método de deslocamento do grupo, segundo o qual um dos robôs é definido como líder que torna-se responsável por determinar a hierarquia do grupo e direcionar o movimento. Da terceira, a definição de novo líder, caso o atual falhe, é feita por consenso entre os membros do grupo.

Tal como foi elaborado, o SAFS apresenta as seguintes características desejáveis em sistemas de múltiplos robôs: 1) descentralização, 2) livre de colisão, 3) adaptação, 4) topologia, 5) dinâmica e 6) estabilidade. A descentralização tem por objetivo distribuir as tarefas de formação entre o grupo para não sobrecarregar um único agente. Por ser livre de colisão, essa estratégia garante que seus robôs não colidirão com obstáculos do ambiente e entre eles próprios, mantendo a integridade e eficiência do grupo. A característica de adaptação 
é responsável por manter a formação em diversas configurações de ambiente, podendo ser utilizada em cenários onde o mapa não é conhecido a priori. A topologia dinâmica possibilita que a formação se ajuste a uma determinada situação, descartando quaisquer formações definidas previamente. A estabilidade garante que o grupo se mantenha coeso independente da configuração do ambiente, da topologia adotada para a formação e da quantidade de robôs.

Através de extensivas simulações computacionais, pôde-se avaliar o comportamento do SAFS. Inicialmente, buscou-se verificar a habilidade dispersiva dos robôs, considerando apenas a força de atração do centroide. Os resultados evidenciaram que o sistema foi capaz de garantir a dispersão no grupo, impedindo colisões internas e, ao mesmo tempo, evitando que os robôs se afastassem demasiadamente. Percebeu-se ainda que, com a diminuição da redundância das leituras sensoriais dos robôs, houve um aumento da área de cobertura do grupo. Posteriormente, avaliou-se que a agregação de forças de atração do centroide, do líder e dos vizinhos pôde estimular o deslocamento do grupo enquanto mantinha a coesão do mesmo. Por último, a robustez da estratégia foi analisada por meio da adição e troca de líder. Quando tais eventos ocorrem, o grupo se expande nas primeiras iterações, exibindo uma pequena oscilação no comportamento dos seguidores, para que, em seguida, uma nova formação se estabeleça com os dois novos grupos. Isso mostra que o grupo é capaz de se adaptar a novas topologias, mantendo-se coeso. Como um todo, os resultados empíricos nesse conjunto de experimentos corroboram que o SAFS possui todas as características esperadas de uma estratégia de formação. O êxito dessa estratégia simples e eficiente foi divulgado em fóruns científicos por meio de artigos:

- DOI, D. T. ; CALVO, R. ; ROMERO, R. A. F. . Sistema de formação inteligente de robôs baseado em PSO aplicado em futebol de robôs. In: XVIII Congresso Brasileiro de Automática, 2010, Bonito, MS, Brasil. XVIII Congresso Brasileiro de Automática, 2010.

- DOI, D. T. ; CALVO, R. ; ROMERO, R. A. F. . Multirobot Formation for Soccer Robots Using Particle Swarm Optimization. In: III Workshop on Computational Intelligence, 2010, São Bernardo do Campo, SP. Proceedings of III Workshop on Computational Intelligence, 2010.

\subsection{Trabalhos futuros}

Como continuidade, pretende-se estudar e analisar a influência de outros parâmetros da estratégia IAS-SS, considerados importantes quando utiliza-se a comunicação indireta, a saber: taxas de evaporação e dispersão de feromônio. De acordo com os experimentos realizados, notou-se que não há um valor 
ótimo para tais parâmetros. No entanto, uma análise mais profunda seria benéfica para confirmar esta hipótese. Espera-se, portanto, que em ambientes reduzidos, taxas menores para a evaporação podem tornar a estratégia mais eficaz, enquanto que em ambientes amplos, é desejável taxas maiores, uma vez que o caminho para percorrer todo o ambiente é maior. O número de robôs também é um ponto que deve ser considerado e analisado para definir a taxa de evaporação. A presença de muitos robôs sugere que a taxa deve ser reduzida. Neste cenário, mesmo após o período em que os robôs já se encontram dispersos, a distância entre eles é curta. Dessa forma, a área destinada a um robô, para ser monitorada, é menor. Outro fator que pode influenciar no desempenho da estratégia é a taxa de dispersão de feromônio, cujo valor indica o tamanho da área atingida pela liberação da substância

Em relação à estratégia SAFS, deseja-se aperfeiçoar as habilidades de mudança e adição de líder. Como observado nas Seções 5.4.3 e 5.4.4, os experimentos foram realizados com o intuito de, somente, demonstrar o comportamento do grupo de robôs quando há a mudança e adição de líder, respectivamente. No entanto, tais eventos foram provocados por um agente externo (o autor desta tese). Assim, alguns parâmetros do sistema foram prédefinidos. Neste sentido, propõe-se uma estratégia de aprendizado que seja capaz de promover o desempenho do sistema, encontrando valores adequados para tais parâmetros. Com esta estratégia, ao invés de fixar um valor para determinar o instante em que o robô líder passa para o estado de saturação positiva/negativa, este deve ser capaz de aprender como interpretar a informação dada pela concentração de feromônio detectada. E, a partir de então, decidir se este é o momento adequado para que ocorra a mudança ou adição de um líder.

Outro ponto a ser pesquisado e incluído na estratégia SAFS é a habilidade de unir grupos. Dados dois ou mais grupos disjuntos, ao se encontrarem (e não serem mais disjuntos), alguns líderes podem passar para a condição de seguidor. Os líderes remanescentes da junção devem ser aqueles cujo histórico de captação de feromônio mostra que sua direção de movimento é favorável à tarefa de exploração. Sendo assim, uma proposta consiste em introduzir aqui uma estratégia de aprendizado para que os robôs sejam aptos em identificar o evento de junção e definir de forma adequada quais líderes devem ser operados no modo seguidor.

Considerando as duas propostas imediatamente anteriores para trabalhos futuros, está prevista a aplicação da estratégia IAS-SS para um grupo de robôs com a capacidade de manter uma formação. Dessa forma, as habilidades do sistema, tais como mudança, adição de líder e junção de grupos, podem ser melhor analisadas. A expectativa é que os robôs mantenham a formação até 
que o líder seja saturado (positiva ou negativamente). Assim, o grupo altera sua direção ou se divide na busca de alcançar a melhor eficiência da tarefa. Uma vez que o grupo esteja particionado, haverá oportunidades para verificar a habilidade de junção.

Para a aplicação de ambas as estratégias de coordenação propostas em ambientes reais, são sugeridas duas abordagens. A primeira consiste em equipar robôs reais com dispositivos que lançam algum tipo de substância química e sensores de odor. Se for considerada a estratégia SAFS, é necessário o desenvolvimento de um método de localização, já que a posição relativa dos robôs são informações úteis para manter a formação. No caso de utilizar a estratégia IAS-SS com robôs isolados, tal método é desnecessário, pois os robôs são guiados e, consequentemente, dispersos no ambiente apenas a partir da concentração de feromônio detectada. Na segunda abordagem, o dispositivo que lança substância química, assim como o sensor de odor, são dispensáveis. Somente com a utilização de um sensor de distância a obstáculo, as estratégias IAS-SS e SAFS podem ser implantadas. Para tanto, aplicando um método de mapeamento do tipo grade de ocupação, as células do mapa gerado podem ser utilizadas também para hospedar outro valor, que indica a quantidade de feromônio virtual. Dessa forma, a área de dispersão da substância virtual corresponde à area de abrangência do sensor de distância, e o mesmo equivale para a detecção. No entanto, independente da estratégia de coordenação adotada, é necessário a aplicação de um método de localização para cada robô manter seu mapa. 


\section{Referências Bibliográficas}

Abaid, N. and Porfiri, M. (2010). Collective behavior of fish shoals in onedimensional annular domains. In American Control Conference (ACC), 2010, pages 63 -68. Citado na página 19.

Agmon, N., Hazon, N., and Kaminka, G. A. (2009). The giving tree: constructing trees for efficient offline and online multi-robot coverage. Annals of Mathematics and Artificial Intelligence, 52(2-4):143-168. Citado na página 14.

Al khawaldah, M., Livatino, S., and Lee, D. (2010). Reduced overlap frontierbased exploration with two cooperating mobile robots. In Industrial Electronics (ISIE), 2010 IEEE International Symposium on, pages 2859 -2864. Citado na página 11.

Alboul, L., Abdul-Rahman, H., Haynes, P., Penders, J., and Tharin, J. (2010). An approach to multi-robot site exploration based on principles of selforganisation. In Liu, H., Ding, H., Xiong, Z., and Zhu, X., editors, Intelligent Robotics and Applications, volume 6425 of Lecture Notes in Computer Science, pages 717-729. Springer Berlin / Heidelberg. 10.1007/978-3-64216587-0_65. Citado nas páginas 15, 25, e 96.

Alighanbari, M. and How, J. P. (2005). Cooperative task assignment of unmanned aerial vehicles in adversarial environments. In American Control Conference (ACC), pages 4661-4666 vol. 7, Portland, OR. Citado na página 22.

Amigoni, F., Basilico, N., and Gatti, N. (2009). Finding the optimal strategies for robotic patrolling with adversaries in topologically-represented environments. In Robotics and Automation, 2009. ICRA 'O9. IEEE International Conference on, pages 819-824. Citado na página 39.

Aoki, I. (1982). A simulation study on the schooling mechanism in fish. Bulletin of the Japanese Society of Scientific Fisheries, 48(8):1081-1088. Citado nas páginas 19 e 22 . 
Argall, B. D., Chernova, S., Veloso, M., and Browning, B. (2009). A survey of robot learning from demonstration. Robot. Auton. Syst., 57(5):469-483. Citado na página 5.

Arkin, R. C. (1999). Behavior-Beased Robotics. MIT Press. Citado na página 4.

Aureli, M. and Porfiri, M. (2010). Coordination of self-propelled particles through external leadership. EPL (Europhysics Letters), 92(4):40004. Citado na página 19.

Balch, T. and Akin, R. (1998). Behavior-based formation control for multirobot teams. IEEE Transactions on Robotics and Automation, 14(6):926-939. Citado na página 90.

Barnes, L., Garcia, R., Fields, M., and Valavanis, K. (2008). Swarm formation control utilizing ground and aerial unmanned systems. In Intelligent Robots and Systems, 2008. IROS 2008. IEEE/RSJ International Conference on, page 4205. Citado na página 22.

Bauer, F., Bristow, J., Folta, D., Hartman, K., Quinn, D., and How, J. P. (1997 (AIAA-1997-3821)). Satellite formation flying using an innovative autonomous control system (AUTOCON) environment. In AIAA Guidance, Navigation, and Control Conference (GNC), New Orleans, LA. Citado na página 22.

Beckers, R., Deneubourg, J. L., and Goss, S. (1992). Trails and u-turns in the selection of a path by the ant lasius niger. Journal of Theoretical Biology, pages 397-415. Citado na página 33.

Bellingham, J., Tillerson, M., Alighanbari, M., and How, J. (2002). Cooperative path planning for multiple uavs in dynamic and uncertain environments. In Decision and Control, 2002, Proceedings of the 41st IEEE Conference on, volume 3, pages 2816 - 2822 vol.3. Citado na página 22 .

Bishop, C. M. (1996). Neural networks for pattern recognition. Oxford University Press. Citado na página 29.

Blum, C. (2005). M. dorigo and t. stützle, , ant colony optimization (2004) mit press,cambridge, ma 300 pp. Artificial Intelligence, 165(2):261-264. Citado na página 31.

Blum, C. and Roli, A. (2003). Metaheuristics in combinatorial optimization: Overview and conceptual comparison. ACM Computing Surveys, 35(3):268308. Citado na página 30. 
Bonabeau, E., Dorigo, M., and Theraulaz, G. (1999). Swarm intelligence: from natural to artificial systems. Oxford University Press, Inc., New York, NY, USA. Citado nas páginas 30, 31, 34, e 40.

Bonabeau, E., Dorigo, M., and Theraulaz, G. (2000). Inspirationfor optimization from social insect behavior. Nature. Citado nas páginas 31 e 49.

Bullnheimer, B., Hartl, R. F., and Strauß, C. (1997). A new rank based version of the ant system - a computational study. Central European Journal for Operations Research and Economics, 7:25-38. Citado na página 38.

Bulusu, N., Heidemann, J., Estrin, D., and Tran, T. (2003). Self-configuring localization systems: Design and experimental evaluation. ACM TRANSACTIONS ON EMBEDDED COMPUTING SYSTEMS, 3:24-60. Citado na página 90.

Burgard, W., Moors, M., Fox, D., Simmons, R., and Thrun, S. (2000). Collaborative multi-robot exploration. In Robotics and Automation, 2000. Proceedings. ICRA 'OO. IEEE International Conference on, volume 1, pages 476-481 vol.1. Citado na página 12 .

Burger, M., Notarstefano, G., Allgower, F., and Bullo, F. (2011). A distributed simplex algorithm and the multi-agent assignment problem. In American Control Conference (ACC), 2011, pages 2639 -2644. Citado na página 23.

Caetano, F., Zara, F., and Jaffé, K. (2002). Formigas: biologia e anatomia. F. H. C. Citado na página 90.

Calvo, R. (2007). Arquitetura híbrida inteligente para navegação autônoma de robôs. Dissertação de Mestrado, ICMC-USP. Citado na página 122 .

Calvo, R., de Oliveira, J., Figueiredo, M., and Francelin Romero, R. (2011a). A distributed, bio-inspired coordination strategy for multiple agent systems applied to surveillance tasks in unknown environments. In Neural Networks (IJCNN), The 2011 International Joint Conference on, pages 3248 3255. Citado na página 56.

Calvo, R., de Oliveira, J., Figueiredo, M., and Francelin Romero, R. (2011b). Inverse aco applied for exploration and surveillance in unknown environments. In COGNITIVE, 2011 : The Third International Conference on Advanced Cognitive Technologies and Applications, pages $142-147$. Citado na página 56.

Calvo, R., de Oliveira, J., Figueiredo, M., and Romero, R. (2011c). Bio-inspired coordination of multiple robots systems and stigmergy mechanims to cooperative exploration and surveillance tasks. In Cybernetics and Intelligent 
Systems (CIS), 2011 IEEE 5th International Conference on, pages 223 -228. Citado na página 56.

Camazine, S., Franks, N. R., Sneyd, J., Bonabeau, E., Deneubourg, J.-L., and Theraula, G. (2001). Self-Organization in Biological Systems. Princeton University Press, Princeton, NJ, USA. Citado na página 31.

Cao, Y., Fukunaga, A., Kahng, A., and Meng, F. (1995). Cooperative mobile robotics: antecedents and directions. In Intelligent Robots and Systems 95. 'Human Robot Interaction and Cooperative Robots', Proceedings. 1995 IEEE/RSJ International Conference on, volume 1, pages 226 -234 vol.1. Citado na página 9.

Castro, L. N. (2006). Fundamentals of Natural Computing: Basic Concepts, Algorithms, and Aplications. Chapman \& Hall/CRC. Citado nas páginas 29, 30,31 , e 34 .

Cheng, T. M. and Savkin, A. V. (2011). Decentralized control for mobile robotic sensor network self-deployment: barrier and sweep coverage problems. Robotica, 29(2):283-294. Citado na página 15.

Cheng, T. M., Savkin, A. V., and Javed, F. (2011). Decentralized control of a group of mobile robots for deployment in sweep coverage. Robot. Auton. Syst., 59:497-507. Citado na página 16.

Chevaleyre, Y. (2004). Theoretical analysis of the multi-agent patrolling problem. In Intelligent Agent Technology, 2004. (IAT 2004). Proceedings. IEEE/WIC/ACM International Conference on, pages 302 - 308. Citado na página 39.

Choset, H. (2001). Coverage for robotics: A survey of recent results. Annals of Mathematics and Artificial Intelligence, 31:113-126. Citado na página 13.

Choset, H. and Pignon, P. (1997). Coverage Path Planning: The Boustrophedon Cellular Decomposition. Citado na página 13.

Chu, H.-N., Glad, A., Simonin, O., Sempe, F., Drogoul, A., and Charpillet, F. (2007). Swarm approaches for the patrolling problem, information propagation vs. pheromone evaporation. In Tools with Artificial Intelligence, 2007. ICTAI 2007. 19th IEEE International Conference on, volume 1, pages 442 449. Citado na página 40.

Consolini, L., Morbidi, F., Prattichizzo, D., and Tosques, M. (2009). Stabilization of a hierarchical formation of unicycle robots with velocity and curvature constraints. Robotics, IEEE Transactions on, 25(5):1176-1184. Citado na página 96. 
Cortes, J., Martinez, S., Karatas, T., and Bullo, F. (2002). Coverage control for mobile sensing networks. In Robotics and Automation, 2002. Proceedings. ICRA 'O2. IEEE International Conference on, volume 2, pages $1327-1332$. Citado na página 90.

Cortes, J., Martinez, S., Karatas, T., and Bullo, F. (2004). Coverage control for mobile sensing networks. Robotics and Automation, IEEE Transactions on, 20(2):243 - 255. Citado nas páginas 13 e 94 .

Couzin, I. D. (2009). Collective cognition in animal groups. Trends in Cognitive Sciences, 13(1):36-43. Citado na página 17.

Couzin, I. D., Ioannou, C. C., Demirel, G., Gross, T., Torney, C. J., Hartnett, A., Conradt, L., Levin, S. A., and Leonard, N. E. (2011). Uninformed Individuals Promote Democratic Consensus in Animal Groups. Science, 334(6062): 1578-1580. Citado na página 19.

Couzin, I. D. and Krause, J. (2003). Self-organization and collective behavior in vertebrates. Advances in the Study of Behavior, 32(1):1-109. Citado na página 17.

Cucker, F. and Smale, S. (2007). Emergent behavior in flocks. Automatic Control, IEEE Transactions on, 52(5):852 -862. Citado na página 19.

Cury, P., Fréon, P., Moloney, C., Shannon, L., and Shin, Y.-J. (2005). Processes and patterns of interactions in marine fish populations : an ecosystem perspective. In The global coastal ocean : multiscale interdisciplinary processes, volume 13 of The sea: Ideas and Observations on Progress in the Study of the Seas, pages 475-554. Harvard University. Citado na página 21.

Dam, J. V. (1998). Environment modelling for mobile robots: neural learning for sensor fusion. PhD thesis, Universiteit van Amsterdam, Faculteit WINS, Amsterdam, The Netherlans. Citado na página 10.

Dasgupta, P. (2008). A multiagent swarming system for distributed automatic target recognition using unmanned aerial vehicles. Systems, Man and $\mathrm{Cy}$ bernetics, Part A: Systems and Humans, IEEE Transactions on, 38(3):549 -563. Citado na página 22.

de Berg, M., Cheong, O., van Kreveld, M., and Overmars, M. (2008). Computational Geometry: Algorithms and Applications. Springer-Verlag, 3rd edition. Citado nas páginas 17 e 93.

de Berg, M., van Kreveld, M., Overmars, M., and Schwarzkopf, O. (2000). Computational Geometry: Algorithms and Applications. Springer-Verlag, second edition. Citado na página 94. 
de Freitas, E., Heimfarth, T., Ferreira, A., Pereira, C., Wagner, F., and Larsson, T. (2010). Decentralized task distribution among cooperative uavs in surveillance systems applications. In Wireless On-demand Network Systems and Services (WONS), 2010 Seventh International Conference on, pages 121 -128 . Citado na página 22.

De La Cruz, C. and Carelli, R. (2006). Dynamic modeling and centralized formation control of mobile robots. In IEEE Industrial Electronics, IECON 2006 - 32nd Annual Conference on, pages 3880 -3885. Citado na página 96.

Deneubourg, Aron, S., Goss, S., and Pasteels, J. M. (1990). The selforganizing exploratory pattern of the argentine ant. Journal of Insect Behavior, 3(2):159-168. Citado nas páginas 33 e 34.

Dimarogonas, D. and Kyriakopoulos, K. (2006). Distributed cooperative control and collision avoidance for multiple kinematic agents. In Decision and Control, 2006 45th IEEE Conference on, pages $721-726$. Citado na página 26.

Domenici, P. and Batty, R. (1997). Escape behavior of solitary herring (Clupea harengus) and comparisons with schooling individuals. Marine Biology, 128. Citado na página 21 .

Dong, W. and Farrell, J. (2008). Consensus of multiple nonholonomic systems. In Decision and Control, 2008. CDC 2008. 47th IEEE Conference on, pages 2270 -2275. Citado na página 96.

Dorigo, M. (1992). Optimization, Learning and Natural Algorithms. PhD thesis, Politecnico di Milano, Italy. Citado nas páginas 30, 35, 43, 49, e 151.

Dorigo, M., Birattari, M., Stützle, T., Libre, U., Bruxelles, D., and Roosevelt, A. F. D. (2006). Ant colony optimization: Artificial ants as a computational intelligence technique. IEEE Comput. Intell. Mag, 1:28-39. Citado nas páginas 31 e 34.

Dorigo, M., Caro, G. D., and Gambardella, L. (1999). Ant algorithms for discrete optimization. Citado nas páginas 31 e 33.

Dorigo, M. and Gambardella, L. M. (1997). Ant colony system: A cooperative learning approach to the travelling salesman problem. IEEE Transactions on Evolutionary Computation, 1(1):53-66. Citado na página 38.

Dorigo, M., Maniezzo, V., and Colorni, A. (1991a). The ant system: An autocatalytic optimizing process. Citado nas páginas 30 e 36. 
Dorigo, M., Maniezzo, V., and Colorni, A. (1991b). Positive feedback as a search strategy. Citado na página 30.

Dudek, G., Jenkin, M. R. M., Milios, E., and Wilkes, D. (1996). A taxonomy for multi-agent robotics. Autonomous Robots, 3:103-134. Citado na página 9.

Dutta, K. (2010). How birds fly together: The dynamics of flocking. Resonance, 15(12):1097-1110. Citado nas páginas 17 e 18.

Elfes, A. (1989). Using occupancy grids for mobile robot perception and navigation. Computer, 22(6):46-57. Citado nas páginas 12, 53, e 123.

Elmaliach, Y., Agmon, N., and Kaminka, G. A. (2009). Multi-robot area patrol under frequency constraints. Annals of Mathematics and Artificial Intelligence, 57(3-4):293-320. Citado na página 39.

Fierro, R., Chaimowicz, L., and Kumar, V. (2005). Multi-robot cooperation. In Ge, S. S. and Lewis, F. L., editors, Autonomous Mobile Robots: Sensing, Control, Decision Making and Applications, volume 309, chapter 11. CRC Press - Taylor \& Francis Group. Citado na página 9.

Fiorelli, E., Leonard, N. E., Bhatta, P., Paley, D. A., Bachmayer, R., and Fratantoni, D. M. (2006). Multi-auv control and adaptive sampling in monterey bay. Oceanic Engineering, IEEE Journal of, 31(4):935 -948. Citado na página 22 .

Franchi, A., Freda, L., Oriolo, G., and Vendittelli, M. (2009). The sensorbased random graph method for cooperative robot exploration. Mechatronics, IEEE/ASME Transactions on, 14(2):163 -175. Citado na página 12.

Frewen, T. A., Couzin, I. D., Kolpas, A., Moehlis, J., Coifman, R., and Kevrekidis, I. G. (2011). Coarse collective dynamics of animal groups. In Gorban, A. N. and Roose, D., editors, Coping with Complexity: Model Reduction and Data Analysis, volume 75 of Lecture Notes in Computational Science and Engineering, pages 299-309. Springer Berlin Heidelberg. Citado na página 17.

Fujii, M., Inamura, W., Murakami, H., Tanaka, K., and Kosuge, K. (2007). Cooperative control of multiple mobile robots transporting a single object with loose handling. In Robotics and Biomimetics, 2007. ROBIO 2007. IEEE International Conference on, pages 816-822. Citado nas páginas 4 e 22 .

Gabriely, Y. and Rimon, E. (2001). Spanning-tree based coverage of continuous areas by a mobile robot. In Robotics and Automation, 2001. Proceedings 2001 ICRA. IEEE International Conference on, volume 2, pages 1927 - 1933 vol.2. Citado na página 14. 
Gage, D. W. (1992). Command control for many-robot systems. NAVAL COMMAND CONTROL AND OCEAN SURVEILLANCE CENTER RDT AND E DIV SAN DIEGO CA. Citado nas páginas 13, 14, e 15.

Ge, S. S. and Fua, C. (2005). Complete multi-robot coverage of unknown environments with minimum repeated coverage. In Robotics and Automation, 2005. ICRA 2005. Proceedings of the 2005 IEEE International Conference on, pages $715-720$. Citado na página 13 .

Giraldeau, L.-A. (2008). Behavioural Ecology, Part Three: Exploiting the Environment. Oxford University Press. Citado na página 21.

Glad, A., Buffet, O., Simonin, O., and Charpillet, F. (2009). Self-organization of patrolling-ant algorithms. In Self-Adaptive and Self-Organizing Systems, 2009. SASO '09. Third IEEE International Conference on, pages $61-70$. Citado na página 40.

Gonçalves, R., Ferreira, S., Pinto, J., Sousa, J., and Gonçalves, G. (2011). Authority sharing in mixed initiative control of multiple uninhabited aerial vehicles. In Harris, D., editor, Engineering Psychology and Cognitive Ergonomics, volume 6781 of Lecture Notes in Computer Science, pages 530539. Springer Berlin / Heidelberg. 10.1007/978-3-642-21741-8_56. Citado na página 22.

Groß, R. and Dorigo, M. (2009). Towards group transport by swarms of robots. International Journal of Bio-Inspired Computation, 1(1-2):1-13. Citado nas páginas 4 e 22.

Gueron, S., Levin, S. A., and Rubenstein, D. I. (1996). The dynamics of herds: From individuals to aggregations. Journal of Theoretical Biology, 182(1):8598. Citado na página 17.

Guibas, L. and Stolfi, J. (1985). Primitives for the manipulation of general subdivisions and the computation of voronoi. ACM Trans. Graph., 4(2):74123. Citado nas páginas 17 e 93.

Haddadi, A., Noroozi, A., Verhoeven, C., and Gill, E. (2008). A novel structured mathematical framework for parallel processing in cooperative satellite swarms. In Systems and Control in Aerospace and Astronautics, 2008. ISSCAA 2008. 2nd International Symposium on, pages $1-6$. Citado na página 22.

Han, Q., Wang, Q., Zhu, X., and Xu, J. (2011). Path planning of mobile robot based on improved ant colony algorithm. In Consumer Electronics, 
Communications and Networks (CECNet), 2011 International Conference on, pages 531 -533. Citado na página 44.

Hazon, N. and Kaminka, G. (2005). Redundancy, efficiency and robustness in multi-robot coverage. In Robotics and Automation, 2005. ICRA 2005. Proceedings of the 2005 IEEE International Conference on, pages 735 - 741 . Citado na página 14 .

Hernandez-Martinez, E. and Aranda-Bricaire, E. (2008). Non-collision conditions in multi-agent robots formation using local potential functions. In Robotics and Automation, 2008. ICRA 2008. IEEE International Conference on, pages 3776 -3781. Citado na página 26.

Higashitani, M., Ishigame, A., and Yasuda, K. (2006). Particle swarm optimization considering the concept of predator-prey behavior. In Evolutionary Computation, 2006. CEC 2006. IEEE Congress on, pages $434-437$. Citado na página 21 .

Howard, A., Mataric, M. J., and Sukhatme, G. S. (2002). Mobile sensor network deployment using potential fields: A distributed, scalable solution to the area coverage problem. In International Symposium on Distributed $\mathrm{Au}$ tonomous Robotics Systems, pages 299-308, Fukuoka, Japan. Citado nas páginas 16 e 26.

Iba, H., Tohge, T., and Inoue, Y. (2004). Cooperative transportation by humanoid robots - solving piano movers' problem. Int. J. Hybrid Intell. Syst., 1:189-201. Citado na página 22.

Inada, Y. (2001). Steering mechanism of fish schools. Complexity International, 8:1-9. Citado na página 19.

Iocchi, L., Nardi, D., and Salerno, M. (2001). Reactivity and deliberation: A survey on multi-robot systems. In Balancing Reactivity and Social Deliberation in Multi-Agent Systems, From RoboCup to Real-World Applications (selected papers from the ECAI 2000 Workshop and additional contributions), pages 9-34, London, UK, UK. Springer-Verlag. Citado nas páginas 9 e 89.

Ishikawa, M. (2009). Behavior analyses of stochastic predator-prey systems under fish predation. In ICCAS-SICE, 2009, pages 5063 -5068. Citado na página 21 .

Jaromczyk, J. and Toussaint, G. (1992). Relative neighborhood graphs and their relatives. Proceedings of the IEEE, 80(9):1502 -1517. Citado na página 94. 
Kadioglu, E. and Papanikolopoulos, N. (2003). A method for transporting a team of miniature robots. In Intelligent Robots and Systems, 2003. (IROS 2003). Proceedings. 2003 IEEE/RSJ International Conference on, volume 3 , pages 2297 - 2302 vol.3. Citado na página 22.

Kaliappan, V. K., Yong, H., Min, D., and Budiyono, A. (2011). Behavior-based decentralized approach for cooperative control of a multiple small scale unmanned helicopter. In Intelligent Systems Design and Applications (ISDA), 2011 11th International Conference on, pages 196 -201. Citado nas páginas 23 e 96.

Kallmann, M., Bieri, H., Thalmann, D., Triangulations, D., and Popular, C. D. T. A. (2003). Fully dynamic constrained delaunay triangulations. Citado nas páginas 17 e 93.

Kelly, S. and Pujari, P. (2010). Propulsive energy harvesting by a fishlike vehicle in a vortex flow: Computational modeling and control. In Decision and Control (CDC), 2010 49th IEEE Conference on, pages 1058-1064. Citado na página 19.

Kerr, W. and Spears, D. (2005). Robotic simulation of gases for a surveillance task. In Intelligent Robots and Systems, 2005. (IROS 2005). 2005 IEEE/RSJ International Conference on, pages 2905 - 2910. Citado na página 22.

Khatib, O. (1985). Real-time obstacle avoidance for manipulators and mobile robots. In Robotics and Automation. Proceedings. 1985 IEEE International Conference on, volume 2, pages 500 - 505. Citado nas páginas 16 e 23.

Knadler, C. (2008). Models of a predator-prey relationship in a closed habitat. In Simulation Conference, 2008. WSC 2008. Winter, pages $2861-2870$. Citado na página 21.

Koenig, S., Szymanski, B., and Liu, Y. (2001). Efficient and inefficient ant coverage methods. Annals of Mathematics and Artificial Intelligence, 31:4176. 10.1023/A:1016665115585. Citado na página 40.

Kong, C. S., Peng, N. A., and Rekleitis, I. (2006). Distributed coverage with multi-robot system. In Robotics and Automation, 2006. ICRA 2006. Proceedings 2006 IEEE International Conference on, pages 2423 -2429. Citado na página 13.

Kumar, S., Lai, T. H., and Arora, A. (2005). Barrier coverage with wireless sensors. In Proceedings of the 11th annual international conference on Mobile computing and networking, MobiCom '05, pages 284-298, New York, NY, USA. ACM. Citado na página 15. 
Kuppan, C., Singaperumal, M., and Nagarajan, T. (2011). Distributed planning and control of multirobot formations with navigation and obstacle avoidance. In Recent Advances in Intelligent Computational Systems (RAICS), 2011 IEEE, pages 621 -626. Citado na página 24.

Latombe, J.-C. (1993). Robot Motion Planning. Kluwer Academic Publishers, Norwell, MA, USA. Citado nas páginas 10 e 16.

Lee, D. (1996). The map-building and exploration strategies of a simple sonarequipped mobile robot. Cambridge University Press, New York, NY, USA. Citado na página 11 .

Lee, J., Choi, J., Lee, B., and Lee, K. (2009). Complete coverage path planning for cleaning task using multiple robots. In Systems, Man and Cybernetics, 2009. SMC 2009. IEEE International Conference on, pages 3618 -3622. Citado nas páginas 4 e 13.

Lee, J.-W. and Lee, J.-J. (2010). Novel ant colony optimization algorithm with path crossover and heterogeneous ants for path planning. In Industrial Technology (ICIT), 2010 IEEE International Conference on, pages 559 -564. Citado na página 44 .

Lee, M., Tarokh, M., and Cross, M. (2010). Fuzzy logic decision making for multi-robot security systems. Artificial Intelligence Review, 34:177-194. 10.1007/s10462-010-9168-8. Citado na página 4.

Lewis, M. A. and Tan, K.-H. (1997). High precision formation control of mobile robots using virtual structures. Auton. Robots, 4:387-403. Citado nas páginas 25 e 96.

Li, Y. and Chen, X. (2005a). Formation control for a multiple robotic system using adaptive neural network. In Wang, J., Liao, X., and Yi, Z., editors, Advances in Neural Networks - ISNN 2005, Second International Symposium on Neural Networks, Chongqing, China, May 30 - June 1, 2005, Proceedings, Part III, volume 3498 of Lecture Notes in Computer Science, pages 228-233. Springer. Citado na página 24.

Li, Y. and Chen, X. (2005b). Mobile robot navigation using particle swarm optimization and adaptive nn. Lecture Notes in Computer Science, 3612:439439. Citado na página 24.

Liu, B., Yu, Y., Zhang, J., and Li, H. (2009). Stability analysis of social foraging swarm with interaction time delays. In Intelligent Systems, 2009. GCIS '09. WRI Global Congress on, volume 1, pages 104 -108. Citado na página 19. 
Lu, J., Liu, J., Couzin, I., and Levin, S. (2008). Emerging collective behaviors of animal groups. In Intelligent Control and Automation, 2008. WCICA 2008. 7th World Congress on, pages 1060 -1065. Citado na página 17.

Luo, L., Chakraborty, N., and Sycara, K. (2011). Multi-robot assignment algorithm for tasks with set precedence constraints. In Robotics and Automation (ICRA), 2011 IEEE International Conference on, pages 2526 -2533. Citado na página 23.

Ma, L. and Schilling, K. (2009). Attitude coordination for swarms of pico- and nano-satellites. In Proc. 60th International Astronautical Congress, Daejeon, Korea, pages 50-55. Citado na página 22.

Machado, A., Ramalho, G., Zucker, J.-D., and Drogoul, A. (2002). Multiagent patrolling: An empirical analysis of alternative architectures. In Sichman, J. S., Bousquet, F., and Davidsson, P., editors, MABS, volume 2581 of Lecture Notes in Computer Science, pages 155-170. Springer. Citado na página 39.

Makarenko, A., Williams, S., Bourgault, F., and Durrant-Whyte, H. (2002). An experiment in integrated exploration. Citado na página 10.

Mannadiar, R. and Rekleitis, I. (2010). Optimal coverage of a known arbitrary environment. In Robotics and Automation (ICRA), 2010 IEEE International Conference on, pages 5525 -5530. Citado na página 13.

Marino, A., Parker, L., Antonelli, G., and Caccavale, F. (2009). Behavioral control for multi-robot perimeter patrol: A finite state automata approach. In Robotics and Automation, 2009. ICRA 'O9. IEEE International Conference on, pages 831 -836. Citado na página 40.

Martinez, S., Cortes, J., and Bullo, F. (2007). Motion coordination with distributed information. Control Systems, IEEE, 27(4):75 -88. Citado na página 94.

Mastellone, S., Mejía, J. S., Stipanović, D. M., and Spong, M. W. (2011). Formation control and coordinated tracking via asymptotic decoupling for lagrangian multi-agent systems. Automatica, 47(11):2355-2363. Citado na página 96.

McKerrow, P. J. (1991). Introduction to robotics. Addison-Wesley. Citado na página 92 .

Meguerdichian, S., Slijepcevic, S., Karayan, V., and Potkonjak, M. (2001). Localized algorithms in wireless ad-hoc networks: location discovery and sensor exposure, in. In Proceedings of the Second ACM International Symposium 
on Mobile Ad Hoc Networking and Computing (MobiHoc2001, pages 106-1 16. Citado na página 90.

Miao, Y.-Q., Khamis, A., and Kamel, M. (2010). Applying anti-flocking model in mobile surveillance systems. In Autonomous and Intelligent Systems (AIS), 2010 International Conference on, pages $1-6$. Citado na página 21 .

Millonas, M. M. (1994). Swarms, phase transitions, and collective intelligence. In Langton, C. G., editor, Artificial Life III, volume XVII of Santa Fe Institute Studies in the Sciences of Complexity, pages 417-445. Addison-Wesley Longman Publishing, New York, NY. Citado na página 30.

Moreau, L. (2005). Stability of multiagent systems with time-dependent communication links. Automatic Control, IEEE Transactions on, 50(2):169 - 182. Citado na página 24.

Morihiro, K., Isokawa, T., Nishimura, H., and Matsui, N. (2006). Characteristics of flocking behavior model by reinforcement learning scheme. In SICEICASE, 2006. International Joint Conference, pages $4551-4556$. Citado na página 20.

Morihiro, K., Nishimura, H., Isokawa, T., and Matsui, N. (2007). Reinforcement learning scheme for grouping and anti-predator behavior. In Proceedings of the 11th international conference, KES 2007 and XVII Italian workshop on neural networks conference on Knowledge-based intelligent information and engineering systems: Part III, KES'07/WIRN'07, pages 115-122, Berlin, Heidelberg. Springer-Verlag. Citado na página 20.

Murphy, R. (2004). Trial by fire [rescue robots]. Robotics Automation Magazine, IEEE, 11(3):50 - 61. Citado na página 4.

Nabet, B., Leonard, N., Couzin, I., and Levin, S. (2009). Dynamics of decision making in animal group motion. Journal of Nonlinear Science, 19:399-435. 10.1007/s00332-008-9038-6. Citado na página 19.

Oboshi, T., Kato, S., Mutoh, A., and Itoh, H. (2002). A simulation study on the form of fish schooling for escape from predator. Citado nas páginas 19 e 20 .

Ogren, P. and Leonard, N. (2002). A tractable convergent dynamic window approach to obstacle avoidance. In Intelligent Robots and Systems, 2002. IEEE/RSJ International Conference on, volume 1, pages 595 - 600 vol.1. Citado na página 24. 
Okabe, A., Boots, B., Sugihara, K., and Chiu, S. N. (2000). Spatial tessellations: Concepts and applications of Voronoi diagrams. Probability and Statistics. Wiley, NYC, 2nd edition. 671 pages. Citado na página 10.

Park, M. G., Jeon, J. H., and Lee, M. C. (2001). Obstacle avoidance for mobile robots using artificial potential field approach with simulated annealing. In Industrial Electronics, 2001. Proceedings. ISIE 2001. IEEE International Symposium on, volume 3, pages 1530 -1535 vol.3. Citado na página 23.

Parker, L. E. (1998). Alliance: An architecture for fault tolerant multi-robot cooperation. IEEE Transactions on Robotics and Automation, 14:220-240. Citado na página 9.

Parker, L. E. (2003). Current research in multirobot systems. Journal of Artificial Life And Robotics, 7(1/2):1-5. Citado na página 89.

Partridge, B. L. (1982). The structure and function of fish schools. Scientific American, 246(6):114-123. Citado nas páginas 18 e 20.

Pasqualetti, F., Franchi, A., and Bullo, F. (2010). On optimal cooperative patrolling. In $C D C$, pages 7153-7158. Citado na página 42.

Peng, H., Huo, M., Liu, Z., and He, Y. (2011). Challenges and technologies for networked multiple uavs cooperative control. In Electrical and Control Engineering (ICECE), 2011 International Conference on, pages 3860 -3863. Citado na página 22.

Portugal, D. and Rocha, R. (2011). A survey on multi-robot patrolling algorithms. In Camarinha-Matos, L., editor, Technological Innovation for Sustainability, volume 349 of IFIP Advances in Information and Communication Technology, pages 139-146. Springer Boston. 10.1007/978-3-642-191701_15. Citado na página 39.

Pota, H., Eaton, R., Katupitiya, J., and Pathirana, S. (2007). Agricultural robotics: A streamlined approach to realization of autonomous farming. In Industrial and Information Systems, 2007. ICIIS 2007. International Conference on, pages 85 -90. Citado na página 4.

Radakov, D. (1973). Schooling in the Ecology of Fish. Halsted Press. Citado na página 18.

Rekleitis, I., Dudek, G., and Milios, E. (2001). Multi-robot collaboration for robust exploration. Annals of Mathematics and Artificial Intelligence, 31:740. Citado na página 11 . 
Ren, W. (2007a). Multi-vehicle consensus with a time-varying reference state. Systems and Letters, 56(7 - 8):474 - 483. Citado na página 23.

Ren, W. (2007b). Second-order consensus algorithm with extensions to switching topologies and reference models. In American Control Conference, 2007. ACC '07, pages 1431 -1436. Citado na página 24.

Ren, W. and Beard, R. (2003). A decentralized scheme for spacecraft formation flying via the virtual structure approach. In American Control Conference, 2003. Proceedings of the 2003, volume 2, pages $1746-1751$. Citado na página 25.

Ren, W. and Beard, R. (2005). Consensus seeking in multiagent systems under dynamically changing interaction topologies. Automatic Control, IEEE Transactions on, 50(5):655 - 661. Citado na página 24.

Reynolds, C. W. (1987). Flocks, herds and schools: A distributed behavioral model. In Proceedings of the 14th annual conference on Computer graphics and interactive techniques, SIGGRAPH '87, pages 25-34, New York, NY, USA. ACM. Citado nas páginas 18, 19, 22, 89, e 123.

Romero, L., Morales, E. F., and Sucar, L. E. (2000). A robust exploration and navigation approach for indoor mobile robots merging local and global strategies. In Proceedings of the International Joint Conference, 7th IberoAmerican Conference on AI: Advances in Artificial Intelligence, IBERAMIASBIA '00, pages 389-398, London, UK. Springer-Verlag. Citado na página 11 .

Russell, S. J. and Norvig, P. (2009). Artificial Intelligence: A Modern Approach. Prentice Hall, 3rd edition. Citado na página 10.

Saaj, C., Lappas, V., and Gazi, V. (2006). Spacecraft swarm navigation and control using artificial potential field and sliding mode control. In Industrial Technology, 2006. ICIT 2006. IEEE International Conference on, pages 2646 -2651. Citado na página 22.

Savkin, A. (2003). Coordinated collective motion of groups of autonomous mobile robots: analysis of vicsek's model. In Decision and Control, 2003. Proceedings. 42nd IEEE Conference on, volume 3, pages 3076 - 3077 Vol.3. Citado na página 24.

Schatz, B., Chameron, S., Beugnon, G., and Collett, T. S. (1999). The use of path integration to guide route learning in ants. Nature, 399(6738):769-777. Citado na página 33. 
Shaw, A. and Mohseni, K. (2011). A fluid dynamic based coordination of a wireless sensor network of unmanned aerial vehicles: 3-d simulation and wireless communication characterization. Sensors Journal, IEEE, 11(3):722 -736. Citado na página 22.

Shewchuck, J. R. (1997). Delaunay refinement mesh generation. Master's thesis, School of Computer Science Computer Science Department, Carnegie Mellon University, Pittsburgh, USA. Citado nas páginas 17 e 93.

Shinchi, T., Kitazoe, T., Nishimura, H., Tabuse, M., Azuma, N., and Aoki, I. (2002). Fractal evaluations of fish school movements in simulations and real observations. Artificial Life and Robotics, 6:36-43. Citado na página 19.

Siegwart, R. and Nourbakhsh, I. R. (2004). Introduction to Autonomous Mobile Robots. Bradford Company, Scituate, MA, USA. Citado na página 4.

Socha, K. and Dorigo, M. (2008). Ant colony optimization for continuous domains. Citado na página 38.

Stilwell, D. and Bay, J. (1993). Toward the development of a material transport system using swarms of ant-like robots. In Robotics and Automation, 1993. Proceedings., 1993 IEEE International Conference on, pages 766 -771 vol.1. Citado na página 22 .

Stipanovic, D., Inalhan, G., Teo, R., and Tomlin, C. (2002). Decentralized overlapping control of a formation of unmanned aerial vehicles. In Decision and Control, 2002, Proceedings of the 41st IEEE Conference on, volume 3, pages 2829 - 2835 vol.3. Citado na página 22 .

Stoeter, S., Rybski, P., Gini, M., and Papanikolopoulos, N. (2002). Autonomous stair-hopping with scout robots. In Intelligent Robots and Systems, 2002. IEEE/RSJ International Conference on, volume 1, pages 721 726 vol.1. Citado na página 22 .

Stützle, T. and Hoos, H. (1997). Max-min ant system and local search for combinatorial optimization problems. Citado na página 38.

Sujit, P., Sousa, J., and Pereira, F. (2009). Uav and auvs coordination for ocean exploration. In OCEANS 2009 - EUROPE, pages 1 -7. Citado na página 22 .

Sumpter, D. J. T. (2006). The principles of collective animal behaviour. Philosophical Transactions: Biological Sciences, 361(1465):5-22. Citado na página 17. 
Sumpter, D. J. T. (2010). Collective Animal Behavior. Princeton University Press, Princeton. Citado nas páginas 17 e 18.

Sundaram, S. and Hadjicostis, C. N. (2007). Distributed consensus and linear functional calculation in networks: an observability perspective. In Proceedings of the 6th international conference on Information processing in sensor networks, IPSN '07, pages 99-108, New York, NY, USA. ACM. Citado na página 23.

Tan, J., Lozano, O., Xi, N., and Sheng, W. (2004). Multiple vehicle systems for sensor network area coverage. In Intelligent Control and Automation, 2004. WCICA 2004. Fifth World Congress on, volume 5, pages 4666 - 4670 Vol.5. Citado nas páginas 13, 17, 24, e 96.

Tanner, H. and Kumar, A. (2005). Towards decentralization of multi-robot navigation functions. In Robotics and Automation, 2005. ICRA 2005. Proceedings of the 2005 IEEE International Conference on, pages $4132-4137$. Citado na página 26.

Tanner, H. G., Jadbabaie, A., and Pappas, G. J. (2007a). Flocking in fixed and switching networks. Automatic Control, IEEE Transactions on, 52(5):863 -868. Citado na página 23.

Tanner, H. G., Jadbabaie, A., and Pappas, G. J. (2007b). Flocking in fixed and switching networks. Automatic Control, IEEE Transactions on, 52(5):863 -868. Citado na página 26.

Toner, J. and Tu, Y. (1995). Long-range order in a two-dimensional dynamical xy model: How birds fly together. Physical Review Letters, 75(23):43264329. Citado na página 17.

Vicsek, T., Czirok, A., Ben-Jacob, E., Cohen, I., and Shochet, O. (1995). Novel type of phase transition in a system of self-driven particles. Physical Review Letters, 75:1226-1229. Citado na página 24.

Viscido, S. V., Parrish, J. K., and Grünbaum, D. (2004). Individual behavior and emergent properties of fish schools: a comparison of observation and theory. Marine Ecology Progress Series, 273:239-249. Citado na página 19.

Wagner, I., Lindenbaum, M., and Bruckstein, A. (1999). Distributed covering by ant-robots using evaporating traces. Robotics and Automation, IEEE Transactions on, 15(5):918 -933. Citado na página 40.

Ward, C. R. (2001). Evolving collective behavior in an artificial ecology. Artificial Life, 7:2001. Citado na página 20. 
Waters, C. M. and Bassler, B. L. (2005). QUORUM SENSING: Cell-to-Cell Communication in Bacteria. Annual Review of Cell and Developmental Biology, 21(1):319-346. Citado na página 17.

Weng, L., Cai, W., Zhang, R., and Song, Y. (2006). Bio-inspired control approach to multiple spacecraft formation flying. In e-Science and Grid Computing, 2006. e-Science 'O6. Second IEEE International Conference on, page 120. Citado na página 22.

Wu, M.-H., Konno, A., and Uchiyama, M. (2011). Cooperative object transportation by multiple humanoid robots. In System Integration (SII), 2011 IEEE/SICE International Symposium on, pages 779 -784. Citado nas páginas 4 e 22 .

Xi, F., He, J., and Liu, Z. (2010). Adaptive fast consensus algorithm for distributed sensor fusion. Signal Process., 90:1693-1699. Citado na página 23.

Xia, Y.-m., Chen, J.-1., and Meng, X.-w. (2008). On the dynamic ant colony algorithm optimization based on multi-pheromones. In Proceedings of the Seventh IEEE/ACIS International Conference on Computer and Information Science (icis 2008), pages 630-635, Washington, DC, USA. IEEE Computer Society. Citado na página 38.

Yamashita, A., Fukuchi, M., Ota, J., Arai, T., and Asama, H. (2000). Motion planning for cooperative transportation of a large object by multiple mobile robots in a 3d environment. In Robotics and Automation, 2000. Proceedings. ICRA 'OO. IEEE International Conference on, volume 4, pages $3144-3151$ vol.4. Citado na página 22.

Yamauchi, B. (1997). A frontier-based approach for autonomous exploration. Computational Intelligence in Robotics and Automation, 1997. CIRA'97., Proceedings., 1997 IEEE International Symposium on, pages 146-151. Citado na página 11.

Yamauchi, B. (1998). Frontier-based exploration using multiple robots. In Proceedings of the second international conference on Autonomous agents, AGENTS '98, pages 47-53, New York, NY, USA. ACM. Citado na página 12.

Yates, C. A., Baker, R. E., Erban, R., and Maini, P. K. (2010). Refining self-propelled particle models for collective behaviour. Can. Appl. Math. Q., 18(3):299-350. Citado na página 19.

Yu, X., Sun, Y., Liu, J., Wu, L., Chen, Y., and Miao, J. (2008). Key techniques for multi-satellite integrated navigation system modeling and controlling. In 
Systems and Control in Aerospace and Astronautics, 2008. ISSCAA 2008. 2nd International Symposium on, pages 1 -6. Citado na página 22.

Zadeh, L. A. (1965). Fuzzy sets. Journal of Information and Control, 8:338 353. Citado na página 122.

Zhang, M., Shen, Y., Wang, Q., and Wang, Y. (2010). Dynamic artificial potential field based multi-robot formation control. In Instrumentation and Measurement Technology Conference (I2MTC), 2010 IEEE, pages 1530-1534. Citado na página 23.

Zhang, R., Li, S., and Chen, Q. (2011). A generalized share potential fields approach to multi-robot coordination. In Computer Science and Automation Engineering (CSAE), 2011 IEEE International Conference on, volume 3, pages 432 -436. Citado na página 23.

Zheng, X., Jain, S., Koenig, S., and Kempe, D. (2005). Multi-robot forest coverage. In Intelligent Robots and Systems, 2005. (IROS 2005). 2005 IEEE/RSJ International Conference on, pages 3852 - 3857. Citado nas páginas 13, 19, e 20 .

Zhu, A. and Yang, S. (2010). A survey on intelligent interaction and cooperative control of multi-robot systems. In Control and Automation (ICCA), 2010 8th IEEE International Conference on, pages 1812 -1817. Citado na página 89. 